\title{
Fibroblast Differentiation \& Models of Human Skin
}

\author{
Jonathan Rakar
}

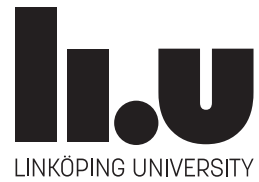

Hand- and Plastic Surgery

Division of Clinical Sciences

Department of Clinical and Experimental Medicine, IKE

Faculty of Medicine and Health Sciences Linköping University, SE-581 83 Linköping, Sweden

Linköping 2016 
(C) Jonathan Rakar, 2016

Images by J. Rakar and S. Sundberg

Printed in Sweden by LiUTryck (2016)

ISSN 0345-0082

ISBN 978-91-7685-849-3 


\section{Populärvetenskaplig sammanfattning}

Denna bok avhandlar en riktning av biomedicinsk forskning som i det långa loppet syftar till att nå bättre och banbrytande sätt att läka våra kroppar. Forskningen vilar på en tredelad grund - viktiga kunskaper som leder mot en generell förståelse för hur celler blir till vävnader, hur vävnader och organ kan manipuleras på ett kliniskt användbart sätt, och till sist hur denna kunskap kan appliceras på människans hudorgan.

Den första delen handlar om cellers identitet, och den stora potentialen som våra egna stamceller har för framtidens läkekonst. Genom att förstå hur celler egentligen fungerar på arvsmassenivå kan vi utöka arsenalen av verktyg vi har för att få celler att bete sig på de sätt som behövs för att skapa nya organ. Vi har jobbat med att karakterisera och manipulera fibroblaster, en av de vanligaste celltyperna i människokroppen, och bland annat tagit fram olika typer av fettceller.

Den andra delen handlar om hur man använder celler, biokemiska faktorer och biokompatibla material för att konstruera vävnader och organ. Innan forskningen når klinisk användbarhet har vi möjlighet att bygga begränsade modellsystem för att studera människans biologi. Cellsystem på labbet är mycket viktiga verktyg för att föra forskningen på vävnadsbyggande framåt.

Den tredje delen behandlar hudforskning specifikt, och här samlas kunskaper från tidigare delarna som är relevanta för mänsklig hud. Här beskrivs användningen av två olika hudmodeller för att undersöka proceser viktiga vid sårläkning. Vidare beskrivs planerna kring ett större påbörjat projekt som syftar till att använda alla tidigare lärdomar och tekniker för att åstadkomma en ny terapi för sårläkning. 



\section{Abstract}

This thesis combines three publications and one manuscript, covering two principal topics: functional differentiation of human fibroblasts and, laboratory models of human skin. The two topics favourably unite in the realm of tissue engineering. This thesis is therefore split into three main parts: 1. a discussion of phenotypic plasticity as it pertains to fibroblasts and the stem cell continuum; 2 . a short review of engineered tissue, with particular focus on soluble factors and materials; and, 3. a motivated review of the biology, diversity and culture of skin, including skin construction.

The intended goal of our research endeavor was to achieve the formulation of a bioactive therapy for skin regeneration. The main hypothesis was that fibroblast-to-keratinocyte differentiation would facilitate wound healing, and that the protocol for such a method could be adapted to clinical translation. The foundation for the hypothesis lay in the differentiation capabilities of primary dermal fibroblasts (Paper I). However, the goal has not yet been achieved. Instead, intermediate work on the construction of skin for the purpose of creating a model test-bed has resulted in two other publications. The use of excised human skin, a formidable reference sample for tissue engineered skin, has been used to investigate a gelatin-based material in re-epithelialization (Paper II). A first attempt at standardizing a constructed skin model also resulted in a publication: an evaluation of melanocyte influences on keratinocyte-mediated contraction (Paper III).

The introduction of melanocytes into a skin model raised questions about other appendages of the integumentary system. Our previous experience with preadipocyte isolation and identification, and our attempts at constructing three-dimensional adipose tissue, motivated further investigations into fibroblast-to-adipocyte differentiation. We investigated the possibility of activating thermogenesis in fibroblasts, a property otherwise reserved for cells of the adipogenic and myogenic lineages. Our attempts were successful, and are presently in manuscript form (Paper IV). Some further experiments and optimizations are necessary before establishing a reproducible protocol for thermogenic induction.

The knowledge obtained through these scientific inquiries have moved us closer to achieving our goals, but methodological advances are still necessary. In the meantime, we have new test-beds for investigating different interactions in skin, and that enables many new questions to be asked and answered. 


\section{Table of Contents}

\section{Prologue:}

HUMANS \& SCIENCE 11

The Scientific Method 12

Human fallacies $\quad 15$

Beauty, Evil and Ethics $\quad 18$

Section References $\quad 22$

\section{Part 1:}

CELLS, STEM CELLS \& DIFFERENTIATION 23

On the identity of cells 24

Adult mesodermal stem cells $\quad 30$

Fibroblast plasticity \&

The heterogeneity of populations $\quad 40$

Differentiation - the phenomenon and the methodology 45

Cellular reprogramming 50

Section References $\quad 58$

\section{Part 2:}

MATERIALS IN TISSUE ENGINEERING 67

Tissue Engineering: the holy trinity 68

Experimental achievements in TE $\quad 80$

Clinical examples of TE constructs $\quad 81$

Criticisms of research norms in the field of TE 84

Section References $\quad 86$

\section{Part 3:}

CONTENTS \& CONSTRUCTION OF SKIN 89

Introduction to the human skin $\quad 90$

Keratinocytes and the epidermis 93

Fibroblasts and the dermis $\quad 106$

Adipocytes and subcutis $\quad 113$

Skin damage and repair $\quad 118$

Skin engineering 123

Work in progress, or: how the parts fit the whole $\quad 129$

Section References 130 
GENERAL MATERIALS \& METHODS

4.1 Cell culture 139

4.2 Preparation of skin models $\quad 142$

4.3 Microscopy 143

4.4 Protein expression and analysis $\quad 144$

4.5 Gene expression analysis $\quad 145$

4.6 General data analysis and statistics 146

DISCUSSIONS OF PAPERS

- Considerations and ideas

Paper I: Fibroblast phenotype shifts

Paper II: Microcarriers in re-epithelialization $\quad 159$

Paper III: Contraction assay in skin model 163

Paper IV: Thermogenesis in fibroblasts $\quad 165$

Section References 167

$\begin{array}{ll}\text { THE END - AND ONWARDS } & 169\end{array}$

$\begin{array}{ll}\text { Acknowledgements } & 171\end{array}$

Full Bibliography 172

$\begin{array}{ll}\text { Paper I } & 189\end{array}$

$\begin{array}{ll}\text { Paper II } & 199\end{array}$

$\begin{array}{ll}\text { Paper III } & 211\end{array}$

Paper IV 221 

Dedicated to my family. 


\section{Prologue: HUMANS \& SCIENCE}

"The Aristotelian tradition also held that one could work out all the laws that govern the universe by pure thought: it was not necessary to check by observation. So no one until Galileo bothered to see whether bodies of different weight did in fact fall at different speeds."

-Stephen Hawking, A Brief History of Time 


\section{The Scientific Method}

Predicting the future is usually considered a "super-power", but the skill is more ubiquitous than the stories of Nostradamus or the Oracle of Delphi leads us to believe. Our brains are biological prediction machines, updating its predictions with each new sensory stimulus in a continuous loop throughout our lives (Hohwy, 2007). Parts of philosophy are fundamentally concerned with questions of our senses and the limits they impose on knowledge. The allegory of Plato's cave gives us an interesting insight in how we remain loyal to our perceived reality and shun opinions and facts that do not fit into our world view. It points out that our defenses can be so strong that we even can resort to violence to defend them, as the cruel fate of the freed slave who has seen the outside of the cave demonstrates. Our senses limit the way we can experience the world around us, our brain tries to make sense of that experience and in so doing, sorts and distorts our impressions. Thus, we are limited in our objectivity, without which we may inadvertently obscure the truth.

Many things we know about the world is based upon empiricism - events such as sunrise or falling down have (to our knowledge) always occurred in a certain way, and can be assumed to occur the same way in the future. In this sense, we can predict the future in a way that give us a practical control of life. The passing of seasons, and the prediction of harvest, gives farmers a useful periodicity for efficient production. Predicting weather and changing winds helps seafarers prepare for conditions on long voyages. Predicting the trajectory of an object allows us to catch or avoid it. As we discover empirical truths we can investigate underlying causes and effects and formulate theories on how they occur, sharing an understanding of phenomena. Preferences and beliefs may colour the reality we perceive but do not change the probability of events, which is why adhering to scientific principles is important.

Amassing a body of knowledge around a related set of questions eventually results in delineating a field of knowledge. Where there used to be natural philosophy there are now instead the subjects of the natural sciences, rather separate from the subjects of the humanities. The shift from philosophy to science has created a separation of knowledge from the individual to a formalized set of axioms and constructions and has proven very useful to predict and understand natural phenomena.

Inevitably, each field of study has its own semantics and categorizations and it is increasingly difficult to reach the knowledge frontier of any specialization without also creating more confined paths of study. There is certainly much to learn in each field, but it is also a matter of learning the language and categories before understanding the unknowns at the frontier. There is a useful concept in martial arts called "shu-ha-ri", the principle of learning, mastering and then 
transcending the limits of the knowledge that came before you (a concept similar to Wittgenstein's ladder).

Rational thinking is critical to understanding natural phenomena, but we as humans eventually succumb to the inner workings of our human psychology. New knowledge is often needed to solve a new problem, and without experimentation the constraints of a problem are often unknown. Successful experimentation enables us to establish causes and effects of an event, and distinguish between them. Under which conditions will the prediction hold true? With what accuracy, or reliability, will the predictions reflect reality? Experimentation is how principle predictions are tested and adjusted to become as accurate as possible.

Empiricism led to popularization of the inductive method of experimental analysis, in the Western world attributed to Francis Bacon (1561-1626). What we today refer to as the scientific revolution is considered to have begun around 1543 with the publication of "On the revolutions of the heavenly spheres" by Copernicus, and culminated with the publication of Newton's "Principia" in 1687. During this period, the "eye of analysis" revolutionized western societies and spawned a tradition of scientific endeavours.

"The artists of the Renaissance said that man's main concern should be for man, and yet there are other things of interest in the world. Even the artists appreciate sunsets, and the ocean waves, and the march of the stars across the heavens. There is then some reason to talk of other things sometimes. As we look into these things, we get an aesthetic pleasure from them directly on observation. There is also a rhythm and a pattern between the phenomena of nature which is not apparent to the eye, but only to the eye of analysis; and it is these rhythms and patterns which we call Physical Laws."

-Richard Feynman, The character of physical law, lecture at Cornell, 1964, transcript p.13 (video freely available online)

The scientific method rests on a simple set of procedures. First, observing and describing a phenomenon and formulating a hypothesis to explain it. Then, using the hypothesis to make a prediction and performing a set of experiments to see whether the prediction is true. That is all. Except, even if the prediction is found to be true, every effort is exerted to try and prove the prediction (hypothesis) wrong - to find any exceptions to the rule. Only when all attempts at falsification have failed, by several different and unrelated experimenters, can the hypothesis be considered scientifically sound and valid. It can be upheld 
as part of a theory, constructed by inductive reasoning and experimentation. Implicit to inductive reasoning is that the evidence, with corroborating experiments, supports a conclusion strongly enough to make it most probably true (or weakly enough to make it unlikely), but never so definitely as to make something absolutely and irrevocably true or false. Hence the utility of statistical methods in modern science.

It seems that formulating and understanding the laws of nature allows us to propose new ways of solving problems, and to make increasingly accurate predictions. If we can understand that nature itself and the laws of nature (as determined by science) are not strictly the same, then we are prepared to understand the utility of the formalism of a scientific method. The laws, as determined by science, formalize a set of relations between occurrences in nature that will empirically hold true given a specific frame of reference. In that frame of reference, science predicts the outcomes of the event solely according to natural law.

As economists may note, this model opens up for continued marginal drift to meet the production optimum as the enabling knowledge increases. As long as our formalized knowledge of nature is incomplete, this also means that there eventually will arise a problem that falls outside our scope of understanding. Hence, the notion that any new answer raises ten new questions. Importantly, even long held truths are not beyond reconsideration in light of new evidence. Thomas Kühn described the idea of paradigm shifts in the book "The struc-

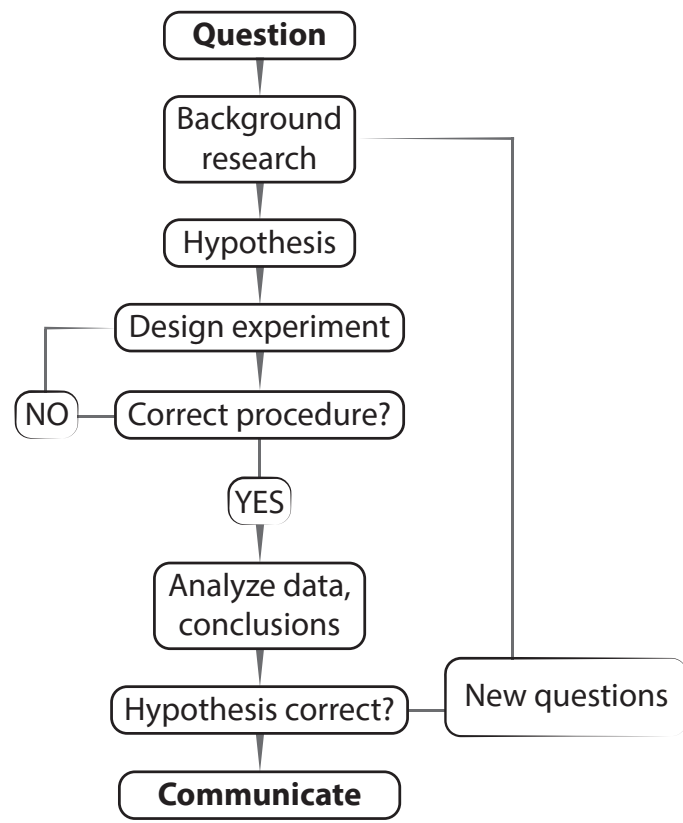
ture of scientific revolutions" (Kuhn, 1962) in which he observes how certain knowledge in a field can shift our understanding of all that preceded it. We remodel the cave, and see all things in a new light.

With acute but biased senses, an advanced prediction machine in our heads to make sense of them, and a philosophical conviction that true laws of nature will never be perfectly defined, it is clear we need a scientific method. It helps us to obtain and communicate useful knowledge across time and distance - despite being human.

Sketch outlining the process of scientific inquiry. 


\section{Human fallacies}

"The next question was - what makes planets go around the sun? At the time of Kepler some people answered this problem by saying that there were angels behind them beating their wings and pushing the planets around an orbit. As you will see, the answer is not very far from the truth. The only difference is that the angels sit in a different direction and their wings push inwards."

-Richard Feynman, the character of physical law, transcript p.18

The human condition is not one to make life easy for the scientific method these two do not very often get along. Humans behave according to personal convictions and interests. Rationality does not always take precedence over preference, and rational thought is often misleading due to knowledge incompleteness. This is why humans attempting to adhere to the scientific method so often fail. Scientific advances in psychology have identified a vast array of cognitive biases that easily eschew our objectivity.

One of the more recognized mantras in the lab is that "assumption is the mother of all fuck-ups". Assumptions are easily carried forward through a false consensus effect and through shared information bias. In the former case, one over-estimates the consensus among peers for one's convictions, and in the latter case the information shared among many peers gains overstated validity due to repeated mention and propagates as a common assumption (Postmes et al., 2001). This is similar to an illusion of truth, where statements that have been heard in the past, regardless of their validity or context, will be remembered and become convincing by mere recognition (repetitive congruence - one of the reasons we are all susceptible to advertisements) (Hasher et al., 1977). Model environments tend to, in themselves, mediate higher self-assessment of preferred values in exposed individuals (Holland, 1985). So simply being a researcher in a university where scientific values are upheld may in fact result in over-stating one's own adherence to scientific standards. The compounded effects of these sources of bias on any one individual are astoundingly difficult to quantify.

Another fascinating psychological bias is known as the Dunning-Kruger effect (Kruger \& Dunning, 1999). This excerpt from the abstract of that paper summarizes it helpfully: 
"People tend to hold overly favorable views of their abilities in many social and intellectual domains. The authors suggest that this overestimation occurs, in part, because people who are unskilled in these domains suffer a dual burden: Not only do these people reach erroneous conclusions and make unfortunate choices, but their incompetence robs them of the metacognitive ability to realize it."

- Excerpt from Abstract (Kruger \& Dunning, 1999).

This is part of the explanation for why it is not only common, but quite sound, for researchers to feel as though the more they learn about a topic the less they know about the field. It is also a reason for why humility can be important when facing new demands on your intellect.

In 1865 Dr. Ignaz P. Semmelweis, a Hungarian obstetrician, died in a mental asylum where he was placed after writing angry letters to leading European obstetricians. A decade earlier Semmelweis had been certain that cleanliness would decrease the incidence of childbed fever at the Vienna hospital in which he was working. He subsequently ordered his interns to wash and disinfect their hands thoroughly before attending to patients, and the incidence dropped dramatically.

The hypothesis underlying his conviction was not accepted by the medical profession and Semmelweis was rejected and ridiculed. His personality, with possibly psychotic traits, caused him to lash out at criticisms and eventually resulted in his dismissal. The difficulty of accepting new evidence contradicting established norms or paradigms is sometimes known as the Semmelweis reflex. Only after Pasteur and others developed the germ theory did Semmelweis, about two decades posthumously, gain recognition as a pioneer of antiseptic procedure (although the original hypothesis of "atmospheric cosmic-telluric changes" did not really hold water). Much of Semmelweis' fate is sometimes attributed to his frustration, rage and ego, and brutishly questioning the cleanliness of a noble profession did not help very much either. He was not the first to propose disinfection (hygiene) as a valuable tool, but the empirical approach of Semmelweis to refine his hypotheses is now a case study in experimental logic. (Dunn, 2005; Loudon, 2005)

\section{Statistics and selection biases}

"There are three kinds of lies: lies, damned lies, and statistics" - a quote popularized by Mark Twain ${ }^{1}$. Statistical mathematics is one way to mitigate subjectivity in the interpretation of data, but its subjectivity is only as solid as its applica-

1. Twain himself attributes it elsewhere, but the original source of the quote is unconfirmed. 
tion (Nuzzo, 2015). The use of statistics and statistical thresholds, the $p$-value in particular, is ubiquitous in scientific writing but has received a fair share of criticism. If statistics are used correctly only in the last step of an experimental pipeline then the selection and hypothesis biases that precede it will still cast doubt over the final conclusions (Leek \& Peng, 2015). The degree of potential experimental failure, statistically speaking, is astounding. In a meta-study by Ioannidis it was predicted that about $50 \%$ of studies showing results with $p<$ 0.05 (the current golden standard of statistical thresholds in biology) are false positives (Ioannidis, 2005). This was considered too severe (S. Goodman \& Greenland, 2007), and a study with a different approach suggested that at most $14 \%( \pm 1 \%)$ were false positives (Jager \& Leek, 2014). Ioannides responded to both papers (Ioannidis, 2007, 2014) and the debate rages on.

Being keen and motivated can lead to believing strongly in one's hypotheses, causing a belief bias. This can result in attentional bias and anchoring - focusing on the expected finding and ignoring other indications within the data (Tversky \& Kahneman, 1974). It is also common in such a state to assign significant meaning to a vague or random stimulus. This can be very difficult to recognize when combined with insufficient experimental controls or alternative inputs, and is exasperated by a lack of intellectual reflection. For an entire field of research such biases can result in false consensus through a bandwagon effect. It is especially likely if authority figures in the field present with overconfidence (Golembiewski, 1964) (which they often do in the biomedical community), or if a popular hypothesis is finally said to be supported (congruency bias) despite lacking strict validity (Chaiken \& Maheswaran, 1994).

There is a degree of innocence in these biases in their somewhat involuntary nature, but with competitive pressures at all levels of academia there is also sufficient motivation to fall into the trap of normal misbehavior (de Vries et al., 2006). This is a difficult problem to tackle because it is not as dramatic as fabrication, falsification or plagiarism and it is a rather widespread behavior. One report states that a third of researchers admit to it, and that $70 \%$ claim to know of normal misbehaviours among colleagues (Fanelli, 2009). It presents itself as questionable management of data - such as ignoring selection biases, narrowing datasets by generous definitions of outliers, diminishing the importance of controls and avoiding to test alternative hypotheses. Several types of misconduct falling under normal misbehaviours relating to the way a study is performed, credited or reported is more common in mid-career than early-career scientists (Martinson et al., 2005).

There are numerous other human fallacies and biases that go without mention in this chapter and I am by no means a scholar of human behaviour. It may soon become necessary to include half an academic degree of behavioural psy- 
chology in any scientific education just to achieve a more productive general level of self-awareness among scientists. Then again, there has been considerable recognition of these problems in mainstream science for at least the past decade. It seems that scientists today need not only battle themselves to remain objective but also their environment, which provides temporal and economic incentives to produce more, and more popular, findings rather than spending time getting everything right. Publish quickly, or perish.

\section{Beauty, Evil and Ethics}

When confronted with an unavoidable problem humans solve it. Some humans perform problem solving even if the problem seems entirely avoidable, and others actively go in search of a problem that has not yet been discovered and then try solving it. Necessity drives the first case, curiosity the second, and obsession the third. In all cases, the scientific method is arguably the only way for reliable knowledge to be attained. But there is also appreciation for an elegant theory, one that optimizes the explanation of a phenomena and sharpens our understanding of it. The simplest form of Darwin's theory, that environmental challenges modifies the statistical survivability of quasi-random genetic traits, is beautifully rational. Einstein's $E=m c^{2}$ is a simple formula with profound implications. Likewise, an elegant experiment can attain aesthetic qualities. Using the transcriptional machinery of thermophiles to create in vitro nucleic acid replication (the Polymerase Chain Reaction; PCR) was a gorgeous insight (and now seems so obvious), much like using the bacterial CRISPR and Cas proteins to edit genes in living organisms.

"Van Gogh didn't call the painting Sleepy Village, Cypress Tree, Church Steeple, Hills. It is the first painting that I know of ... [in which] the background is the subject of the painting, and that background is the night sky, and it elevated the cosmos to become fair game to the artist. I submit to you that science, scientific discovery, especially cosmic discovery, does not become mainstream until the artists embrace the fruits of those discoveries. So I applaud Vincent van Gogh for thinking that the sky is what mattered more than anything in the foreground for this painting."

-Neil DeGrasse Tyson, astrophysicist, commenting on van Gogh's Starry Night, Arizona State University, 2014

Beauty (and your opinion of van Gogh) aside, there are many examples of horrible events that have been attributed to scientists or scientific discoveries. Technological advantage has a huge impact on the balance of geopolitical power (especially in times of war), and consequently the science produced during war has a tendency to focus on massive destruction. The atomic bomb may be 


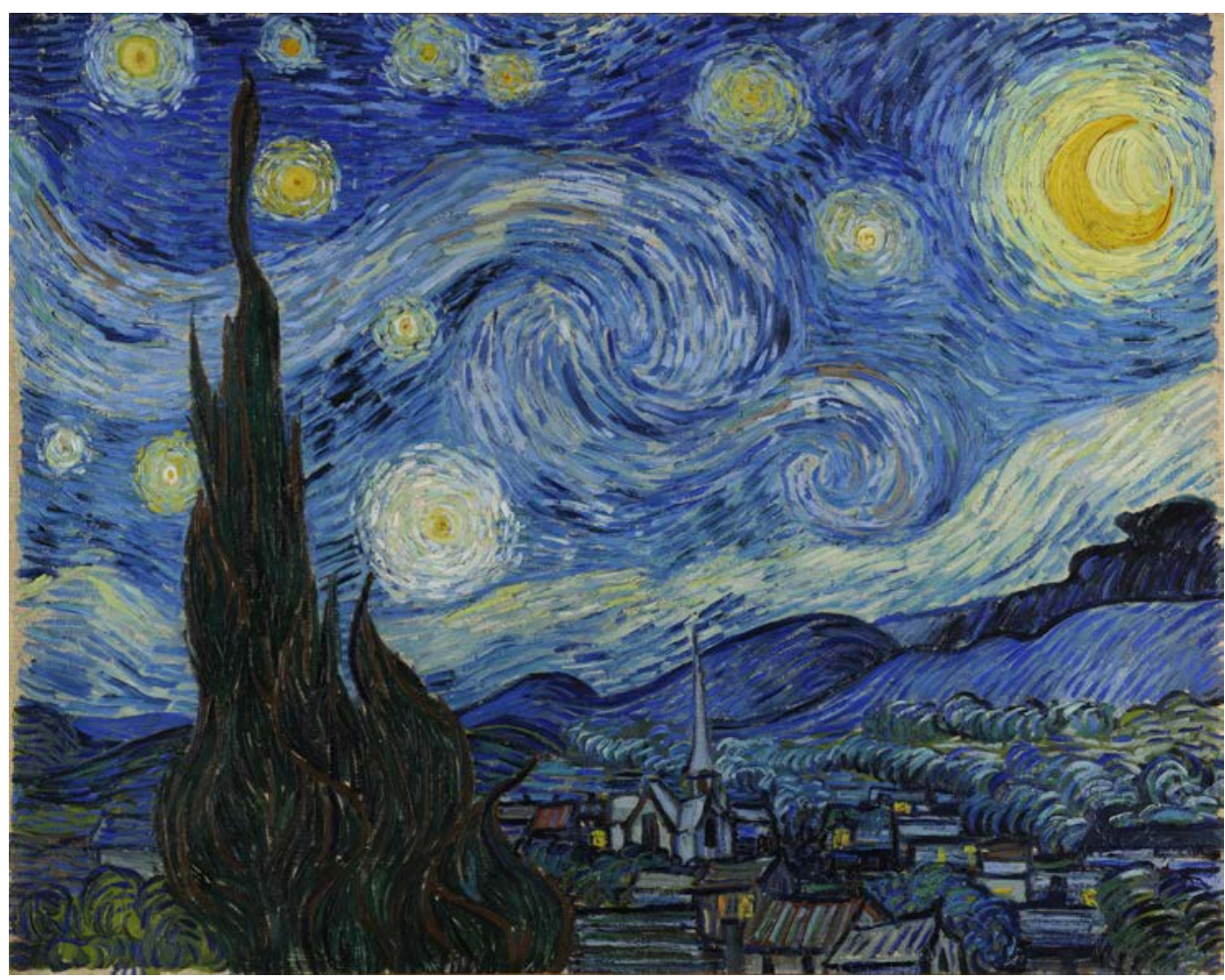

Photograph of van Gogh's Starry Night.

(image in Public domain; bgEuwDxel93-Pg at Google Cultural Institute)

the example of this. There is no worldwide ban on atomic weapons probably because of the need of nations to maintain an insurance of "mutually assured destruction". There is, however, a ban on what is possibly a worse threat than nuclear arms: biological weapons. The Biological Weapons Convention (1975) is signed and ratified by nearly all countries and it bans the "development, production, acquisition, transfer, retention, stockpiling and use of biological and toxin weapons"2.

Some of the most notorious unethical research stems from WWII, such as the research on human limits during extreme environmental exposure. The World Medical Association was set up after WWII (in 1946) with the aim of setting global ethical guidelines for physicians. The Declaration of Geneva, signed in 1948, even included a modern version of the Hippocratic oath. Continued work led to establishment of the Committee on Medical Ethics (1952) which was working on the issues raised during the Nuremberg trials regarding human experimentation without regard to the subjects' well-being. The result was a guide to ethics in biomedical research involving human subjects, the Declaration of Helsinki, signed in 1964. This was further detailed and revised in 1975

2. From the introductory text of the Convention as described on the official homepage of the United Nations Office at Geneva (www.unog.ch), accessed 2015-10-13 
in response to developing technologies and clarifying the differences between research with elements of therapeutic care versus research for scientific purposes. The document has been revised since, and is continually modernized.

Science itself is as "good" as the people doing it, which is why setting standards of conduct is important to minimize the risk of chaos and destruction. From a utilitarian perspective that which benefits the greatest majority the most is what is mostly right. In consequentialism it is held that beneficial actions must be carried out and actions that do not benefit man must be left alone. Deliberate omission and voluntary acts resulting in the same outcome are no different. Predicting the future, in human terms, has a high probability of leading to good and must therefore be considered ethically most right. Increasing our collective knowledge of the world is the right thing to do. From a deontological perspective, where the act and not the outcome determines righteousness, only action motivated by good will is truly intrinsically good. It says nothing then of the value of knowledge itself, but given that mutual understanding, education and co-operation creates an inclusive world in which good will is more easily shared such a world should be considered ethically sound. These attributes are enabled by knowledge; which science can provide. So if increased knowledge for the betterment of mankind is your goal as a scientist, then you are righteous.

Regardless of your personal view on ethics, right and wrong, you have a minimum of ethical safety to fall back on by following the set guidelines of conduct when you are in doubt. How to perform the experiments in an ethical way is what the ethical guidelines and regulations are all about. 
I wish I could state that the work presented in this thesis is without bias, but that would make me somewhat inhuman. On the one hand, an increased awareness of the extent of sensory, psychological as well as intellectual biases that may taint my work, allows me to try to mitigate their effects. On the other hand, economic incentives, time constraints, a culture of publishing, and the academic environment could counteract my efforts.

Our research has followed all the ethical rules and guidelines as set by the university, the country of Sweden, the European Union, and international conventions. In the end, while I may question many choices made along the way, I believe that I have represented my data truthfully. How to perform scientific research may be a study in rationality, but one must certainly learn how to apply this in reality, given our human nature. Time will tell whether our conclusions have been drawn correctly, but in this thesis deeper discussions opened by our research will at least find a medium to expand in. 


\section{Section References}

Chaiken, S. \& Maheswaran, D. (1994). Heuristic processing can bias systematic processing: effects of source credibility, argument ambiguity, and task importance on attitude judgment. J Pers Soc Psychol, 66(3), 460-473

de Vries, R., Anderson, M. S. and Martinson, B. C. (2006). Normal Misbehavior: Scientists Talk about the Ethics of Research. J Empir Res Hum Res Ethics, 1(1), 43-50

Dunn, P. M. (2005). Ignac Semmelweis (1818-1865) of Budapest and the prevention of puerperal fever. Arch Dis Child Fetal Neonatal Ed, 90(4), F345-348

Fanelli, D. (2009). How many scientists fabricate and falsify research? A systematic review and meta-analysis of survey data. PLoS One, 4(5), e5738

Golembiewski, R. T. (1964). Authority as a Problem in Overlays: A Concept for Action and Analysis. Administrative Science Quarterly, 9(1), 23-49

Goodman, S. \& Greenland, S. (2007). Why most published research findings are false: problems in the analysis. PLoS Med, 4(4), e168

Hasher, L., Goldstein, D. and Toppino, T. (1977). Frequency and the conference of referential validity. Journal of Verbal Learning and Verbal Behavior, 16(1), 107-112

Hohwy, J. (2007). Functional Integration and the Mind. Synthese, 159(3), 315-328

Holland, J. L. (1985) [Book]. Making vocational choices: a theory of vocational personalities and work environments. Prentice-Hall.

loannidis, J. P. (2005). Why most published research findings are false. PLoS Med, 2(8), e124

loannidis, J. P. (2007). Why most published research findings are false: author's reply to Goodman and Greenland. PLoS Med, 4(6), e215

loannidis, J. P. (2014). Discussion: Why "An estimate of the science-wise false discovery rate and application to the top medical literature" is false. Biostatistics, 15(1), 28-36; discussion 39-45

Jager, L. R. \& Leek, J. T. (2014). An estimate of the science-wise false discovery rate and application to the top medical literature. Biostatistics, 15(1), 1-12

Kruger, J. \& Dunning, D. (1999). Unskilled and unaware of it: how difficulties in recognizing one's own incompetence lead to inflated self-assessments. J Pers Soc Psychol, 77(6), 1121-1134

Kuhn, T. S. (1962) [Book]. The structure of scientific revolutions. Chicago, Univ. of Chicago Pr.

Leek, J. T. \& Peng, R. D. (2015). Statistics: P values are just the tip of the iceberg. Nature, 520(7549), 612

Loudon, I. (2005). Semmelweis and his thesis. J R Soc Med, 98(12), 555

Martinson, B. C., Anderson, M. S. and de Vries, R. (2005). Scientists behaving badly. Nature, 435(7043), 737-738

Nuzzo, R. (2015). How scientists fool themselves - and how they can stop. Nature, 526(7572), 182-185

Postmes, T., Spears, R. and Cihangir, S. (2001). Quality of decision making and group norms. J Pers Soc Psychol, 80(6), 918-930

Tversky, A. \& Kahneman, D. (1974). Judgment under Uncertainty: Heuristics and Biases. Science, 185(4157), 1124-1131 


\section{Part 1: \\ CELLS, STEM CELLS \& DIFFERENTIATION}




\section{On the identity of cells}

Biology does not begin with the question of the chicken or the egg, but simply with an egg and a sperm. Each with one unique set of chromosomes, they combine to form the first complete diploid cell of a new life. The cell division cascade that follows confers increasing specialization to groups of cells, and ideally results in the formation of a foetus to be born as a brand new human.

The first few cells are totipotent, meaning that they can each support the creation of any known human cell type - likely even create an entire body, if required (Driesch, 1893). Cell division continues, multiplying the number of cells inside the "zona pellucida" (analogous to an egg-shell). After about 5 days and roughly equally many cell divisions $(32+$ cells), and for the next two days, an obvious cellular specification occurs: the trophoblasts that will later become the amnion and placenta and infiltrate the host; and the inner cell mass (embryoblast), poised to develop into the new human (and amnion and yolk sac). This inner cell mass is a common source of embryonic stem cells.

At this stage these cells are considered pluripotent because they can produce any cell type of the human body. As the inner cell mass grows, through cell division, the cells become differently stimulated resulting in a myriad of synchronized molecular activities. After another 10-14 days the inner cell mass undergoes additional stages of growth and organization and the three main germlines appear: the ectoderm, the mesoderm and the endoderm. All subsequent tissue is then classically defined as having ectodermal, mesodermal or endodermal origins.
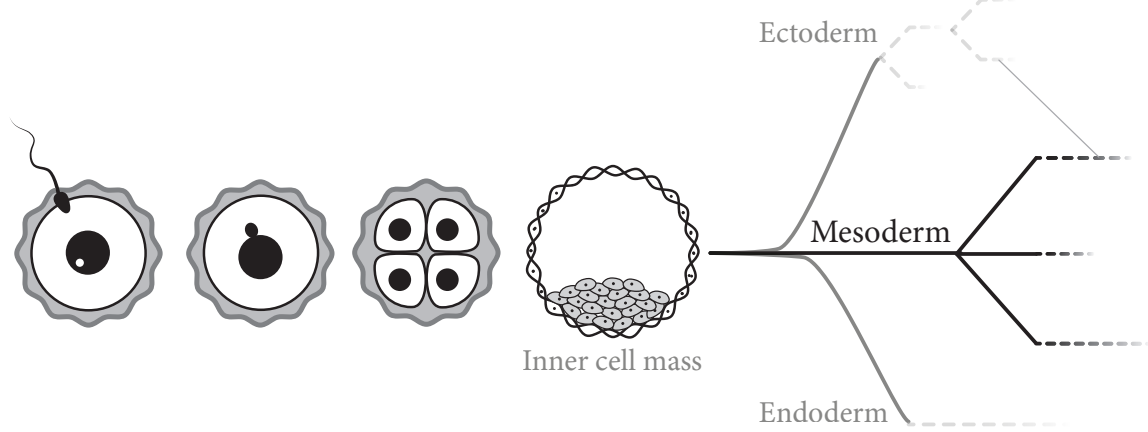

Simplified view of the progression from fertilization to gastrulation and differentiation of the three germ-lines. Later, some lineages again converge as mature cells.

The endoderm will develop into the "insides", that is liver, the respiratory tract, pancreas, endocrine glands, gastrointestinal tube and more. The mesoderm ("inbetween" layer) becomes the skeleton, connective tissue, fat, circulatory system, lymphatic system, muscles and bone marrow. The ectoderm ("outer" layer) becomes the epidermis, including hair, nails, cornea (altogether termed the integumentary system), and interestingly also the peripheral and central 
nervous systems (neuroectoderm: brain, spinal cord and nerves). In later stages, mesodermal lineages also arise from the neuroectoderm.

In the subsequent days and weeks, the three germlines will themselves specialize and start creating multiple primordial tissues, which will become positioned and connected appropriately as they grow and develop. After germ-line specification (endo-, meso-, and ectoderm), the cells are considered multipotent, meaning that they give rise to any subsequent cells within their lineage, such as the haematopoietic stem cell and its differentiated blood cell offspring. There may be different degrees of multipotency, restricting as the cell becomes more specialized until they become progenitor cells - able to give rise to a predetermined terminally differentiated cell type or line of precursors.

\section{Historical context of specification}

The idea of a biochemical essence that is present in all cells and determines how the first cell develops into a full body is over 200 years old. In the late 1800 's the competing theories of development were those of preformation $v s$. epigenesis, or autonomous $v s$. conditional specification. Preformation suggested that all cells had the information necessary for autonomous specification of their adult fate, and was supported by lesioning certain cells in the early embryo resulting in an embryo missing those features. Epigenesis instead suggested that all cells had all the information, and that the process of cellular development was conditional upon interactions with neighboring cells.

August Weismann, in proposing his germ plasm theory (Weismann et al., 1893), suggested four approaches to investigating specification: causing a cellular defect in the embryo, isolating parts of the embryo to observe continued development, recombining the order of cells in the early embryo, transplanting parts of the embryo to another embryo .

Wilhelm Roux killed one of the two blastomeres of an amphibian embryo with a hot needle and observed that the surviving blastomere continued to produce half an embryo (Roux, 1881). These findings supported the preformation idea. In an attempt to replicate these findings, Hans Driesch separated the four blastomeres of a sea urchin and allowed each to develop separately (Driesch, 1893). In what seemed like a paradox, they were all capable of producing whole embryos, instead of resulting in four quarters - supporting epigenesis.

Driesch continued to perform mechanical perturbations of the embryo, and switching positions of cells, and yet despite these efforts he obtained complete 
embryos $^{3}$. While the relationship between nucleus and cytoplasm was assumed to be important for the expression of the nuclear essence, the development of embryological theory also came to involve the extracellular milieu as an important factor for continued specification (Hertwig, 1900). Further experiments, notably by Spemann, showed that the embryo developed certain parts that exerted control over the developmental organization of the embryo as a whole. Hilde Mangold, working under Spemann's supervision, continued experimenting with the blastopore lip, termed the organizer. This proved the existence of a spatiotemporal feature explaining epigenesis, solving the paradox.

The organizer has the role of inducing cells of the embryo to specify as an organized whole, and is the starting point of gastrulation. We now know that the cells of the organizer are of mesodermal origin, and exert influence on the development of the ectoderm. The blastula secretes bone morphogenetic protein (BMP)-4 which induced skin in the ectoderm, but the organizer blocks BMP4 through secretion of Chordin and Noggin (there are also numerous other molecular cues). This results in the ectoderm near the organizer to develop along a neuroectodermal fate instead of becoming skin. On a larger scale, these signaling cascades also determined dorsal-ventral patterning in most animal species. (reviewed in (De Robertis, 2009))

The development of the mesoderm has been explained by a three-signal model (germ layer specification extensively reviewed in (Kiecker et al., 2016)). Candidate factors for mesodermal specification include fibroblast growth factors (FGF), transforming growth factors beta (TGF- $\beta$ ) (specifically Activin A, and members of the BMP family), and Wnt/ $\beta$-catenin signaling (Kiecker et al., 2016).

Many molecular signals that organize embryological development have been unraveled. We know about some molecular signals required for the specification of the germ layers, the further induction of fates, the development of primordial tissues, and their differentiation to maturity. Of the debate between preformation and epigenesis, the latter has survived. It is also evident that there are foundations for both conditional and autonomous specification, the autonomous being the default state of any cell in a mundane environment, and the conditional being its response to extracellular cues.

3. Unable to form a new theoretical framework of the seemingly paradoxical results (both preformation and epigenesis could be supported by different experiments), Driesch postulated a philosophical idea of vitalism - that the essence of all living cells was beyond physical manipulation of man, and continued his career as a professor of philosophy. 


\section{Epigenetics and cellular identity}

All cells share the fertilized egg as their common ancestor, and so they all also share the same genetics ${ }^{4}$. The DNA serves as a library of blueprints (genes) for the production of functional proteins and is unique for each individual, but exists as near-perfect identical copies within each cell of an individual's body. John Gurdon believed that, in theory, all cells have the necessary information to become any other cell of the body (Gurdon et al., 1958).

How the DNA is used is regulated by the cell (a function of lineage and environment), so we end up with groups of cells that have the same DNA regulation on account of their local environment during development and the common ancestry during cell replication, and therefore the same biological capabilities (Hertwig, 1894). Such a grouping of cells with the same (or similar) functional DNA regulation becomes defined as a "cell type" and given a unique name, like "fibroblast" or "keratinocyte". There are types with very specific functions, such as melanocytes, that require a very strict supporting environment. There are also very tolerant cells that are highly adaptable to changes in their surroundings, such as fibroblasts.

The DNA sequence may be the unique determinant for an individual organism but regulation of the DNA machinery is what determines the biological functions of cells. The past few decades have seen important expansions on the central dogma, complicating the idea of transcripts from gene sequences being translated into protein sequences, folded into proteins and post-translationally modified into activated proteins, into one that has developed into the field of epigenetics: how the state of the DNA is regulated to determine when and how genes are made available.

Conrad Waddington is renowned for his model of the epigenetic landscape (Waddington, 1936; Slack, 2002), sketching a landscape inspired by the paths carved by water to illustrate the choices, and irreversibility of those choices, as a cell develops from a pluripotent cell along its path toward a defined lineage. Waddington's work invokes embryological organizers that determine developmental fates, and builds on the characterizations by Spemann and Mangold, among many others (Waddington, 1936).

The DNA in humans is organized in 23 pairs of chromosomes, packed together by histones and other protein complexes. The smallest unit of chromatin fiber is organized in nucleosomes - 146 bp DNA wrapped around a histone octamer. The nucleosomes form a $10 \mathrm{~nm}$ fiber which folds into a $30 \mathrm{~nm}$ chromatin fiber, but the organization beyond that is largely unknown (Lucas et al., 2011).

4. With specific exceptions: haploid germline cells, chimerism, immune gene-scrambling, acquired mutations and viruses etc 


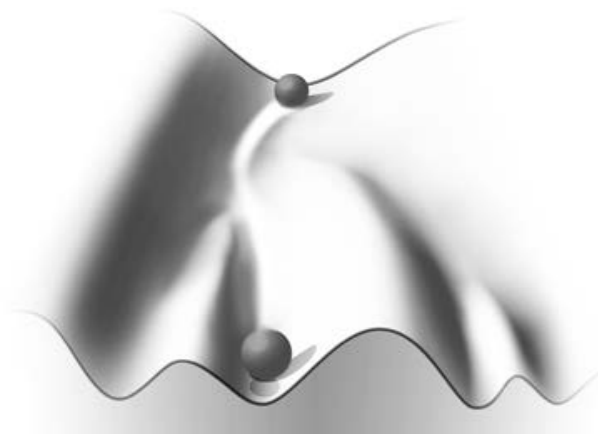

Sketch of Waddington's landscape, showing a cell developing along one of several possible choices. (adapted from Waddington, 1957)

A number of models have been proposed that invoke descriptions of transcription factories (Iborra et al., 1996), where DNA is recruited to, and drawn through, relatively large and immobile polymerase complexes resulting in rosette-like structures (Lucas et al., 2011). This new understanding of chromatin organization has huge implications on how we can think about the recruitment of factors, and action of transcriptional regulators in the nucleus (Chakalova $\&$ Fraser, 2010). The nuclear architecture, its organization and dynamics, promotes the temporal and spatial segregation of DNA and regulating factors and mediates epigenetic regulation. The epigenome refers to the sum total of cellular mechanisms that are responsible for mediating the proper execution of genomic programs (Qureshi \& Mehler, 2010), but the mechanisms of epigenetics are still far from fully understood (Goldberg et al., 2007).

Epigenetics can be summarized as mitotically and meiotically inheritable alteration to chromatin structure that are not coded in the sequence of DNA itself (Levenson \& Sweatt, 2005). There are three primary modes of epigenetic regulation: DNA methylation, histone modifications, and microRNAs. Methylation of DNA involves covalently modifying Cytosine in CpG islands resulting in repression of gene expression. The various DNA methyltransferases are implicated in a number of cellular functions, including differentiation, cell fate determination and genomic imprinting (Li \& Zhao, 2008).

Histones, protein complexes that bind and organize DNA, can be phosphorylated, methylated or acetylated (and more), resulting in activation or repression depending on where the modification is located. The complexity and importance of histone modification is illustrated by the discussion of a histone code (Cosgrove \& Wolberger, 2005). It is important for maintaining regulation and stability of chromatin state during gene expression and mitosis. Histone acetyltransferases and histone deacetylases are the two main families of enzymes that catalyze acetylation modifications, and they are included in important complexes, such as the Polycomb Group proteins, that are important regulators of gene expression states in early stem cells (T. I. Lee et al., 2006). 
RNA interference is a family of mechanisms whereby short strands of microRNA (miRNA) result in the destruction of complementary gene transcripts, hindering translation. By genetic knock-out experiments, it has become clear that miRNA mechanisms are crucial regulators of embryonic development (Bernstein et al., 2003; J. Liu et al., 2004; Yang et al., 2005). There is evidence of cross-talk between the different epigenetic mechanisms, but the full complexity is yet to be unraveled (Li \& Zhao, 2008).

Our understanding of cellular identity is on the whole still incomplete. The defining characteristics have traditionally been morphology and anatomical location, but with the development of protein recognition methods the expression of key proteins have become more heavily relied upon. Protein profiles are themselves incomplete, but with some understanding of function the use of protein profiling together with anatomical location and morphology is sufficient to distinguish many cell types.

Current technological developments are allowing a genomic approach to refine the definitions of cells (Lenz et al., 2015) and eventually also more finely distinguish between them. Gene expression occurs prior to protein expression, and can help identifying cells progressing through lineage development. Newly developed single-cell gene expression techniques have vastly increased the understanding of cellular identity. The state of the DNA at certain loci (epigenetic markers) provides further defining variables that help determine cell type and stage.

Likely, the categorical semantics of cellular identity will need to develop somewhat (Askenasy et al., 2006; Tajbakhsh, 2009). A cell of a certain type may be considered active or dormant (quiescent), in development or in replicative senescence, a stem cell or terminally differentiated, but where exactly is the border between different cell types? Are cell types all sufficiently dissimilar that the ridges in Waddington's landscape are impassable, or are cell type characterizations more strongly reliant on the current functions of the cell? In some cases, the switch of a single gene in a lineage context defines a transient cell type (Zandi et al., 2010), whereas the activation of a whole set of genetic cascades defines the activity, not type of cell, in other cases (Dayem et al., 2003).

A cell that stores and regulates fat, an adipocyte, has a different definition requirement than a fibroblast that has been induced to store and regulate fat. They may seem functionally and morphologically similar, but cannot be considered the same cell type because of our knowledge of their different lineages. Differentiation changes are also often limited to a laboratory context, so what relevance such cell inductions have in the human body, or if they even occur, is in many cases uncertain. 
Today, cell type definitions are seen in their specific context, and where the knowledge seems more complete the definitions are also more detailed. With increasing understanding of cellular mechanisms, we should also gain a greater appreciation for the defining characteristics of cell types, and perhaps separate lineage from function in a more useful manner. One might imagine a cell definition system based on DNA state at a resolution that provides statistically informative details about temporal development, lineage relationships, and functional characteristics and that can distinguish very small cell populations in the adult.

\section{Adult mesodermal stem cells}

Most of the human biological development occurs in utero, so nearly all tissue has become specialized by the time of birth. Terminal differentiation and tissue development completes in the first few years of life meaning that the majority of cells are more or less tissue-specific from then on. As we grow into adults, our cells become preoccupied with tissue homeostasis rather than growth and development. At this stage, adult cells are capable of maintaining most aspects of their tissue functions, including repairing damage.

The inevitability of aging and death lends some rationality to the thought that the infinite capacities of stem cells are somehow lost during our lifetimes, an obvious hint that stem cells do not remain in adults. However, the biological paradigm has switched to one that supports the notion of stem cells being comparatively few in number but omnipresent. The "adult" in adult stem cell refers to stem cells found in humans in adulthood, cells that remain for most of our lifespan. The shift was, in part perhaps, initiated by the realization that blood cells (and other rapidly renewing tissue) were continually replenished throughout life.

One of the determining differences between a cell and a stem cell is the theoretical capability for stem cells to replicate indefinitely (thereby considered immortal). It was only in the 1960's that knowledge was gained of a finite cellular life-span (Hayflick \& Moorhead, 1961). The mechanism was eventually identified as the miniscule degradation of telomere end-caps of the chromosomes at each cell division (Szostak \& Blackburn, 1982). Stem cells, unlike normal cells, express the gene hTERT which gives rise to the enzyme telomerase, which has the capability of maintaining telomere length (Greider \& Blackburn, 1985). Once telomeres are sufficiently shortened, cells enter a non-dividing end-state which protects against DNA replication problems during cell division but leaves the cells senescent. This is why cell replication ends at Hayflick's limit, after roughly 40 cell divisions. 
Stem cells divide asymmetrically, creating a stem cell copy and a more committed progenitor cell. This allows the stem cell to maintain its population size while providing for cell amplification. Usually, the immediate generations following the stem cell division are transit amplifying cells (Potten, 1986). Their phenotype becomes more determined and they proliferate to create a noticeable increase in cell numbers dedicated to terminal differentiation. The asymmetric division is called upon in adults when the need arises for the stem cell pool to replenish cells of their tissue.

The discovery of the hematopoietic stem cells of the bone marrow (a process beginning with Cohnheim, Pappenheim and others, from the mid-1800's (Becker et al., 1963; Ramalho-Santos \& Willenbring, 2007; Maehle, 2011)) eventually led to attempts to treat radiation damage and blood cancers using allogeneic bone marrow transplantation. After partial success in mouse models (Rekers et al., 1950), a human trial was performed by E.D. Thomas (Thomas et al., 1957), now considered the pioneer of bone marrow transplantation.

The first six-patient trial was not successful in saving the patients beyond 100 days, but a subsequent 100-person trial a decade later was (Henig \& Zuckerman, 2014). The reason for the different outcomes was the discovery of human leukocyte antigens (HLA) around the same time (Dausset, 1958), which allowed compatibility screening and made transplantation a possible treatment for blood cancers and radiation damage (both Dausset, in 1984, and Thomas, 1990, received the Nobel prize for their work).

By the 1960's, the marrow stromal cells were recognized as a heterogeneous fibroblast population residing near the haematopoietic cells. Friedenstein and colleagues used fibroblast colony forming assays (CFU-F) to investigate bone marrow fibroblasts and their capacity for microenvironment maintenance and differentiation (Friedenstein et al., 1974; Friedenstein et al., 1976). Believed to have an important role in supporting hematopoiesis, Friedenstein adopted the hypothesis proposed by Alexander Maximow (Maximow, 1902), of a stromal-hematopoietic relationship dictating hematopoiesis (Friedenstein, 1989).

Friedenstein's work showed the importance of growth factors such as TGF, EGF, FGF and PDGF for maintenance and differentiation of multipotent cells in vitro (Kuznetsov et al., 1997). This research also expanded our understanding of surface antigen profiles of the stromal populations, laying much groundwork for today's use of CD markers in the stromal-haematopoietic system in particular. Today, the haematopoietic system is arguably the most delineated and defined system of cell development, and serves as a strong example for the delineation of any hierarchical adult cell development system.

Adult stem cells are necessarily present in all renewable tissue (Leblond et al., 
1976). It was long held that the brain was devoid of stem cells, a final bastion of non-renewal. This was supported by the sensitive and strictly controlled environment of the brain, and the belief that neuronal plasticity rather than healing or regeneration was the main mechanism for coping with tissue trauma. The reputed "father of modern neurobiology" Santiago Ramón y Cajal considered the brain a quiescent organ - unable to create new cells postnatally (Gonzalez-Perez, 2012). Small pools of stem cells were discovered in the mouse striatum by Reynolds and Weiss in 1992 (Reynolds et al., 1992) that could be engaged in creating new neurons. When finally, such cells were also found in humans (Sanai et al., 2004) this allowed us to accept the notion that our body contains pools of stem cells within all tissues, which has boosted research into ways of manipulating these cells to help patients recover from disease.

It has been suggested that early stem cells can be maintained into adulthood by dispersion into all the different tissues as they develop (Kucia et al., 2006). Identification of epiblast-derived cells in the adult bone marrow raises the question of whether these cells continuously contribute to the renewal of tissues, and thus can be reactivated for tissue regeneration (De Miguel et al., 2009). Such pluripotent cells have been found in many adult tissues (Kim et al., 2014), but their existence remains controversial - both in terms of scientific reproducibility and theoretical basis (Miyanishi et al., 2013).

\section{Clinical potential and considerations}

The understanding that stem cells remain in adulthood allows for the belief that the regenerative capabilities of prenatal humans may also remain somehow in the adult. Regenerative medicine is the field focused on harnessing the body's regenerative capabilities, and tissue resident stem cells are targets of particular interest. The emergence of regenerative medicine, cellular engineering and tissue engineering really amplified the amount of research done on adult stem cells during the 1990's and onwards.

The potential of unlocking not only human regeneration but also understanding of how to construct "body parts in the lab" (Kratz, 2005), has spurned a race towards clinical applications. With this amazing potential, backed by the life-saving results of bone marrow transplantation, the focus on clinical applications of stem cells is too important to neglect.

The findings of Dausset helped Thomas to design a more successful regimen for bone marrow transplants by showing the need for donor-recipient matching of HLA type. The HLA molecules are surface markers present on most cells in our bodies that allow our immune cells to recognize our own cells as self. When foreign cells with mismatched HLA come in contact with immune cells, or foreign peptides are presented in conjunction with a compatible HLA to the 
immune cells, the cells of the immune system react in concert to destroy these cells that are considered intruders.

When a non-compatible transplantation is performed the immune reaction, termed host-vs-graft or graft-vs-host reactions depending on which immune cells start reacting, causes the destruction of otherwise healthy tissue and can threaten the life of the patient. Cells of the immune system that would react to the foreign material can be inactivated by various types of immunosuppressant treatments. This may allow the transplantation to succeed, but instead immunocompromises the patient, which can lead to other life-threatening problems.

Allogeneic transplants are matched in a way to avoid immune reactions, and we now have a good idea of how compatible different types of transplants need to be for likely success. Allogeneic transplants are still problematic because of the scarcity of allogeneic donors. This is marginally alleviated by the use of xenotransplants, using material from pigs for example, but this is still immunologically complicated ${ }^{5}$.

Autologous transplants, where the donor is also the recipient, completely removes the immunological problem since the material is fully compatible; to some degree it also addresses the problem of scarcity. There are obvious problems with this option. First of all, in cases of organ failure there are no functional autologous organs available. Secondly, in cases such as cartilage destruction in the knee, while there are sources of cartilage available, harvesting will cause a new wound in the healthy tissue while not perfectly healing the recipient site - resulting in two damaged sites instead of one. Both of these problems may possibly be overcome by instead harvesting stem cells, creating new tissue in the lab, and giving back the autologous cells or constructs to heal the patient.

This brings us to the third problem of autologous material: the use of autologous cells to engineer new tissue adds between several weeks to several months to the treatment of the patient since cells need to be isolated, expanded, differentiated, correctly constructed and quality controlled before being returned. If we are able to produce standardized functional methods for tissue creation in a timely manner, then the promises of autologous stem cells and tissue engineering can be fulfilled. The most popular proposition for solving this problem today is to use prefabricated biocompatible materials that require only autologous stem cells to become functional upon transplantation. A proposition that seems to be more difficult in practice than it sounds.

Damaged heart muscle may be partially repaired by transplanting autologous stem cells, but it is not a standard clinical procedure as these trials lack a large

5. The use of transgenic pigs for xenotransplantation was recently reviewed in: (Niemann \& Petersen, 2016). 
systematic body of evidence for success (Willerson, 2015). Damaged blood vessels (Shinoka \& Breuer, 2008) and urinary tracts can be repaired by giving back tubes engineered from autologous cells (Fossum et al., 2007). Damaged articular cartilage may be repaired by autologous chondrocyte implantation (Brittberg et al., 1994). There are many applications for autologous cell therapy, and having to only isolate one cell source to enable any and all of these options holds great clinical promises.

One major boon for cell-based therapy is the low immunogenicity displayed by mesenchymal stem cells (MSC) and similar adult multipotent progenitor cells. This may allow for both allogeneic as well as autologous therapies. It is relatively easy to avoid immunogenic host-vs-graft reactions from allogeneic sources of MSC as they may not elicit alloreactive proliferation even in HLA-incompatible individuals (Le Blanc et al., 2003). Furthermore, anti-inflammatory and immune-modulating effects have also been attributed to MSC (Bartosh et al., 2010).

Administering these adult stem cells through the blood-stream is considered the least invasive, and safest, route of delivery. However, there have been issues with cells transplanted into the blood-stream collecting in the lungs and being destroyed (Schrepfer et al., 2007; Fischer et al., 2009), and there may exist issues with mechanical activation of clotting factors after stem cell infusion (Tatsumi et al., 2013). The relatively large size of infused cells can also block the blood flow in the microvasculature causing a thromboembolism (Toma et al., 2009). Tissue factor activation, and the appearance of thromboembolisms, may be alleviated by heparin coating of cells before injection (Gleeson et al., 2015).

One motivation behind intravenous injection of stem cells is their suggested ability of homing-in on damaged tissue from the circulation (Endres et al., 2007; J. Wu et al., 2008). Several mechanisms have been suggested to explain the homing ability, but their relevance are yet to be determined (Eseonu \& De Bari, 2015). The efficiency of this homing characteristic has been very low, and is also a function of the distance to the damaged tissue from the injection site and the choice of delivery (aspects of MSC homing are discussed in: (Karp \& Leng Teo, 2009)). The extent to which homing is clinically relevant remains unclear.

It is very clear, however, that we need a better understanding of which cell sources are best for specific therapies and how these cells should be handled in a laboratory setting. Only with proper definitions and standardizations can the safety of clinical interventions be maintained. So far, the majority of trials involving stem cell infusion have had little adverse effects, but in some few cases the patients have died. While our knowledge of biology principally supports the use of stem cell therapy, we have yet to achieve standards of application. 


\section{MSC}

The marrow stromal cells defined by Friedenstein are generally known today as MSC (Horwitz et al., 2005). Mesenchymal stem cells, multipotent stem cells, mesodermal stem cells, marrow-derived multipotent stromal cells (and more) can all be found abbreviated "MSC". There are also numerous versions of the MSC abbreviation, all-in-all reflecting the erratic and explosive way that the field has grown in the past half-century.

Some consider the MSC to be the most potent of adult stem cells. Whether that is supported by biology or a result of congruency bias (focused research data) is yet to be determined. Briefly, MSC are considered a multipotent mesodermal stem cell population primarily found in the bone marrow stroma. MSCs, given a supportive environment, can give rise to all mesodermal cell types.

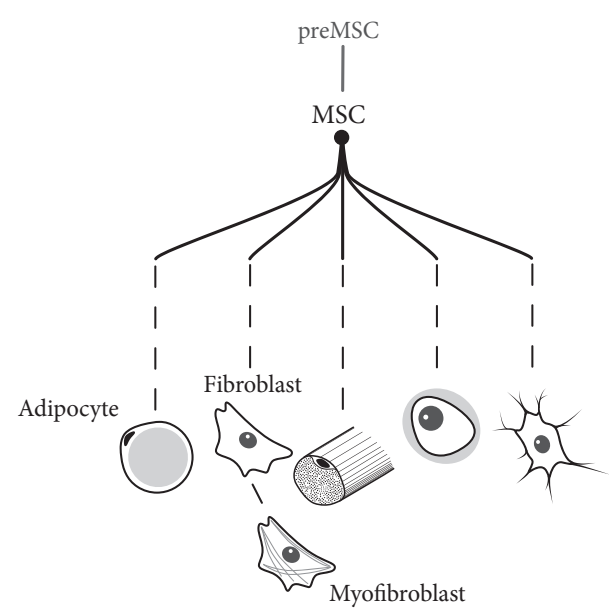

A simple view of the differentiation potential of MSC. Each extra dash represents a reported intermediate stage. (no label: muscle, cartilage, bone)

With the breadth of MSC research, including human cells as well as murine and other model systems, maintaining reproducibility is a problem for the field (Horwitz et al., 2005). One major reason for the varied terminology is that researchers cannot be certain that the population of MSC they have obtained is in fact the same population that other groups have obtained. The most important tool for defining cell populations has been the use of flow cytometry with panels of antibodies targeting cell surface epitopes. The antigens and epitopes have been compiled in a list of markers for cluster of differentiation, commonly known as CD markers.

Analysis panels of CD markers leads to defining CD profiles for cell populations, becoming part of the cell type definition by consensus. Alas, the CD markers that are queried have varied by research group, providing a serious source of discord and hindering direct comparisons between bodies of re- 
search. In recognition of the need for consensus and in lieu of seemingly arbitrary use of terminology the scientific community surrounding the research into MSC (the Mesenchymal and Tissue Stem Cell Committee of the International Society for Cellular Therapy) has agreed upon minimal standards for MSC definitions, including minimal criteria for the CD marker profile of MSC (Dominici et al., 2006).

The minimal criteria defining MSC are: plastic-adherent under standard culture conditions; expression of CD105, CD73, CD90 but not CD45, CD34, CD14, CD11b, CD79alpha, CD19 or HLA-DR; ability to differentiate to osteoblasts, chondrocytes and adipocytes in vitro (Dominici et al., 2006).

Multilineage differentiation protocols using supplemented medium based differentiation in vitro are readily available and easy to implement, but there is a danger that the foundational protocols are dated with respect to both phenotype characterization and inducing factors. This has led to an inflation of multilineage reports of questionable quality. There are several versions of differentiation protocols for each cell type, but there is a distinct lack of quantification of the differences in the resulting cell phenotypes.

There have also been obvious signs that starting populations show slight variations in their readiness to differentiate to the different lineages, but such variations are poorly understood and under-researched. The work towards harmonization of CD marker profiles and MSC isolation procedures are necessary to maintain the quality and trustworthiness of MSC research, but it is equally important to proceed with research into the resulting phenotypes after differentiation. Only then can we begin to understand what the functional limits are for the cells that we obtain through different protocols of in vitro differentiation. One approach to MSC standardization under in vitro conditions, is to obtain them by differentiation induced pluripotent stem cells, and thereby control their initial phenotype to a greater extent (Frobel et al., 2014).

The differentiation along mesodermal lineages is a requirement for the perceived biological consistency of the cell development framework of MSC. Still, there are reports of MSC differentiation along non-mesodermal lineages (Frenette et al., 2013). In theory, the MSC - like most other cells - contain the genetic information to produce any other cell types, but - like most other cells - their genomic landscape should not be so easily manipulated.

The jump from a mesodermal commitment to an ectodermal, or endodermal, fate is semantically considered a transdifferentiation event, and it reflects the stringency with which biologists have adhered to the model of progressive choice and restriction, like Waddington's. The reports of non-mesodermal differentiation are more varied than the more standardized mesodermal mul- 
tilineage protocols, and there is seldom enough corroborating evidence that such results are fully established or understood - and the problem of defining starting populations remains.

\section{ADSC}

Adipose tissue cells can be divided into two factions when isolated: the stromal-vascular faction (SVF), and the adipocyte faction. Mature adipocytes are filled with lipids and clustered, delineated by fine membranes, and float in culture. The cells residing near the vasculature, in the stroma of the tissue, are plastic adherent fibroblastic cells with the capacity for multilineage differentiation. The cells near the vasculature are responsible for creating new fat, and the discovery led to focusing more on the SVF (reviewed in: (Cawthorn et al., 2012)).

Liposuction is a popular elective surgery that has become a relatively safe and routine clinical procedure. The excised fat contains numerous cells, including preadipocytes - the precursor to adipocytes. Patricia Zuk and colleagues (Zuk et al., 2001) showed that the preadipocytes themselves were at least as potent as any known MSC in terms of in vitro differentiation, but were more easily obtainable and in larger quantities. Several studies have confirmed the potency of preadipocytes, or ADSCs (Adipose-derived (mesenchymal) stem cells).

The suggested sorting procedure for ADSC has varied with research group, and remains without clear consensus. The expression of CD markers on ADSC overlaps with MSC, with some differences in CD49f, CD54 and CD10 expression (Yanez et al., 2006). Another report suggests that ADSC are (within context) CD34+, CD31-, CD104b-, SMA- (C. S. Lin et al., 2010). There seems to be little practical difference in the cellular utility of ADSC and MSC, and perhaps ADSC are simply to be considered a version of MSC residing in adipose tissue (Hass et al., 2011).

While the fat deposits in our bodies can be considered part of the adipose organ in its entirety, there are distinct depots which develop discretely at different pre- and post-natal times (Spalding et al., 2008). The earliest fat deposits appearing during embryological development seem to arise from a common mesodermal progenitor, but the adult bone marrow also contains a multilineage adipocyte precursor (considered the MSC) (Gregoire et al., 1998). Although adipose development stems from mesodermal development, the split between other connective tissues and fat is yet to be determined (Cserjesi et al., 1995). Brown adipose tissue comes from the myogenic lineage, and intradermal deposits originate with embryonic dermal fibroblasts. 


\section{Pericytes}

Pericytes are located in the periphery of the circulatory system, and were discovered in the 1870's by Rouget (Krueger \& Bechmann, 2010) ${ }^{6}$. Since then, at least three variants have been distinguished histologically but even these populations have become recognized as being heterogeneous (Zimmermann, 1923; Krueger \& Bechmann, 2010). The pericytes are studied in their major roles in blood-brain barrier maintenance (reviewed in: (Dore-Duffy, 2008)), angiogenesis and neovascularization (reviewed in: (Bergers \& Song, 2005)). These cells seem to be able to function both as maintainers of dynamic microenvironments as well as respond with differentiation (Schor et al., 1995; Collett et al., 2003; Farrington-Rock et al., 2004).

The pericytes, found on capillary walls throughout the body, are myogenic in vivo and ex vivo but show multipotency, and their suggested profile is CD146+ NG2+ PDGFR $\beta+$ ALP+ CD34- CD45-vWF- CD144- (Crisan et al., 2008). They show similar plasticity as MSC, along with adhering to the minimal requirement of MSC definitions, but have been suggested to be mesenchymal progenies of the embryonic mesoangioblast which may account for their localization and surface marker profile (Dellavalle et al., 2007). Mesoangioblasts may be possible to isolate from adult tissue (Minasi et al., 2002), but whether these are in fact the same cell type is as yet undetermined. The embryonic hemangioblast is a proposed mesodermal precursor of the vascular and haematopoietic lineages (Choi, 2002), and may also be a candidate pericyte precursor (Bergers \& Song, 2005).

MSC, ADSC and pericytes are all mesodermally related multipotent adult stem cells. It is not clear which cell type is their last common precursor. All three cell types are described as heterogeneous, and are distributed throughout our bodies, but found in conjunction with slightly different niches. But how different are their niches, really? The MSC are cells of the bone-marrow stroma, a highly vascularized tissue in tight communication with the haematopoietic system. The ADSC are found in the SVF of adipose tissue, along the vasculature and in tight communication with the adipose organ. The pericytes are found along the vasculature throughout our bodies and organs, in tight communication with the endothelial and smooth-muscle cells.

The many striking similarities have opened for the discussion that MSC are pericytes (Crisan et al., 2008). A source of skeletal progenitors in the bone marrow have been identified as CD146+ subendothelial cells (Sacchetti et al., 2007), and these may be the same cells as characterized by Crisan et al. They showed that the pericytes express the minimal CD-profile of MSC directly

6. I was unable to obtain Charles-Marie Rouget's original text at the time of writing, but three of his texts (1873, 1874, 1879) are cited in Krueger \& Bechman, 2010. 
upon isolation, and that long-term culture resulted in an MSC phenotype with maintained marker profile. Furthermore, clonal populations of long-term cultures also maintained MSC characteristics and could contribute to tissue regeneration in mouse models.

The evidence for similarity is striking, but it is possible that not all pericytes are MSC (Caplan, 2008). Crisan et al. suggested that the pericytes were unable to differentiate along haematopoietic or neuronal lineages, but there exist previous conflicting studies that suggest subsets of pericytes-like cells are haematopoietic precursors (Kiel et al., 2005), and may differentiate to microglia (Maxwell \& Kruger, 1965). The lack of neuroectodermal potential has since been corroborated (Lojewski et al., 2015), but the heterogeneity of plasticity seems evident.

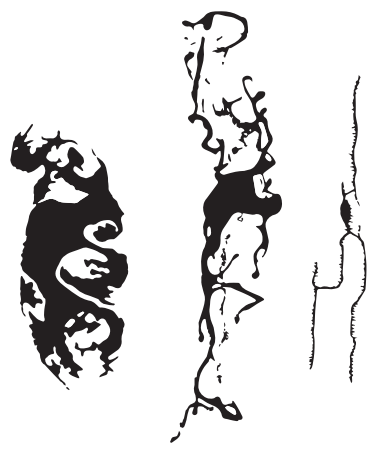

Sketches of different pericytes, adapted from Zimmermann, 1923.

Not to scale. 


\section{Fibroblast plasticity \& The heterogeneity of populations}

The fibroblasts are a diverse and resilient population of cells, present in all connective tissue in the body, but they are difficult to unambiguously identify (Sorrell \& Caplan, 2009). Fibroblasts in different parts of the body arise from different embryonic origins; fibroblasts in the face and neck regions originate from the neural crest, while dorsal skin originates from the dermato-myotome and ventral skin comes from the lateral plate mesoderm (Sriram et al., 2015). Two populations of mouse embryonic fibroblasts can be distinguished by their expression (or not) of Engrailed 1 (Rinkevich et al., 2015). Even human dermal fibroblasts arise from at least two distinct developmental pathways, with differing lineage restriction (Driskell et al., 2013).

The connective tissue can be highly instructive for development of specific tissue as a whole (Kollar, 1986). Body patterning during development occurs through cross-talk between homeobox (HOX)-genes, bone morphogenetic proteins (BMP), sonic hedgehog (Shh) and fibroblast growth factors (FGF), among several protein families. In the apical ectodermal ridge, which controls limb-bud formation, mesenchymal and epithelial cross-talk involve FGF4, 8, 9 and 17 (AER-FGFs) and mesenchymally derived FGF10, Shh and Gremlin 1 (a BMP antagonist) (Boulet et al., 2004). Spatiotemporal co-linearity of HOX-cluster (HOX-A, -B, -C and -D) expression controls the development of correct body patterning (Duboule \& Morata, 1994). HOX-A and -D clusters are able to activate $\mathrm{Shh}$, linking spatiotemporal patterning to anterior-posterior patterning (Galli et al., 2010), and HOX-FGF interactions are both permissive and instructive to proximal-distal patterning (Mariani et al., 2008). Maintenance of the HOX transcriptional program in adult fibroblasts serves as a source of positional memory to differentially pattern epithelia during homeostasis and regeneration (Rinn et al., 2008).

Is it plausible, then, that patterning epigenetics also regulate the identity of fibroblasts? Clearly, HOX, Shh, and FGF signaling are relevant for fibroblasts from early embryonic stages of development to adult tissue homeostasis. Dermal fibroblasts show a strong component of epigenetic memory in cell culture from primary tissue, even after several generations of daughter cells, related to cell state and donor age (Ivanov et al., 2016). While induction of pluripotency (iPSC) shows some evidence of epigenetic remnants stemming from the adult cell source, the phenotypes of differentiated cells from both iPSC sources and embryonic stem cell sources were epigenetically similar and functionally equivalent (Hewitt et al., 2011). While epigenetic patterning seems to regulate priming of the fibroblasts, particularly in their response to reciprocal signaling, there is little evidence that patterning epigenetics results in lineage restriction 
specific to a fibroblasts phenotype.

Phenotype plasticity is reduced over time due to progressive gene silencing; genes active in earlier progenitors are gradually silenced as subsets of cell type-specific genes are turned on (Lunyak \& Rosenfeld, 2008) - this is paramount to the Waddington model. The progression is a result of compacting of the chromatin as its accessibility and positioning within nuclear domains undergo dynamic changes. Differentiation leads to the restructuring of the chromatin accompanied by the change in the global nuclear architecture, thus allowing the pluripotent nature of the embryonic stem cell genome to become more condensed, and therefore more transcriptionally restrained with maturation of the heterochromatin (Lunyak \& Rosenfeld, 2008). However, it is becoming obvious that this progression in neither uniform, linear or irreversible across all developing or adult cells. Epigenetic landscapes that define cellular identity in adult tissues are dynamic, facilitating cellular de-differentiation and trans-differentiation in the setting of injury (Rajagopal \& Stanger, 2016).

What exactly are the choices made by embryonic precursors to become lineage-restricted fibroblasts, and when do they occur? The answers are not universal. The heterogeneity of connective tissue fibroblast populations, even in adults, have been proven by lineage tracing experiments, but the progression of restriction is still unclear. Furthermore, fibroblasts arise even from non-mesodermal lineages. Altogether, this supports the notion that perhaps several cell types, but fibroblasts in particular, can be more likened to a cellular program, than a cellular identity. Expanding on this idea, the impetus for committed lineage restriction among connective tissue cells does not have to be so strong as to disallow a dynamic range of heterogenic phenotypes, restricted more or less in local niches and sub-populations.

\section{Our foray into fibroblast differentiation}

Early work in our lab explored the possibility of using the MSC differentiation protocols popularized in the 1990's (Pittenger et al., 1999) to differentiate fibroblasts (Junker et al., 2010). The results published by my predecessors showed that the MSC protocols could successfully be applied to primary human dermal fibroblasts. This raised some concerns, especially considering that the study from which the differentiation methods were replicated used a population of fibroblasts as a negative control group (Pittenger et al., 1999).

At the time, the term used for fibroblast differentiation was "transdifferentiation" indicating that differentiated cells from one lineage underwent further differentiation to become cells of another lineage. In terms of Waddington's landscape, this is akin to jumping to a parallel track of lineage development, rather than merely proceeding along it. Today, with the availability of genetic 
protocols of differentiation, the term has sometimes become synonymous with direct reprogramming. Altogether, the colloquial use of transdifferentiation implies differentiating one cell type to another (not part of that lineage) without an intermediate progenitor stage.

Our initial hypothesis, echoing the words of Gurdon, was that since each cell contains the genes necessary to become any other cell all that is needed is the right environment. This should apply also to the fibroblasts. The hypothesis now was that the population of fibroblasts was in fact a heterogeneous mixture of more or less potent cells - a reasonable assumption given other reports on dermal stem cell populations. To begin unravelling the how and why of the differentiation success, further experiments were performed on clonal populations of these fibroblasts (Junker et al., 2010). Would it be possible to find distinct clones within the primary fibroblast cultures that would give rise to more potent and distinguishable populations? Mechanical single-cell cloning ensued - single cells were plated anew, one per culture dish, using a microscope and a micromanipulator, and cultured until confluence.

Approximately forty clonal populations were expanded and stored, and about ten of them were analyzed and compared. Some differences in differentiation efficiency were noted, but all assayed populations showed multilineage differentiation results comparable to the primary population. Flow cytometry was used to investigate CD marker profiles for the primary population as well as several of the clones, but only slight differences could be detected. Ultimately, using the differences to perform selective sorting did not prove useful. Re-analysis of the selectively enriched population after one passage showed that the marker distribution had reverted to the pre-sorted state. The results were difficult to publish and initially caused some dismay; we were unable to clearly identify distinct populations with our panel of CD markers (CD4, 8, 9, 13, 14, $19,29,34,44,45,90,105,106)$.

After further consideration it was clear that several new hypotheses could be formed. Firstly, the population of primary fibroblasts is heterogeneous, even when removing endothelial cells, ectodermal cells and haematopoietic cells, and selecting for adherent cells proliferating in DMEM/FCS medium. Nonetheless, the population looks to be stable in its heterogeneity, meaning that even selectively enriching for certain markers causes the culture to adjust to some preferred distribution. Is this distribution defining for the dermal niche, albeit bastardized by in vitro conditions? Or is this a general type of distribution of stromal cells; a standard population configuration for maintenance of connective tissue?

Secondly, the question arises of what the limits of the fibroblast phenotype actually are. If the phenotype is a measurable continuum ranging from a 
multipotent fibroblastic cell to a quiescent matrix-producer, then is that still a distinct cell type? Do the fibroblasts switch from one side to the other, or is it a progression along the lines of terminal differentiation? The idea of a continuum of cellular potency has been raised in other contexts as well (Askenasy et al., 2006). In particular, the fibroblast continuum may be principally comparable to an MSC continuum. It could be that the fibroblast and the MSC/pericyte are two ends of the same spectrum (Haniffa et al., 2009).

Haniffa et al. compare several reports of the MSC immunomodulatory attributes with those of the fibroblasts and highlight the biological and molecular similarity between the cell types. While there are differences in expression profiles of fibroblasts and MSC, there are also differences between MSC from different locations, and between fibroblasts from different anatomical sites (Haniffa et al., 2009), explained partly by the anatomical differences in expression of HOX-family genes (Chang et al., 2002).

In terms of cellular identity, our understanding of the fibroblast is rather limited. The finer distinctions of sub-populations, the range of activities in vivo, and the developmental progression are not yet fully understood. Their relation to the adult mesodermal stem cells, both from functional and developmental perspectives, may be closer than we have traditionally thought.

\section{Myofibroblasts}

Myofibroblasts are important cellular components of wound healing. They are distinguished from other fibroblasts by their expression of (alpha) smooth muscle actin, which provides the molecular machinery for enhanced contraction forces. The contractile phenotype serves a role in wound closure and is responsible for scarring. Transforming growth factor (TGF)- $\beta_{1}$ is an established factor for fibroblast to myofibroblast differentiation (R. A. Evans et al., 2003), but it also occurs in response to mechanical tension (Junker et al., 2008). Myofibroblasts, beside their contractile properties, are adept at producing collagen I-rich matrix (Oda et al., 1988), which is the predominant matrix constituent in scarring.

After myofibroblasts are no longer needed in a wounding situation their numbers drastically diminish. Myofibroblasts diminish in number mainly through apoptosis, but inhibiting Smad (2/3) and abrogating TGF- $\beta_{1}$ signaling can also attenuate the myofibroblast phenotype (Webber et al., 2009). Fibroblasts may not be exclusive sources of myofibroblasts (Real et al., 2005). 


\section{Cancer associated fibroblasts}

The hypothesis being driven in this thesis is that of the fibroblast being a versatile and highly responsive cell type, and it finds support in research of cancer-associated fibroblasts. Cancer-associated fibroblasts are themselves genetically unaltered, but behave in erratic ways to support the associated tumors (Kalluri \& Zeisberg, 2006). The flexibility with which fibroblasts are able to adapt to become supportive to the pathological signaling of tumors is evidence for their broad repertoire of signaling adaptation.

Fibroblasts respond by activation, proliferation, and myofibroblast differentiation in response to secretion of TGF- $\beta$, platelet derived growth factor (PDGF) and FGF2 by the tumor cells (Dvorak, 1986). There is evidence that cancer-associated fibroblasts, but not normal fibroblasts, are able to stimulate new tumor formation (Olumi et al., 1999). The abnormal fibroblasts tend to alter their expression of insulin-like growth factor (IGF), hepatocyte growth factor (HGF), keratinocyte growth factor (KGF/FGF7) and show abnormal migration and proliferation (Olumi et al., 1999; Östman \& Augsten, 2009). While much is yet to be discovered about the heterogenic changes underlying the cancer-associated phenotype, evidence suggests that epigenetic mechanisms may play a large part in the aberrant state of the stromal cells (Hu et al., 2005). 


\section{Differentiation - the phenomenon and the methodology}

Differentiation is the term used for the progression of the cell from one stable state to another. In terms of development along lineages it is likened to the path taken by water along tributaries, using theoretical attractors as a way to define the topology, which is eloquently illustrated by the Waddington landscape. The term is more often used for the specific change to a certain state from a known precursor state.

The different phenotypes of fibroblasts that are known to occur in vivo are differentiated from the general fibroblast cell type, not from a known stem cell precursor. The shift from human dermal fibroblast to myofibroblast is a differentiation that embodies a weaker connotation of the word differentiation, than does the differentiation from MSC to osteoblast, for example. In the spirit of varying the semantics of our field we have proceeded to talk about phenotypic induction (in Paper I), as a term associated with causing a phenotypic shift, which is a suggestion for a loosely descriptive variant of differentiation used in the same sense as during early embryogenesis. The myofibroblast shift only alters some of the fibroblast behavior, and is at least partly reversible, whereas the shift from MSC to osteoblast may include intermediate phenotypes, switches nearly the entire genetic program to a new state, and is not considered physiologically reversible (osteoblast loss of phenotype does not produce MSC).

Part of the explanation for a contextually variable connotation of the word differentiation is that the changes within the cell nucleus can be vastly different. The differentiation of red blood cells includes a final stage of enucleation, and differentiation of keratinocytes includes processes akin to programmed cell death resulting the cornified envelope. Both cases are justly considered terminal differentiation, a stronger version of the term differentiation. Unfortunately, the literature is full of references to a dichotomy between stem cells (including precursors) and terminally differentiated cells, whereas the evidence does not necessarily support the widespread use of the term terminal differentiation (Askenasy et al., 2006; Tajbakhsh, 2009). The differentiation of myofibroblasts includes the expression of a smooth muscle actin and the up-regulation of specific collagens. While myofibroblasts, just as fibroblasts, are traditionally considered terminally differentiated cell types we have ample evidence showing that the fibroblast phenotype is not in as terminal a state as the examples of the dead keratinocytes or the red blood cells. The gain, or activation, of cellular functions should not necessarily imply a new terminal phenotype.

Regulation of genetic programs involve differently potent genetic cascades, and one can therefore consider the Waddington landscape to be a vast oversimplification in terms of the possible configuration of the cellular developmental choices available. One might consider certain genetic changes during 
a differentiation event to be functionally enabling at the expense of previous functions, whereas another cascade results in a phenotypic restriction with associated functions. The irreversibility of a differentiation, and thereby the idea of phenotype progression being unidirectional, may not be as simple as biology textbooks have us believe. From the perspective of embryological development, the Waddigton model is helpful in illustrating key developmental pathways, but the contextual misapplication of the model for experimental cellular differentiation may be an underlying cause of the heated discussion surrounding extralineage fates, and the use of the term transdifferentiation.

Cell culture experiments using cellular differentiation are sometimes based on evidence from embryological development. The temporal progression is important in some cases, while the different factors can be supplemented simultaneously in other cases. Our understanding of any given phenotype is still too incomplete to be certain of the importance of the resulting differences owing to subtle changes to temporal or biochemical cues.

The differentiation protocols hitherto discussed are medium-based. This means that active factors are added to the cell culture medium to exert effects through cellular responses to the supplemented factors, mimicking the stimulation of factors in a developmental environment. This then is mostly a function of stimulating receptors to instigate cascades that lead to a change in gene expression and subsequently protein expression. There are also less elegant ways of stimulation, such as adding poisonous compounds like DMSO or widely disruptive agents like valproic acid, with more chemically direct and dramatic effects on the biochemistry of the cells.

A question that remains in lieu of adding biochemical factors to cell cultures is whether they result in up-regulation of functions that would never happen in vivo, and thus act in a purely mechanistic fashion, or if the supplementation results in an adaptive reconfiguration and true cell type induction. Is there even technically a difference between functional up-regulation, and phenotypic induction? If a cell readily up-regulates a function it must follow that the epigenetic requirements for that function to be activated are already met, given the specific stimulus.

\section{Differentiation in vitro - a critical appraisal}

There are good reasons for attempting to go beyond the conventional in studying cellular phenotype plasticity - only then can unexpected discoveries occur. There are several cases of differentiation experiments that, while seemingly interesting at the time of experimentation, may not be as valid as they are presented. We have worked through our share of doubt with fibroblast differentiation, and there are still aspects worth discussing. 
The commonly used medium for osteoblast differentiation (Pittenger et al., 1999 ) includes beta-glycerophosphate (BGP) to enhance mineralization. Mineralization can occur through inflammatory mediators as well, such as IL1- $\beta$ (Ferreira et al., 2013), but this hypothesis is rarely tested in differentiation assays. Pyrophosphate inhibits bone mineralization, in tandem with osteopontin expression, and inhibits alkaline phosphatase activity (Addison et al., 2007). Osteopontin often occurs in gene or protein assays of osteogenesis, but the balance between mineralization and calcification is not often investigated. One of the most well used markers, osteocalcin, is also found in other tissues, notably adipose tissue (Foresta et al., 2010), and a percentage of cells under osteogenic conditions tend to differentiate to adipocytes instead (Schack et al., 2013). In analyses of cultures, the presence of minority populations dilutes the results of the whole, and is especially an issue during gene expression analyses. The von Kossa staining, often used to show presence of bone matrix, is not sufficient to confirm bone formation in vitro (Bonewald et al., 2003).

These are only some of the issues surrounding one differentiation target. There are still problems surrounding consistency of media formulations, differences in biological activity of variations on medium supplements, variability in starting cell source, batch-to-batch variation of serum, and inconsistencies of experimental timing. The analysis of differentiation can be quite complex, and this is all too seldom considered in multilineage differentiation reports, with assumptions of the validity of well-used markers prevailing, and a lack of effort on the comparison and quantification of apparent phenotypes.

Recently, STAP cells were introduced as an easier way to obtain induced pluripotent cells (Obokata et al., 2014). The paper was followed up by a second, wherein the STAP cells were shown to be totipotent, rather than merely pluripotent. Both reports were published in Nature. A number of questions were raised on the validity of the papers, based on the rather surprising method of induction: sub-lethal stress by exposure to $\mathrm{pH} 5.7$ for half an hour. The counter-intuitive method caused initial skepticism, but given the well-known authors and the double publication in the well-renowned journal Nature, many scientists wanted to wait for replications and more mechanistic insights before judging the validity of the studies. One study refuting STAP cells was submitted to Nature, but after being rejected, was published under free open access (Tang et al., 2014). This, together with further unanswered comments on the validity of the data in the original STAP reports led to retractions of both STAP papers. One of the original senior authors published a new and revised protocol and reaffirmed belief in the STAP cells, but replication efforts fail, even by the original authors. The likely explanation for the pluripotency was the mix-in or switching of STAP cells for embryonic stem cells (Konno et al., 2015). 
The example of the STAP cells shows a different problem than that of the earlier example of osteogenic differentiation. Both types of problems do however occur, and demand adherence to a sound scientific mindset to be avoided.

We recently attempted to differentiate fibroblasts to keratinocytes, perhaps a particularly challenging endeavor owing to the non-mesodermal origins of keratinocytes. Only a few reports exist on similar medium-induced transdifferentiation: keratinocyte-like cells from blood cells (Medina et al., 2007; Medina et al., 2009), from MSC (Paunescu et al., 2007; Mendez et al., 2014), from ADSC (Chavez-Munoz et al., 2013), and induced pluripotent stem cells (Bilousova et al., 2011). We were unable to apply these methods fully, and obtained interesting but inconclusive results. Then we saw a report that presented the development of a vascularized skin construct using subcutaneous ADSC (Chan et al., 2012). The primary stimuli for epidermal induction was retinoic acid and fenofibrate, and culture on a collagen gel. We could not replicate this with either fibroblasts or preadipocytes. They isolated cells in a way that the cell type was difficult to ascertain, and the presence of epidermal cells could not be ruled out. Corroborating reports have been published, without fully addressing the potential for contamination by non-ADSC sources (CD90+, CD105+ and STRO1+ selection only) (Natesan et al., 2013).

There are numerous reports of the differentiation of MSC along non-mesodermal lineages. In particular, standard protocols for neuronal differentiation of MSC have been published (Woodbury et al., 2000; Dezawa et al., 2004). We have conducted a number of pilot studies using Woodbury medium, Woodbury-Dezawa variants, and our own versions (Woodbury-Kratz; unpublished data). We were unable to obtain neurons, but we concluded that the suggested marker profile (Tau, NeuN, GFAP, beta-III-tubulin, NF-H, etc) was weakly positive in fibroblast cultures, and not truly determinant for neurons. Furthermore, abberant staining was evident in many cultures after the induction. We also looked at the resting membrane potential and could not find evidence of action potential in the differentiated cultures. The electrophysiological data did not support neurogenesis. Time-lapse imaging after the pre-induction and induction procedures showed that the major event was not differentiation, but apoptosis and necrosis.

Despite the many reports of neuronal differentiation we were unable to replicate them. We also found weaknesses in neuronal characterization in most reports. Bertani et al. published a more critical appraisal of such neuronal differentiation and concluded that the morphological changes of MSC undergoing neurogenic differentiation was caused by cytotoxic effects, attributable to the factors BHA and/or DMSO (Bertani et al., 2005). They also concluded, as we had done, that the confirmation of neuronal differentiation based solely on 
morphological changes and limited marker expression should not be considered sufficient proof.

After significant review of the literature we concluded that neuronal differentiation of fibroblasts was not something we would pursue. However, the work of Vierbuchen et al. opened up a completely new avenue of research: direct reprogramming (Vierbuchen et al., 2010). It showed the most convincing proof of neuronal differentiation from non-neuronal sources that had been published so far, with proper neuronal markers, subtype classification, and electrophysiological data.

Our planned efforts at inducing keratinocytes from fibroblasts, if pursued, would have to rely on reprogramming approaches rather than media induction, for greatest chance of success. The evidence for success using supplemented media induction is far too weak, and the potential of reprogramming far too alluring. 


\section{Cellular reprogramming}

\section{iPSC}

Gurdon developed the technique of somatic cell nuclear transfer when he replaced the nucleus of a frog's egg with the nucleus of an adult frog cell (Gurdon, 1962). Believing that the DNA present in the adult nucleus should in theory support the requirements of the egg, and thus also considering differentiation to be a non-destructive series of events, he thought that the egg could somehow confer a pluripotent state to the nucleus (Gurdon et al., 1975). The eggs with transferred nuclei could hatch, proving the principle. This technique was instrumental in the development of the first mammalian clone - Dolly, the sheep (Wilmut et al., 1997).

James Thomson reported the first acquisition of stable human embryonic stem cell lines (Thomson et al., 1998), which gave researchers a new and very valuable tool for research into human biology. The use of embryonic stem cells from humans became fraught with ethical misgivings in colloquial media, and in USA in particular, causing some difficulties for scientists working with such cells.

Shinya Yamanaka, after years of investigating which factors were core for maintaining stemness, published a ground-breaking paper together with Kazutoshi Takahashi (Takahashi \& Yamanaka, 2006). In it they claimed to have produced pluripotent stem cells from adult mouse fibroblasts. The finding quickly became the focus of intense research, and in 2007 both Yamanaka (Takahashi et al., 2007) and Thomson (Yu et al., 2007) published the generation of human pluripotent cells, mere days apart, using different combinations of four genetic factors. As it were, following a particularly politicized debate over the use of embryonic stem cell research in the USA, the news of these induced pluripotent cells was very welcome.

The research showed that inserting four active genes into fibroblasts was enough to reprogram them into a pluripotent state, coined: induced pluripotent stem cells (iPSC). Relating once again to Waddington's landscape, the iPSC method created a path from a "terminally differentiated" cell (the fibroblast), all the way back, up to the starting point: the pluripotent cell (embryonic stem cell equivalent). Yamanaka and Gurdon were jointly awarded the 2012 Nobel prize in medicine for discovering that mature cells can be reprogrammed to pluripotency.

There are numerous advantages of iPSC over other types of stem cells. The standardization of a protocol for obtaining iPSC from any cells in culture, such as human fibroblasts, is oftentimes preferable to the isolation of less potent cells 
from more difficult sources, such as MSC. They obviate the need for embryonic stem cells in many sub-fields of research, as iPSC are easier to control, easier to obtain and less controversial. There is still a need for both MSC and embryonic stem cell research, but the availability of iPSC provides a viable human alternative to cells of foetal origin or from invasive patient biopsies.

The iPSC allows new systems of genetic disease modeling. By isolating fibroblasts from patients with genetic aberrations, these fibroblasts can be genetically repaired and reprogrammed to iPSC and compared with non-corrected iPSC from the same source, leading to new insights into the importance and identification of genes relevant for disease states. Conversely, a number of iPSC cultures can be created form the same source of cells, each with unique genetic modifications.

The many confounding factors associated with cells from multiple individuals or isolation procedures can be overcome by needing only to retrieve one cell type for expansion, and through iPSC, obtain any cell type through standardized differentiation techniques. This allows a new method design for investigating differentiation and phenotypes.

The technique for obtaining iPSC relies on the transfection of a minimal number of genes into the target cells. Takahashi and Yamanaka's first report specified OCT3/4, SOX2, c-MYC, and KLF4 (Takahashi \& Yamanaka, 2006) to convert mouse fibroblasts to pluripotency. Thomson's group used OCT4, SOX2, NANOG, and LIN28 (Yu et al., 2007). While there is significant overlap of factors, the differences spawned much debate and a need for more focus on epigenetic methods to analyze the differences in the iPSC populations obtained.

More cell types than dermal fibroblasts were reprogrammed to pluripotency: CD34+ blood cells (Loh et al., 2009), keratinocytes (Aasen et al., 2008), renal tubular cells from urine (T. Zhou et al., 2011), kidney mesangial cells (B. Song et al., 2011). Once expression of the exogenous genes occurs the genomic landscape is reprogrammed into a state of pluripotency, and after only a few days the cellular state becomes stable, obviating any need for further gene transfection.

Methylation state analysis of areas of the genome started showing different profiles in the iPSC of different sources and gene-combinations (Nishino et al., 2011). It showed that epigenetic events, such as DNA methylation, are crucial for the induction of pluripotency (D. S. Lee et al., 2014). While the "Yamanaka factors" are now the most common set for iPSC generation of most cell types, the dissimilarities between epigenetic states of autologous pluripotent stem cells and iPSC are widely recognized (Lister et al., 2011). The importance of the 
epigenetic differences is still not obvious, but this has not hindered progress in the use of iPSC.

\section{Direct reprogramming}

With iPSC available, obtaining human neurons is an exercise in reprogramming the fibroblasts to pluripotency, then differentiating those cells along the neuroectodermal lineage and finally instigating neuronal specification.

However, Thomas Vierbuchen and colleagues hypothesized that if it was possible to reprogram a fibroblast to an embryonic stem cell equivalent, it should be possible to achieve reprogramming of fibroblasts to neurons - all that was required was the appropriate combination of genes: ASCL1, BRN2 (Pou3f2) and MYT1L (Vierbuchen et al., 2010). Their paper proved to be another important step for cell biology, and shortly thereafter a number of targeted reprogrammings were published.

Fibroblasts were induced to neuronal precursor cells, that could further be differentiated to both astrocytes and neurons using combinations of BRN2, FOXG1 and/or SOX2 (Lujan et al., 2012). Ieda and colleagues published a recipe for reprogramming fibroblasts directly to cardiomyocytes using GATA4, MEF2C, and TBX5 (Ieda et al., 2010). An earlier use of reprogramming, and in vivo no less, was to transform glucagon-producing cells to insulin producing cells, using NGN3, PDX1 and MAFA, to rescue diabetic mice (Q. Zhou et al., 2008).

In many ways, the iPSC and direct reprogramming methodology is proving Gurdon's postulation that all cells possess the ability to become any other cell, given the right stimulus. The difficulty of direct reprogramming is knowledge of the factors to be used. The process of finding the minimal combination of genes that produce a desired outcome is firstly an arduous exercise in gene-screening. Secondly, the process of verifying the resultant cell type relies on careful comparisons of not only cellular function and gene activity, but also of the epigenetic landscape.

Recently, an attempt at simplifying the process of factor identification has been suggested. The use of computational prediction and bioinformatics has allowed for the creation of an algorithm that produces guesses at which genes are required to reprogram a source cell into a target cell (Rackham et al., 2016). It is too early to say how accurate these predictions are, but the authors presented guesses in line with known reprogramming recipes, and tested a fibroblast to keratinocyte conversion using FOXQ1, SOX9, MAFB, CDH1, FOS and REL, which seemed successful. 


\section{Reprogramming and transfection techniques}

There are a number of techniques available for delivery of genes into cells. The two main distinguishing features of transfection variants is whether the intent is to permanently or temporarily add genes to the cells. Stable transfection results in the incorporation of the exogenous genetic material into the genome of the cells, whereas transient transfection results in the presence of the genes in the cells over a few days, after which the genes are broken down. Cellular reprogramming requires only transient transfections, so this is preferable to stable incorporation which may otherwise modify cellular behavior unpredictably.

Viruses replicate by hijacking the functions of the infected cell for the production of new viruses. They do this by penetrating the cell and presenting their genetic material for replication. After the genes are copied, the proteins are produced, assembled, and new viruses are created inside the cell. Modified viruses are therefore highly adept at injecting genes into cells, which is useful for researchers.

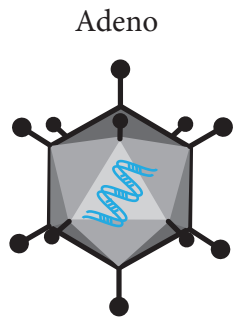

DNA
Lenti

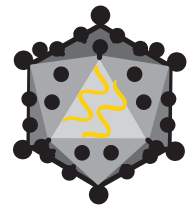

RNA
Sendai

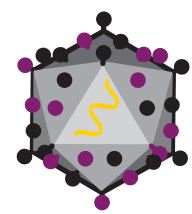

RNA

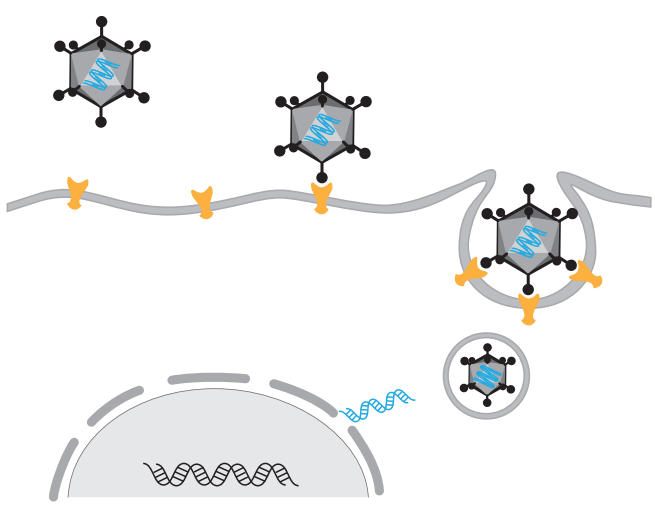

Three different types of virus commonly used for transfection, and receptor-mediated uptake of virus into the cell.

Both Thomson and Yamanaka originally used lentiviral vectors, packaged in 293FT or PLAT-E cells. This is a well-known and readily available retroviral delivery system that results in genomic integration of the material. The efficiency 
of reprogramming is relatively high, but even after excision of the genes from the genome a footprint remains in the transduced cells (Rao \& Malik, 2012). Development of polycistronic vectors containing all four factors in one vector, and a loxP site that allows the sequences to be excised by transfection of cre recombinase, modified the efficiency but simplified the procedure (Sommer et al., 2010). Sommer et al. used an Adeno-cre vector for the excision of the expression cassette.

The sendai virus is a feasible option for non-integrating, transient, transfection of iPSC factors (Fusaki et al., 2009; Fujie et al., 2014). The system can also provide relatively high efficiency and leaves the genome unaltered, but sendai vectors can be both expensive and technically difficult to construct (Rao \& Malik, 2012).

Adenoviral systems have also been used for iPSC generation without genomic integration (Stadtfeld et al., 2008; W. Zhou \& Freed, 2009; Tashiro et al., 2010). Adenoviral systems, while leaving no footprint, can be technically challenging and have shown low efficiency of iPSC generation (Rao \& Malik, 2012).

Generally, the genes of interest are inserted into a plasmid - a circular double-stranded DNA. The plasmid can be packaged into a virus, or it can be transfected into the cells, depending on its design. Bacteria are very adept at managing and replicating plasmids. It is a natural way for populations of bacteria to share genetic information. We use this feature to introduce the plasmids into a laboratory-grade bacterial population, such as the $\mathrm{DH} 5 \mathrm{a}$ e. coli, which then amplifies the plasmid as the population grows, giving us a way to synthesize large batches of transfectable plasmids.

By adding a few additional genes or sequences into the plasmid it can be optimized for bacterial amplification. The plasmid requires an origin of replication (ORI), which marks the start of bacterial genetic replication. There also needs to be a system for selecting the survival of bacteria that contain the correct plasmid, while killing the other bacteria to optimize the plasmid amplification. This can be achieved by adding a gene for antibiotic resistance, which in turn requires a promoter so that this gene becomes transcribed in the bacteria. The bacteria are subsequently grown in the antibiotic, ensuring the survival of only those bacteria that are producing the rescue factor coded by the resistance gene available only in the introduced plasmid. By purifying the DNA from the bacteria we can then collect large amounts of plasmids with the gene(s) we want to transfect into mammalian cells.

If the plasmid is a vector intended for viral delivery, it is then transfected into a packaging cell line together with a vector coding for viral particles. HEK293 is a common hepatic family of cell lines used for this purpose. The cells man- 
ufacture viral proteins coded by the viral vector, and the genetic material from the plasmid is encapsulated into the newly produced, but replication deficient, viruses. The viruses are replication deficient as a safety and control feature, meaning that they cannot reproduce outside the packaging cell line. The virus particles are thus amplified and collected for use in later transfection.

There are a number of non-viral techniques for introducing genetic material into mammalian cells. Plasmids can be designed for direct transduction into cells, without the use of viral vectors. Micelles of fatty acids are able to fuse with the cell membrane and in doing so introduce any contents into the cell cytoplasm. This is lipid-mediated transfection - a very common way to transfect cells, including packaging cells, with reagents available from many biotechnology companies. In general, achievable transfection efficiencies range between $20 \%$ and $80 \%$ depending on the cell type and reagents used, typically lower than with viral methods.

Another popular method is electroporation, in which a swift electrical current causes a membrane hyperpolarization that allows the genetic material to enter the cells. This requires special instrumentation, and yields similar efficiencies as lipid-mediated techniques in general, but may be more suitable for specific cases (cell types and material).

We have designed a plasmid intended for reprogramming of fibroblasts to induced cardiomyocytes and then induced keratinocytes. The idea was to use both a mammalian selection system, and a bacterial selection system, to improve the relative yield of transfected cells after transient non-viral transfection. The bacterial amplification uses carbenicillin selection, an ampicillin analogue, and a gene for ampicillin resistance $\left(A m p^{R}\right)$. The mammalian selection is based on adding puromycin to the growth media, a cellular toxin that kills mammalian cells, and the rescue gene $\left(\mathrm{Puro}^{\mathrm{R}}\right)$ that codes for a puromycin transporter that removes puromycin from cells, enabling their survival. Any cell that receives the plasmid and is capable of reading it, will produce both the transfected proteins of interest and the rescue protein ensuring survival only of those cells that are successfully transfected.

We used a strong mammalian promoter from the cytomegalovirus (CMV) to ensure high levels of transcription after transfection. To further optimize the transfection rate we designed the gene sequences by selecting for codons that would optimize the use of the pool of tRNA typically available in human cells. We also added Kozak-sequences before the gene of interest and designed the expression cassette with several pairs of unique restriction sites to enable future editing. The backbone is a modification and combination of pPUR and pCIneo, totaling about $4900 \mathrm{bp}$ without inserted genes. 


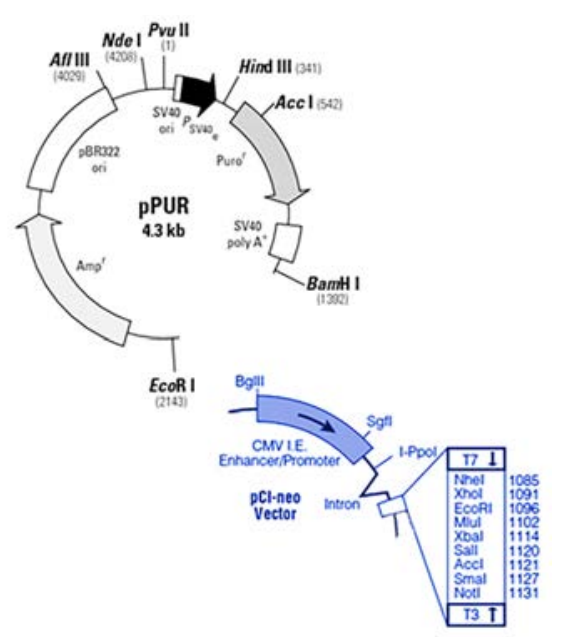

Sketch of our plasmid showing the two different parts that were combined.

We created three versions of this plasmid ${ }^{7}$, each with its own fluorescent reporter gene: td-Tomato (red fluorescence), eGFP (green fluorescence), and Azure (blue fluorescence), trying to match intensities and sizes as much as possible. In this way, we could provide a signal detectable through fluorescence microscopy that indicates successful transfection, transcription and translation for three plasmids simultaneously.

Reprogramming can be done without the use of plasmids to introduce genetic material. An interesting use of transfection was the introduction of synthetic modified mRNA (Warren et al., 2010), ready to be translated into protein. They modified the RNA bases by substituting cytidine with 5-methylcytidine and uridine with pseudouridine and also added the interferon inhibitor B18R to avoid cellular defenses that break down free mRNA. The production and use of the synthetic mRNA seems somewhat difficult to reproduce, but clarifying protocols have been published (Mandal \& Rossi, 2013). Additional optimizations of the culture procedures, such as adding valproic acid and low-oxygen milieu, as well as adding LIN28 as a fifth factor in addition to the Yamanaka factors, provided a relatively high reprogramming efficiency.

The use of micro-RNA (miRNA) in iPSC generation has also been successful. iPSC generation with the Yamanaka-factors (minus c-MYC) can be enhanced by co-transfection with miR-291-3p, miR-294 and miR-295 (Judson et al., 2009). Taking it a step further, using only the miR302/367 cluster (located in intron 8 of the LARP7 gene) as a single polycistronic primary transcript (through lentiviral delivery), together with HDAC2 suppression, can also generate iPSC (Anokye-Danso et al., 2011).

7. The plasmid synthesis and cloning was performed by Entelechon, Germany (now part of Eurofins Genomics). 
There are a number of approaches to cellular reprogramming. Methods that do not modify the genome of the target cells may be more relevant for future therapeutic uses, and some promising approaches are still hampered by low reprogramming efficiencies, high costs, or high technical demands. As the techniques improve, we will have a greater choice of methods aligning with our research goals and priorities. 


\section{Section References}

Aasen, T., Raya, A., Barrero, M. J., Garreta, E., Consiglio, A., Gonzalez, F., . . Izpisua Belmonte, J. C. (2008). Efficient and rapid generation of induced pluripotent stem cells from human keratinocytes. Nat Biotechnol, 26(11), 1276-1284

Addison, W. N., Azari, F., Sorensen, E. S., Kaartinen, M. T. and McKee, M. D. (2007). Pyrophosphate inhibits mineralization of osteoblast cultures by binding to mineral, up-regulating osteopontin, and inhibiting alkaline phosphatase activity. J Biol Chem, 282(21), 15872-15883

Anokye-Danso, F., Trivedi, C. M., Juhr, D., Gupta, M., Cui, Z., Tian, Y., ... Morrisey, E. E. (2011). Highly efficient miRNA-mediated reprogramming of mouse and human somatic cells to pluripotency. Cell Stem Cell, 8(4), 376-388

Askenasy, N., Yaniv, I., Stein, J. and Sharkis, S. J. (2006). Our perception of developmental plasticity: esse est percipi (to be is to be perceived)? Curr Stem Cell Res Ther, 1(1), 85-94

Bartosh, T. J., Ylostalo, J. H., Mohammadipoor, A., Bazhanov, N., Coble, K., Claypool, K., . . Prockop, D. J. (2010). Aggregation of human mesenchymal stromal cells (MSCs) into 3D spheroids enhances their antiinflammatory properties. Proc Natl Acad Sci U S A, 107(31), 13724-13729

Becker, A. J., Mc, C. E. and Till, J. E. (1963). Cytological demonstration of the clonal nature of spleen colonies derived from transplanted mouse marrow cells. Nature, 197, 452-454

Bergers, G. \& Song, S. (2005). The role of pericytes in blood-vessel formation and maintenance. Neuro Oncol, 7(4), 452-464

Bernstein, E., Kim, S. Y., Carmell, M. A., Murchison, E. P., Alcorn, H., Li, M. Z., . . Hannon, G. J. (2003). Dicer is essential for mouse development. Nat Genet, 35(3), 215-217

Bertani, N., Malatesta, P., Volpi, G., Sonego, P. and Perris, R. (2005). Neurogenic potential of human mesenchymal stem cells revisited: analysis by immunostaining, time-lapse video and microarray. J Cell Sci, 118(Pt 17), 3925-3936

Bilousova, G., Chen, J. and Roop, D. R. (2011). Differentiation of mouse induced pluripotent stem cells into a multipotent keratinocyte lineage. J Invest Dermatol, 131(4), 857-864

Bonewald, L. F., Harris, S. E., Rosser, J., Dallas, M. R., Dallas, S. L., Camacho, N. P., . . Boskey, A. (2003). von Kossa staining alone is not sufficient to confirm that mineralization in vitro represents bone formation. Calcif Tissue Int, 72(5), 537-547

Boulet, A. M., Moon, A. M., Arenkiel, B. R. and Capecchi, M. R. (2004). The roles of Fgf4 and Fgf8 in limb bud initiation and outgrowth. Developmental Biology, 273(2), 361-372

Brittberg, M., Lindahl, A., Nilsson, A., Ohlsson, C., Isaksson, O. and Peterson, L. (1994). Treatment of Deep Cartilage Defects in the Knee with Autologous Chondrocyte Transplantation. New England Journal of Medicine, 331(14), 889-895

Caplan, A. I. (2008). All MSCs are pericytes? Cell Stem Cell, 3(3), 229-230

Cawthorn, W. P., Scheller, E. L. and MacDougald, O. A. (2012). Adipose tissue stem cells meet preadipocyte commitment: going back to the future. J Lipid Res, 53(2), 227-246

Chakalova, L. \& Fraser, P. (2010). Organization of transcription. Cold Spring Harb Perspect Biol, 2(9), a000729

Chan, R. K., Zamora, D. O., Wrice, N. L., Baer, D. G., Renz, E. M., Christy, R. J. and Natesan, S. (2012). Development of a vascularized skin construct using adipose-derived stem cells from debrided burned skin. Stem Cells Int, 2012, 841203

Chang, H. Y., Chi, J. T., Dudoit, S., Bondre, C., van de Rijn, M., Botstein, D. and Brown, P. O. (2002). Diversity, topographic differentiation, and positional memory in human fibroblasts. Proc Natl Acad Sci U S A, 99(20), 12877-12882

Chavez-Munoz, C., Nguyen, K. T., Xu, W., Hong, S. J., Mustoe, T. A. and Galiano, R. D. (2013). Transdifferentiation of adipose-derived stem cells into keratinocyte-like cells: engineering a stratified epidermis. PLoS One, 8(12), e80587

Choi, K. (2002). The hemangioblast: a common progenitor of hematopoietic and endothelial cells. J Hematother Stem Cell Res, 11(1), 91-101

Collett, G., Wood, A., Alexander, M. Y., Varnum, B. C., Boot-Handford, R. P., Ohanian, V., . . Canfield, A. E. (2003). Receptor tyrosine kinase AxI modulates the osteogenic differentiation of pericytes. Circ Res, 92(10), 1123-1129

Cosgrove, M. S. \& Wolberger, C. (2005). How does the histone code work? Biochem Cell Biol, 83(4), 468-476

Crisan, M., Yap, S., Casteilla, L., Chen, C. W., Corselli, M., Park, T. S., . . Peault, B. (2008). A perivascular origin for mesenchymal stem cells in multiple human organs. Cell Stem Cell, 3(3), 301-313

Cserjesi, P., Brown, D., Ligon, K. L., Lyons, G. E., Copeland, N. G., Gilbert, D. J., . . Olson, E. N. (1995). Scleraxis: a basic helix-loop-helix protein that prefigures skeletal formation during mouse embryogenesis. Development, 121(4), 1099-1110 
Dausset, J. (1958). Immuno-hematologie des leucocytes. Bibl Paediatr, 14(66), 29-56

Dayem, M. A., Moreilhon, C., Turchi, L., Magnone, V., Christen, R., Ponzio, G. and Barbry, P. (2003). Early gene expression in wounded human keratinocytes revealed by DNA microarray analysis. Comp Funct Genomics, 4(1), 47-55

De Miguel, M. P., Arnalich Montiel, F., Lopez Iglesias, P., Blazquez Martinez, A. and Nistal, M. (2009). Epiblast-derived stem cells in embryonic and adult tissues. Int J Dev Biol, 53(8-10), 1529-1540

De Robertis, E. M. (2009). Spemann's organizer and the self-regulation of embryonic fields. Mech Dev, 126(11-12), 925-941

Dellavalle, A., Sampaolesi, M., Tonlorenzi, R., Tagliafico, E., Sacchetti, B., Perani, L., . . Cossu, G. (2007). Pericytes of human skeletal muscle are myogenic precursors distinct from satellite cells. Nat Cell Biol, 9(3), 255-267

Dezawa, M., Kanno, H., Hoshino, M., Cho, H., Matsumoto, N., Itokazu, Y., . . Ide, C. (2004). Specific induction of neuronal cells from bone marrow stromal cells and application for autologous transplantation. J Clin Invest, 113(12), 1701-1710

Dominici, M., Le Blanc, K., Mueller, I., Slaper-Cortenbach, I., Marini, F., Krause, D., ... Horwitz, E. (2006). Minimal criteria for defining multipotent mesenchymal stromal cells. The International Society for Cellular Therapy position statement. Cytotherapy, 8(4), 315-317

Dore-Duffy, P. (2008). Pericytes: pluripotent cells of the blood brain barrier. Curr Pharm Des, 14(16), $1581-1593$

Driesch, H. (1893). Zur Verlagerung der Blastomeren des Echinideneies. Anatomischer Anzeiger, 8, 348-357

Driskell, R. R., Lichtenberger, B. M., Hoste, E., Kretzschmar, K., Simons, B. D., Charalambous, M., ... Watt, F. M. (2013). Distinct fibroblast lineages determine dermal architecture in skin development and repair. Nature, 504(7479), 277-281

Duboule, D. \& Morata, G. (1994). Colinearity and functional hierarchy among genes of the homeotic complexes. Trends in Genetics, 10(10), 358-364

Dvorak, H. F. (1986). Tumors: wounds that do not heal. Similarities between tumor stroma generation and wound healing. N Engl J Med, 315(26), 1650-1659

Endres, M., Neumann, K., Haupl, T., Erggelet, C., Ringe, J., Sittinger, M. and Kaps, C. (2007). Synovial fluid recruits human mesenchymal progenitors from subchondral spongious bone marrow. $J$ Orthop Res, 25(10), 1299-1307

Eseonu, O. I. \& De Bari, C. (2015). Homing of mesenchymal stem cells: mechanistic or stochastic? Implications for targeted delivery in arthritis. Rheumatology (Oxford), 54(2), 210-218

Evans, R. A., Tian, Y. C., Steadman, R. and Phillips, A. O. (2003). TGF-beta1-mediated fibroblast-myofibroblast terminal differentiation-the role of Smad proteins. Exp Cell Res, 282(2), 90-100

Farrington-Rock, C., Crofts, N. J., Doherty, M. J., Ashton, B. A., Griffin-Jones, C. and Canfield, A. E. (2004). Chondrogenic and adipogenic potential of microvascular pericytes. Circulation, 110(15), 2226-2232

Ferreira, E., Porter, R. M., Wehling, N., O'Sullivan, R. P., Liu, F., Boskey, A., .. . Wells, J. W. (2013). Inflammatory cytokines induce a unique mineralizing phenotype in mesenchymal stem cells derived from human bone marrow. J Biol Chem, 288(41), 29494-29505

Fischer, U. M., Harting, M. T., Jimenez, F., Monzon-Posadas, W. O., Xue, H., Savitz, S. I., . . Cox, C. S., Jr. (2009). Pulmonary passage is a major obstacle for intravenous stem cell delivery: the pulmonary first-pass effect. Stem Cells Dev, 18(5), 683-692

Foresta, C., Strapazzon, G., De Toni, L., Gianesello, L., Calcagno, A., Pilon, C., . . Vettor, R. (2010). Evidence for osteocalcin production by adipose tissue and its role in human metabolism. J Clin Endocrinol Metab, 95(7), 3502-3506

Fossum, M., Svensson, J., Kratz, G. and Nordenskjold, A. (2007). Autologous in vitro cultured urothelium in hypospadias repair. J Pediatr Urol, 3(1), 10-18

Frenette, P. S., Pinho, S., Lucas, D. and Scheiermann, C. (2013). Mesenchymal stem cell: keystone of the hematopoietic stem cell niche and a stepping-stone for regenerative medicine. Annu Rev Immunol, 31, 285-316

Friedenstein, A. J., Deriglasova, U. F., Kulagina, N. N., Panasuk, A. F., Rudakowa, S. F., Luria, E. A. and Ruadkow, I. A. (1974). Precursors for fibroblasts in different populations of hematopoietic cells as detected by the in vitro colony assay method. Exp Hematol, 2(2), 83-92

Friedenstein, A. J., Gorskaja, J. F. and Kulagina, N. N. (1976). Fibroblast precursors in normal and irradiated mouse hematopoietic organs. Exp Hematol, 4(5), 267-274

Friedenstein, A. J. (1989). Stromal-hematopoietic interrelationships: Maximov's ideas and modern models. Haematol Blood Transfus, 32, 159-167

Frobel, J., Hemeda, H., Lenz, M., Abagnale, G., Joussen, S., Denecke, B., . . Wagner, W. (2014). Epigenetic rejuvenation of mesenchymal stromal cells derived from induced pluripotent stem cells. 
Stem Cell Reports, 3(3), 414-422

Fujie, Y., Fusaki, N., Katayama, T., Hamasaki, M., Soejima, Y., Soga, M., ... Era, T. (2014). New type of Sendai virus vector provides transgene-free iPS cells derived from chimpanzee blood. PLOS One, 9(12), e113052

Fusaki, N., Ban, H., Nishiyama, A., Saeki, K. and Hasegawa, M. (2009). Efficient induction of transgene-free human pluripotent stem cells using a vector based on Sendai virus, an RNA virus that does not integrate into the host genome. Proc Jpn Acad Ser B Phys Biol Sci, 85(8), 348362

Galli, A., Robay, D., Osterwalder, M., Bao, X., Bénazet, J.-D., Tariq, M., . . Zeller, R. (2010). Distinct Roles of Hand2 in Initiating Polarity and Posterior Shh Expression during the Onset of Mouse Limb Bud Development. PLoS Genet, 6(4), e1000901

Gleeson, B. M., Martin, K., Ali, M. T., Kumar, A. H., Pillai, M. G., Kumar, S. P., . . Caplice, N. M. (2015). Bone Marrow-Derived Mesenchymal Stem Cells Have Innate Procoagulant Activity and Cause Microvascular Obstruction Following Intracoronary Delivery: Amelioration by Antithrombin Therapy. Stem Cells, 33(9), 2726-2737

Goldberg, A. D., Allis, C. D. and Bernstein, E. (2007). Epigenetics: a landscape takes shape. Cell, 128(4), 635-638

Gonzalez-Perez, O. (2012). Neural stem cells in the adult human brain. Biol Biomed Rep, 2(1), 59-69

Gregoire, F. M., Smas, C. M. and Sul, H. S. (1998). Understanding adipocyte differentiation. Physiol Rev, 78(3), 783-809

Greider, C. W. \& Blackburn, E. H. (1985). Identification of a specific telomere terminal transferase activity in Tetrahymena extracts. Cell, 43(2 Pt 1), 405-413

Gurdon, J. B., Elsdale, T. R. and Fischberg, M. (1958). Sexually mature individuals of Xenopus laevis from the transplantation of single somatic nuclei. Nature, 182(4627), 64-65

Gurdon, J. B. (1962). The transplantation of nuclei between two species of Xenopus. Dev Biol, 5, 68-83

Gurdon, J. B., Laskey, R. A. and Reeves, O. R. (1975). The developmental capacity of nuclei transplanted from keratinized skin cells of adult frogs. J Embryol Exp Morphol, 34(1), 93-112

Haniffa, M. A., Collin, M. P., Buckley, C. D. and Dazzi, F. (2009). Mesenchymal stem cells: the fibroblasts' new clothes? Haematologica, 94(2), 258-263

Hass, R., Kasper, C., Bohm, S. and Jacobs, R. (2011). Different populations and sources of human mesenchymal stem cells (MSC): A comparison of adult and neonatal tissue-derived MSC. Cell Commun Signal, 9, 12

Hayflick, L. \& Moorhead, P. S. (1961). The serial cultivation of human diploid cell strains. Exp Cell Res, $25,585-621$

Henig, I. \& Zuckerman, T. (2014). Hematopoietic stem cell transplantation-50 years of evolution and future perspectives. Rambam Maimonides Med J, 5(4), e0028

Hertwig, O. (1894) [Book]. Zeit- und Streitfragen der Biologie / von Prof. Dr. Oscar Hertwig (Vol. 1). Jena :, G. Fischer.

Hertwig, O. (1900) [Book]. Die Elemente der Entwicklungslehre des Menschen und der Wirbeltiere : Anleitung und Repetitorium für Studierende und Aertze. Jena :, G. Fischer.

Hewitt, K. J., Shamis, Y., Hayman, R. B., Margvelashvili, M., Dong, S., Carlson, M. W. and Garlick, J. A. (2011). Epigenetic and phenotypic profile of fibroblasts derived from induced pluripotent stem cells. PLoS One, 6(2), e17128

Horwitz, E. M., Le Blanc, K., Dominici, M., Mueller, I., Slaper-Cortenbach, I., Marini, F. C., ... The International Society for Cellular Therapy (2005). Clarification of the nomenclature for MSC: The International Society for Cellular Therapy position statement. Cytotherapy, 7(5), 393-395

Hu, M., Yao, J., Cai, L., Bachman, K. E., van den Brule, F., Velculescu, V. and Polyak, K. (2005). Distinct epigenetic changes in the stromal cells of breast cancers. Nat Genet, 37(8), 899-905

Iborra, F. J., Pombo, A., Jackson, D. A. and Cook, P. R. (1996). Active RNA polymerases are localized within discrete transcription "factories" in human nuclei. J Cell Sci, 109 ( Pt 6), 1427-1436

leda, M., Fu, J. D., Delgado-Olguin, P., Vedantham, V., Hayashi, Y., Bruneau, B. G. and Srivastava, D. (2010). Direct reprogramming of fibroblasts into functional cardiomyocytes by defined factors. Cell, 142(3), 375-386

Ivanov, N. A., Tao, R., Chenoweth, J. G., Brandtjen, A., Mighdoll, M. I., Genova, J. D., . . Jaffe, A. E. (2016). Strong Components of Epigenetic Memory in Cultured Human Fibroblasts Related to Site of Origin and Donor Age. PLoS Genet, 12(2), e1005819

Judson, R. L., Babiarz, J. E., Venere, M. and Blelloch, R. (2009). Embryonic stem cell-specific microRNAs promote induced pluripotency. Nat Biotechnol, 27(5), 459-461

Junker, J. P., Kratz, C., Tollback, A. and Kratz, G. (2008). Mechanical tension stimulates the transdifferentiation of fibroblasts into myofibroblasts in human burn scars. Burns, 34(7), 942-946

Junker, J. P., Sommar, P., Skog, M., Johnson, H. and Kratz, G. (2010). Adipogenic, chondrogenic and os- 
teogenic differentiation of clonally derived human dermal fibroblasts. Cells Tissues Organs, 191(2), 105-118

Kalluri, R. \& Zeisberg, M. (2006). Fibroblasts in cancer. Nat Rev Cancer, 6(5), 392-401

Karp, J. M. \& Leng Teo, G. S. (2009). Mesenchymal stem cell homing: the devil is in the details. Cell Stem Cell, 4(3), 206-216

Kiecker, C., Bates, T. and Bell, E. (2016). Molecular specification of germ layers in vertebrate embryos. Cell Mol Life Sci, 73(5), 923-947

Kiel, M. J., Yilmaz, O. H., Iwashita, T., Yilmaz, O. H., Terhorst, C. and Morrison, S. J. (2005). SLAM family receptors distinguish hematopoietic stem and progenitor cells and reveal endothelial niches for stem cells. Cell, 121(7), 1109-1121

Kim, Y., Jeong, J., Kang, H., Lim, J., Heo, J., Ratajczak, J., . . Shin, D. M. (2014). The molecular nature of very small embryonic-like stem cells in adult tissues. Int J Stem Cells, 7(2), 55-62

Kollar, E. J. (1986). Tissue interactions in development of teeth and related ectodermal derivatives. Dev Biol (N Y 1985), 4, 297-313

Konno, D., Kasukawa, T., Hashimoto, K., Itoh, T., Suetsugu, T., Miura, I., . . Matsuzaki, F. (2015). STAP cells are derived from ES cells. Nature, 525(7570), E4-E5

Kratz, G. (2005). Body parts from the laboratory bench. Br J Surg, 92(4), 385-386

Krueger, M. \& Bechmann, I. (2010). CNS pericytes: concepts, misconceptions, and a way out. Glia, 58(1), 1-10

Kucia, M., Machalinski, B. and Ratajczak, M. Z. (2006). The developmental deposition of epiblast/germ cell-line derived cells in various organs as a hypothetical explanation of stem cell plasticity? Acta Neurobiol Exp (Wars), 66(4), 331-341

Kuznetsov, S. A., Friedenstein, A. J. and Robey, P. G. (1997). Factors required for bone marrow stromal fibroblast colony formation in vitro. Br J Haematol, 97(3), 561-570

Le Blanc, K., Tammik, C., Rosendahl, K., Zetterberg, E. and Ringden, O. (2003). HLA expression and immunologic properties of differentiated and undifferentiated mesenchymal stem cells. Exp Hematol, 31(10), 890-896

Leblond, C. P., Cairnie, A. B., Lala, P. K., Osmond, D. G. and McGill University (1976) [Book]. Stem cells of renewing cell populations: proceedings of a symposium held in October 1975 at McGill University, Montreal, in tribute to C. P. Leblond on the occasion of his sixty-fifth birthday. Academic Press.

Lee, D. S., Shin, J. Y., Tonge, P. D., Puri, M. C., Lee, S., Park, H., . . Seo, J. S. (2014). An epigenomic roadmap to induced pluripotency reveals DNA methylation as a reprogramming modulator. Nat Commun, 5, 5619

Lee, T. I., Jenner, R. G., Boyer, L. A., Guenther, M. G., Levine, S. S., Kumar, R. M., . . Young, R. A. (2006). Control of developmental regulators by Polycomb in human embryonic stem cells. Cell, 125(2), 301-313

Lenz, M., Goetzke, R., Schenk, A., Schubert, C., Veeck, J., Hemeda, H., . . Wagner, W. (2015). Epigenetic biomarker to support classification into pluripotent and non-pluripotent cells. Sci Rep, 5, 8973

Levenson, J. M. \& Sweatt, J. D. (2005). Epigenetic mechanisms in memory formation. Nat Rev Neurosci, 6(2), 108-118

Li, X. \& Zhao, X. (2008). Epigenetic regulation of mammalian stem cells. Stem Cells Dev, 17(6), 10431052

Lin, C. S., Xin, Z. C., Deng, C. H., Ning, H., Lin, G. and Lue, T. F. (2010). Defining adipose tissue-derived stem cells in tissue and in culture. Histol Histopathol, 25(6), 807-815

Lister, R., Pelizzola, M., Kida, Y. S., Hawkins, R. D., Nery, J. R., Hon, G., . . Ecker, J. R. (2011). Hotspots of aberrant epigenomic reprogramming in human induced pluripotent stem cells. Nature, 471(7336), 68-73

Liu, J., Carmell, M. A., Rivas, F. V., Marsden, C. G., Thomson, J. M., Song, J. J., . . Hannon, G. J. (2004). Argonaute2 is the catalytic engine of mammalian RNAi. Science, 305(5689), 1437-1441

Loh, Y. H., Agarwal, S., Park, I. H., Urbach, A., Huo, H., Heffner, G. C., ... Daley, G. Q. (2009). Generation of induced pluripotent stem cells from human blood. Blood, 113(22), 5476-5479

Lojewski, X., Srimasorn, S., Rauh, J., Francke, S., Wobus, M., Taylor, V., ... Hermann, A. (2015). Perivascular Mesenchymal Stem Cells From the Adult Human Brain Harbor No Instrinsic Neuroectodermal but High Mesodermal Differentiation Potential. Stem Cells Transl Med, 4(10), 1223-1233

Lucas, J. S., Bossen, C. and Murre, C. (2011). Transcription and recombination factories: common features? Curr Opin Cell Biol, 23(3), 318-324

Lujan, E., Chanda, S., Ahlenius, H., Sudhof, T. C. and Wernig, M. (2012). Direct conversion of mouse fibroblasts to self-renewing, tripotent neural precursor cells. Proc Natl Acad Sci U S A, 109(7), 
2527-2532

Lunyak, V. V. \& Rosenfeld, M. G. (2008). Epigenetic regulation of stem cell fate. Hum Mol Genet, 17(R1), R28-36

Maehle, A.-H. (2011). Ambiguous cells: the emergence of the stem cell concept in the nineteenth and twentieth centuries. Notes and Records of the Royal Society

Mandal, P. K. \& Rossi, D. J. (2013). Reprogramming human fibroblasts to pluripotency using modified mRNA. Nat Protoc, 8(3), 568-582

Mariani, F. V., Ahn, C. P. and Martin, G. R. (2008). Genetic evidence that FGFs have an instructive role in limb proximal-distal patterning. Nature, 453(7193), 401-405

Maximow, A. A. (1902) [Book]. Experimentelle Untersuchungen über die entzündliche Neubildung von Bindegewebe. G. Fischer.

Maxwell, D. S. \& Kruger, L. (1965). Small Blood Vessels and the Origin of Phagocytes in the Rat Cerebral Cortex Following Heavy Particle Irradiation. Exp Neurol, 12, 33-54

Medina, A., Kilani, R. T., Carr, N., Brown, E. and Ghahary, A. (2007). Transdifferentiation of peripheral blood mononuclear cells into epithelial-like cells. Am J Pathol, 171(4), 1140-1152

Medina, A., Brown, E., Carr, N. and Ghahary, A. (2009). Circulating monocytes have the capacity to be transdifferentiated into keratinocyte-like cells. Wound Repair Regen, 17(2), 268-277

Mendez, J. J., Ghaedi, M., Steinbacher, D. and Niklason, L. E. (2014). Epithelial cell differentiation of human mesenchymal stromal cells in decellularized lung scaffolds. Tissue Eng Part A, 20(1112), 1735-1746

Minasi, M. G., Riminucci, M., De Angelis, L., Borello, U., Berarducci, B., Innocenzi, A., . . Cossu, G. (2002). The meso-angioblast: a multipotent, self-renewing cell that originates from the dorsal aorta and differentiates into most mesodermal tissues. Development, 129(11), 2773-2783

Miyanishi, M., Mori, Y., Seita, J., Chen, J. Y., Karten, S., Chan, C. K., . . Weissman, I. L. (2013). Do pluripotent stem cells exist in adult mice as very small embryonic stem cells? Stem Cell Reports, 1(2), 198-208

Natesan, S., Zamora, D. O., Wrice, N. L., Baer, D. G. and Christy, R. J. (2013). Bilayer hydrogel with autologous stem cells derived from debrided human burn skin for improved skin regeneration. $J$ Burn Care Res, 34(1), 18-30

Niemann, H. \& Petersen, B. (2016). The production of multi-transgenic pigs: update and perspectives for xenotransplantation. Transgenic Res

Nishino, K., Toyoda, M., Yamazaki-Inoue, M., Fukawatase, Y., Chikazawa, E., Sakaguchi, H., . . Umezawa, A. (2011). DNA methylation dynamics in human induced pluripotent stem cells over time. PLoS Genet, 7(5), e1002085

Obokata, H., Wakayama, T., Sasai, Y., Kojima, K., Vacanti, M. P., Niwa, H., . . Vacanti, C. A. (2014). Retraction: Stimulus-triggered fate conversion of somatic cells into pluripotency. Nature, 511(7507), 112

Oda, D., Gown, A. M., Vande Berg, J. S. and Stern, R. (1988). The fibroblast-like nature of myofibroblasts. Exp Mol Pathol, 49(3), 316-329

Olumi, A. F., Grossfeld, G. D., Hayward, S. W., Carroll, P. R., Tlsty, T. D. and Cunha, G. R. (1999). Carcinoma-associated fibroblasts direct tumor progression of initiated human prostatic epithelium. Cancer Res, 59(19), 5002-5011

Paunescu, V., Deak, E., Herman, D., Siska, I. R., Tanasie, G., Bunu, C., . . Seifried, E. (2007). In vitro differentiation of human mesenchymal stem cells to epithelial lineage. J Cell Mol Med, 11(3), 502-508

Pittenger, M. F., Mackay, A. M., Beck, S. C., Jaiswal, R. K., Douglas, R., Mosca, J. D., . . Marshak, D. R. (1999). Multilineage potential of adult human mesenchymal stem cells. Science, 284(5411), 143-147

Potten, C. S. (1986). Cell cycles in cell hierarchies. Int J Radiat Biol Relat Stud Phys Chem Med, 49(2), 257-278

Qureshi, I. A. \& Mehler, M. F. (2010). Impact of nuclear organization and dynamics on epigenetic regulation in the central nervous system: implications for neurological disease states. Ann NY Acad Sci, 1204 Suppl, E20-37

Rackham, O. J., Firas, J., Fang, H., Oates, M. E., Holmes, M. L., Knaupp, A. S., . . Gough, J. (2016). A predictive computational framework for direct reprogramming between human cell types. Nat Genet

Rajagopal, J. \& Stanger, B. Z. (2016). Plasticity in the Adult: How Should the Waddington Diagram Be Applied to Regenerating Tissues? Developmental Cell, 36(2), 133-137

Ramalho-Santos, M. \& Willenbring, H. (2007). On the Origin of the Term 'Stem Cell'. Cell Stem Cell, $1(1), 35-38$

Rao, M. S. \& Malik, N. (2012). Assessing iPSC reprogramming methods for their suitability in transla- 
tional medicine. J Cell Biochem, 113(10), 3061-3068

Real, C., Glavieux-Pardanaud, C., Vaigot, P., Le-Douarin, N. and Dupin, E. (2005). The instability of the neural crest phenotypes: Schwann cells can differentiate into myofibroblasts. Int J Dev Biol, 49(2-3), 151-159

Rekers, P. E., Coulter, M. P. and Warren, S. L. (1950). Effect of transplantation of bone marrow into irradiated animals. Archives of Surgery, 60(4), 635-667

Reynolds, B. A., Tetzlaff, W. and Weiss, S. (1992). A multipotent EGF-responsive striatal embryonic progenitor cell produces neurons and astrocytes. J Neurosci, 12(11), 4565-4574

Rinkevich, Y., Walmsley, G. G., Hu, M. S., Maan, Z. N., Newman, A. M., Drukker, M., . . Longaker, M. T. (2015). Skin fibrosis. Identification and isolation of a dermal lineage with intrinsic fibrogenic potential. Science, 348(6232), aaa2151

Rinn, J. L., Wang, J. K., Allen, N., Brugmann, S. A., Mikels, A. J., Liu, H., ... Chang, H. Y. (2008). A dermal HOX transcriptional program regulates site-specific epidermal fate. Genes Dev, 22(3), 303307

Roux, W. (1881) [Book]. Der Kampf der Theile im Organismus. Ein Beitrag zur vervollständigung der mechanischen Zweckmässigkeitslehre, von Wilhelm Roux. Leipzig, W. Engelmann.

Sacchetti, B., Funari, A., Michienzi, S., Di Cesare, S., Piersanti, S., Saggio, I., . . Bianco, P. (2007). Self-renewing osteoprogenitors in bone marrow sinusoids can organize a hematopoietic microenvironment. Cell, 131(2), 324-336

Sanai, N., Tramontin, A. D., Quinones-Hinojosa, A., Barbaro, N. M., Gupta, N., Kunwar, S., .. . Alvarez-Buylla, A. (2004). Unique astrocyte ribbon in adult human brain contains neural stem cells but lacks chain migration. Nature, 427(6976), 740-744

Schack, L. M., Noack, S., Winkler, R., Wissmann, G., Behrens, P., Wellmann, M., ... Hoffmann, A. (2013). The Phosphate Source Influences Gene Expression and Quality of Mineralization during Osteogenic Differentiation of Human Mesenchymal Stem Cells. PLoS One, 8(6), e65943

Schor, A. M., Canfield, A. E., Sutton, A. B., Arciniegas, E. and Allen, T. D. (1995). Pericyte differentiation. Clin Orthop Relat Res(313), 81-91

Schrepfer, S., Deuse, T., Reichenspurner, H., Fischbein, M. P., Robbins, R. C. and Pelletier, M. P. (2007). Stem cell transplantation: the lung barrier. Transplant Proc, 39(2), 573-576

Shinoka, T. \& Breuer, C. (2008). Tissue-engineered blood vessels in pediatric cardiac surgery. Yale J Biol Med, 81(4), 161-166

Slack, J. M. (2002). Conrad Hal Waddington: the last Renaissance biologist? Nat Rev Genet, 3(11), 889895

Sommer, C. A., Sommer, A. G., Longmire, T. A., Christodoulou, C., Thomas, D. D., Gostissa, M., ... Mostoslavsky, G. (2010). Excision of reprogramming transgenes improves the differentiation potential of iPS cells generated with a single excisable vector. Stem Cells, 28(1), 64-74

Song, B., Niclis, J. C., Alikhan, M. A., Sakkal, S., Sylvain, A., Kerr, P. G., . . Ricardo, S. D. (2011). Generation of induced pluripotent stem cells from human kidney mesangial cells. J Am Soc Nephrol, 22(7), 1213-1220

Sorrell, J. M. \& Caplan, A. I. (2009). Fibroblasts-a diverse population at the center of it all. Int Rev Cell Mol Biol, 276, 161-214

Spalding, K. L., Arner, E., Westermark, P. O., Bernard, S., Buchholz, B. A., Bergmann, O., . . A Arner, P. (2008). Dynamics of fat cell turnover in humans. Nature, 453(7196), 783-787

Sriram, G., Bigliardi, P. L. and Bigliardi-Qi, M. (2015). Fibroblast heterogeneity and its implications for engineering organotypic skin models in vitro. Eur J Cell Biol, 94(11), 483-512

Stadtfeld, M., Nagaya, M., Utikal, J., Weir, G. and Hochedlinger, K. (2008). Induced pluripotent stem cells generated without viral integration. Science, 322(5903), 945-949

Szostak, J. W. \& Blackburn, E. H. (1982). Cloning yeast telomeres on linear plasmid vectors. Cell, 29(1), 245-255

Tajbakhsh, S. (2009). Stem cell: what's in a name? Nature Reports stem cells(Commentary)

Takahashi, K. \& Yamanaka, S. (2006). Induction of pluripotent stem cells from mouse embryonic and adult fibroblast cultures by defined factors. Cell, 126(4), 663-676

Takahashi, K., Tanabe, K., Ohnuki, M., Narita, M., Ichisaka, T., Tomoda, K. and Yamanaka, S. (2007). Induction of pluripotent stem cells from adult human fibroblasts by defined factors. Cell, 131(5), 861-872

Tang, M. K., Lo, L. M., Shi, W. T., Yao, Y., Lee, H. S. S. and Lee, K. K. H. (2014). Transient acid treatment cannot induce neonatal somatic cells to become pluripotent stem cells [version 1; referees: 2 approved]. F1000Research, 3(102)

Tashiro, K., Kawabata, K., Inamura, M., Takayama, K., Furukawa, N., Sakurai, F., . . Mizuguchi, H. (2010). Adenovirus vector-mediated efficient transduction into human embryonic and induced pluripotent stem cells. Cell Reprogram, 12(5), 501-507 
Tatsumi, K., Ohashi, K., Matsubara, Y., Kohori, A., Ohno, T., Kakidachi, H., . . . Okano, T. (2013). Tissue factor triggers procoagulation in transplanted mesenchymal stem cells leading to thromboembolism. Biochem Biophys Res Commun, 431(2), 203-209

Thomas, E. D., Lochte, H. L., Jr., Lu, W. C. and Ferrebee, J. W. (1957). Intravenous infusion of bone marrow in patients receiving radiation and chemotherapy. N Engl J Med, 257(11), 491-496

Thomson, J. A., Itskovitz-Eldor, J., Shapiro, S. S., Waknitz, M. A., Swiergiel, J. J., Marshall, V. S. and Jones, J. M. (1998). Embryonic stem cell lines derived from human blastocysts. Science, 282(5391), 1145-1147

Toma, C., Wagner, W. R., Bowry, S., Schwartz, A. and Villanueva, F. (2009). Fate of culture-expanded mesenchymal stem cells in the microvasculature: in vivo observations of cell kinetics. Circ Res, 104(3), 398-402

Waddington, C. H. (1936). The Problems of Embryology. Br Med J, 2(3956), 862-864

Warren, L., Manos, P. D., Ahfeldt, T., Loh, Y. H., Li, H., Lau, F., . . Rossi, D. J. (2010). Highly efficient reprogramming to pluripotency and directed differentiation of human cells with synthetic modified mRNA. Cell Stem Cell, 7(5), 618-630

Webber, J., Meran, S., Steadman, R. and Phillips, A. (2009). Hyaluronan orchestrates transforming growth factor-beta1-dependent maintenance of myofibroblast phenotype. J Biol Chem, 284(14), 9083-9092

Weismann, A., Parker, W. N. and Rönnfeldt, H. (1893) [Book]. The germ-plasm; a theory of heredity. New York, Scribner's.

Vierbuchen, T., Ostermeier, A., Pang, Z. P., Kokubu, Y., Sudhof, T. C. and Wernig, M. (2010). Direct conversion of fibroblasts to functional neurons by defined factors. Nature, 463(7284), 10351041

Willerson, J. T. (2015). Stem cell therapy for cardiovascular diseases: a progressive journey. Curr Opin Cardiol, 30(3), 205-212

Wilmut, I., Schnieke, A. E., McWhir, J., Kind, A. J. and Campbell, K. H. (1997). Viable offspring derived from fetal and adult mammalian cells. Nature, 385(6619), 810-813

Woodbury, D., Schwarz, E. J., Prockop, D. J. and Black, I. B. (2000). Adult rat and human bone marrow stromal cells differentiate into neurons. J Neurosci Res, 61(4), 364-370

Wu, J., Sun, Z., Sun, H. S., Wu, J., Weisel, R. D., Keating, A., . . Li, R. K. (2008). Intravenously administered bone marrow cells migrate to damaged brain tissue and improve neural function in ischemic rats. Cell Transplant, 16(10), 993-1005

Yanez, R., Lamana, M. L., Garcia-Castro, J., Colmenero, I., Ramirez, M. and Bueren, J. A. (2006). Adipose tissue-derived mesenchymal stem cells have in vivo immunosuppressive properties applicable for the control of the graft-versus-host disease. Stem Cells, 24(11), 2582-2591

Yang, W. J., Yang, D. D., Na, S., Sandusky, G. E., Zhang, Q. and Zhao, G. (2005). Dicer is required for embryonic angiogenesis during mouse development. J Biol Chem, 280(10), 9330-9335

Yu, J., Vodyanik, M. A., Smuga-Otto, K., Antosiewicz-Bourget, J., Frane, J. L., Tian, S., . . Thomson, J. A. (2007). Induced pluripotent stem cell lines derived from human somatic cells. Science, 318(5858), 1917-1920

Zandi, S., Bryder, D. and Sigvardsson, M. (2010). Load and lock: the molecular mechanisms of B-lymphocyte commitment. Immunol Rev, 238(1), 47-62

Zhou, Q., Brown, J., Kanarek, A., Rajagopal, J. and Melton, D. A. (2008). In vivo reprogramming of adult pancreatic exocrine cells to beta-cells. Nature, 455(7213), 627-632

Zhou, T., Benda, C., Duzinger, S., Huang, Y., Li, X., Li, Y., . . Esteban, M. A. (2011). Generation of induced pluripotent stem cells from urine. J Am Soc Nephrol, 22(7), 1221-1228

Zhou, W. \& Freed, C. R. (2009). Adenoviral gene delivery can reprogram human fibroblasts to induced pluripotent stem cells. Stem Cells, 27(11), 2667-2674

Zimmermann, K. W. (1923). Der feinere Bau der Blutcapillaren. Zeitschrift für Anatomie und Entwicklungsgeschichte, 68(1), 29-109

Zuk, P. A., Zhu, M., Mizuno, H., Huang, J., Futrell, J. W., Katz, A. J., . . Hedrick, M. H. (2001). Multilineage cells from human adipose tissue: implications for cell-based therapies. Tissue Eng, 7(2), 211-228

Östman, A. \& Augsten, M. (2009). Cancer-associated fibroblasts and tumor growth--bystanders turning into key players. Curr Opin Genet Dev, 19(1), 67-73 


\section{Part 2: \\ MATERIALS IN TISSUE ENGINEERING}

"We are all sculptors and painters, and our material is our own flesh and blood and bones"

- from "Walden" by Henry David Thoreau (Thoreau, 1854)

The vision of advanced cell cultures and laboratory techniques is the construction of functional tissue: Tissue Engineering (TE). Cells can be taken from a patient, cultured in the lab, and given back as functional tissue that is also fully immunologically compatible. The concept of autologous transplantation negates the need for immunosuppressive treatments. Today however, this is practically limited to cellular therapies (allogeneic and autologous cell transplantation) since most TE constructs are insufficient and impractical for clinical application.

The parallel research into how cells and tissue are actually created leads to the idea that we may yet tap into the obscured ability in adult tissue of complete regeneration: regenerative medicine (RM). Therapies might consist of a localized infusion of proteins or genes that allow the body to heal itself without further complicated surgical interventions.

Together, TE and RM (TERM) combine in a giant field of research trying to use advanced laboratory techniques to construct and repair tissues and organs while also attempting to elucidate the molecular signals and mechanisms of tissue repair and regeneration. The efficacy is low for today's TE-based therapies, mainly because the construction techniques are not yet fully developed and at a satisfactory clinical level. The use of approximate, or limited, tissue is still an important milestone for laboratory research into cells and tissues. A partially constructed tissue-set may be used as a type of model system for various aspects of the tissue biology, and therefore holds great utility for furthering preclinical research. 


\section{Tissue Engineering: the holy trinity}

The junction between cellular biology, molecular biology, and materials science sets the stage for tissue engineering. The study of cells, biochemical factors and materials together inches us closer to using cells as building blocks for human replacement parts (Bell, 1991, 2000). The term "tissue engineering" was coined at a National Science Foundation committee meeting in 1987 (Nerem, 2006).

Cells, extracellular matrix, and soluble factors are the three families of materials used in the creation of any tissue. The right cells need the right cues, and will be at home in the right extracellular environment. The requirements of many cell types have been determined for in vitro maintenance and development, but when adding additional cell-types to a culture system the biological cross-talk can make the system very complex. In principle, most tissues are largely self-organizing, but that still requires a correctly instructive environment which is rarely a trivial laboratory exercise.

Advances in cell culture techniques allows for three-dimensional cultures, spatially more similar to their native home. The molecular environment of the native extracellular matrix of any tissue is still very difficult to mimic, so even in three-dimensional cultures the substrate complexity is relatively poorly approximated. A number of approaches to provide a suitable spatial and physical matrix have been attempted, and various ways of providing molecular cues have been variously successful.

There is some consensus that each cell type is differently suited for a particular culture, and that each cell type has a different range of optimal conditions. Research looking into the range of a particular cell type is as important as research aimed at optimizing the conditions for a particular outcome. TE lies in the intersection of materials science, cell signaling biochemistry and cell culture techniques, but the number of fields that have contributed to TE is staggering (Viola et al., 2003). 


\section{Principles of Tissue Engineering}

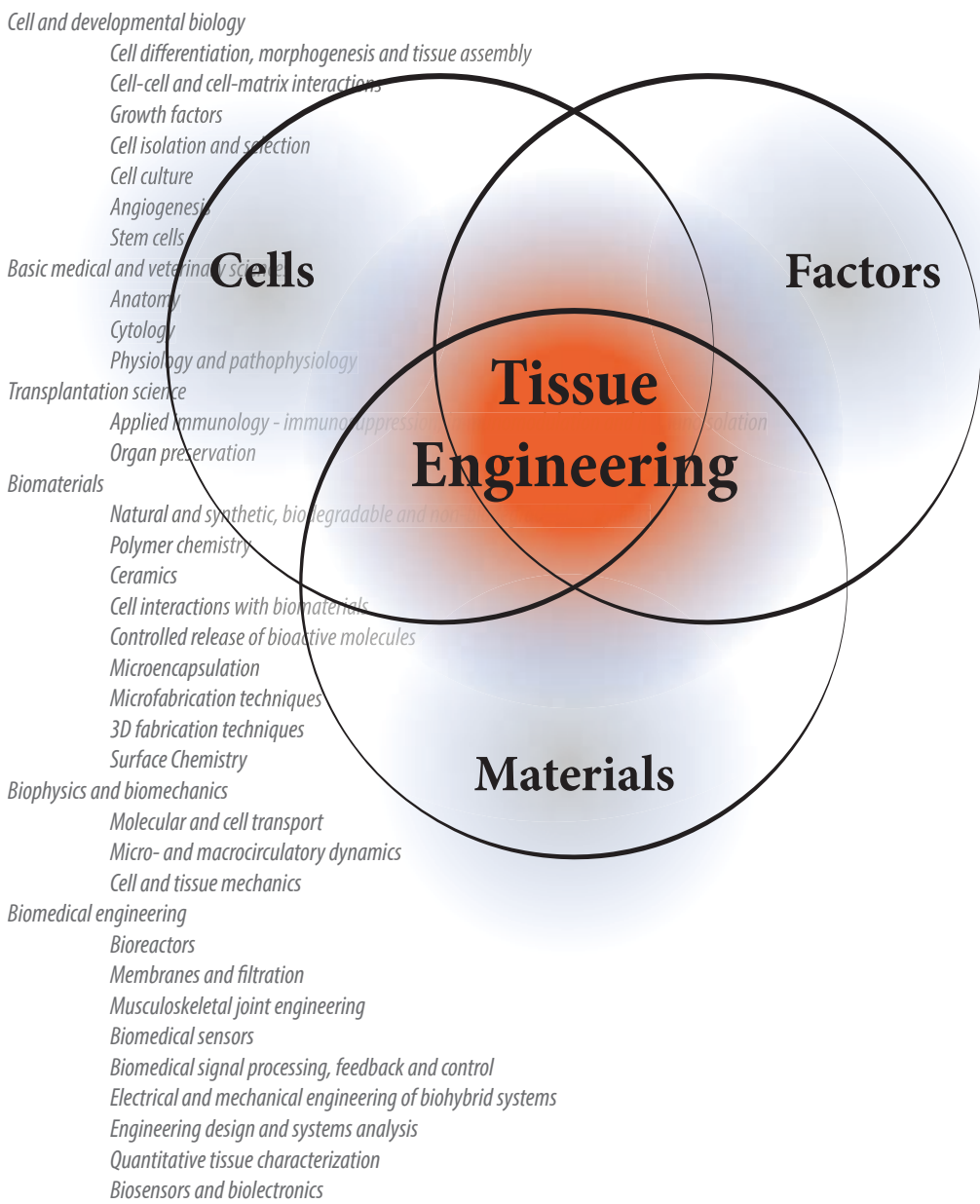

This image represent the different contributions to tissue engineering and how knowledge from multiple disciplines are needed to form the field. Adapted from (Viola et al., 2003) 


\section{Cells: sources and considerations}

Each tissue in the body is associated with a number of cell types, and usually one that is central to the function of the tissue. That central cell type may be obtained by sacrificing animals, by biopsy of a human donor, by cadaveric donors or by using a stem cell source as the starting material. Each of the options imply ethical considerations, and direct biopsies are impractical for some cell types. Stem cell sources are usually more practical, but require more time in the lab for expansion and differentiation, after which tissue reconstruction may begin.

Embryonic stem cells are pluripotent and therefore hold promise for obtaining any cell type of the body. However, they suffer from phenotypic volatility, spontaneously producing teratomas in culture, and they are allogeneic at best and very difficult to obtain. Popularization of the promise of embryonic stem cells for future therapies has fueled the niche market of saving cord blood or the umbilical cord in conjunction with birthing. Embryonic stem cells are also hampered by ethical misgivings, public misconceptions and non-harmonized global legislation.

In contrast, adult stem cells can be autologous, are versatile enough for numerous cell applications, yet controllable and stable. MSC are often considered particularly suitable for TE applications. Sources include bone marrow biopsies and, to some extent, circulating stem cells obtainable from blood isolation. The ADSCs are more easily obtained through lipoaspirate, and resident dermal stem cells are also more readily biopsied than bone marrow. There is as yet no real consensus on the best source of stem cells for all applications, but there are preferences for most specific types of tissue. The availability of iPSC has also expanded the possibilities for research into tissue construction.

The ideal source of cells for TE is easily obtainable, by minimally invasive means, easy to expand and culture, is well-characterized and clinically safe and, in the case of stem cells, easily differentiated to a number of target cells by standardized protocols.

\section{Cell signaling: guiding and stimulating fates}

Cell culture media are generally formulated for one of four different purposes: to maintain or expand cells, to functionally activate cells for a particular purpose, to differentiate cells, or to support tissue development. There are numerous formulations known for the various cell types, but many media share similar basal formulations designed to meet fundamental nutritional needs of cells.

Harry Eagle, along with many other scientists in the 1950's, performed sub- 
stantial research on the requirements of cells for in vitro maintenance, leading to the formulation of the famous Eagle's medium (Eagle, 1955, 1958). He noted particularly the stoichiometric relationships between amino acids and vitamins, energy, and certain growth factors necessary for cells to survive in culture. With notable contribution from Alfred Dulbecco, the resulting formulation of Dulbecco's Modified Eagle's Medium (DMEM) is the basis of many modern cell culture media (Jayme et al., 1997). To provide the final nutritional contents, $10 \%$ (per volume) serum is often added. Such is, for example, the complete formulation of fibroblast culture medium (DMEM $+10 \%$ fetal calf serum (FCS)).

The proportion of serum, and its source, can have significant effects on the proliferative drive of the medium, depending on cell type. Lowering the amount to around $1 \%$ serum keeps cells alive, but slows their proliferation, while adding $30 \%$ or more can cause enormous cellular proliferation over a short period of time. The content of serum is source- and batch-variable and largely undefined by GLP/GMP standards. For many cell types there are now "fully defined" media that include proprietary mixtures of factors designed to replace the need for serum. Another problem with the use of serum is the accelerated in vitro effects as cells adapt to their artificial environment, at the expense of their native phenotype, and favor propagation over homeostasis.

Small molecules can have immense effects on cellular behavior, some have precise effects and others affect the cells very broadly. Lipophilic ligands, such as steroid hormones and some vitamins, can bind to nuclear receptors which directly influence gene expression or DNA conformational changes. Dexamethasone, for example, can freely diffuse across cell membranes, bind the glucocorticoid receptor, enter the nucleus and activate gene expression cascades. These can be very broadly activating molecules, affecting strong signaling cascades that have various effects on cell phenotype and behavior.

Other molecules, such as cytokines, chemokines, some hormones, and cell adhesion molecules, are dependent on cell surface receptors to relay signals into the cell, which can result in anything from gene expression changes to changes in electrolyte balance, or activation of other cascades that prime for, or modulate, signals from the environment. These effects are used in medium-based differentiation of cells, where the culture medium is supplemented with molecules targeting specific cascades to push cells towards a sought-after end-state or behavior. The action of the supplements largely depends on the receptivity of the cells.

Ions are also important for biological functions. Ions from the growth medium, such as potassium, sodium and chlorine, can be actively or passively transported across cell membranes thereby changing the membrane potential and stim- 


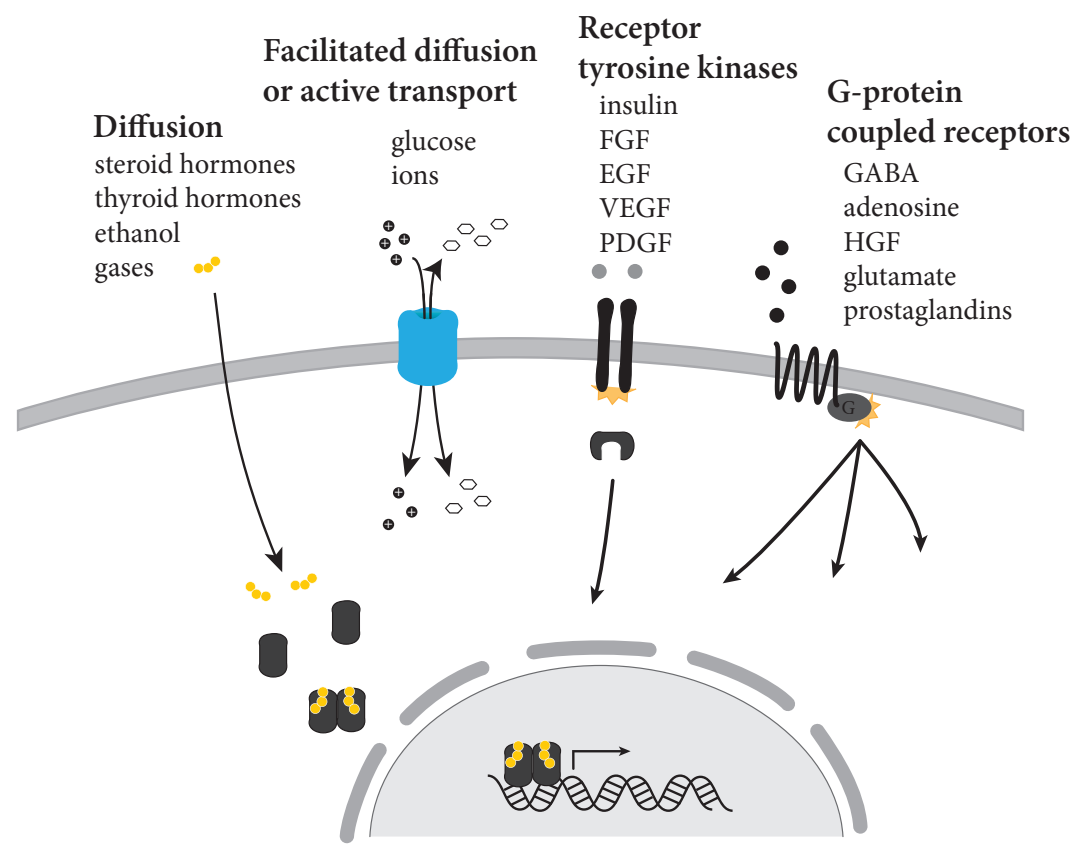

Modes of signaling and examples of molecules. Lipid-based hormones are hydrophobic and can diffuse across the membrane. Hydrophilic molecules require facilitated diffusion, and other forms include active transport or ligand gated channels (ABC and SLC-superfamilies). Receptor tyrosine kinases (RTK) and G-protein coupled receptors (GPCR) transduce the binding event to intracellular signals.

ulate voltage-sensitive molecules. Calcium is important for many intracellular signaling events, and can even be important for cellular differentiation. Magnesium, and other metal ions, are important co-factors for several enzymes.

Manipulating the energetics of cells can be important for controlling cellular behavior. Adenosine triphosphate, ATP, is the typical energy currency of the cell, and various factors can target ATP-regulating cellular systems to modify the energy pool available, or how the cells distribute it.

Many factors are available for purchase from pharmaceutical and biotechnology companies, but slight molecular differences and mixture formats still introduce variations in culture protocols. Factors that are difficult to obtain through commercial means can instead be isolated from their native environment, produced in transgenic microorganisms or selectively synthesized as amino acid sequences. There is also the possibility of in vitro translation systems, but the efficacy of each approach is determined by the molecular configuration that confers the desired activity, and the limits of each system to obtain such a configuration.

Microorganism production of proteins can be based on human transgenes, resulting in perfect sequences, but may fail because of limits in the post-trans- 
lational capabilities of the system. The biological activity may require certain carbohydrate or phosphate modifications at correct positions, or the protein folding may be dependent on specialized chaperone proteins that may not be available in those systems. In some cases, shorter peptides may be synthesized by amino acid sequences, and in other cases enzymatic treatment of longer peptides may produce active sub-units that can be used for medium supplementation.

In many cases, the identity of desired molecules or their amounts are unknown, in which case biological mixtures can be used which are likely to include the necessary stimuli. The use of serum is a well-known example of such an approach, providing a number of unidentified biological components that enable cells to thrive in culture. In certain formulations of keratinocyte media, it is common to use bovine pituitary extract, which likely contains a number of hormones and signaling factors that have not been fully identified or quantified.

Another common approach is to use conditioned media, obtained by using a more or less defined culture medium to cultivate a certain cell type. The cells continually exchange substances with the medium in which they are cultivated, and so enrich the medium with any number of produced factors. By applying the used, enriched, medium to another cell culture these molecules are transferred onto the second culture and enrich their environment much like in a co-culture system. Conditioned media can enhance differentiation protocols, but the factors which confer the enhancing effects are largely unknown.

Co-cultures that divide one cell culture format into two or more separate compartments, each populated with different cell types, can be designed to allow free exchange of medium and soluble factors, but without cell-cell contact. This is a direct and reciprocal form of the conditioned media approach, and can have large effects on co-cultured cell types. If the culture allows cell-cell contact, there are often even stronger effects on the reciprocal signaling, and the cells develop together according to their genetic programming.

In many cases of co-culture, the media can (and should) be simplified since the cells can feed each other with regulating factors. Early keratinocyte cultures, and several forms of stem cell cultures, use irradiated or mitomycin-treated fibroblasts, that are thereby stopped from proliferating, as a "feeder-layer" upon which the keratinocytes or stem cells are cultured. The feeder layer can maintain a matrix and secrete molecules to create a supportive environment ( $\mathrm{Lu}$ et al., 2012).

By adding dexamethasone, insulin, isobutyl-methyl-xanthine (IBMX), and indomethacine or rosiglitazone, the adipogenic program can be activated in 
preadipocytes, causing the development of adipocytes (Pittenger et al., 1999). By adding these factors to cultures of a variety of cell types, an adipogenic program can be stimulated even if the initial cells are not strictly obtained from an adipogenic lineage. Insulin can induce proliferation and differentiation, partly through action on IGF-receptors, while also stimulating glucose uptake, stimulating protein synthesis and inhibiting lipolysis, among other actions. Dexamethasone and IBMX function together to activate PPARG, the key regulator of adipogenesis, and the important co-regulators CEBPB and CEBPD. IBMX may function through increasing intracellular cAMP levels which activates protein kinase A, required for transcriptional activation of PPARG. Indomethacine and rosiglitazone are PPARG agonists, which further boosts the activity of the key regulator. The concentrations of each substance can vary greatly in different reports (Scott et al., 2011).

There is a philosophical difference between mimicking nature to produce specific tissue in the lab, and adding factors with known outcomes in a combination that produces a sought after functional phenotype. Many of today's supplementation protocols uses a combination of physiological analogues and boosting specific effects through biochemical stimuli. Some factors, such as ascorbic acid (vitamin C), are known for stimulating the production of extracellular matrix in some cell types (also fibroblasts) (Freiberger et al., 1980). This is frequently used with the intention of obtaining a thicker culture with more matrix components. Beta-glycerophosphate is also used with similar application: to stimulate matrix mineralization (Coe et al., 1992). Both ascorbic acid and beta-glycerophosphate act on cellular cascades to stimulate matrix production, without necessarily affecting the identity of the cells any more profoundly.

There are many factors that can be used in cell cultures. Synthetic molecules can be used as ligands to specific receptors. They can modulate cellular actions by either activating or blocking receptors, or by competing with endogenous molecules. Matrix components can also be used to stimulate matrix production in a feed-back signaling cascade. Relying on integrin signaling events, polymers containing recognition sequences can induce enhanced matrix-homeostatic activity in cells. Even modifications to the environment, such as altered viscosity of the medium, shear stress, $\mathrm{pH}$ or temperature have been used to regulate cellular behavior in cultures.

\section{Extracellular matrices: scaffolds for cells and tissue}

Cells in the body are always surrounded by extracellular matrix, it defines the environment in which they live. The matrix can differ greatly between tissue types, in the extremes ranging from blood to bone. The physical properties of 
the matrix, with attributes such as tensile strength, stiffness/elasticity, density/ porosity, water content/hydrophobicity, and topography directly modulates the actions of cells. The biochemical properties are also important for forming the environment, determining things like susceptibility to enzymes, degradation products and rates, the attachment of secreted factors to the matrix and how they are released, and influence of the matrix on local $\mathrm{pH}$ and buffering.

Substrate stiffness influences cell behavior, likely through surface mechanotransducers that link the external response of the matrix to the contractile action cytoskeletal components. The viability of adherent cells is anchorage dependent (Discher et al., 2005). The cytoskeleton becomes linked to the extracellular matrix through integrins, cadherins and other surface molecules, and contractile forces are created by the action of proteins such as actin and myosin.

Signaling through focal adhesions can transduce the mechanical stimulus to intracellular signaling cascades, regulating gene expression and protein activation (Engler et al., 2006). Rho and ROCK proteins, involved in regulating shape and movement of cells, seem to be directly involved in MSC lineage commitment by complex feed-back regulated actions dependent in part on actin-myosin generated tension (McBeath et al., 2004).

The surface topography can be instructive in the orientation of cells, and the alignment of the matrix produced by the cells (Guillemette et al., 2009). The control of topography and stiffness, and thus cell and matrix alignment, can provide a more physiological foundation for tissue development by instructing appropriate self-assembly. Self-assembly, important in nanotechnology, is in principle applicable at all scales (Whitesides \& Grzybowski, 2002) and is an important aspect of tissue development in TE (Jakab et al., 2004).

To some extent, all materials in TE are necessarily biocompatible. There are principally two categories of materials in tissue engineering: synthetic and natural. The materials in each category are either biodegradable, or not. The preference of material rests largely on the purpose and demands of the application. Synthetic non-degradable materials are typically used clinically as prosthetics, and include titanium replacements for bone defects, stents to open and stabilize vessels and airways, and more complex machinery like pacemakers or neural electrodes. Their primary use in the laboratory is as part of bioreactors or advanced cell culture systems. We have investigated cellular behavior on a plastic conductive polymer, PEDOT, coated with PSS (PEDOT-PSS), for the purposes of using an electronically active cell culture substrate. Two potential applications include preferential attachment of cells based on electronic addressing, and detachment of cell layers by switching voltages. 


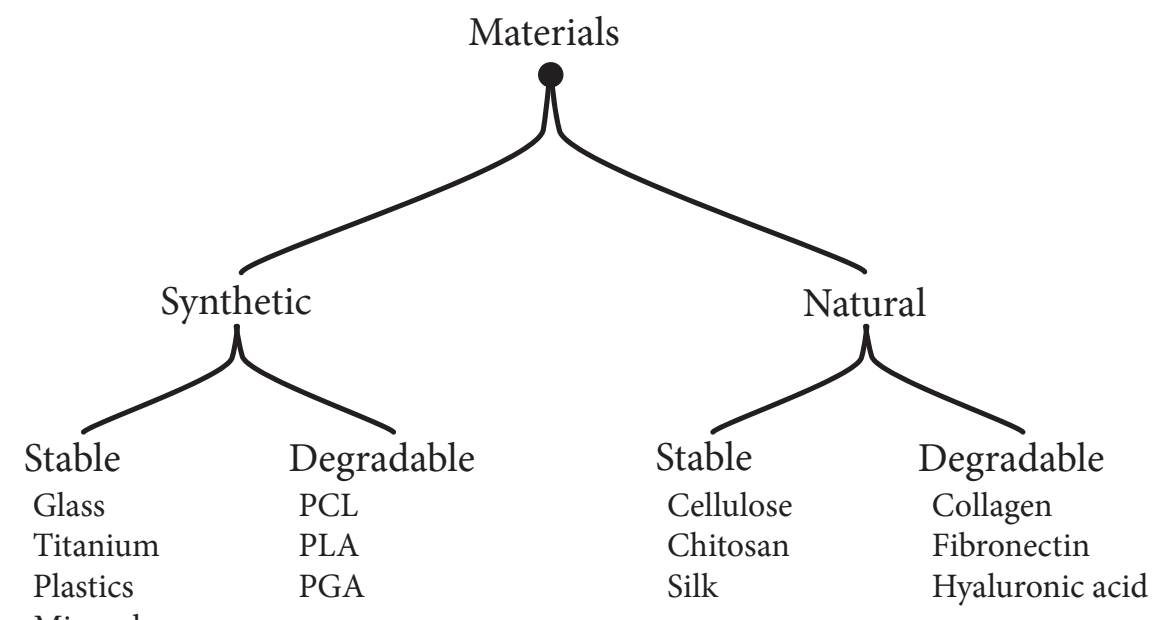

Minerals

A generalized overview of materials in tissue engineering. Some stable materials can be made degradable, and some natural materials can be manufactured synthetically.

A number of biodegradable synthetic polymers are commonly used for tissue construction. Synthetic polymers tend to be easier to manufacture on a large scale, with less variation than natural materials (Vacanti et al., 1998). Advances in chemistry allows systematic alteration to the manufacturing process to obtain standardized variations of polymer properties. Polyethylene glycol (PEG)-based hydrogels can be used to mimic natural matrices for a number of TE applications (Goktas et al., 2015). These hydrogels are easily manufactured in composites, and can be tuned to achieve different rates of degradation, biochemistry and physical properties (Ulbricht et al., 2014).

A popular technique for constructing scaffolds is electrospinning, where polymers such as polycaprolactone (PCL), polylactic acid (PLA), and polyglycolic acid (PGA) are commonly used (Rim et al., 2013). Electrospinning enables control of fiber diameter, scaffold density, orientation, and material biochemistry, allowing for the creation of biomimetic matrices. Fiber-based TE is a whole sub-field of methods and applications (reviewed in: (Tamayol et al., 2013)). We have used electrospun PCL scaffolds for cartilage constructs and skin constructs (unpublished, manuscript pending) in both random and aligned orientations. We used 13\% PCL in chloroform:methanol (4:1) and 15\% PCL in ascetic acid:pyridine (19:1), and observed different fiber morphology (diameters ranging from 100 to $2000 \mathrm{~nm}$ ). The scaffolds were stable enough to be manipulated, even with cells cultured on it, and the material properties seemed to confer altered behavior of cells (we found increased COL10A1 and SOX9 expression, and Alcian Blue positive staining; unpublished results).

Perhaps the most widely used material in TE is collagen, and its derivative gelatin (Vacanti et al., 1998). It is natural, biodegradable and readily available. 

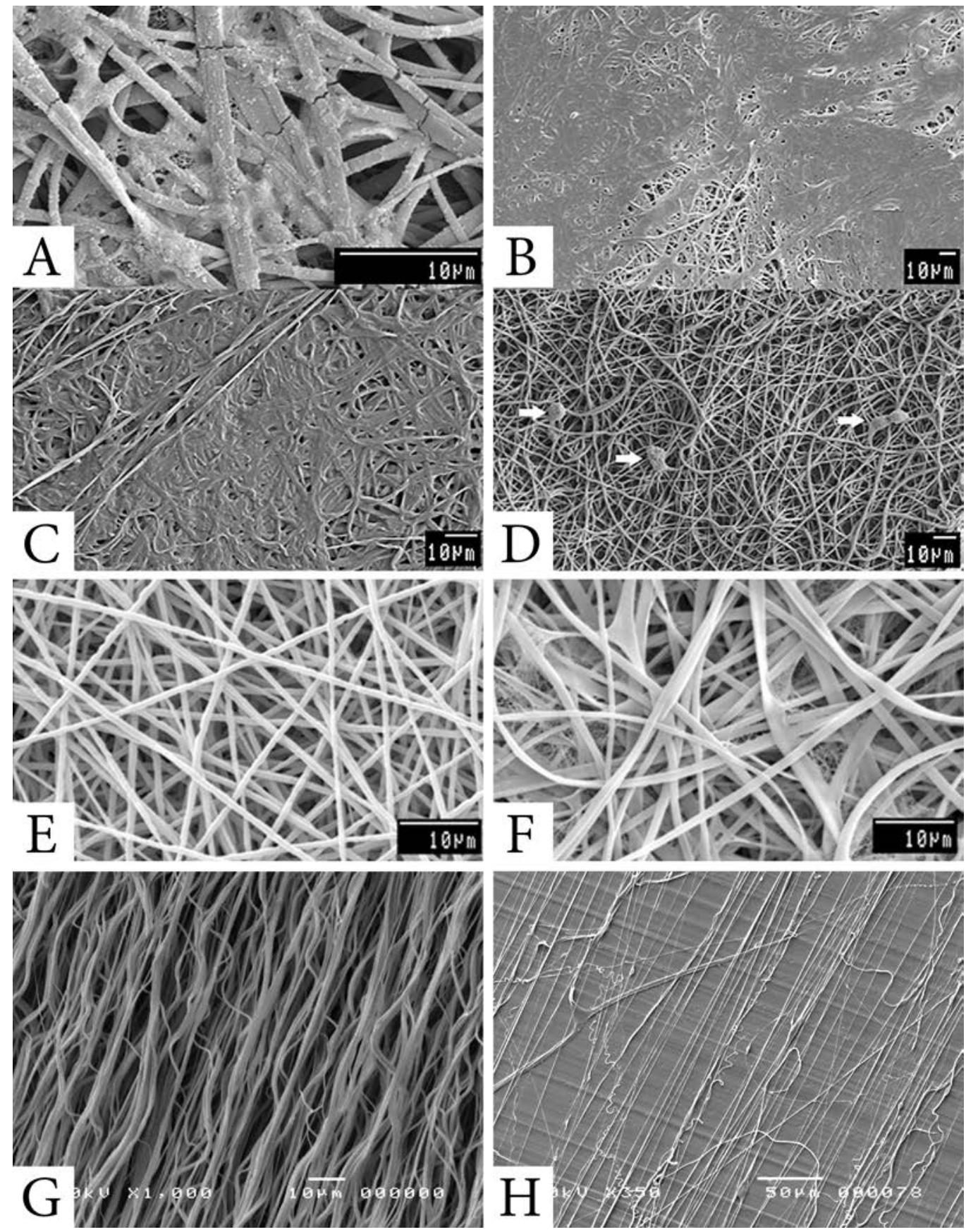

Scanning electron microscopy images of electrospun polycraprolactone (PCL).

A: Unaligned PCL (13\%) spun in Acetic acid-pyridine, seeded with fibroblasts after 1 week. B: A, after 3 weeks. C: A, after 5 weeks. D: PCL (13\%) Chloroform-Methanol, with fibroblasts, after 5 weeks (arrows). E: PCL (13\%) Chloroform-Methanol. F: PCL (13\%) Acetic acid-Pyridine. G: Aligned PCL (13\%) Chloroform-Methanol. H: Aligned PCL (9\%) Acetone. 


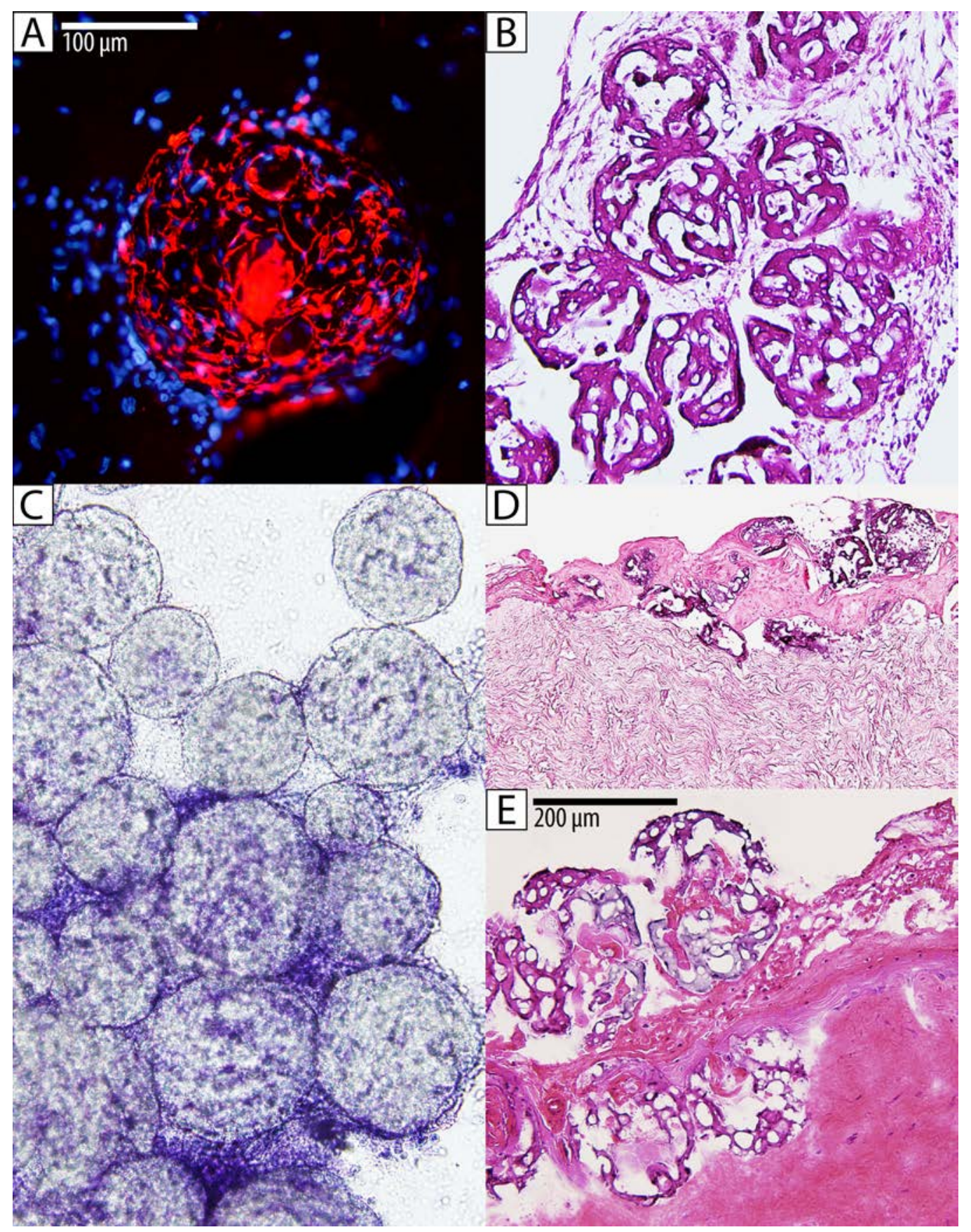

Various uses of microcarriers (MC).

A: Confocal image of MC embedded in dermis, populated with cells (nuclei stained with DAPI, blue). B: MC in endothelial cell culture (H\&E stained). C: MCs agglomerated by cellular adhesion (MTT viability stained cells). D: MC embedded in neoepidermis (H\&E). E: MC during re-epithelialization; some populated by dermis, some populated by epidermis ( $\mathrm{H} \& \mathrm{E})$. 
Collagens are ubiquitous in the stroma of most tissues, and most cells are able to produce and remodel collagen-based matrices. Fibrin, fibronectin, and hyaluronan are also frequently used. A drawback with such material is the overall limits of quality control and differences in the material depending on their source of origin. There are also greater risks of biological contamination than for synthetic materials. Natural materials, while originating from natural sources, may not necessarily be natural to the setting in which they are applied. Cellulose, chitosan and silk materials can be obtained through large-scale production, alleviating some of the problems of standardization. These can be difficult for mammalian cells to degrade, but they can be functionalized and tuned, making them useful in some TE applications.

We have used (including in Paper II) gelatin-based material in the form of porous spherical sponges, called microcarriers (CultiSpher-S, manufactured by PerCell Biolytica, Sweden). The microcarriers have interconnected pores at an average diameter of $20 \mu \mathrm{m}$, with an outer diameter of around $200 \mu \mathrm{m}$ (Lönnqvist et al., 2015). This makes them easily manipulated in solution, provides ample surface area for the attachment of cells, and injectable and pipettable. The microcarriers are biodegradable, expected to be degraded within three months of implantation into the human dermis (Huss et al., 2010).

Most materials can be modified and functionalized by binding of bioactive factors and short peptides or carbohydrates to the matrix. The presence of recognition domains on the substrate can regulate cell behavior and fates. Interactions between human pluripotent cells and their matrix occurs through a number of different specific cell adhesion molecules and, physiologically, the matrix molecules of their niche, and can regulate their pluripotency (reviewed in (Lambshead et al., 2013)). Cell adhesion molecules bind to short molecular recognition domains of the matrix proteins, and those peptide sequences can be synthesized and attached to synthetic surfaces. Fibronectin is recognized by integrins through the Arg-Gly-Asp, or RGD, motif (D'Souza et al., 1991), so attaching RGD motifs to the material can provide biologically relevant adhesive properties.

The choice of material ultimately reflects the intended use of the TE constructs. For in vitro models and investigations there are reasonably few restrictions, but for intended in vivo use the range of materials is significantly narrower. Any material modification and functionalization has to be approved for in vivo use by ethical committees. Materials aimed at clinical uses have to be further cleared and registered through regulatory authorities. The definition of tissue-engineered products is not yet harmonized across the world, and many procedures have not so far been regulated, other than by the quality and safety protocols of hospitals or clinics (Lloyd-Evans, 2004). 


\section{Experimental achievements in TE}

In some cases, the following examples have been precursors to clinical applications, most are still clinically unfeasible but very valuable as experimental laboratory systems. In all cases, their achievements have imparted valuable knowledge to medical science and have had, or will have, impact on future therapies. Such is, after all, the goal of medical research as a whole.

The image of the human ear grown on the back of a mouse created headlines when it appeared. The ear was produced by implanting synthetic polymer scaffolds seeded with bovine chondrocytes under the skin of nude mice (Cao et al., 1997). After 12 weeks, the scaffolds were analyzed and showed formation of cartilage as well as some vascular structure. It was an eye-catching proof that biocompatible implants in a mammal could be a viable option for certain therapies, such as auricular reconstructions. The scaffolds were cast in a mold of a child's ear, to demonstrate a potential utility for reconstructive surgery.

One approach to obtain correct scaffolds, both in terms of shape and molecular composition, is to remove the organs of interest and decellularize them. The naked matrix can then be re-seeded with new cells, and the organ transplanted. This technique has been used to obtain kidneys which were transplanted into rat, and showed basic functions (J. J. Song et al., 2013). The group had similar success with recellularized lung (Ott et al., 2010), and heart (Ott et al., 2008).

A few interesting achievements have been reported using principles of guided self-assembly. Refinement of neurosphere cultures led to a protocol for manufacturing a three-dimensional neural model for cortical studies - a "minibrain" (Dingle et al., 2015). The neurosphere is electronically active and contains all neuronal cell types. A further study reports the construction of an interconnected neurosphere array, allowing signaling experiments between bundles of neuronal microtissue (Jeong et al., 2015). Such models could provide a fine test-bed for investigations into neural tissue development, homeostasis, and disease modeling.

The most complex structure yet replicated in a culture dish is the retina of a mouse. Starting with embryonic stem cell aggregates, the developmental stages were replicated in vitro to obtain a fully stratified retinal tissue (Eiraku et al., 2011). The authors suggest that this research eventually may open up for the transplantation of artificial retinal tissue sheets instead of simple cell grafting. 


\section{Clinical examples of TE constructs}

With all the promises of TE, how far have we come today? There are notable difficulties associated with TE. The techniques are still usually awkward and cumbersome, and often produce very variable constructs. A simple construct can take several weeks in the lab, meaning that any clinically oriented TE will substantially delay patient treatment. Nonetheless, there have been a number of cases and trials of TE constructs in patients, some of these are outlined below. Skin, one of the more popular subjects in TE, is reviewed in Part 3.

\section{Urethras}

Hypospadias are congenital malformations in the urinary tracts that are surgically treated, often in young patients. Mild forms are easily corrected with low incidence of complications, whereas more severe forms can be surgically challenging. Free skin grafts have been used, with varying success (Hendren \& Crooks, 1980), and buccal mucosa (Duckett et al., 1995; Etker, 1996). Material advances in TE saw the use of inert collagen materials as a promising option (Atala et al., 1999). An autologous construct was used, based on acellular dermis seeded with urothelial cells, on six patients with reasonable success, including a 3 to 5 year follow-up (Fossum et al., 2007).

Surgical treatment of hypospadias with oral mucosa yields good results. Its harvest is relatively simple and well-tolerated by patients, but it still creates damaged donor sites. The view that tissue-engineered constructs with different cell types should eventually be used as grafts of choice in substitution urethroplasty procedures is supported by a body of research (recently reviewed in: (Atala et al., 2015)). There is still research to be done to find out which protocols can become the new gold standard, but successes in early trials show that engineering of suitable constructs is both possible and feasible for some patient groups.

\section{Bladder}

The first bioengineered, autologous, bladders were transplanted into a select patient group with the aim of providing only an increased bladder capacity (Atala et al., 2006). The follow-up showed successful surgeries and improved capacities, and this has been considered a milestone achievement for TE. A major weakness with the construct is the limited innervation achieved, making it uncertain whether this approach is clinically applicable to other patient groups, or feasible in terms of the required resources (Hakenberg, 2006).

The procedures were altered during the three years of the trial to improve the outcomes for the patients, and patients were followed up to five years post-op- 
eratively. Initially, a collagen-based matrix derived from decellularized bladder mucosa was used, but animal studies suggested that a polyglycolic acid (PGA) scaffold covered with omentum would provide better results (Oberpenning et al., 1999). Further modifications used a collagen-PGA composite scaffold in the final patients. The material was molded into a bladder-shape, with dimensions adapted to each individual patient. Smooth muscle cells, expanded under standard conditions, were seeded on the outside. After 48 hours the insides were seeded with urothelial cells, and the constructs were implanted within four days. The time between obtaining autologous cells and implantation was around two months. (Atala et al., 2006)

Intestinal cytoplasty is considered the gold standard, wherein parts of the intestine are used to repair the bladder. Problems are associated with the damage to the otherwise healthy donor site, and the behavior of the tissue in the new niche. This does motivate the endeavor to find alternative treatments through TE, but the trials of Atala et al. must be replicated and refined to become considered the method of choice for even a sub-set of patients requiring new bladders (Chung, 2006).

\section{Cardiovascular engineering}

The relative simplicity of vascular constructs, in terms of tissue complexity, makes this area very interesting for early efforts into vascular engineering. Engineered vascular grafts have been transplanted clinically, for use in low-pressure systems (Shin'oka et al., 2005). Successful application of vascular autografts have been performed in several early trials (G. Matsumura et al., 2003). A TE pulmonary artery was implantated in a young girl, using a PCL-PLA copolymer with woven PGA support seeded with autologous endothelial cells expanded from explant culture (Shin'oka et al., 2001). The construct was $1 \mathrm{~cm}$ in diameter, $2 \mathrm{~cm}$ long and $1 \mathrm{~mm}$ thick. Follow-up showed no adverse effects, and normal vascular function, seven months post-operatively.

Cardiac patches can be constructed using similar engineering techniques, but with cardiomyocytes instead of endothelial cells. Such constructs are prevalent in animal models. Heart valves may also be a feasible early target for TE constructs. Engineered xeno-autologous heart valves have been implanted in humans (Goldstein et al., 2000).

The mechanical demands of high-pressure vasculature on the grafts makes their clinical use more challenging. By developing material choices using animal models we may be approaching suitable materials and construction protocols that will be safe for human use. Perhaps further developments into the use of decellularized hearts will be an early approach to clinical application. 


\section{Cornea}

The cornea is a challenging tissue to bioengineer because of its transparency and necessary lack of vascularization. Using material engineering approaches, a scaffold based on recombinant human collagen III was manufactured, and subsequently implanted into ten patients (Fagerholm et al., 2010). The scaffolds showed promising results after a 24-month follow-up, but did not fully outperform previous clinical standards for corneal replacements.

Previously, corneal reconstruction had been attempted using cell sheets of oral mucosal epithelium in four patients (Nishida et al., 2004). The results were not as good, owing to infiltration of occasional blood vessels, and lack of full transparency. Visual acuity improved during the first ten weeks, then remained stable. Follow-up studies of the different approaches of corneal substitution are needed, but the use of collagen scaffolds were ascribed great promise both in production feasibility and end results.

\section{Trachea}

"One should be cautious about taking immature preclinical concepts from the laboratory to the clinic without sophisticated scientific foundation"

- Mertsching, Walles \& Macchiarini (Mertsching et al., 2004)

First attempts at creating a substitute airway were based on acellular trachea, repopulated with autologous endothelial cells and mesenchymal stem cells, and transplanted into a patient (Macchiarini et al., 2008). Although described as a success, the material was changed in later trials. Instead, the patented synthetic material POSS-PCU (Ahmed et al., 2011) was used. Synthetic trachea scaffolds of POSS-PCU were populated with autologous stem cells and implanted in another patient (Jungebluth et al., 2011). Again, the report concluded that successful organ regeneration has been accomplished (Jungebluth et al., 2011). Regrettably, the constructs were not sufficiently engineered to be successful over time, and all most of the patients have died or are hospitalized for their foreseeable future. The research conduct of the principal investigator is under question, and the story was recently covered by a Swedish documentary film team ${ }^{8}$. A brief review on these reports concludes that "the currently available published articles on bioengineered tracheas and the resulting media attention endanger the field of tracheal replacement and the field of tissue engineering as a whole" (Delaere \& Van Raemdonck, 2014). There are other approaches to tracheal repair, such as tracheal autotransplantation (Loos et al., 2015).

8. Dokument Inifrån: Experimenten, produced by Bosse Lindquist, 2016 


\section{Criticisms of research norms in the field of TE}

The practice of exaggerating language to describe hypothetical imminent applications of science for the purpose of sharing a positive evaluation of the field will itself lead to the subscription to bias by the authors, even if they merely believe themselves to follow the established semantic norms of the field (Eiser \& Pancer, 1979). The exaggerating language is particularly prominent in popular science, and it appeases popular media to report on the soon-to-come scientific advances that will ensure we can replace or repair any part of our bodies. The connotations of a face transplant, a new bladder, or a biosynthetic airway with stem cells, are vastly different for medical professionals and a non-trained audience, and this discrepancy creates a vast ridge between expectations and realistic outcomes. The immense potential of TE for nearly all areas of tissue and organ repair fuels a strong drive to be first to publish human clinical applications of novel therapies. One can only hope that funding bodies are not fooled by the embellished descriptions of the near future that are so prevalent in the field of TE, especially in public communications.

Tissue Engineering is a very complex field compared to many other more delineated areas of biomedicine. The interdisciplinarity of TE is mostly considered an enriching and positive aspect of the field, but in reality it truly demands great knowledge of many different areas of research, which means that groups of scientists from different knowledge backgrounds must learn to work together; and individual scientists in a TE lab must learn, deeply, aspects of science not necessarily part of their basic training. Add the pressures of production, the limited resources and highly competitive academic environment, and the reality of TE is that very few laboratories have the resources or implicit knowledge for truly ground-breaking production. This is changing for the better as understanding of the demands of TE are saturating academic science, creating more focused and interdisciplinary graduates and principle investigators that understand the necessary interplay between clinicians, cell biologists, bioinformaticians, biochemists and material engineers and their individual roles for specific TE projects.

One interesting node of the interdisciplinary network in TE is the entrepreneurial aspect. The trend of filing patents as part of an academic career, and the increasing availability of academia-linked startup incubators has created quite a noticeable trend to be first-to-market with any conceivably useful material,
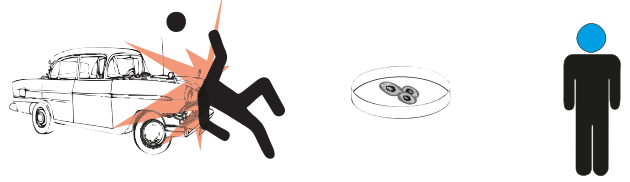

The promise of stem cells and Tissue Engineering. 
construct or analysis that has come from TE research. While this can be a very beneficial way to improve the speed at which scientific discoveries are made available to their targeted patient groups it also adds certain incentives and pressures to the research process, and may especially influence the phrasing of concluding remarks of research papers. Furthermore, commercial interests can represent a highly volatile support for researchers. Good news implies favorable market reactions, usually translating to increased stock market value or investment opportunities, whereas tentative or negative research findings conversely results in lowered market expectations. Coupling financial market volatility to research endeavors in this way can be problematic since the two realms of action (research and finance) generally work in very different temporal realities. Research, as a quest for increased knowledge, is necessarily a long-term endeavor, while companies generally work toward positive financial quarter results. The statements issued by companies lean toward non-scientific descriptions of scientific achievements, and tend to relay a very promising future outlook, regardless of the technical caveats presented by researchers.

"Over 10 successful tracheal replacement surgeries using regenerated treacheas have been performed under compassionate use exemptions at institutions in the USA, Sweden and Russia."

- Harvard Apparatus Regenerative Technology, 2016 ${ }^{9}$, manufacturer of the bioreactors used in the criticized trachea-replacements.

9. http://www.harvardapparatusregen.com/are-regen-organ-in-humans. Accessed 2016-02-08 20:20. Their spelling. 


\section{Section References}

Ahmed, M., Ghanbari, H., Cousins, B. G., Hamilton, G. and Seifalian, A. M. (2011). Small calibre polyhedral oligomeric silsesquioxane nanocomposite cardiovascular grafts: influence of porosity on the structure, haemocompatibility and mechanical properties. Acta Biomater, 7(11), 3857-3867

Atala, A., Guzman, L. and Retik, A. B. (1999). A novel inert collagen matrix for hypospadias repair. J Urol, 162(3 Pt 2), 1148-1151

Atala, A., Bauer, S. B., Soker, S., Yoo, J. J. and Retik, A. B. (2006). Tissue-engineered autologous bladders for patients needing cystoplasty. Lancet, 367(9518), 1241-1246

Atala, A., Danilevskiy, M., Lyundup, A., Glybochko, P., Butnaru, D., Vinarov, A. and Yoo, J. J. (2015). The potential role of tissue-engineered urethral substitution: clinical and preclinical studies. $J$ Tissue Eng Regen Med

Bell, E. (1991). Tissue engineering: a perspective. J Cell Biochem, 45(3), 239-241

Bell, E. (2000). TISSUE ENGINEERING IN PERSPECTIVE A2 - Vacanti, R.P., Lanza, R., Langer, J. Principles of Tissue Engineering (Second Edition) (pp. xxxv-xli). San Diego: Academic Press.

Cao, Y., Vacanti, J. P., Paige, K. T., Upton, J. and Vacanti, C. A. (1997). Transplantation of chondrocytes utilizing a polymer-cell construct to produce tissue-engineered cartilage in the shape of a human ear. Plast Reconstr Surg, 100(2), 297-302; discussion 303-294

Chung, S. Y. (2006). Bladder tissue-engineering: a new practical solution? Lancet, 367(9518), 12151216

Coe, M. R., Summers, T. A., Parsons, S. J., Boskey, A. L. and Balian, G. (1992). Matrix mineralization in hypertrophic chondrocyte cultures. Beta glycerophosphate increases type $X$ collagen messenger RNA and the specific activity of pp60c-src kinase. Bone Miner, 18(2), 91-106

D'Souza, S. E., Ginsberg, M. H. and Plow, E. F. (1991). Arginyl-glycyl-aspartic acid (RGD): a cell adhesion motif. Trends Biochem Sci, 16(7), 246-250

Delaere, P. R. \& Van Raemdonck, D. (2014). The trachea: the first tissue-engineered organ? J Thorac Cardiovasc Surg, 147(4), 1128-1132

Dingle, Y. T., Boutin, M. E., Chirila, A. M., Livi, L. L., Labriola, N. R., Jakubek, L. M., ... Hoffman-Kim, D. (2015). Three-Dimensional Neural Spheroid Culture: An In Vitro Model for Cortical Studies. Tissue Eng Part C Methods, 21(12), 1274-1283

Discher, D. E., Janmey, P. and Wang, Y. L. (2005). Tissue cells feel and respond to the stiffness of their substrate. Science, 310(5751), 1139-1143

Duckett, J. W., Coplen, D., Ewalt, D. and Baskin, L. S. (1995). Buccal mucosal urethral replacement. J Urol, 153(5), 1660-1663

Eagle, H. (1955). The minimum vitamin requirements of the $L$ and HeLa cells in tissue culture, the production of specific vitamin deficiencies, and their cure. J Exp Med, 102(5), 595-600

Eagle, H. (1958). Amino acid metabolism in human cell cultures. Fed Proc, 17(4), 985-986

Eiraku, M., Takata, N., Ishibashi, H., Kawada, M., Sakakura, E., Okuda, S., . . Sasai, Y. (2011). Self-organizing optic-cup morphogenesis in three-dimensional culture. Nature, 472(7341), 51-56

Eiser, J. R. \& Pancer, S. M. (1979). Attitudinal effects of the use of evaluatively biased language. European Journal of Social Psychology, 9(1), 39-47

Engler, A. J., Sen, S., Sweeney, H. L. and Discher, D. E. (2006). Matrix elasticity directs stem cell lineage specification. Cell, 126(4), 677-689

Etker, S. (1996). Re: Buccal mucosal urethral replacement. J Urol, 155(4), 1395

Fagerholm, P., Lagali, N. S., Merrett, K., Jackson, W. B., Munger, R., Liu, Y., .. . Griffith, M. (2010). A biosynthetic alternative to human donor tissue for inducing corneal regeneration: 24-month follow-up of a phase 1 clinical study. Sci Transl Med, 2(46), 46ra61

Fossum, M., Svensson, J., Kratz, G. and Nordenskjold, A. (2007). Autologous in vitro cultured urothelium in hypospadias repair. J Pediatr Urol, 3(1), 10-18

Freiberger, H., Grove, D., Sivarajah, A. and Pinnell, S. R. (1980). Procollagen I synthesis in human skin fibroblasts: effect on culture conditions on biosynthesis. J Invest Dermatol, 75(5), 425-430

Goktas, M., Cinar, G., Orujalipoor, I., Ide, S., Tekinay, A. B. and Guler, M. O. (2015). Self-assembled peptide amphiphile nanofibers and peg composite hydrogels as tunable ECM mimetic microenvironment. Biomacromolecules, 16(4), 1247-1258

Goldstein, S., Clarke, D. R., Walsh, S. P., Black, K. S. and O'Brien, M. F. (2000). Transpecies heart valve transplant: advanced studies of a bioengineered xeno-autograft. Ann Thorac Surg, 70(6), 1962-1969

Guillemette, M. D., Cui, B., Roy, E., Gauvin, R., Giasson, C. J., Esch, M. B., . . Auger, F. A. (2009). Surface topography induces 3D self-orientation of cells and extracellular matrix resulting in improved tissue function. Integr Biol (Camb), 1(2), 196-204 
Hakenberg, O. W. (2006). Re: tissue-engineered autologous bladders for patients needing cystoplasty. Eur Urol, 50(2), 382-383

Hendren, W. H. \& Crooks, K. K. (1980). Tubed free skin graft for construction of male urethra. J Urol, 123(6), 858-861

Huss, F. R., Nyman, E., Bolin, J. S. and Kratz, G. (2010). Use of macroporous gelatine spheres as a biodegradable scaffold for guided tissue regeneration of healthy dermis in humans: an in vivo study. J Plast Reconstr Aesthet Surg, 63(5), 848-857

Jakab, K., Neagu, A., Mironov, V., Markwald, R. R. and Forgacs, G. (2004). Engineering biological structures of prescribed shape using self-assembling multicellular systems. Proc Natl Acad Sci U S A, 101(9), 2864-2869

Jayme, D., Watanabe, T. and Shimada, T. (1997). Basal medium development for serum-free culture: a historical perspective. Cytotechnology, 23(1-3), 95-101

Jeong, G. S., Chang, J. Y., Park, J. S., Lee, S. A., Park, D., Woo, J., . . . Lee, S. H. (2015). Networked neural spheroid by neuro-bundle mimicking nervous system created by topology effect. Mol Brain, 8, 17

Jungebluth, P., Alici, E., Baiguera, S., Le Blanc, K., Blomberg, P., Bozoky, B., .. Macchiarini, P. (2011). Tracheobronchial transplantation with a stem-cell-seeded bioartificial nanocomposite: a proof-of-concept study. Lancet, 378(9808), 1997-2004

Lambshead, J. W., Meagher, L., O'Brien, C. and Laslett, A. L. (2013). Defining synthetic surfaces for human pluripotent stem cell culture. Cell Regen (Lond), 2(1), 7

Lloyd-Evans, M. (2004). Regulating tissue engineering. Materials Today, 7(5), 48-55

Loos, E., Meulemans, J., Vranckx, J., Poorten, V. V. and Delaere, P. (2015). Tracheal Autotransplantation for Functional Reconstruction of Extended Hemilaryngectomy Defects: A Single-Center Experience in $\mathbf{3 0}$ Patients. Ann Surg Oncol

Lu, R., Bian, F., Lin, J., Su, Z., Qu, Y., Pflugfelder, S. C. and Li, D. Q. (2012). Identification of human fibroblast cell lines as a feeder layer for human corneal epithelial regeneration. PLoS One, 7(6), e38825

Lönnqvist, S., Rakar, J., Briheim, K. and Kratz, G. (2015). Biodegradable Gelatin Microcarriers Facilitate Re-Epithelialization of Human Cutaneous Wounds - An In Vitro Study in Human Skin. PLOS One, 10(6), e0128093

Macchiarini, P., Jungebluth, P., Go, T., Asnaghi, M. A., Rees, L. E., Cogan, T. A., .. Birchall, M. A. (2008). Clinical transplantation of a tissue-engineered airway. Lancet, 372(9655), 2023-2030

Matsumura, G., Hibino, N., Ikada, Y., Kurosawa, H. and Shin'oka, T. (2003). Successful application of tissue engineered vascular autografts: clinical experience. Biomaterials, 24(13), 2303-2308

McBeath, R., Pirone, D. M., Nelson, C. M., Bhadriraju, K. and Chen, C. S. (2004). Cell shape, cytoskeletal tension, and RhoA regulate stem cell lineage commitment. Dev Cell, 6(4), 483-495

Mertsching, H., Walles, T. and Macchiarini, P. (2004). Replacement of the trachea with an autologous aortic graft. Ann Thorac Surg, 78(3), 1132-1133; author reply 1133

Nerem, R. M. (2006). Tissue engineering: the hope, the hype, and the future. Tissue Eng, 12(5), 11431150

Nishida, K., Yamato, M., Hayashida, Y., Watanabe, K., Yamamoto, K., Adachi, E., . . Tano, Y. (2004). Corneal reconstruction with tissue-engineered cell sheets composed of autologous oral mucosal epithelium. N Engl J Med, 351(12), 1187-1196

Oberpenning, F., Meng, J., Yoo, J. J. and Atala, A. (1999). De novo reconstitution of a functional mammalian urinary bladder by tissue engineering. Nat Biotechnol, 17(2), 149-155

Ott, H. C., Matthiesen, T. S., Goh, S. K., Black, L. D., Kren, S. M., Netoff, T. I. and Taylor, D. A. (2008). Perfusion-decellularized matrix: using nature's platform to engineer a bioartificial heart. Nat Med, 14(2), 213-221

Ott, H. C., Clippinger, B., Conrad, C., Schuetz, C., Pomerantseva, I., Ikonomou, L., . . Vacanti, J. P. (2010). Regeneration and orthotopic transplantation of a bioartificial lung. Nat Med, 16(8), 927-933

Pittenger, M. F., Mackay, A. M., Beck, S. C., Jaiswal, R. K., Douglas, R., Mosca, J. D., . . Marshak, D. R. (1999). Multilineage potential of adult human mesenchymal stem cells. Science, 284(5411), 143-147

Rim, N. G., Shin, C. S. and Shin, H. (2013). Current approaches to electrospun nanofibers for tissue engineering. Biomed Mater, 8(1), 014102

Scott, M. A., Nguyen, V. T., Levi, B. and James, A. W. (2011). Current methods of adipogenic differentiation of mesenchymal stem cells. Stem Cells Dev, 20(10), 1793-1804

Shin'oka, T., Imai, Y. and Ikada, Y. (2001). Transplantation of a tissue-engineered pulmonary artery. $N$ Engl J Med, 344(7), 532-533

Shin'oka, T., Matsumura, G., Hibino, N., Naito, Y., Watanabe, M., Konuma, T., . . Kurosawa, H. (2005). Midterm clinical result of tissue-engineered vascular autografts seeded with autologous 
bone marrow cells. J Thorac Cardiovasc Surg, 129(6), 1330-1338

Song, J. J., Guyette, J. P., Gilpin, S. E., Gonzalez, G., Vacanti, J. P. and Ott, H. C. (2013). Regeneration and experimental orthotopic transplantation of a bioengineered kidney. Nat Med, 19(5), 646651

Tamayol, A., Akbari, M., Annabi, N., Paul, A., Khademhosseini, A. and Juncker, D. (2013). Fiber-based tissue engineering: Progress, challenges, and opportunities. Biotechnol Adv, 31(5), 669-687

Thoreau, H. (1854) [Book]. Walden; or, Life in the Woods. Ticknor and Fields: Boston.

Ulbricht, J., Jordan, R. and Luxenhofer, R. (2014). On the biodegradability of polyethylene glycol, polypeptoids and poly(2-oxazoline)s. Biomaterials, 35(17), 4848-4861

Vacanti, J. P., Langer, R., Upton, J. and Marler, J. J. (1998). Transplantation of cells in matrices for tissue regeneration. Adv Drug Deliv Rev, 33(1-2), 165-182

Whitesides, G. M. \& Grzybowski, B. (2002). Self-assembly at all scales. Science, 295(5564), 2418-2421

Viola, J., Lal, B. and Grad, O. (2003). The Emergence of Tissue Engineering as a Research Field (nsf0450). Retrieved from The National Science Foundation, 4201 Wilson Boulevard, Arlington, Virginia 22230, USA: http://www.nsf.gov/pubs/2004/nsf0450/start.htm 


\section{Part 3: \\ CONTENTS \& \\ CONSTRUCTION OF SKIN}

The field of research surrounding human skin is particularly well-positioned to reap early benefits from advancements in both TE and cell biology. Few organs are as trivialized as the skin, and few problems are as diverse and common as problems of the skin in modern healthcare.

The resources devoted to skin-related research are quite large, and advancement in research technologies such as tissue engineered skin models are very important for the advancement of knowledge in many areas. Traditionally, TE skin has been focused on the creation of viable skin substitutes for clinical use, but the recognition of the value of skin models for research in conjunction with the difficulties encountered in constructing real skin analogues has meant a shift toward focusing research on limited models for specific research purposes.

The skin of pigs is most similar to human skin, making pigs the most biologically useful animal model for skin research. Pigs are ethically and practically more demanding than smaller animal models, and are not yet as easily genetically modified or controlled. Testing of compounds as health hazards or irritants is largely carried out on small animals, such as mice, rats and rabbits. The skin-care industry has been particularly reliant on testing for irritants on animals, which is now severely restricted in the EU. The need for such testing has not abated, and so there is a new drive to obtain useful and validated methods of testing that do not require animals. Tissue engineered skin has become a natural point of focus. There are several suggestions for skin models, but none of them are as functional as natural skin, and none seem sufficient to replace natural skin in all areas of testing - yet. 


\section{Introduction to the human skin}

Skin is usually the first thing you see when meeting another person but rarely something you take special note of. That is, unless you find yourself judging someone by skin tone or if you are facing someone with damaged skin, in which case skin can have a huge impact simply by its aesthetic value. The integumentary system is the name given to all the parts of the skin, including hair and nails.

The epidermis is the outer protective layer of the skin, consisting of keratinocytes, and always regenerating. Its basal layer is also home to melanocytes; they produce our pigments. The epidermis rests on the dermis, populated by fibroblasts, which contains vasculature and the different appendages of skin. These include hair follicles and the various glands and nerve-structures. Beneath the dermis is the subcutaneous adipose layer that defines our leanness and provides systemic metabolic functions.

Any number of these functions are destroyed or confounded when skin is damaged. The hospitals are full of skin wounds, some of the worst being burn wounds and non-healing wounds. When normal healing no longer works for patients in spite of the best wound therapies it is necessary to use more advanced methods such as skin or cell transplantation.

Skin transplantation, or skin grafting, is still a very crude method saving lives but providing imperfect results. The aesthetic of skin is itself an important attribute, unlike for most other organs. Enormous collective research effort is expended to find better solutions to repairing and replacing skin.

\section{Layers of skin}

It is easy to regard skin in terms of layers since this is its predominant histological organization, but it is a simplification with regard to the microanatomical structures found in skin.

The outermost layer - the epidermis - is a tough, creased and relatively thick sheet of keratinocytes described as a keratinized stratified squamous epithelium. The outermost keratinocytes are dead cells that are strongly connected to each other through interlocking proteins (keratins), carbohydrates and oil. The innermost layer of keratinocytes, at the basal layer, exist briefly in a niche among melanocytes, stem cells and fibroblasts. As new keratinocytes are produced here they push the older, more connected, keratinocytes outward to begin their dying journey and in this manner the skin is forever renewed throughout our lifetime as our old skin desquamates and turns to dust.

The epidermis, then, begins with the basal layer and ends with the cornified 


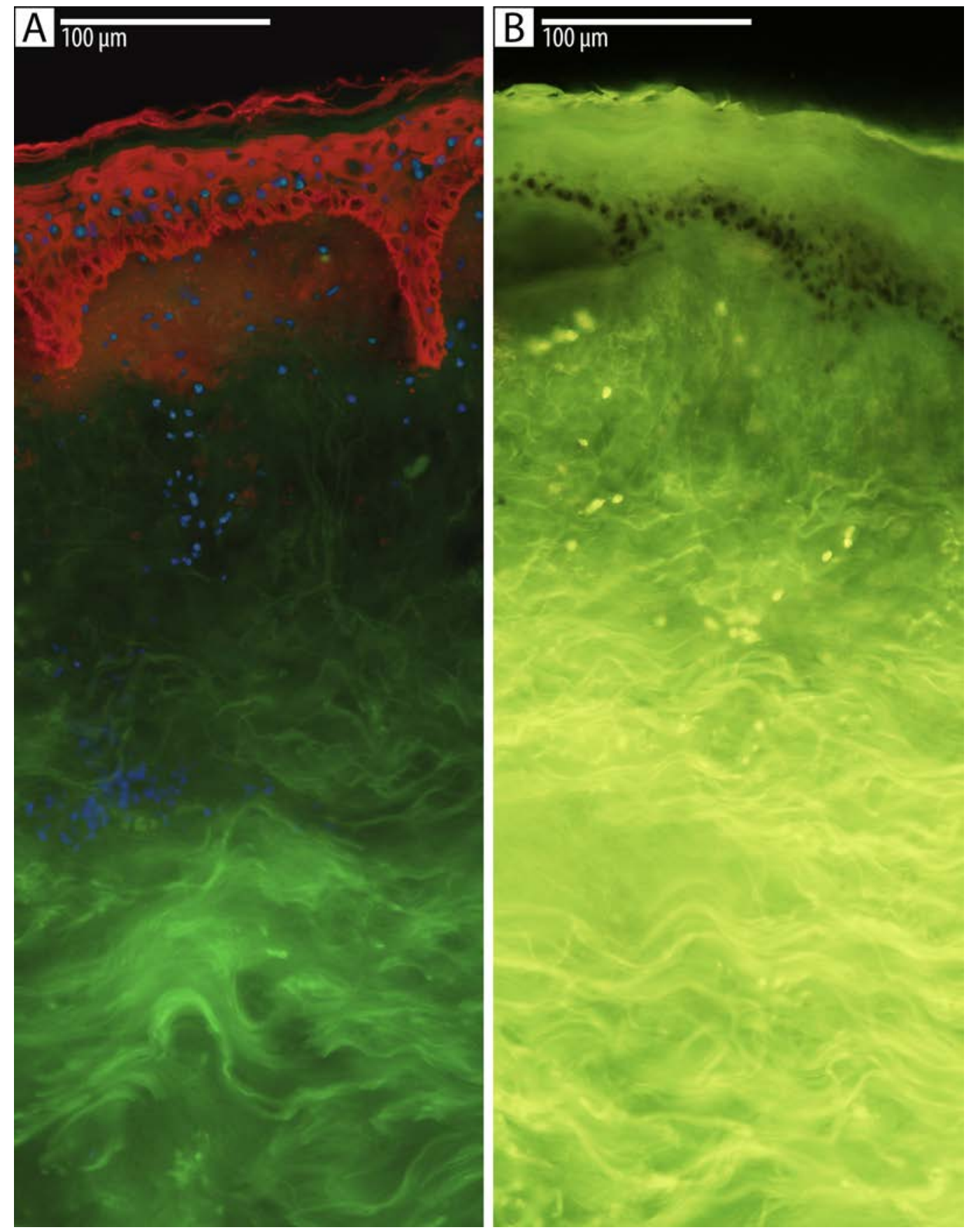

Sections of skin viewed through fluorescence microscopy.

A: The epidermis is stained red with anti-pancytokeratin antibodies, dermal collagens in green, and nuclei in blue. B: Autofluorescence of $150 \mu \mathrm{m}$ section of skin viewed through green fluorescence filters; the border between dermis and epidermis is clearly visible, and the differences between papillary and reticular dermis extracellular matrix orientation is obvious. 
envelope. The basal layer is the niche that contains the stem cells for the epidermis, thus part of its renewing capacity, and the pigment-producing melanocytes. This layer rests on the dermo-epidermal junction, which separates the epidermis from the underlying dermis - the skin's connective tissue. The dermis contains many of the microanatomical structures of the skin, such as follicles, nerves and capillaries. While the epidermis is tough and tear-resistant the dermis is more soft and elastic.

The subcutaneous layer of fat which is found beneath the dermis, called the hypodermis, is three-dimensionally pliable and slippery. So when pinching your skin, the epidermis, which has a high threshold for tearing, remains largely unperturbed whereas the elasticity of the dermis and the subcutaneous fat allows you to move the pinched area around but makes it bounce back once released. The subcutaneous fat is also the main determinant for the perceived thickness of the skin (the pinch) which is why pinching the skin in certain areas, such as by calipers (Orphanidou et al., 1994), can be a useful way of exploring your leanness.

This layer model also includes defined sub-divisions of the dermis and epidermis. Most of these classifications come from microscopic observation of the histological features of the tissue, and have little relevance beyond histomorphometric analysis. The epidermis can be classified into five strata: the outermost stratum corneum, the three intermediate strata (in order from outside-in) - stratum lucidum, granulosum, spinosum - and finally the basal layer (stratum basale).

There are two sub-divisions of the dermis, identified by the typical density of the organization of fibers and cells. The less dense and more chaotic papillary layer sits directly beneath the epidermis and the more aligned and dense reticular layer sits below.

The layers quite strictly demarcate the location of the four most prominent cell types: the keratinocytes in the epidermis, the melanocytes in the basal layer, the fibroblasts in the dermis and the adipocytes in the subcutaneous fat. It is important to remember, however, that each layer provides signals and feedback to each of the other layers (Briggaman \& Wheeler, 1971) making this an organ, not just a bunch of haphazard bioware. It is prudent to consider the influence of the cross-talk between compartments when studying any one part of the skin.

The layers and microanatomical structures of skin, are each identified by a main cell component and a typical type and organization of matrix. The cells can be isolated and cultured using known media, but the reconstruction of the whole skin is still very difficult. So far, only simplified models of skin have been 
constructed, and only approximate natural layers can be cultured. The simplified skin models are used to look at specific question of skin biology, and each findings bring us a small step closer to understanding how to construct better substitutes.

\section{Keratinocytes and the epidermis}

Keratinocytes conform to a strictly controlled progress of differentiation with the effect of together creating and maintaining our epidermis. The keratinocytes at the basal layer are regularly cuboidal and express cell adhesion molecules that allow them to anchor to the basal lamina. The basal lamina, like that of many such basal membranes found around adipose tissue and vasculature, predominantly consists of collagen IV and laminin 5 (322) molecular networks, but also other collagens (VII, XVII), perlecan and proteoglycans such as heparan sulfate (Behrens et al., 2012).

Keratinocytes can secrete matrix molecules, in concert with fibroblasts, that interact and form the basal membrane (Larjava et al., 1993; Eckhart et al., 2003). Keratinocytes express $\alpha_{6} \beta_{4}$-integrins, used to anchor to the basal lamina through hemidesmosomes, and $\alpha_{3} \beta_{1}$-integrins, to anchor through focal adhesions. The anchoring creates mechanotransducing signaling links between the extracellular matrix and the cytoskeleton (N. D. Evans et al., 2013), forming a closely interconnected basal niche involving fibroblasts, melanocytes and keratinocytes (also Merkel cells and Langerhans cells), with multiple modes of cross-talk.

The basal niche contains proliferative keratinocytes, and is also believed to contain epidermal stem cells. Surprisingly, the identification of keratinocyte stem cells is still not unequivocal. While there certainly must exist keratinocyte stem cells in the interfollicular epidermis, efforts at isolation and characterization have not been conclusive (Fortunel \& Martin, 2012). Suggested stem cell markers include expression of keratin 15 (Bose et al., 2013), 14, 19, CD71, and p63 (Houben et al., 2007) but all are either unspecific or difficult to verify. Bright expression of integrin alpha6, in conjunction with dim CD71 has been used for flow cytometric sorting of stem cells (Schlüter et al., 2011), but again, proof of specificity is lacking as indeed is a reproducible quantification of the marker expression.

We have considered the idea of using telomerase identification, as a general marker for stem cells, in conjunction with limited shotgun proteomics and gel electrophoresis to identify correlation with putative stem cell markers. Using in-situ hybridization in skin sections together with immunofluorescent techniques targeting the most promising candidates might provide new ideas 


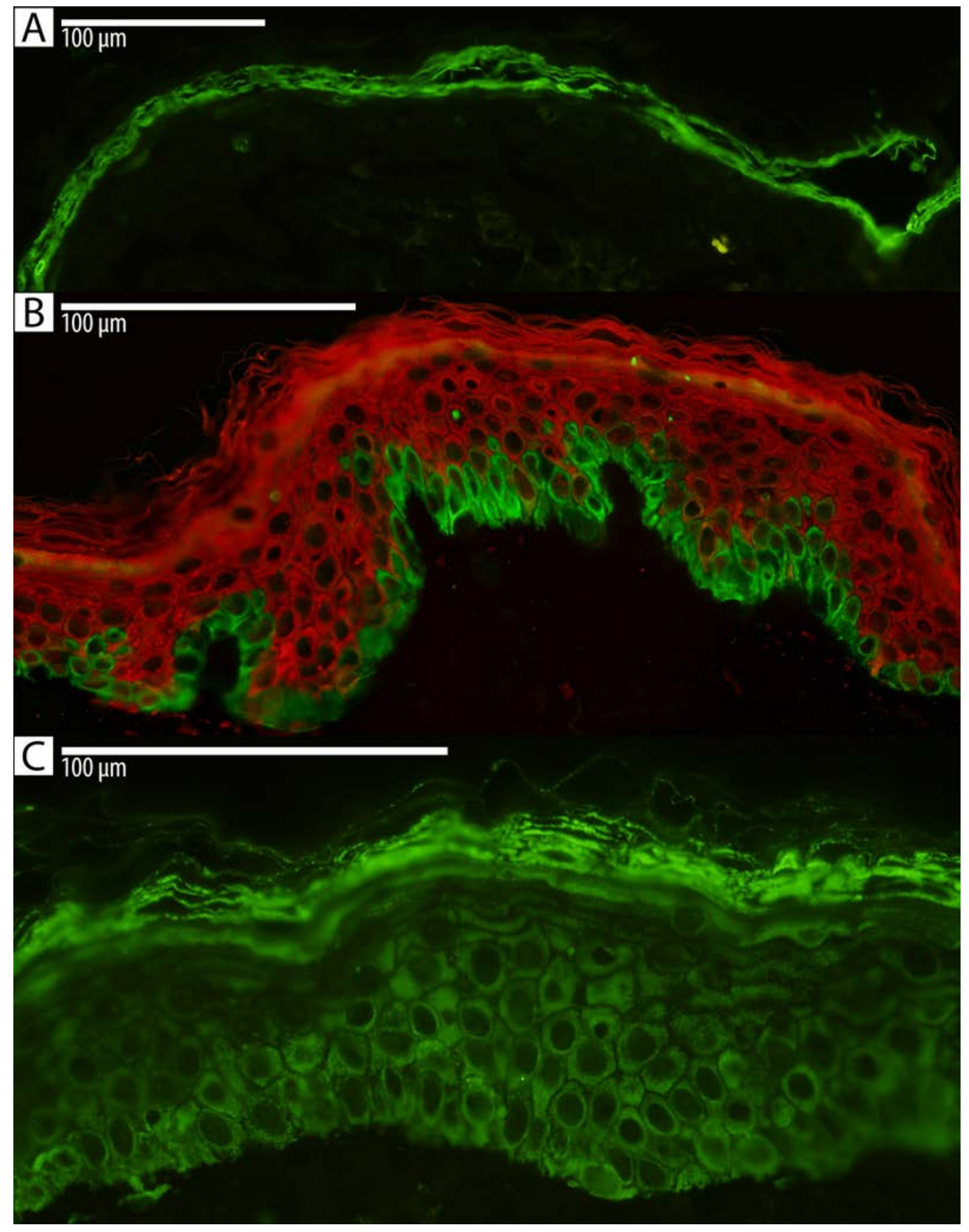

Fluorescence photographs of the epidermis.

A: Filaggrin staining in the cornified layer of the epidermis (green). B: Differential staining of keratin 5 (green) and keratin 10 (red) shows that basal keratinocytes change their expression once they begin to differentiate. C: Unspecific keratin staining of the epidermis (green) shows the cellular morphology of the different layers of the epidermis. 
for Boolean stem cell markers. It is unclear whether telomerase is limited to keratinocyte stem cells or if, like the previous markers, telomerase is present in a more fluid population of keratinocytes (Harle-Bachor \& Boukamp, 1996).

In general, the assumption has been that slow cycling stem cells give rise to transit amplifying keratinocytes that cause exponentially increased keratinocyte numbers which subsequently differentiate - a model of a tissue-specific governed hierarchy (Schlüter et al., 2011). A version of this, the spiral model of diminishing stemness, allows for a gradual loss of stemness as keratinocytes become more differentiated (Potten \& Loeffler, 1990). A more stochastic view has emerged, departing from a hierarchical model, involving functional plasticity switching in stem cells and their direct progeny (reviewed in a plasticity context in: (Wabik \& Jones, 2015)).

Recently, the model of epidermal turnover has been refined (Roshan et al., 2016). Roshan et al. suggest that keratinocytes switch between balanced or expanding modes in response to ROCK 2 mediation as a result of actin signaling events. In balanced mode, mitosis results in a new balanced and a new differentiating cell at equal probability. In expanding mode, mitosis results in $90 \%$ expanding, and only $10 \%$ differentiating keratinocytes. The expanding mode is responsible for holoclones in culture, while balanced mode results in paraclones and meroclones. The authors conclude that the two interconvertible modes may be viewed within a wider perspective of behavioral plasticity of adult stem and progenitor cells, involving population asymmetry and stochastic fate (Roshan et al., 2016).

The loss of basal anchorage can be a signal to initiate the differentiation cascade. However, it seems likely that the superposition of differentiating keratinocytes is a consequence rather than a cause of differentiation onset (Watt \& Green, 1982). The involvement of cell shape (Watt \& Green, 1981) and actin signaling (McMullan et al., 2003; Nanba et al., 2013) in differentiation is consistent with concomitant anchorage changes. Active and passive physical forces elicit behavioral changes in basal keratinocytes, both through cytoskeletal remodeling and though extracellular anchorage dependent mechanisms (Mao \& Baum, 2015).

Involucrin has been used as an early marker for keratinocyte differentiation (Banks-Schlegel \& Green, 1981; Watt \& Green, 1981). An even earlier marker of differentiation is the adjustment of actin filaments from a radial organization to a peripheral one (Nanba et al., 2013), forming the cytoskeletal support for the eventual appearance of a protein envelope. The most distinguishing, and abundant, proteins of epithelia are the keratins, and their expression also undergoes distinct differentiation-induced changes, clearly demarcating the basal from the supra-basal compartments. 


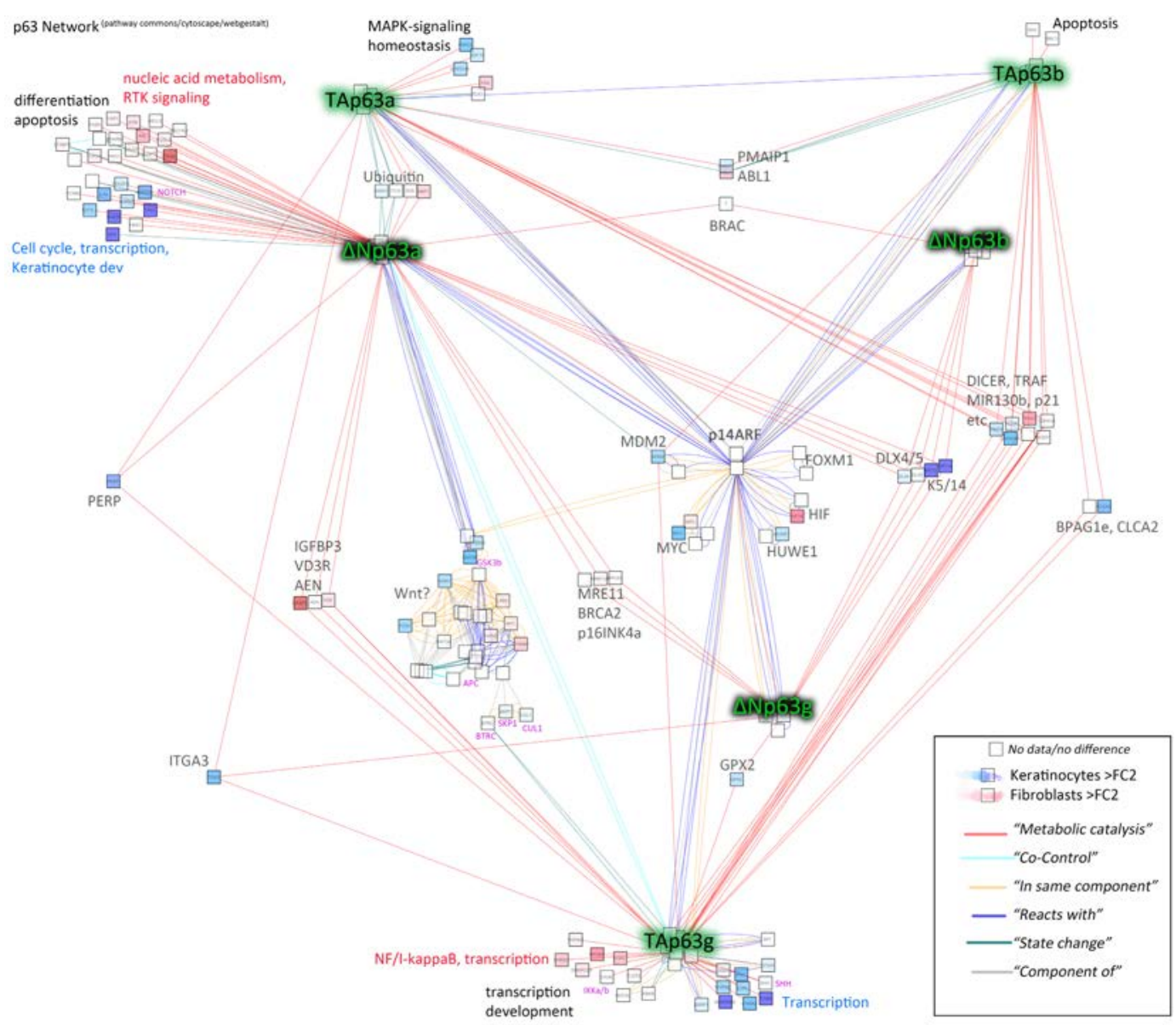

Molecular network around p63 isoforms. Colour of lines indicates relationship. Each square represents a gene. The colour of the square indicates if the the gene was more highly expressed in keratinocytes (more blue) or fibroblasts (more red), as determined by our own microarray data.

In the primordial epithelium, when the epidermis is yet to fully develop, the pre-keratinocytes produce keratins 8 and 18, and this is common to all types of primordial epithelia in the body. As the epithelia mature so too does their molecular expression, which becomes more specific to each type of epithelium. The basal keratinocytes of the mature epidermis express keratins 5 and 14, while they switch their production to keratins 1 and 10 upon differentiation. The keratins exist in obligate pairs, which is why keratin 8 and 18, 5 and 14, or 1 and 10 are always found together. Keratins $1 / 10$ and 5/14 mark different stages of keratinocyte differentiation in the developed epidermis. Keratins modulate cellular growth, apoptosis and motility (reviewed in: (Pan et al., 2013)), affirming more than a passive role in keratinocyte differentiation.

As keratinocytes move away from the basal layer and switch their keratin production a number of other changes also occur. The differentiation cascade 
intensifies the cell-cell interactions as the cells come closer to the surface, while instigating a terminal differentiation akin to early stages of apoptosis. The p63, p53 and p73 family of proteins are closely related (reviewed in: (Levrero et al., 2000)), and p53 is the master regulator of apoptosis in all cells of the body (reviewed in: (Fridman \& Lowe, 2003)). While apoptosis ends in the controlled breakup of cells into small vesicles, the terminal differentiation of keratinocytes instead ends in covalent linkage between the cytoskeletons of adjacent cells through dense bundles of keratins, mediated largely through the action of transglutaminases. The master regulating protein p63 is essential for keratinocyte differentiation, and the result is not apoptosis but cornification (Eckhart et al., 2013).

The p63 network interactions are numerous during keratinocyte differentiation, including immediate down-stream BMP7, FGFR2b, JAG1/2, NOTCH1/3 (Carroll et al., 2006; Laurikkala et al., 2006). Regulation by p63 includes direct transcriptional activation of genes in the epidermal differentiation complex (EDC) as well as epigenetic changes relating to methylation states of promoters within and outside of the EDC (Pozzi et al., 2009). Part of the action of p63 is to control chromatin state at the EDC, keratin type I/II loci and the keratin-associated protein locus, a control mediated through SATB1 activity (Fessing et al., 2011).

The TP63 gene actually results in six isoforms of p63 through alternative splicing, two principal isoforms differing in the N-terminal: TAp63 and $\triangle \mathrm{Np} 63$, each with three isoforms differing in the C-terminal: $\alpha, \beta$, and $\gamma$. The TAp63 isoforms are seemingly not really involved in epidermal homeostasis. The $\Delta$ Np63 isoforms are thought to possess distinct biological functions, and at least both $\Delta \mathrm{Np} 63 \alpha$ and $\Delta \mathrm{Np} 63 \beta$ are required for normal epidermal development. The p63 isoforms have been extensively reviewed (Romano \& Sinha, 2011).

The granular layer, stratum granulosum, contains keratinocytes that have begun to manufacture keratohyalin granules containing pro-filaggrin. Loricin aids in the linkage of the granules to the protein envelope. By this time, the keratinocytes have strengthened their intercellular anchoring. Keratin intermediate filament networks are linked through the desmosomes, containing plakoglobin, desmoplakin and plakophilin intracellularly, and desmoglein and desmocollin extracellularly. The cytoskeletal actin microfilaments are linked though peri-desmosomal adherens junctions. (Houben et al., 2007)

In the final stages of cornification, lamellar bodies (organelles) are extruded into the extracellular space and generate the extracellular lipid matrix containing ceramides, cholesterol and free fatty acids. The interconnected lipids and protein network create the hydrophobic protective barrier of the skin. Desqua- 
mation, the final fate of the keratinocytes, occurs through regulated action of catalytic enzymes that disrupt the corneodesmosomes. All processes come to a synchronized conclusion. (Houben et al., 2007)

\section{Keratinocytes in vitro}

Keratinizing cell lines were first cultured from teratoma explants from mice, and the requirement of irradiated 3T3 fibroblasts feeder cells was evident (Rheinwald \& Green, 1975a). In an attempt at establishing a normal keratinocyte culture, keratinocytes were successfully serially cultured under similar conditions (Rheinwald \& Green, 1975b). The first described medium was supplemented with $20 \%$ serum and $0.1-0.4 \mu \mathrm{g} / \mathrm{ml}$ hydrocortisone, a supplement that showed dose-dependent effects on colony stratification. It was evident that the keratinocyte cultures produced colonies that stratified, and eventually cornified, showing properties of the cornified envelope morphologically similar but not identical to normal cornified epidermis (Sun \& Green, 1976). The medium used for these cultures was DMEM with $20 \%$ serum and $30 \mathrm{ng} / \mathrm{ml} \mathrm{EGF} \mathrm{(epi-}$ dermal growth factor), a supplement which stimulated growth rate and colony forming efficiency, and which increased the proportion of non-cornified keratinocytes. They also reported that inclusion of EGF stimulated proliferation of contaminating dermal fibroblasts, which were normally suppressed by the 3T3 fibroblasts in the absence of EGF.

The continued development of human keratinocyte culture (early review: (Green et al., 1979)) identified the importance of EGF as described above, and the importance of increased cAMP for the rapid growth of keratinocytes. Isoproterenol $\left(10^{-6} \mathrm{M}\right)$ increased adenylyl cyclase activity, resulting in elevated levels of cAMP, but the supplement described as more effective was cholera toxin $\left(10^{-11}\right.$ to $\left.10^{-10} \mathrm{M}\right)$. The result was the production of a reasonably natural stratified epidermis, that could be grafted to help reconstitute an epidermis. Calcium concentration was also identified as a determinant for keratinocyte stratification (Hennings et al., 1980; Watt \& Green, 1982).

The application of dispase (T. Matsumura et al., 1975) allowed the keratin sheets to be detached from the plastic. It also showed that no keratinocytes remained attached to the plastic beneath the epithelial sheet. Conversely, if fibroblasts were present in the culture these were detached from the epithelial sheet and remained attached to the plastic (Green et al., 1979). The culture of epidermal sheets eventually led to clinically applied autograft alternatives (O’Connor et al., 1981; Compton et al., 1989). 

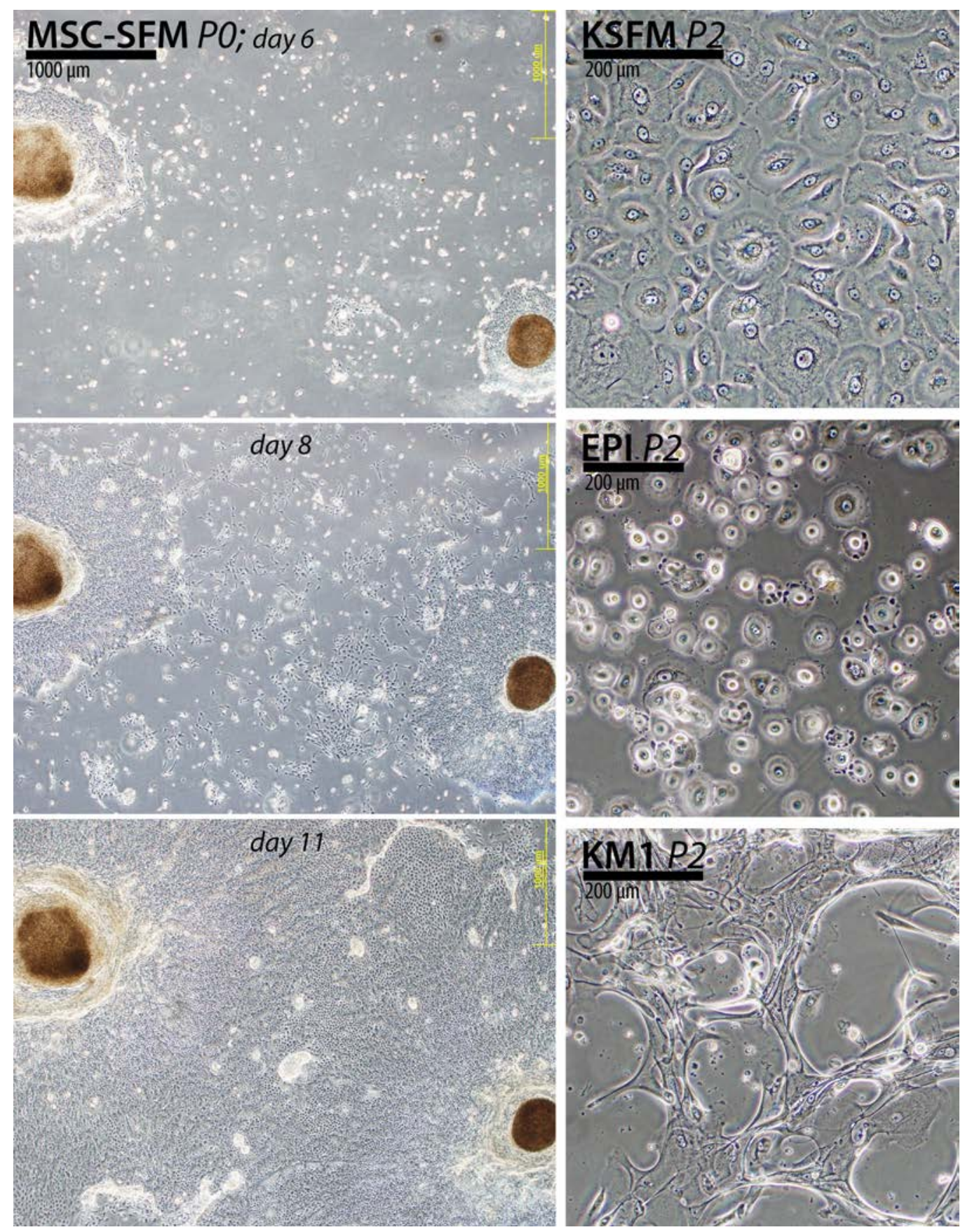

Cultures of human primary keratinocytes under different media.

MSC-SFM P0: colonies photographed over several days quickly grew together under mesenchymal stem cell - serum-free medium. KSFM P2: this is standard keratinocyte serum free medium. EPI P2: a medium designed for stimulating epithelial maturation. KM1 P2: a medium designed for co-cultures in skin constructs. $\mathrm{P}=$ passage number, $\mathrm{P} 0$ means plating after primary isolation. 


\section{Melanocytes and pigmentation}

Dispersed throughout the basal layer are melanin-producing melanocytes. They migrate to the basal epidermis from the neural crest during embryogenesis (Chadwick et al., 2012). Melanocytes are dendritic cells with many long processes interspersed throughout the first few layers of the epidermis. Increasing amounts of UV-light, meaning increasing doses of sunlight, causes the melanocytes to increase their production of melanin. Melanocytes also produce pigment for the hair follicles, and they are also present in the cochlea (Tachibana, 1999; Uehara et al., 2009), brain (Goldgeier et al., 1984; Zecca et al., 2003), and adipose tissue (Randhawa et al., 2009) and several other sites ${ }^{10}$. The retinal pigment epithelium of the eyes is also made up of another pigment-producing cell type (Brenner \& Hearing, 2008).

Melanocytes produce the pigment melanin in vesicles called melanosomes. In the epidermis, the melanosomes are shuttled to the melanocyte dendrites from where they are transferred to keratinocytes. Each melanocyte produces and deposits melanin for around 25-40 keratinocytes (X. Wu \& Hammer, 2014). The melanin is then deposited as a protective layer on the keratinocyte nucleus to minimize UV-induced DNA damage. Both the melanosome shedding and uptake are actively controlled by the cells, but the exact mechanisms are only partially understood (X. Wu \& Hammer, 2014).

Melanogenesis occurs through the key regulation of melanocortin-1 receptor (MC1R), which is activated after UV-stimulation of alpha-melanocyte stimulating hormone ( $\alpha \mathrm{MSH})$, agouti signaling protein (ASP) and adrenocorticotrophic hormone (ACTH) (Abdel-Malek et al., 2000). These mechanisms increase melanin production but does not alter the ratios of the melanins, which come in two variants: eumelanin (brown-black) and phaeomelanin (redbrown), and their relative ratios determine an individual's phototype (reviewed in: (Chadwick et al., 2012)).

The amino acid tyrosine is hydroxylated to DOPA (dihydroxyphenylananine) by tyrosinase, an enzyme which can be used to stain melanocytes in the epidermis. Further enzymatic activity converts DOPA to phaeomelanin. Phaeomelanin can be converted by TRP1 and TRP2 enzymes to eumelanin. Melanosomes are committed to either of the two biosynthesis pathways, each melanosome producing either eumelanin or phaeomelanin but not both, although both melanosome-types can coexist within the same cell (Slominski et al., 2005). The two pigments differ in their production of free radicals when exposed to UV radiation, providing part of an explanation for why light-skinned individuals

10. Melanin has also been identified, in vertebrates, in: spleen, liver, kidney, brain, pineal gland, inner ear, eye, lung, connective tissues, testes, choroid, heart, peritoneum, muscles, venom glands and tumors (Dubey \& Roulin, 2014) 

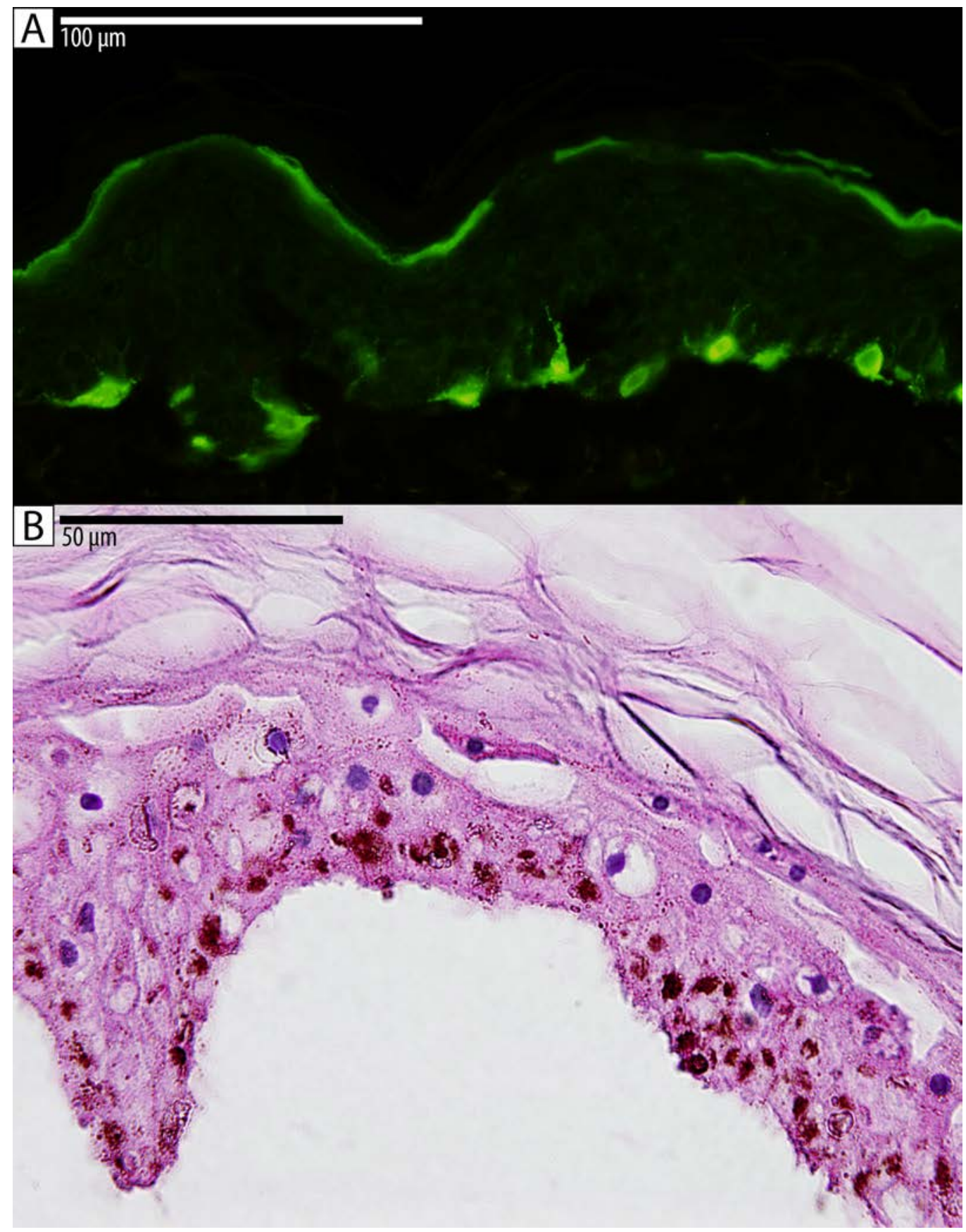

Melanocytes in the interfollicular epidermis.

A: Melanocytes stained for tyrosinase (green; basal layer) showing dendrites extending into the early suprabasal layer. B: H\&E staining showing the brown staining of melanin in the epidermis. 

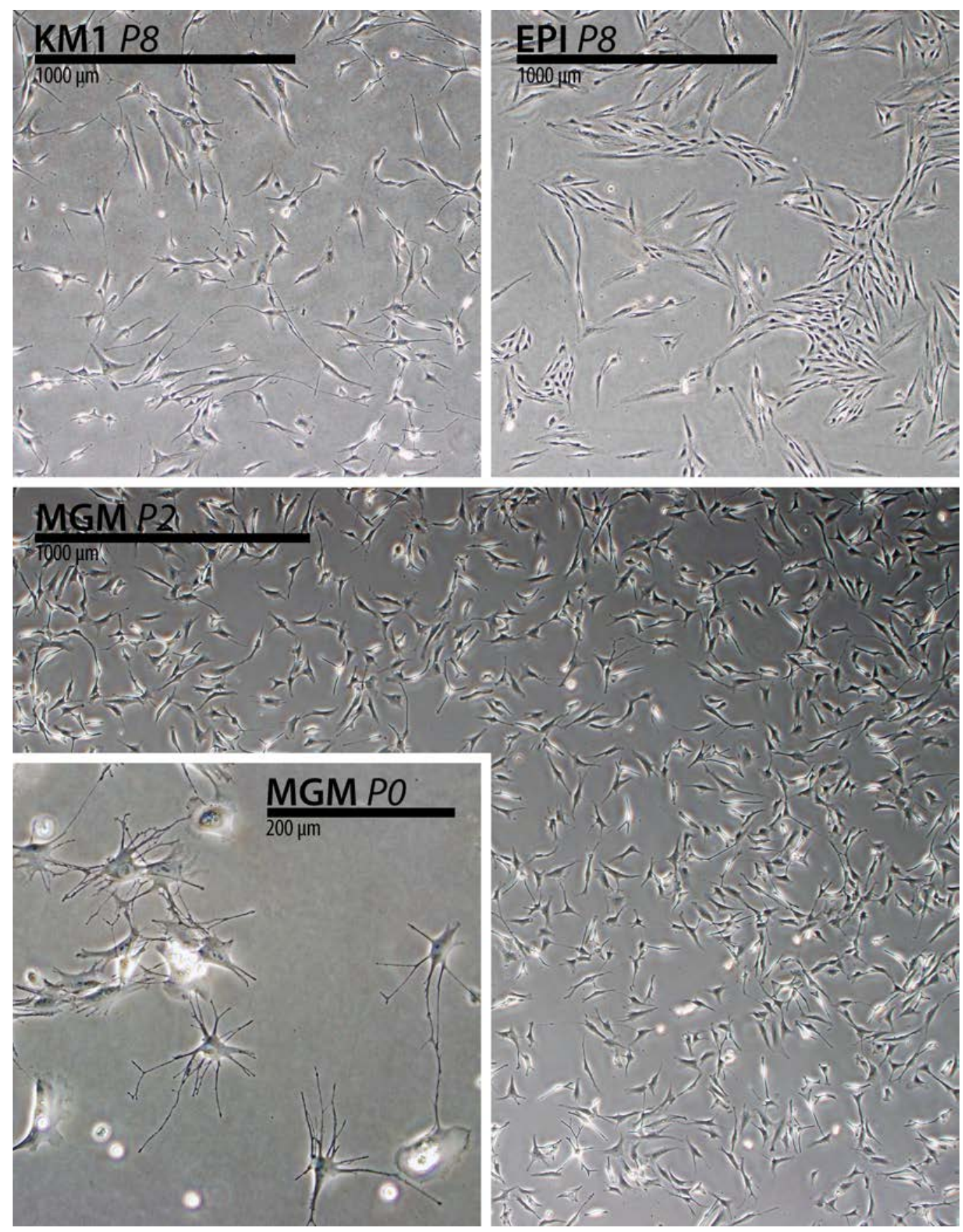

\section{Cultures of human primary melanocytes.}

KM1 P8: melanocytes in this medium showed longer, thin, dendritic structures. EPI P8: melanocytes under epithelialization medium showed more bi-polar morphology and unusual growth patterns. MGM P2: Normal culture under melanocyte growth medium. MGM P0: melanocytes loose their dendritic morphology after some days in culture, but this primary isolation still shows their more natural morphology. $\mathrm{P}=$ passage. 
are more prone to DNA damage and skin-related cancer (Lassalle et al., 2003).

Melanosomal $\mathrm{pH}$ is near neutral in dark skin, and so optimal for the eumelanin reaction, while melanosomal $\mathrm{pH}$ in pale skin is lower and therefore not optimal for tyrosinase or TRP1/2 enzymatic activity (Smith et al., 2004). Sunlight exposure therefore causes higher intensity of the phototype, but not significant change to the ratio of pigments (ratio of melanins). One theory for the differently varying pigmentation in human populations is that MC1R mutations are allowed in Europe due to lack of selection (neutral theory), while there is an environmental selection for maintaining MC1R in Africa (functional constraint)(Rees, 2000). However, the presence of internal melanocytes (inside the body), where sunlight is not a factor for selection, creates an interesting situation for evolutionary change: selection pressures will not be the same for both internal and external melanin, meaning that a reduction of the strength of the genetic correlation between the production of internal and external melanin may appear in order to evolve them independently (Dubey \& Roulin, 2014).

Keratinocytes regulate the distribution of melanosomes differently in light and dark skin (Minwalla et al., 2001). Clustering occurs in light skin, whereas individual melanosomes are distributed in keratinocytes in darker skin. These effects might be linked to the $\mathrm{pH}$-differences that also determine the enzymatic activity that produces eumelanin, and their effects on actin transport or acid phosphatase activity. On a larger scale, the keratinocytes are responsible for patterning the pigment in the epidermis by specifically regulating melanosome uptake from melanocytes (Weiner et al., 2014). Melanocytes seem to selectively form connections with basal and first-layer suprabasal keratinocytes, protecting the least differentiated keratinocytes, and together they form the epidermal-melanin unit (Weiner et al., 2014; X. Wu \& Hammer, 2014).

It has become evident that melanocytes do not simply serve the purpose of producing pigment for protecting against sunlight. Melanins can scavenge reactive heavy metals, prevents the accumulation of quinones, act as free radical scavengers to alleviate oxidative stress, and bind various drug compounds (Dubey \& Roulin, 2014). Melanocytes in the heart regulate tissue stiffness and regulate calcium homeostasis, and melanocytes in the inner ear are required for proper development and maintenance of the hearing function (Dubey \& Roulin, 2014)dNote $>$. A more radical theory proposes that melanin serves as a way for vertebrates to convert sunlight to metabolic use ("melanophotometabolism") (G. Goodman \& Bercovich, 2008). Could it be that melanocytes also serve more diverse functions in the skin?

Melanocytes have been cultured since the early 1980's (Eisinger \& Marko, 1982). Early attempts at culture failed because the melanocytes do not survive and proliferate under common media formulations based around serum. 
Instead, the media included TPA (12-O-tetradecanoyl-phorbol-13-acetate), IBMX and cholera toxin. Later investigations proposed the use of FGF2 (bFGF) supplementation, together with dbcAMP or IBMX (Halaban et al., 1987), to replace some of the effects of TPA. Other media formulations have since been proposed (Kormos et al., 2011). It has become accepted that melanocytes in culture lose their in vivo morphology, and change from dendritic to spindle-shaped (a decade of melanocyte culture, reviewed in: (Yaar \& Gilchrest, 1991)). Co-cultures with keratinocytes showed that keratinocytes instruct melanocytes to properly locate in the basal niche, whereas other epithelial cells did not (De Luca et al., 1988). Attempts at culturing pre-melanocytes, or melanocyte stem cells, are progressing and will hopefully provide new options for investigating melanocyte, and skin, biology (reviewed in: (S. J. Lin \& Chuong, 2011)).

\section{Hair follicles}

Hair follicles are a hot topic within skin research, being involved in numerous cross-talk within the skin. From having assumed that hair follicles are only created during embryogenesis, there is some evidence that new hair follicles can be created during wound healing (Ito et al., 2007; Gay et al., 2013), giving hope to many researchers that one might eventually find a cure for baldness.

A number of signals from the dermis and epidermis regulates hair follicle actions (Millar, 2002). The formation of hair follicles occurs during embryogenesis and relies on signals from both dermal and epidermal cells that cause fate changes in both cell populations, resulting in differentiation of the hair shaft, root sheaths, and dermal papilla (Hardy, 1992). Follicles can experience cyclic growth in response to hormonal regulation. The hair follicle cycles between a resting stage (telogen), an involution (catagen), and expansion (anagen). The onset of anagen involves action of IGF1 and FGF7, resulting in hair germ and upper bulge cell proliferation, while the cessation of anagen involves FGF5 and EGF signaling (Paus \& Cotsarelis, 1999). Anagen essentially recapitulates follicle development. Catagen, conversely, is dominated by extensive apoptosis of follicular keratinocytes, as the dermal papilla moves up to the hair bulge and condenses (Paus \& Cotsarelis, 1999).

Multiple stem cell populations have been identified in the hair follicle, but these and epidermal stem cells should be considered separate populations (Ito et al., 2005). Self-renewal and differentiation are balanced in each compartment. The hair follicles contain cell reserves activated upon wounding to provide an influx of keratinocytes to the regenerating epidermis but, contrary to early predictions, the hair follicle does not contribute cells to normal epidermal turnover (Ito et al., 2005). 


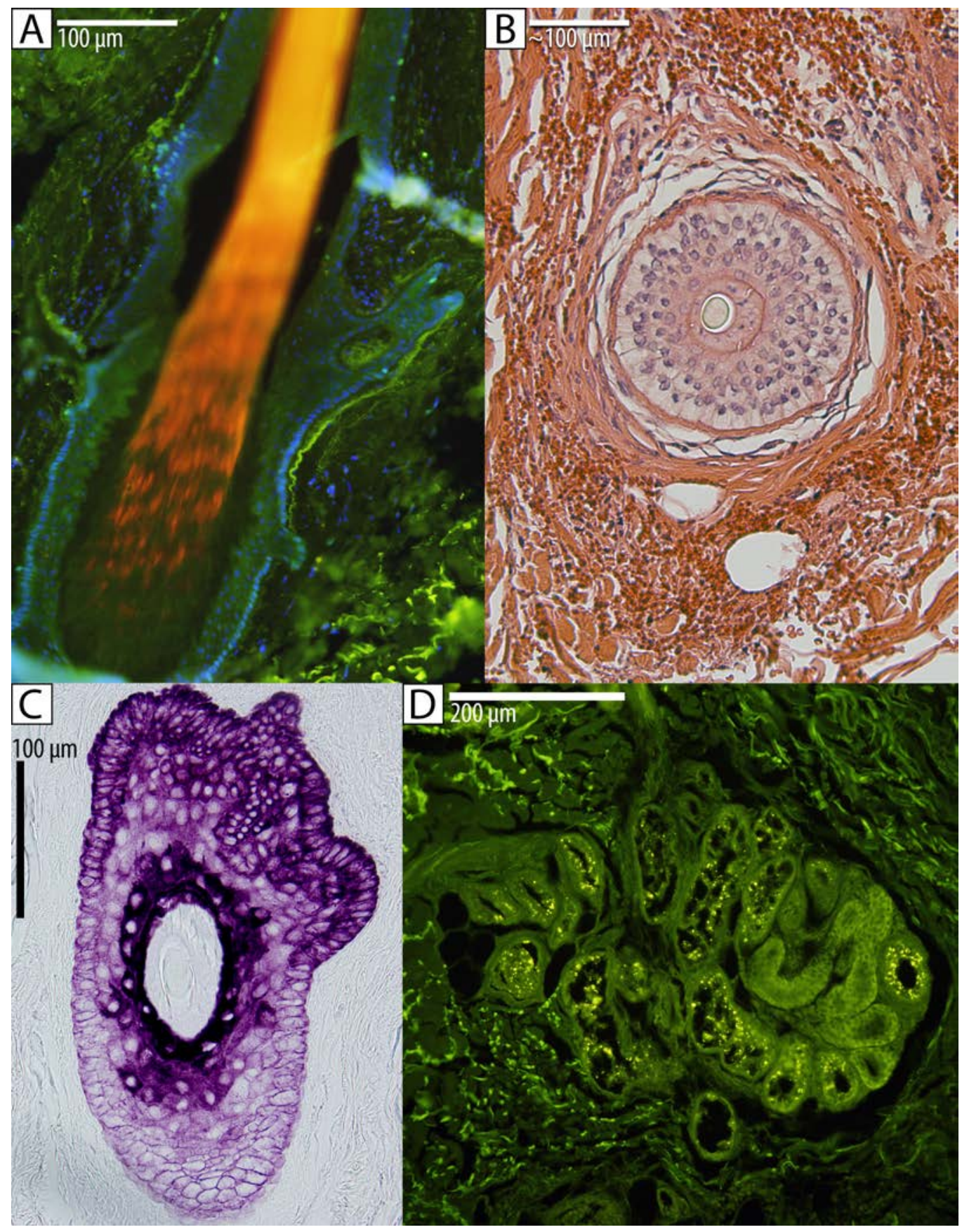

Various views of hair follicles.

A: Fluorescence image of a hair (orange) in its follicle. The image shows high background fluorescence; nuclei stained with DAPI (blue). B: Cross-section of a hair-follicle with weak H\&E staining. C: Angled cross-section of hair follicle including part of the bulge, stained with H\&E. D: Autofluorescence of a sebaceous gland found in proximity to the hair follicle in A. 
The dermal papilla is a store of mesodermal stem cells with extensive differentiation capacity, being able to produce neurons, glia, smooth muscle cells, adipocytes and more (partly reviewed in: (Driskell et al., 2011)). The surprising plasticity was confirmed by lineage tracing studies in mouse (Jinno et al., 2010), indicating that the hair follicle environment, rather than the developmental origin of the cells, induces expression of genes related to the neural-crest and supports generation of neural-crest derivatives (Driskell et al., 2011).

The bulge contains stem cells (Cotsarelis et al., 1990) and they can repopulate the epithelial layers of the entire hair follicle (Oshima et al., 2001). At least three other distinct stem or progenitor populations exist at different depths of the hair follicle, with some distinguishing protein marker expression, but they all seem to arise from a common precursor traced to the mesenchymal condensate that initiates follicle development (Watt \& Jensen, 2009).

Sebaceous glands are adnexal to hair follicles, secreting oil along the hairs and onto the surface of the skin, and contain their own stem cell population (Watt \& Jensen, 2009). Piloerector muscles are the miniscule muscles that cause hairs to stand during a cold breeze or goosebumps. They are likely formed from a fibroblast lineage (Driskell et al., 2013).

\section{Fibroblasts and the dermis}

Fibroblasts are tasked with the production and maintenance of the connective tissues in the whole body, including the dermis. Through secretion of degrading enzymes such as matrix metalloproteinases (MMP) as well as matrix proteins (collagens, fibronectin, etc), they can construct and remodel the dermis to support the other cell types and appendages that reside there. Fibroblasts also interact with the other cells through a variety of signaling mechanisms, including direct cell-contact, matrix modifications, and paracrine signals. In a way, fibroblasts are a heterogeneous population of cells at the center of organ and tissue physiology (Sorrell \& Caplan, 2009), .

The papillary/reticular division is most obvious by the distinct features of the matrix in each layer but there is increasing evidence that the fibroblasts are of two distinct developmental lineages (D. G. Janson et al., 2012; Driskell et al., 2013). In mouse, the upper fibroblasts expressed more Blimp1/Prdm1, Lrig1 and CD26, whereas Sca1 and Dlk1 was expressed in the lower fibroblasts. Lineage tracing showed that the papillary fibroblasts contributed exclusively to upper dermis, including dermal papillae, the piloerector muscles and dermal sheath of the hair follicle, while the lower fibroblasts contributed to reticular dermis, hypodermis, and adipocytes of the subcutis (Driskell et al., 2013). The 
two fibroblast populations differently support the epidermis, and there is evidence that papillary fibroblasts convert to a reticular type with age (D. Janson et al., 2013).

Tissue-specific expression and synthesis of structural proteins and glycoprotein components vary considerably among different types of connective tissues, resulting in unique functional and biological characteristics of the extracellular matrix (reviewed in: (Gelse et al., 2003)). Collagen is a superfamily with many known genetic variants, manufactured in a triple helical structure (as homoor heterotrimers of alpha-chains), with a distinct amino-acid repeat sequence (Gly-X-Y). Collagen synthesis in the dermis is similar to the rate of muscle protein production, making it a slow production protein under normal circumstances (el-Harake et al., 1998). In culture, the production of collagen I, III and $\mathrm{AB}$ (later known as collagen $\mathrm{V}$ ) was similar between reticular and papillary fibroblasts, the only detected difference being the higher type I pro-collagen levels in conditioned media of reticular fibroblasts (Tajima \& Pinnell, 1981).

Collagen I (usually consisting of two $\alpha 1$ and one $\alpha 2$ chains; $\alpha 1_{2} \alpha 2$ ) is the predominant form in dermis (and is the most abundant collagen in the body), and is usually found in composites together with collagen III $\left(\alpha 1_{3}\right)$. These are both fibril-forming collagens, and may create fibrils around a core of collagen $\mathrm{V}(\alpha 1(\mathrm{~V}) \alpha 2(\mathrm{~V}) \alpha 3(\mathrm{~V}))$. Collagen I provides tensile stiffness, and collagen III contributes to the reticular network in dermis, and has a tendency to associate with elastic fibers. Fibrillar collagens spontaneously aggregate into structural networks. Collagens IX ( $\alpha 1(\mathrm{IX}) \alpha 2(\mathrm{IX}) \alpha 3(\mathrm{IX}))$ and XIV ( $\left.\alpha 1(\mathrm{XIV})_{3}\right)$, called fibril-associated collagens with interrupted triple helices (FACIT), associate with the collagen I fibers and may promote proper matrix production and dermal structure (Ansorge et al., 2009). Collagen IV ( $\alpha 1(\mathrm{IV})_{2} \alpha 2(\mathrm{IV})$ ) is the most important component of basal membranes, including that of the epidermis, vessels and other structures. Collagen VII $\left(\alpha 1(\mathrm{VII})_{3}\right)$ and the transmembrane collagen XVII $\left(\alpha 1(\mathrm{XVII})_{3}\right)$ are also required components of the epidermal basement membrane (Aumailley et al., 2006). Collagen VI (a1 $\alpha 2 \alpha 3)$ is a microfibrillar collagen found in nearly all connective tissue, forming an independent microfibrillar network. (Mainly summarized from: (Gelse et al., 2003))

Collagens may be most prominent, but the dermis also consists of elastin, fibronectin ( 20 splice variants), fibulins (7 proteins), fibrillin (3 proteins), latent TGF-b binding proteins (4 proteins), laminins (16 proteins), matrilins (4 proteins), nidogens ( 2 proteins), tenascins (4 proteins), thrombospondins (5 proteins), vitronectin and proteoglycans (more than 40 species) (Krieg \& Aumailley, 2011). Deposition and assembly of extracellular matrix proteins into insoluble and complex polymers is adapted to development, tissue remodeling, repair, ageing and wound healing, making stiffness and compliance of 
tissues important factors regulating the functions of the cells embedded into, or apposed, to the matrices (Ingber, 2003).

The dermal matrix is instructive to fibroblasts, while the fibroblasts also control it. Bi-directional signaling is mediated by anchoring proteins, such as integrins. Adaptor proteins associating with the cytoplasmic tails of integrins cause differential ligand-binding activity of integrins and, conversely, the extracellular ligand-binding, clustering or pulling on integrins triggers the recruitment of cytoskeletal adaptor proteins (Hynes, 2002). Some of the adaptors include Src tyrosine kinases, which activate guanine-exchange factors, GTPase-activating proteins and other down-stream G-protein cascades - including activation of Rho-GTPases and eventually Rho kinase (ROCK), which results in a myriad of cytoskeletal activity (Huveneers \& Danen, 2009). Fibroblasts express both isoforms of ROCK (I and II), and they are central mediators of a number of phenotype-defining pathways including TGF- $\beta$ signaling and consequently also myofibroblast differentiation (Harvey et al., 2007).

The fibroblasts are a very resilient population of cells, surviving several days in culture in un-enriched media, surviving relatively harsh treatments and even allowing cultures several passages beyond the expected Hayflick limit. The resilience, expansion rate and ease of isolation of these fibroblasts make them highly suitable for in vitro experimentation. However, characterization of fibroblasts is very elusive (Sorrell \& Caplan, 2009) and it can therefore be difficult to ascertain the purity and identity of the cells in culture.

\section{Interactions with the epidermis}

The requirement of a dermis for the survival of the epidermis is clear, not least by the use of feeder fibroblasts in culture. In the short term, the role of the dermis seems facultative rather than instructive, based on research showing that even non-dermal connective tissue supports a healthy epidermal homeostasis (Briggaman \& Wheeler, 1971). Further insights have revealed that not only differences in connective tissues, but also the dermis of different anatomical sites, are indeed variously instructive to the development of the epidermis (Johansson \& Headon, 2014). One molecular explanation is the different activity of HOX-genes which control anatomical patterning during development.

The first growth factor to be discovered in epidermal-mesenchymal interactions was FGF7, or keratinocyte growth factor (KGF), and it is rapidly expressed during wounding (Werner et al., 2007). Mainly keratinocytes express the basal membrane components laminin 5 and collagen IV, but they need fibroblast interactions to produce a complete basal lamina. The actions of soluble factors from fibroblasts, probably EGF, KGF/FGF7 and GM-CSF, rather than cell-cell interactions are sufficient to establish the basal lamina (El Ghalbzouri 

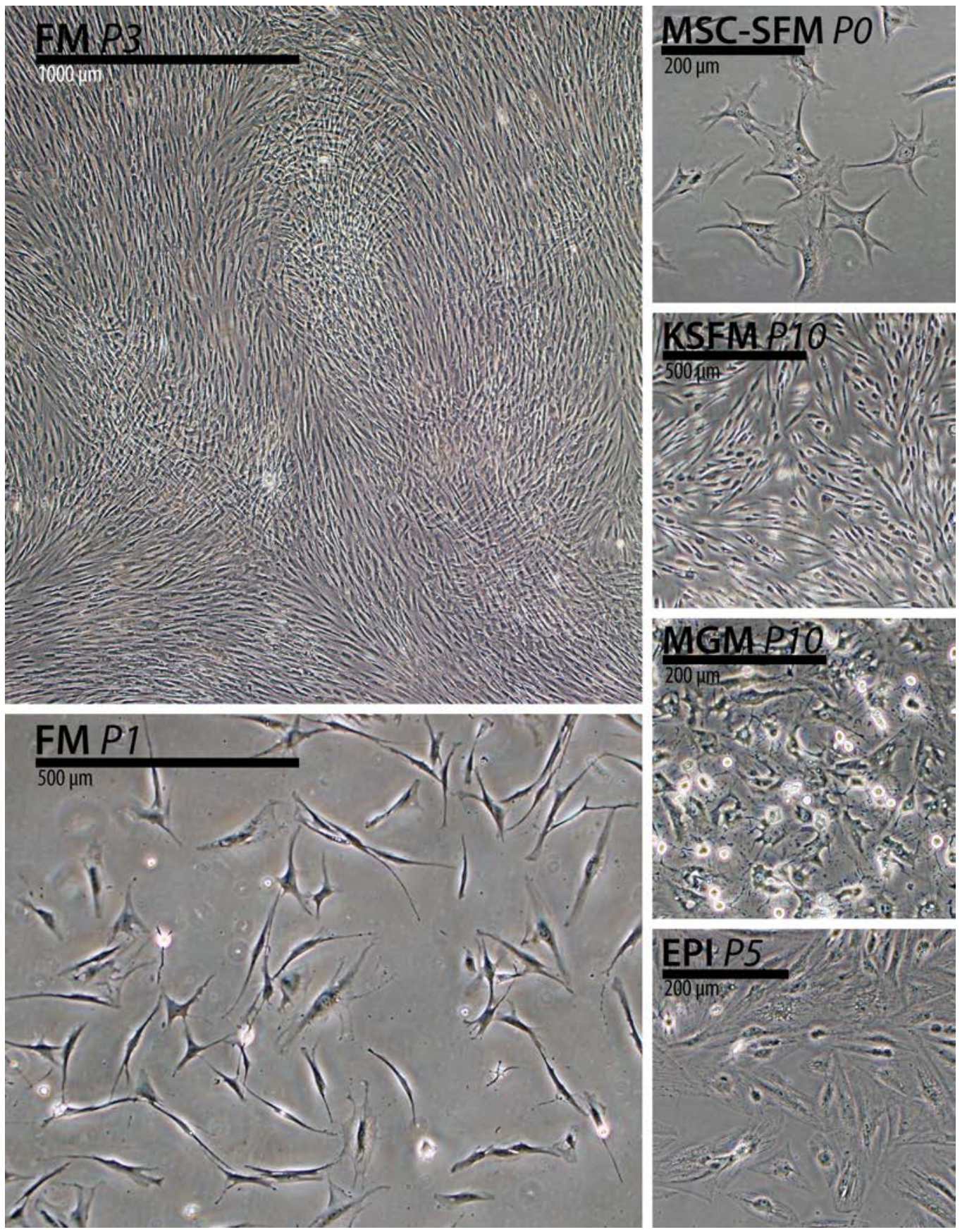

Cultures of primary human fibroblasts. FM P3: this is a normal view of a superconfluent culture, showing distinct growing patterns. FM P1: close-up of an early passage shows the heterogeneity of the culture, including tiny stellate cells, long spindle-shaped cells, and flattened polygonal cells. MSC-SFM P0: fibroblasts cultured in mesenchymal stem cell medium showed less heterogeneity and interesting, uniform, growth patterns. KSFM P10: cultures under keratinocyte medium become shorter and more homogenous. MGM P10: melanocyte medium induces stellate shapes and altered growth inhibition. EPI P5: epithelialization medium made fibroblasts flat and polygonal, and very similar to preadipocytes. 
\& Ponec, 2004). Laminin 5 and nidogen basal membranes could be created by keratinocytes under fibroblast-conditioned medium, but fibroblast- and keratinocyte-conditioned medium was required for keratinocytes to deposit collagen IV and down-regulate keratin 16 and 17, markers of keratinocyte activation.

Fibroblasts secrete DKK1 which affects both melanocytes and keratinocytes (Yamaguchi et al., 2007). In melanocytes, DKK1 inhibits Wnt/b-catenin signaling which inhibits melanogenesis through MiTF and down-stream effectors. In keratinocytes, DKK1 reduces melanosome uptake and induces a thicker and less pigmented epidermis (Slominski et al., 2005). Other factors also influence melanocytes, namely TGF- $\beta$, IFN- $\gamma$, TNFa, IL1 and IL6 which can be produced by fibroblasts (Mauviel et al., 1991; Rady et al., 1995; Boxman et al., 1996; Bashir et al., 2009).

Keratinocytes produce a number of factors that influence fibroblast matrix production (IL-1, IL-6, IL-7, IL-8, IL-10, IL-12, IL-15, IL-18 and IL-20, interferon (IFN)- $\alpha$, IFN- $\beta$ and IFN- $\gamma$, platelet-derived growth factor (PDGF), transforming growth factor (TGF) $\beta$ and tumour necrosis factor (TNF)- $\alpha$ ) (Grone, 2002; Harrison et al., 2006). Keratinocyte cytokines down-regulate collagen I and type I procollagen production, while FGF2 (bFGF), IGF-1 and proinflammatory (TNFa) cytokines up-regulate it (Harrison et al., 2006). Keratinocytes influence down-regulation of fibroblast fibronectin (Harrison et al., 2005).

\section{Vasculature and lymphatics}

The vasculature looks very similar in most of our body, but there are anatomically specific layouts, such as in the liver, and cellular and molecular variations, such as the blood-brain barrier. The principle geometry of the branching blood supply remains the same. Any cells are normally within 10 to $100 \mu \mathrm{m}$ of the blood supply (Pittman, 2011) to ensure sufficient nutrient diffusion and sustain a viable cellular environment, except for certain avascular tissues like cartilage and epidermis. The vasculature consists of endothelial cells lining the lumen of the blood vessels, a lumen supported by connective tissue, vascular smooth muscle cells that relax or contract to control the diameter of the vessels, and pericytes. Capillaries are numerous small interconnected blood vessels, at their smallest really only the result of single endothelial cells twisted and connected into tubular structures (Pittman, 2011). This configuration adds up to a huge surface area that is relatively leaky and therefore provides superior molecular exchange between the tissue interstitial fluid and the blood stream.

Deeper arterioles with thick smooth-muscle walls and an internal elastic lamina feed the cutaneous network. Thinner, superficial arterioles branch up and create dermal papillary loops that have been likened to a candelabra structure (the loops are the candles). Separate arteriole loops feed appendages such as 
hair follicles. Typically, the cutaneous vasculature is described as having a superficial and a deeper (reticular) plexus, but the highly branching and anastomosed vasculature is not so discretely organized. (Swerlick, 1997)

Beside nutrient supply and metabolic waste removal, the vasculature also serves as the conduit to the skin for immune cells. The skin contains local Mast cells in the dermis and Langerhan's cells reaching up through the basal layer, but immune cells are quickly recruited through the blood supply when needed. The vasculature is activated during inflammation, causing dilatation and exudation of fluid through increased permeability. Factors such as VEGF-A, TNF- $\alpha$, IL- 6, IL- $1 \beta$ are inflammatory mediators, and endothelial cell responses include expression of E-selectin, ICAM1, and VCAM1, which interact with leukocytes and assist with their diapedesis (Huggenberger \& Detmar, 2011).

The vasculature plays a vital role in surveillance of the skin and thermoregulation. Skin temperature, rather than core temperature, plays a signaling role in the decision to behaviorally thermoregulate, but this behavior does not occur in the absence of autonomic thermoregulation (Schlader et al., 2013). Autonomic signals, such as adrenergic stimuli, mediate vasoconstriction through noradrenaline, neuropeptide Y, and ATP (Thompson-Torgerson et al., 2008).

In contrast to vascular endothelial cells, those of the lymphatic capillaries overlap, lack tight junctions and mural cells, have only a rudimentary or no basement membrane, and are linked to the extracellular matrix by fibrillin-containing anchoring filaments (Swerlick, 1997). Tissue fluid, containing cells and macromolecules, can directly enter the lymphatic capillaries. The lymphatic vessels tightly follow adjacent to the vasculature of the dermis without making direct contact (anastomoses), and lymph vessels enter neither the subcutaneous adipose tissue nor the epidermis (Skobe \& Detmar, 2000). The endothelial cells of arteries, veins and lymph are differentially defined by the master regulators NOTCH1, COUP-TFII and PROX1 through cross-control mechanisms; arterial endothelial cells express NOTCH1, while venous endothelial cells express COUP-TFII. Lymphatic endothelial cells express all three, and so are proposed as a precursor state for endothelial cells, through a PROX1-mediated equilibrium of regulator activity (Kang et al., 2010).

\section{Sensors}

Physical sensing is important for maintaining a safe relationship with environmental challenges. The dermis contains a number of neuronal structures that signal sensing, pressure and temperature to the central nervous system. Several sensors have been described, and differ in their distribution across anatomical sites: lamellated corpuscles (Vater-Pacini, Golgi-Mazzoni, Ruffini), tactile corpuscles (Wagner-Meissner), end bulbs (Krause), tactile meniscus (Merkel), and 
free nerve-endings (Olry \& Haines, 2000).

Merkel cells, named after their discoverer Friedrich Merkel (Merkel, 1875), were believed to be important for registering touch (he just called them "Tastzelle" - touch cells). Krause had described the endbulbs, Cohnheim had discovered free nerve endings - confirmed by Langerhans and Eberth to exist in the skin - and Meissner's corpuscles were already well-known, as were those of Vater-Pacini. Yet, at the time of Merkel's publication, anatomists still felt that their understanding of the sensory apparatus of the skin was incomplete (Merkel, 1875). Merkel cells, located near the basal niche (basal epidermis and dermal papilla), may play a role in the developmental organization of the dermal nerve plexus (Narisawa et al., 1992). They are neurosecretory mechanotransducing nerve complexes (Haeberle et al., 2004; Woo et al., 2014), responsible for mediating gentle-touch, sense of shapes, edges and textures through slowly adapting type I responses (Nakatani et al., 2015). Merkel cells are miultiafferented low-threshold mechanoreceptors and have nociceptive capabilities (Pare et al., 2001). They seem to be of epidermal lineage, express PIEZO2, and can be discriminated from keratinocytes by staining for keratin 20 (Tilling et al., 2014).

Other corpuscles in the skin primarily function as mechanoreceptors. Ruffini's corpuscles are slow-adapting stretch receptors. Pacinian corpuscles register high-frequency vibrations $(250-350 \mathrm{~Hz})$ and are quick to adapt, mediating sensing of fine textures. Meissner's corpuscles have a higher threshold of activation, and respond best to low-frequency vibrations $(30-50 \mathrm{~Hz})$, making them suitable for registering coarse textures and skin depression. Both types are differently distributed in the skin (and body), with different morphologies, but both consist of connective-tissue-encapsulated Schwann cell lamellae. (Purves et al., 2001)

Merkel cell-neurite complexes and Meissner's corpuscles have been shown to regenerate after skin damage (reviewed in: (Dubovy \& Aldskogius, 1996; Widera et al., 2012)). Explanations of the regenerative capacity range from the presence of neural crest stem cells distributed in the skin (Sieber-Blum \& Grim, 2004; Nagase et al., 2007) to the dynamic plasticity of Schwann cells (Dupin et al., 2003; Real et al., 2005).

Nerve fibers are the axons from projecting neurons located in the dorsal root ganglia (DRG) or trigeminal ganglia (TG). Large fibers $(A \beta)$ are thickly myelinated and carry light touch and mechanical information. Small, thinly myelinated $(\mathrm{A} \delta$ ) or unmyelinated $(\mathrm{C})$ fibers are responsible for pain and temperature sensation. A $\delta$ fibers constitute $\sim 80 \%$ of the primary sensory nerve fibers; C fibers comprise $\sim 20 \%$ of the primary afferents (reviewed in: (Chuquilin et al., 2016)). Non-myelinating nerve fibers from dorsal root ganglia enter 
the skin where they spread out to form a complex network, with nerve endings even entering the epidermal layers (Arthur \& Shelley, 1959). The dermal nerve plexus is primarily located in the upper $25 \mu \mathrm{m}$ of the dermis, co-located with the capillary bed, and regularly accompanied by single Schwann cells (Tschachler et al., 2004).

Thermosensing occurs through dedicated warm- or cold-sensing fibers, and noxious temperatures are detected by both $\mathrm{A} \delta$ and $\mathrm{C}$ fiber nociceptors (Hensel et al., 1974; Chuquilin et al., 2016). Fibers express transient receptor potential ion channels (TRP). Sensing of non-noxious cold (between 12 and $26^{\circ} \mathrm{C}$ ) is mediated through TRPM8, noxious cold (starting from about $18^{\circ} \mathrm{C}$, pain increases linearly to $0^{\circ} \mathrm{C}$ ) through TRPA1 and NAV 1.8, non-noxious heat (30 to $50^{\circ} \mathrm{C}$ ) through TRPV3 and 4 , and noxious heat (from $47^{\circ} \mathrm{C}$ and up) through TRPV1 and 2 (reviewed in depth in: (Schepers \& Ringkamp, 2010)). Some of the TRP channels may be multimodal, also responding to mechanical and chemical stimuli (Schepers \& Ringkamp, 2010).

Widera et al. conclude their review of nervous regenerative capacity: "A definitive identification of the cellular base of regeneration remains a future challenge, the elucidation of which may help to develop effective treatments for acute injuries and age-related diseases accompanied by loss of mechanoreceptors" (Widera et al., 2012). As always, more studies are needed before we can fully understand the complexities of biology.

\section{Adipocytes and subcutis}

The adipose organ contains some highly conserved mechanisms ranging across organisms (Suh et al., 2007). Besides its role in storing fat to provide fuel in times of need, the adipose organ is also the body's largest endocrine organ, secreting adipokines (Spiegelman \& Flier, 2001). The adipose organ is very dynamic - it can increase and decrease in our lifetimes, but the number of cells remains fairly constant. About $10 \%$ of fat cell are renewed annually, showing that adipocytes are regenerated in adults, and that the tissue is highly regulated (Spalding et al., 2008). Fat is assumed to develop from the mesodermal lineage, but ectodermal lineage cells in the head and neck region also give rise to mesodermal lineages locally, including adipose tissue (Gesta et al., 2007). $\mathrm{Wnt} / \beta$-catenin signaling controls adipogenic cell fate within the lower dermis, and can block fibroblast to adipocyte differentiation during development (Mastrogiannaki et al., 2016).

The subcutaneous adipose tissue is organized as lobules of cells filled with fat, separated by thin layers of collagen IV-rich membranes. Residing along these membranes, and particularly in the intersection of lobule membranes and near 
vasculature, are the adipose stromal cells, which includes the preadipocytes. This organization is similar in all adipose tissue. However, some differences in skin adipose deposits may motivate a renewed categorization of adipose tissue in the skin, normally referred to as subcutis, hypodermis or subcutaneous adipose. Adipose tissue at different depths vary in their expression of metabolic proteins and signaling (Walker et al., 2007), and differences in intradermal and subdermal adipose tissue predict the occurrence of cellulites (Querleux et al., 2002). Adipose deposits can also be classified according to their extralobular stroma - large and deep deposits show large and tightly packed adipocytes linked with weak nets of collagen fibers and poor interspersed vasculature; another deposit is more stromal, with more vascularity and adipocytes wrapped in collagen fibers; and yet another has more notable stromal component with thick fibrous shells around the adipocytes (Sbarbati et al., 2010). The intradermal adipose tissue is dispersed in the lower dermis, but above the classic subcutaneous layer, and they are often erroneously synonymized (Driskell et al., 2014).

There are several points of cross-talk between intradermal adipocytes and the other skin compartments. Adipocyte growth and hair follicle oscillation are synchronized, showing a degree of linkage between the intradermal adipocytes and epidermal tissue compartments. The synchronicity may be mediated by PDGF produced in sub-follicular preadipocytes (Festa et al., 2011). Conversely, epidermal Wnt/ $\beta$-catenin signaling regulates adipogenic differentiation, BMP2, BMP6 and IGF2 were likely candidates for the epidermal-adipocyte differentiation interaction. EGF, serving many roles in the skin, can also have a negative impact on adipocyte differentiation (Serrero \& Mills, 1991). Adipocytes mediate recruitment of fibroblasts during wound healing (Schmidt \& Horsley, 2013). The intradermal adipose deposit is a key defensive player with remarkable potential for modifying systemic metabolism, immune function, and physiology (Alexander et al., 2015).

\section{BAT vs. WAT}

Adipose tissue is predominantly white adipose tissue (WAT), and this is what is referred to when referring to fat, unless otherwise specified. WAT is tasked with storing lipids, secreting adipokines, and metabolic responses. Brown adipose tissue (BAT) has been increasingly recognized as the main site of non-shivering thermogenesis in mammals, and there are indications that it is also the site of the process called diet-induced thermogenesis (Giralt \& Villarroya, 2013). BAT, while also storing fat and responding to metabolic signals, also expresses uncoupling protein 1 (UCP1). UCP1 is a mitochondrial protein that short-circuits ATP production, and instead uses the proton gradient across the mitochondrial membrane to generate heat, a process known as thermogen- 


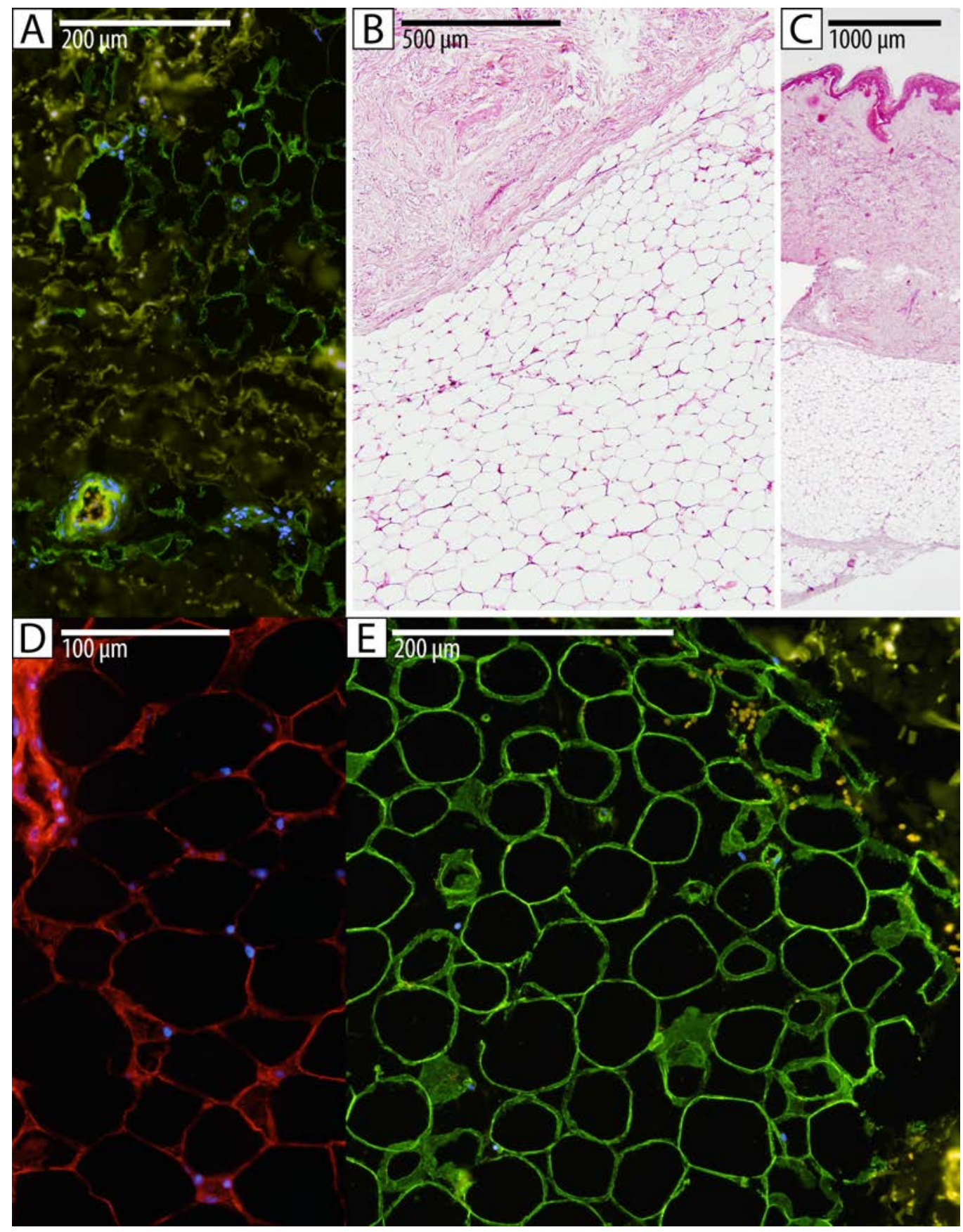

A look at subdermal adipose deposits.

A: Intradermal deposits of adipocytes and blood vessels are outlined in green staining for the collagen IV in basement membranes. Nuclei in DAPI (blue). B: Subcutaneous fat stained with H\&E. C: Lower magnification of B showing the whole skin, down to the subcutis. Stained with H\&E. D: Collagen IV staining, again, but this time the DAPI nuclei (blue) show the location of cells in the adipose stroma. A blood vessel is also stained. E: Subcutaneous fat stained with collagen IV (green). 
esis. The lipid storage in BAT is used as fuel for the thermogenic reaction.

BAT was first discovered in rodents, and later in human infants. These findings triggered the initiation of several studies all dedicated to test the hypothesis that adult humans do have significant amounts of metabolically active BAT, and in April 2009 three independent studies demonstrating the presence of such tissue in adult humans were published (Lidell et al., 2014). Thermogenesis provides a peripheral mode of heat generation that can influence local body temperature outside the scope of central regulation. It is believed that thermogenic deposits in adults contribute to extreme tolerance behavior to cold environments, such as swimming in winter oceans. The variability of the thermogenic tissue in humans seems to be significant.

BAT and WAT differ significantly in their origins. WAT develops from the adipogenic lineage, while BAT originates with the myogenic lineage. There is also another version of BAT, which comes from the adipogenic lineage and is found interspersed with WAT, instead of as a separate BAT deposit. Brown-inwhite (BRITE), also known as Beige, adipocytes are WAT that have undergone browning to obtain a thermogenic profile. The BRITEs are also found in rodents, but show a different protein profile to human BRITE. There may still be other versions of thermogenic cells. Experiments suggest that human infants, like rodents, possess bona fide BAT, containing classical brown adipocytes (Lidell et al., 2014). However, human supraclavicular BAT might consist of both BAT and BRITE adipocytes (J. Wu et al., 2012).

UCP1 expression is a definitive marker for thermogenic activity but does not distinguish between BAT or BRITE cells. Myogenic transcription factors, such as MYF5, can distinguish between the adipogenic and myogenic lineages, and thereby also between BAT and BRITE. Other markers of BAT include ZIC1, LHX8, PRDM16, PDK4, EVA1, HSPB7, and that distinguish BRITE: TNFRSF9, TBX1, TMEM26, CD137, CITED1, SHOX2. (Cristancho \& Lazar, 2011; Smorlesi et al., 2012; Giralt \& Villarroya, 2013)

There is no evidence that thermogenesis has a prominent role in subcutaneous adipose tissue, but as a subject for metabolic study it is still very interesting. Stimulation of thermogenesis occurs through adrenergic stress, exposure to cold and thyroid hormone T3, and this can be simulated in culture (P. Lee et al., 2014; Park et al., 2014). We show that such stimuli, in conjunction with adipogenic cues, activates thermogenesis in primary fibroblast cultures (and preadipocyte cultures) in the manuscript attached to this thesis (Paper IV). 

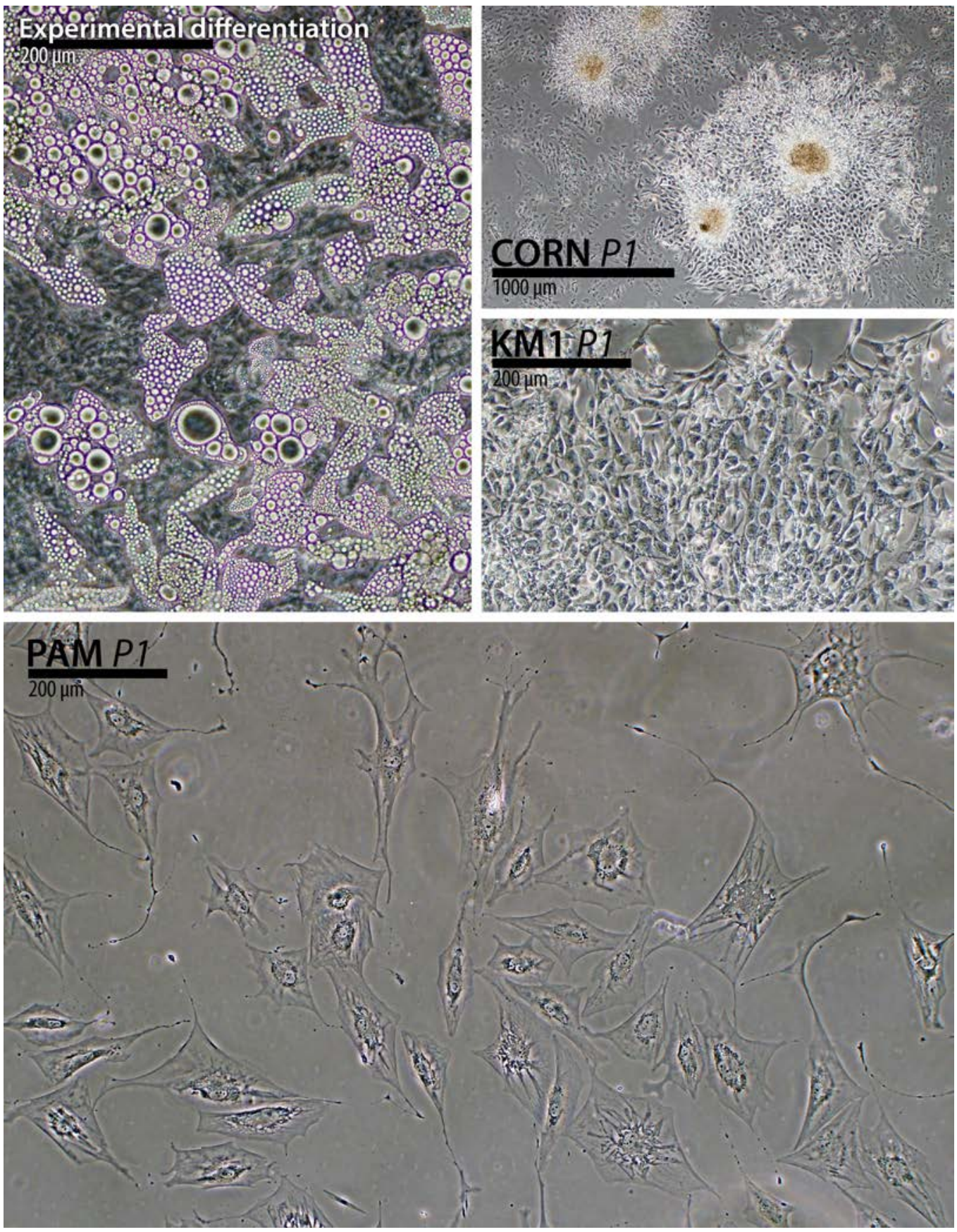

Cultures of human primary preadipocytes. PAM P1: A typical early culture of flattened and polygonal preadipocytes, cultured in preadpocyte medium. Experimental differentiation: Various attempts were made to obtain a self-organizing 3D culture of fat, here showig well-developed lipid vesicles in high-density culture. CORN P1: Medium intended to enhance cornification in skin constructs selected sub-populations in preadipocyte cultures that grew as holoclones, but the rest became necrotic. KM1 P1: Very different morphologies were evident in preadipocyte cultures under an epidermal medium, KM1. 


\section{Skin damage and repair}

The skin protects our insides from the world around us, and is continually damaged while trying to fulfill that role. Skin homeostasis is often challenged by infections, wounds, chemicals, burns and even sunlight. Any breach in our skin is a potential health hazard because we become susceptible to infections and blood loss. If bacteria are able to enter our blood-stream unchecked they can multiply very rapidly and create a systemic shock, sepsis, which is lethal if not treated in time.

The cornified layer affords us a practical level of physical protection but ultraviolet radiation and certain chemical challenges can still damage our skin cells. The broad-spectrum radiation from the sun includes ultraviolet rays (UV): longer-wavelength UV-A, which causes oxidative stress, and shorter-wavelength UV-B that can damage DNA (Brenner \& Hearing, 2008). Oxidative stress can under normal conditions be counteracted by antioxidants, but in extreme cases results in cellular toxicity. A photon of UV-B can cause thymidine-dimers in the DNA which can normally be repaired by DNA repair mechanisms. Melanosomes serve to protect the epidermal cells from excessive UV damage.

During embryonic and early foetal development wounds heal by perfect regeneration (Colwell et al., 2003), but this process of healing is not fully maintained after birth. Instead, we react with a quick response healing mechanism that more swiftly stops bleeding and closes wounds to avoid further potentially life-threatening encounters with the outside environment. The downside is that the healing site becomes scarred and imperfect.

A skin wound comes in many varieties, each one so unique that it is sometimes difficult for researchers to standardize an experimental wound setup. The wounds we experience are of different depths, at different anatomical sites, of different sizes and with different environmental challenges (a clean scalpel cut is very different from scraping against a rock). The chain of events that occurs in all cases can be generalized, but in reality each event can be complicated by any number of factors.

A wound that only disrupts the epidermis will heal easily by accelerated keratinocyte proliferation, and re-epithelialization without major involvement of the immune system (only slight inflammation). The basal keratinocytes will survive in large enough numbers beneath and around the wound so that they can migrate and divide to repopulate the epidermis. There is little environmental challenge and negligible blood loss. The area will be weakened by the lack of complete and cornified epidermis, but is expected to return to normal within two weeks (Beam, 2007). 
A wound that goes deeper, well into the dermis, will break the basal layer and therefore challenge the keratinocytes more. They cannot repopulate the wound site until they have a supportive dermis to grow on, and then a layer of keratinocytes need to first re-epithelialize the wound bed. The disruption of the dermis will also break the vasculature causing more substantial bleeding and inflammation. With the bleeding comes cells and other blood constituents. Now the blood-clotting cascade will be activated.

Fibrinogen polymerization into a fibrin clot is mediated by thrombin, which is released from platelets at a wound site. The formation is dependent on either of three different substantial cascades of coagulation factor recruitment and activation. Once the clot has formed, the fibrinolytic cascades begin to degrade it. Plasminogen is cleaved into plasmin by tissue plasminogen activator released from endothelial cells, and binds to fibrin. Elastase and cathepsin $G$ are produced by neutrophils and also contribute to fibrinolysis. (reviewed in: (Sidelmann et al., 2000))

Factors from the blood and platelets, such as PDGF, chemokines and cytokines, activate fibroblasts, macrophages and neutrophils. Monocytes are recruited from the blood through various molecular signals, including TGF- $\beta$, MCP1 and other chemoattractants, and differentiate into activated macrophages. They produce potent signals in the form of VEGF, TGF- $\alpha$ and $-\beta_{1 / 2 / 3}$, IL1, FGF, which further drive the cellular activity in the wound. Neutrophils and macrophages cleanse the wound area from particles (including bacteria). TGF- $\beta$ and VEGF also signal the production of fibrous tissue by fibroblasts and myofibroblasts, eventually leading to contraction and scar formation. (Singer \& Clark, 1999)

PDGF is a family of homo- and heterodimeric factors including PDGF-AA, $-\mathrm{AB},-\mathrm{BB},-\mathrm{CC}$ and $-\mathrm{DD}$. They bind to transmembrane tyrosine kinase receptors (PDGFR $\alpha \alpha, \alpha \beta$ and $\beta \beta$ ). Correct levels of PDGF are important for normal wound healing; low expression of PDGF is associated with chronic ulcers, and high expression is associated with hypertrophic scarring and keloids. (Werner \& Grose, 2003)

FGF is a growth-factor family of at least 22 known members, binding to four FGF receptors with varying affinities (FGFR-1, $-2,-3,-4$, plus splice variants). The members of FGF have a broad repertoire of mitogenic stimuli for various cells types, except FGF7 which is also known as keratinocyte growth factor (KGF) and specifically targets epithelial cells. Wound repair is stimulated by at least FGF-1, -2, -4, -7 and -10 (Werner \& Grose, 2003). We have seen that FGF21 stimulation can induce FGF21 gene expression in fibroblasts (unpublished data; see Paper IV manuscript).

The EGF (epidermal growth factor) family is comprised of EGF, TGF- $\alpha$, HB- 
EGF, amphiregulin, epiregulin, neuregulins and other members. They bind to four high-affinity receptors: EGFR, HER2, HER3 and HER4. EGFR is increased during early wound healing and subsequently decreases in concert with a decline in epidermal thickness, suggesting a role in re-epithelialization. (Werner \& Grose, 2003)

TGF- $\beta$ is a diverse superfamily of proteins, important in embryogenesis as well as in adult homeostasis. The family includes TGF- $\beta_{1^{\prime}-2}$ and ${ }_{-3}$, BMPs, inhibins and activins and others, and they bind to heteromeric membrane receptor complexes, with down-stream signaling modulated in part by SMADs and other signaling mechanisms. TGF- $\beta$ has several roles in wound healing, but some findings show paradoxical roles. Re-epithelialization is modulated by TGF- $\beta$, but its role is not clear. TGF- $\beta$ is known to stimulate fibroblast activity, especially myofibroblast differentiation, which have essential roles in wound healing, but abrogating TGF- $\beta$ can also have a positive effect on minimizing scar formation. The precise roles at different concentrations of the three main TGF- $\beta$ members are not yet fully understood. (Werner \& Grose, 2003)

VEGF (vascular endothelial growth factor) is also a family of proteins important to wound healing, especially vasculogenesis and neovascularization. All of these families, as well as BMPs (bone morphogenetic proteins), Activins, NGF (neural growth factor), Angiopoietins, CTGFs (connective tissue growth factors), GM-CSF (granulocyte macrophage colony-stimulating factor), various chemokines and scatter factors are reviewed in relation to wound healing in great detail in: (Werner \& Grose, 2003). The wound healing process is one of the most complex molecular concerts that occur in the adult body (Gurtner et al., 2008).

Re-epithelialization begins immediately after wounding, with wound-edge keratinocytes becoming activated possibly through loss of contact inhibition, EGF and KGF (Singer \& Clark, 1999). Desmosomes weaken, relieving keratinocytes of some of their cell-cell adhesion, and actin-mediated motility increases (Gabbiani et al., 1978). Weakening of hemidesmosomes allows lateral movement of keratinocytes, and through their integrin repertoire they maneuver through the interface between the collagenous dermis and the fibrin clot (Singer \& Clark, 1999). The release of plasminogen activator (which leads to degradation of fibrin) and collagenases (which cleave dermal collagens) allows the keratinocytes to carve their way between the wound bed and the clot (Bugge et al., 1996; Pilcher et al., 1997). Within the first two days, a wave of wound-edge proliferation ensues, the result of which is the increased repopulation of the wound with more keratinocytes. A new basal membrane is formed in tandem with the proliferation from the wound edges. Keratinocytes revert to their normal epidermal homeostasis once re-epithelialization is completed. 
Within four days of the wounding, the wounded dermis begins to form granulation tissue. Fibroblasts (and immune cells) move into the clot to begin new matrix formation and support neovascularization. Several mitogenic factors stimulate neoangiogenesis, such as FGF, VEGF, angiogenin, angiopoietin 1 and thombospondin. Once the fibrin of the clot has been replaced with fibrous collagen matrix, most of the fibroblasts undergo apoptosis to create a relatively acellular scar tissue. Much of the new capillaries also disintegrate through endothelial cell apoptosis. Slow remodeling of the scar tissue ensues, but can take years to complete. (Singer \& Clark, 1999)

The melanocytes are not as easily replaced after wounding. They either reappear sporadically over time or do not reappear at all, causing a lack of pigmentation over the scar (Chadwick et al., 2012). Their impetus for regeneration is not yet completely understood, but some evidence suggest that wound-edge melanocytes proliferate and migrate after re-epithelialization is completed (Hirobe, 1983). Lack of pigmentation can accentuate scars, which can cause aesthetic displeasure among suffering individuals.

Challenges to wound healing include poor circulation, particularly in the extremities. Diabetic and arthritic patients, and patients with problematic blood pressure can develop wounds that heal very slowly. These difficult-to-heal wounds, often referred to as chronic wounds, are very problematic for the patient, and the healthcare system is not particularly successful at treating them. Many interventions are designed to improve chronic wound therapy, but so far most approaches are insufficient.

\section{Skin in the clinic}

Wounds are a major source of morbidity to patients and a major cost to hospital and community healthcare providers, the true extent of which is obscure due to lacking evidence (Posnett et al., 2009). It is difficult to analyze skin wound impact on healthcare because wounds are so diverse and so prevalent. A study was carried out at Karolinska Hospital in Stockholm, Sweden, to identify all wounds, wound types and characteristics among patients receiving care at the hospital (Lindholm et al., 2005). The study found that one in five patients at the 93 participating care units of the hospital had skin wounds that needed treatment (408 patients, of 2172 participating, had a total of 668 wounds). Wounds ranged from 0.1 to $600 \mathrm{~cm}^{2}$ with duration from one day to 30 years, and were categorized as pressure ulcers, leg and foot ulcers, and other wounds (which included traumatic, postoperative, transplantations, fistulas, burns and other). Wounds are prevalent, have diverse and often unknown etiology, and varied progression and severity.

A study from the United Kingdom aimed to estimate the cost of wound care 
for a local population (Drew et al., 2007). A total of 1644 wounded patients were included, with a total of 2300 wounds. Including estimates for dressings etc, nurse time, and inpatient costs provided a total estimate of GBP 15 to 18 million, translating to GBP 2.5-3.1 million per 100,000 covered populous, or 2 to $3 \%$ of the local health care budget. This study did not analyze the societal and individual costs associated with diminished capacity or health impact.

Another Swedish study, this time from Uppsala, looked at prevalence and care of chronic wounds (Lindholm et al., 1999). They included leg and foot ulcers (406 patients), pressure ulcers (117), and other wounds (171) in a total population of 694 patients with wounds. After a three-month follow-up, $28 \%$ of pressure ulcers, $40 \%$ of leg ulcers and $61 \%$ of other wounds had healed. The majority of patients were over 70 years old, and $25 \%$ were also diagnosed with diabetes. Time dedicated to dressing changes alone was equivalent to 57 fulltime nurse employments.

While information on the overall prevalence and costs of wound care in the acute sector is limited, it is likely that $27-50 \%$ of acute hospital beds in Europe are occupied on any given day by patients with a wound (Posnett et al., 2009). Estimates for the United States of America suggest that chronic wounds affect 6.5 million patients, costing USD 25 billion annually (Sen et al., 2009). The authors emphasize the need for research into wound healing biology and the use of model systems. The authors remark:

"The immense economic and social impact of wounds in our society calls for allocation of a higher level of research resources to understand biological mechanisms underlying the complexities noted in problem wounds", p.767, (Sen et al., 2009)

Good wound care is vital and should not be underestimated. The many facets of wound healing biology and skin regeneration are interesting targets of biological research, both for their potential importance to basic biology as well as for their impact on individual patients and society as a whole. Small incremental therapeutic improvements can provide huge healthcare benefits.

In addition to the clinical picture of wounds, there are numerous other skin-related clinical problems such as skin cancers, scarring, irritation, psoriasis, keloids, pigmentation aberrations, skin-related mutations affecting the physical barrier, hair and nail disorders and many more. Skin is also very important in reconstructive surgery and a major subject of cosmetic surgery. Scarring and pigmentation may be clinical problems, but can also motivate elective surgery for aesthetic reasons. 


\section{Skin engineering}

The evident self-organization of keratinocyte cultures into epidermal sheets provided early impetus to create clinically relevant epidermal substitutes. The importance of the keratinocyte-fibroblast relation was also made evident by co-culture requirements (prior to more advanced media formulations). Taking this further, providing both epidermal and dermal components in co-culture systems allowed further studies on skin biology. The Bell model was an early approach to such a skin construct (Bell et al., 1981; Bell et al., 1984). It was made by cultured fibroblasts and collagen matrix, upon which keratinocytes were seeded from explants. Epidermal morphogenesis was reported (for human cells) after about three weeks in culture, while similar constructs using rat cells were successfully engrafted in vivo and survived the lifespan of the host (over two years).

A few different lines of research have since developed. On the one hand, the intercellular relations between different skin compartments need to be identified and replicated. On the other hand, the actual extracellular organization of the different skin compartments or their molecular content is not easily replicated by collagen hydrogels and need to be further understood and developed. In either case, the paracellular interactions and extracellular organization are both important for functions in skin homeostasis and response to injury.

A slight modification of the Bell model was used to create standardized wounds to investigate events in wound healing (Stephens et al., 1996). The main alteration was the use of an additional acellular collagen lattice, upon which the dermal fibroblast and collagen matrix was placed. This made the wound parameters easier to control in the culture dish, while providing a collagen substrate in the wound bed that was better than culture plastic.

Use of collagen hydrogels is simple and popular, but there are significant drawbacks in the poor integrity and high water content of the gels. One proposed solution is to use compression forces to exude water and compact the collagen. This can be done while embedded cells remain viable, and results in a much stronger construct that is easier to handle for transplant (Ananta et al., 2012). To successfully perform the compression, additional stabilizing material components were added in the gels, consisting of a sheet of vicryl. Similar ideas of compression have been used in the more extreme application of collagen-based cartilage matrix engineering.

The Bell model was used to create a pigmented skin equivalent to study melanosome transfer to keratinocytes (Topol et al., 1986). This showed that the model could be useful for studying specific aspects of tissue development, and on the other hand, that dermal equivalents with UVB-induced pigmentation 
could be created. We used a principally similar model for the contraction study of Paper III - embedding fibroblasts in a collagen (bovine type I) hydrogel lattice, seeding melanocytes on the surface, and then keratinocytes on top (Rakar et al., 2015). The natural pigmentation hue (phototype) of an individual can be replicated using autologous cells in such constructs (Bottcher-Haberzeth et al., 2015). Theoretical models predicting the distribution of melanocytes in the basal layer have been published, and these would be promising subjects for investigation in pigmented skin constructs (Thingnes et al., 2012). Using melanocyte stem cells might also provide models for investigating age-related changes, such as greying hair, and the mechanisms of melanocyte regeneration in wound-healing (J. H. Lee \& Fisher, 2014).

The nutrient requirements of most tissues demand access to blood supply, and any transplanted tissue must certainly be directly connected to the blood flow to avoid necrosis. The creation of multilayered constructs beyond simplified dermis and epidermis includes efforts at vascularization. Including endothelial cells in the dermal component showed that capillary-like structures could self-assemble in a skin construct (Black et al., 1998). In fact, simple plating of endothelial cells on a collagen or matrigel causes self-assembly into capillary-like structures (Goodwin, 2007), which shows that the ability remains inherent to the cells in vitro. A more controlled approach recently involved fibronectin- and gelatin-coated single fibroblasts, 3D-printed in layers interspersed with coated endothelial cells, to create a vascular dermis which also supported an epidermis (Matsusaki et al., 2015). Other attempts at such constructs include the differentiation of preadipocytes to a vascularized dermis, in a dermal equivalent using PEGylated fibrin and chitosan microspheres (Natesan et al., 2011).

Adipose tissue has been very difficult to create in a culture setting because its organization is complex and is not suitable for a two-dimensional, or flat layer based approach. One solution is to utilize magnetic levitation spheroid culture of the isolated stromal-vascular fraction (Daquinag et al., 2013). In the absence of the exotic equipment needed for levitation, we attempted to construct 3D-adipose tissue by cultivating preadipocytes under adipogenic media in gelatin microcarriers. The purpose was to create a subcutaneous equivalent to combine with the other components of engineered skin, but the microscopic analysis was not optimized to determine our degree of success (unpublished data). In preadipocyte-fibroblast co-cultures using advanced experimental media we were able to obtain a thick differentiated layer of adipocytes, but further development is necessary to evaluate our progress.

Innervated skin constructs are difficult to produce, and whether the sensory functions can be adequately integrated into a nervous system upon skin en- 


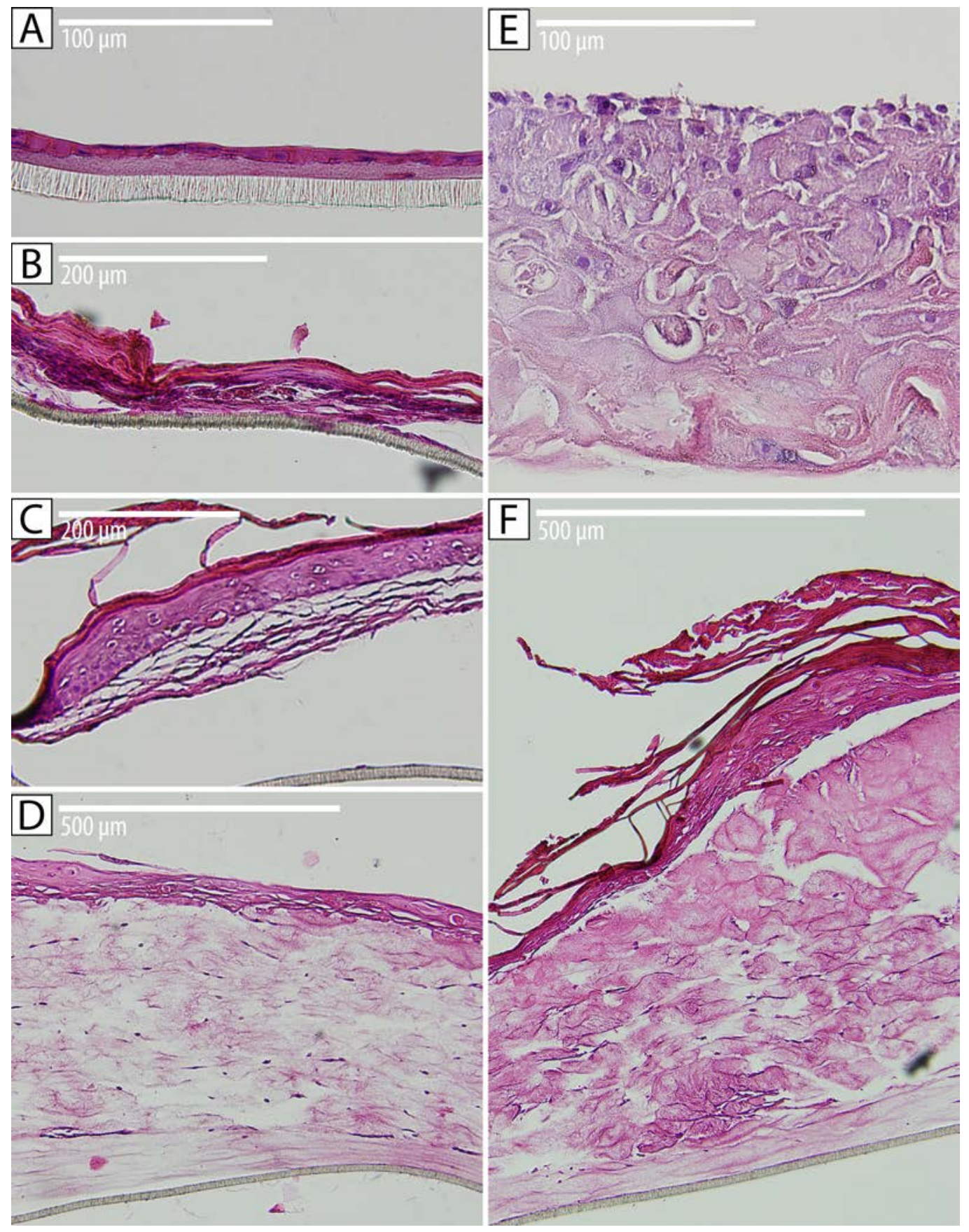

\section{Tissue Engineered Skin: Development - Haematoxylin \& Eosin stained paraffin sections.}

A: Early models of skin with fibroblasts and keratinocytes on plastic inserts. B: Enhanced epidermal development with optimized media and airlift. C: Adjusted media, adjusted cell numbers, and overall improvements. D: Using collagen gels for a more bulky dermis, including a layer of acellular collagen. E: Early models were less developed than ... F: ... later models, which show improved dermal and epidermal components, and can include preadipocytes and melanocytes. 
graftment is still uncertain. However, re-innervation does occur in engrafted skin equivalents (English et al., 1992), proving that innervation is in principle supported. Similar approaches have been partly successful (Lebonvallet et al., 2012), and indicate that re-innervation might be possible in skin constructs. We performed a pilot study incorporating a simple Bell-skin setup in a cell-culture insert, and cultured neural stem cells in the well below. We saw some indication that sprouting into the dermis occurred, but our staining was inconclusive, and we have not proceeded with further experiments. Using the same approach, a rat-tail collagen type I gel containing human fibroblasts and stratified keratinocytes was placed on a polyester/polypropylene matrix seeded with porcine dorsal root ganglion neurons, and the construct was used to investigate the effects of neuropeptide signaling on keratinocyte behavior (Roggenkamp et al., 2013).

Lack of circulation limits the investigation of wound healing in skin substitutes. Some aspects, such as re-epithelialization and other more isolated events, can be investigated. Using acellular porcine dermis, combining bulge cells and dermal papilla cells improved the wound healing process and generated hair bud-like structures within 14 days (Leiros et al., 2014). We used excised human skin to create a wound model (Kratz, 1998), in which we looked at the ability of microcarriers to influence re-epithelialization (Paper II in this thesis).

One of the drawbacks with three-dimensional constructs is the difficulty in observing the cells microscopically. Advances in microscopy have provided some solutions, but these are not yet very common. A wound-model has been analyzed using two-photon microscopy with some success (Torkian et al., 2004). The use of spectromicroscopy may also provide a solution; Raman microscopy has been used to look at epidermal permeability (Franzen et al., 2013a; Franzen et al., 2013b; Franzen et al., 2015), and may prove useful for several types of constructs.

Products emerging from skin engineering are aimed at clinical use or for standardized irritant testing to replace animal models. While no construct can yet fully mimic natural human skin, there are some options available for alleviating the need for extensive autotransplants or animal studies. EpiSkin ${ }^{\mathrm{Tx}}$ is a human reconstructed epidermis supported by a collagen matrix aimed at toxicological studies (Alepee et al., 2016). It is limited by only allowing the study of an isolated epidermis, without underlying tissue. Dermagraft ${ }^{\mathrm{tm}}$ is a prefabricated human cell dermal equivalent, constructed by allowing fibroblasts to create a matrix around a biodegradeable polyglactin (vicryl) mesh scaffold, aimed at treating foot and leg ulcers. It shows little gains compared to standard treatments, but it may be useful in select wound types (Harding et al., 2013). Apligraf ${ }^{\text {im }}$ is a prefabricated human cell bilayer construct with bovine collagen type 1 and 


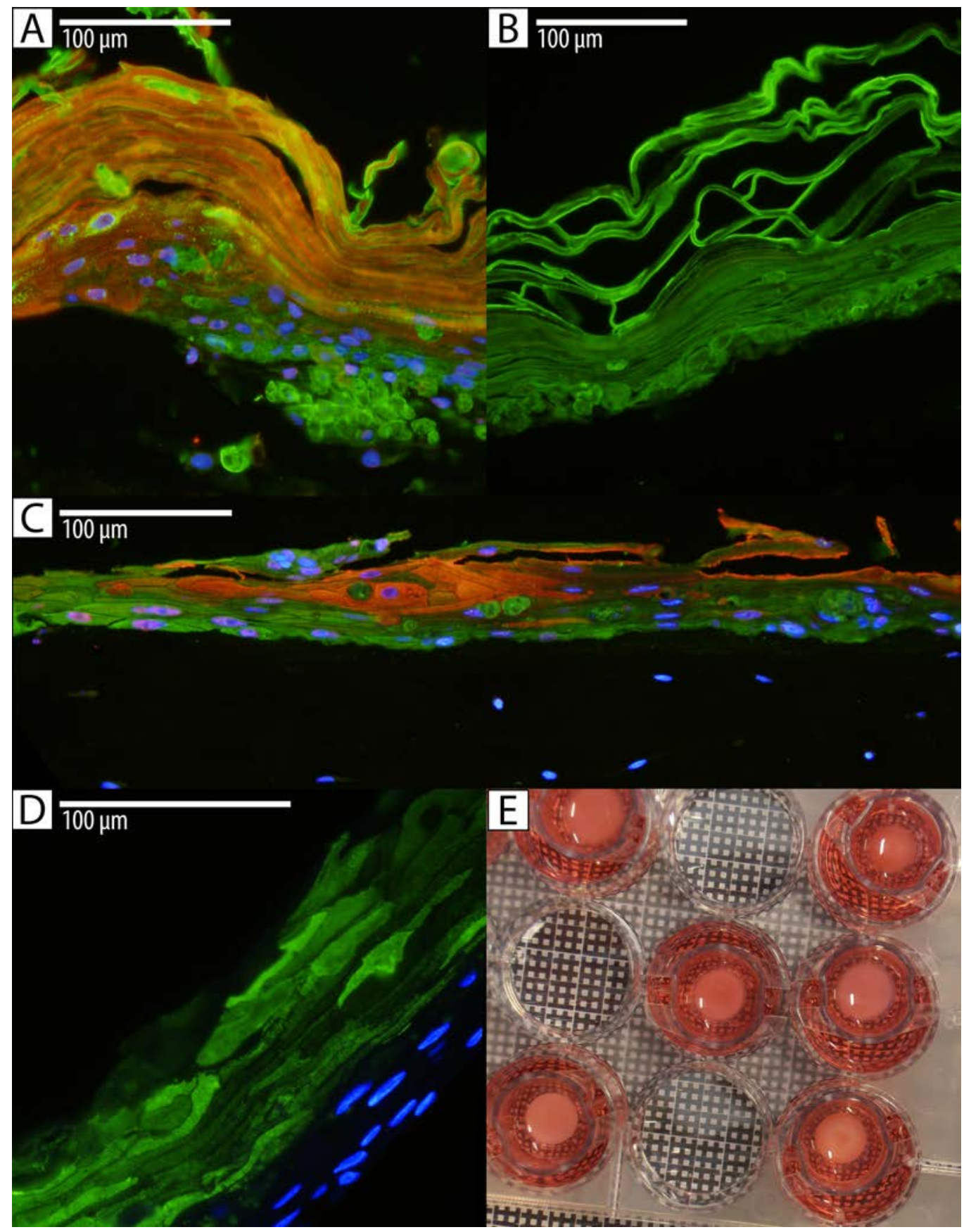

Tissue engineered skin.

A: Keratin 5 (green) is still expressed in most of the epidermis, but keratin 10 is only expressed higher up. B: Modified media enhanced cornification (pancytokeratin staining). C: Thin, not yet cornified epidermis with Krt 5 (green) and Krt 10 (red) distribution, on a populated dermis (blue: DAPI nuclei). D: Filaggrin expression (green) on top of unstained epidermal cells (blue nuclei, DAPI). E: Standard 12-well format with inserts used for skin construction and assays. 
fibroblasts covered by a stratified epidermis. Both products are considered advanced wound care matrices for ulcers, but evidence of economic feasibility is questionable (Hankin et al., 2012; Rice et al., 2015).

There are numerous variants and replications of most of these skin constructs, and the list of examples is far from exhaustive. With advances in folliculogenesis, innervation and matrix engineering we will eventually be able to construct more complete models of human skin with appendages. 


\section{Work in progress, or: how the parts fit the whole}

The two skin-related scientific papers included in this thesis (papers II and III) each use different models for the purpose of testing specific aspects of skin biology. For our research focus in a larger perspective, the use of multiple models and contrasting their functionality gives us insights into their relative strengths and weaknesses, and hopefully this knowledge will be useful for future studies.

My overarching goal was to use differentiation techniques to obtain all cell types necessary for the construction of an advanced skin substitute. We have already looked into creating adipose cells and endothelia from fibroblasts. Next, we have been trying to obtain epidermal cells, and finally pigment cells, nerves and hair follicle cells.

The validating of keratinocyte-like differentiated fibroblasts would require a feasible test-bed in the form of in vitro skin models, to prove stratification and re-epithelialization functionality. Such a skin model could also be used to investigate the formation of subcutaneous fat, of pigmentation and other components of the skin, becoming a test-bed for functional analysis after cellular differentiation.

We believe that the ability to create such a model, and to differentiate all main cell types from a single source, would translate into important knowledge for improved wound therapy in the clinic. The goal is therefore motivated by basic science, by applied biology, by clinical needs, as well as financial and moral incentives. 


\section{Section References}

Abdel-Malek, Z., Scott, M. C., Suzuki, I., Tada, A., Im, S., Lamoreux, L., .. . Hearing, V. J. (2000). The melanocortin-1 receptor is a key regulator of human cutaneous pigmentation. Pigment Cell Res, 13 Suppl 8, 156-162

Alepee, N., Hibatallah, J., Klaric, M., Mewes, K. R., Pfannenbecker, U. and McNamee, P. (2016). Assessment of Cosmetic Ingredients in the In Vitro Reconstructed Human Epidermis Test Method EpiSkin Using HPLC/UPLC-Spectrophotometry in the MTT-Reduction Assay. Toxicol In Vitro

Alexander, C. M., Kasza, I., Yen, C. L., Reeder, S. B., Hernando, D., Gallo, R. L., . . MacDougald, O. A. (2015). Dermal white adipose tissue: a new component of the thermogenic response. J Lipid Res, 56(11), 2061-2069

Ananta, M., Brown, R. A. and Mudera, V. (2012). A rapid fabricated living dermal equivalent for skin tissue engineering: an in vivo evaluation in an acute wound model. Tissue Eng Part A, 18(34), 353-361

Ansorge, H. L., Meng, X., Zhang, G., Veit, G., Sun, M., Klement, J. F., ... Birk, D. E. (2009). Type XIV Collagen Regulates Fibrillogenesis: PREMATURE COLLAGEN FIBRIL GROWTH AND TISSUE DYSFUNCTION IN NULL MICE. J Biol Chem, 284(13), 8427-8438

Arthur, R. P. \& Shelley, W. B. (1959). The innervation of human epidermis. J Invest Dermatol, 32(3), 397-411

Aumailley, M., Has, C., Tunggal, L. and Bruckner-Tuderman, L. (2006). Molecular basis of inherited skin-blistering disorders, and therapeutic implications. Expert Rev Mol Med, 8(24), 1-21

Banks-Schlegel, S. \& Green, H. (1981). Involucrin synthesis and tissue assembly by keratinocytes in natural and cultured human epithelia. J Cell Biol, 90(3), 732-737

Bashir, M. M., Sharma, M. R. and Werth, V. P. (2009). TNF-alpha production in the skin. Arch Dermatol Res, 301(1), 87-91

Beam, J. W. (2007). Management of superficial to partial-thickness wounds. J Athl Train, 42(3), 422424

Behrens, D. T., Villone, D., Koch, M., Brunner, G., Sorokin, L., Robenek, H., . . Hansen, U. (2012). The epidermal basement membrane is a composite of separate laminin- or collagen IV-containing networks connected by aggregated perlecan, but not by nidogens. J Biol Chem, 287(22), 18700-18709

Bell, E., Ehrlich, H. P., Buttle, D. J. and Nakatsuji, T. (1981). Living tissue formed in vitro and accepted as skin-equivalent tissue of full thickness. Science, 211(4486), 1052-1054

Bell, E., Sher, S. and Hull, B. (1984). The living skin-equivalent as a structural and immunological model in skin grafting. Scan Electron Microsc(Pt 4), 1957-1962

Black, A. F., Berthod, F., L'Heureux, N., Germain, L. and Auger, F. A. (1998). In vitro reconstruction of a human capillary-like network in a tissue-engineered skin equivalent. FASEB J, 12(13), 13311340

Bose, A., Teh, M. T., Mackenzie, I. C. and Waseem, A. (2013). Keratin k15 as a biomarker of epidermal stem cells. Int J Mol Sci, 14(10), 19385-19398

Bottcher-Haberzeth, S., Biedermann, T., Klar, A. S., Widmer, D. S., Neuhaus, K., Schiestl, C., . . Reichmann, E. (2015). Characterization of pigmented dermo-epidermal skin substitutes in a longterm in vivo assay. Exp Dermatol, 24(1), 16-21

Boxman, I. L., Ruwhof, C., Boerman, O. C., Lowik, C. W. and Ponec, M. (1996). Role of fibroblasts in the regulation of proinflammatory interleukin IL-1, IL- 6 and IL-8 levels induced by keratinocyte-derived IL-1. Arch Dermatol Res, 288(7), 391-398

Brenner, M. \& Hearing, V. J. (2008). The protective role of melanin against UV damage in human skin. Photochem Photobiol, 84(3), 539-549

Briggaman, R. A. \& Wheeler, C. E., Jr. (1971). Epidermal-dermal interactions in adult human skin. II. The nature of the dermal influence. J Invest Dermatol, 56(1), 18-26

Bugge, T. H., Kombrinck, K. W., Flick, M. J., Daugherty, C. C., Danton, M. J. and Degen, J. L. (1996). Loss of fibrinogen rescues mice from the pleiotropic effects of plasminogen deficiency. Cell, 87(4), 709-719

Carroll, D. K., Carroll, J. S., Leong, C. O., Cheng, F., Brown, M., Mills, A. A., . . Ellisen, L. W. (2006). p63 regulates an adhesion programme and cell survival in epithelial cells. Nat Cell Biol, 8(6), 551-561

Chadwick, S., Heath, R. and Shah, M. (2012). Abnormal pigmentation within cutaneous scars: A complication of wound healing. Indian J Plast Surg, 45(2), 403-411

Chuquilin, M., Alghalith, Y. and Fernandez, K. H. (2016). Neurocutaneous disease: Cutaneous neuroanatomy and mechanisms of itch and pain. J Am Acad Dermatol, 74(2), 197-212

Colwell, A. S., Longaker, M. T. and Lorenz, H. P. (2003). Fetal wound healing. Front Biosci, 8, s1240-1248 
Compton, C. C., Gill, J. M., Bradford, D. A., Regauer, S., Gallico, G. G. and O'Connor, N. E. (1989). Skin regenerated from cultured epithelial autografts on full-thickness burn wounds from 6 days to 5 years after grafting. A light, electron microscopic and immunohistochemical study. Lab Invest, 60(5), 600-612

Cotsarelis, G., Sun, T. T. and Lavker, R. M. (1990). Label-retaining cells reside in the bulge area of pilosebaceous unit: implications for follicular stem cells, hair cycle, and skin carcinogenesis. Cell, 61(7), 1329-1337

Cristancho, A. G. \& Lazar, M. A. (2011). Forming functional fat: a growing understanding of adipocyte differentiation. Nat Rev Mol Cell Biol, 12(11), 722-734

Daquinag, A. C., Souza, G. R. and Kolonin, M. G. (2013). Adipose tissue engineering in three-dimensional levitation tissue culture system based on magnetic nanoparticles. Tissue Eng Part $C$ Methods, 19(5), 336-344

De Luca, M., D’Anna, F., Bondanza, S., Franzi, A. T. and Cancedda, R. (1988). Human epithelial cells induce human melanocyte growth in vitro but only skin keratinocytes regulate its proper differentiation in the absence of dermis. J Cell Biol, 107(5), 1919-1926

Drew, P., Posnett, J., Rusling, L. and Wound Care Audit, T. (2007). The cost of wound care for a local population in England. Int Wound J, 4(2), 149-155

Driskell, R. R., Clavel, C., Rendl, M. and Watt, F. M. (2011). Hair follicle dermal papilla cells at a glance. J Cell Sci, 124(Pt 8), 1179-1182

Driskell, R. R., Lichtenberger, B. M., Hoste, E., Kretzschmar, K., Simons, B. D., Charalambous, M., .. . Watt, F. M. (2013). Distinct fibroblast lineages determine dermal architecture in skin development and repair. Nature, 504(7479), 277-281

Driskell, R. R., Jahoda, C. A., Chuong, C. M., Watt, F. M. and Horsley, V. (2014). Defining dermal adipose tissue. Exp Dermatol, 23(9), 629-631

Dubey, S. \& Roulin, A. (2014). Evolutionary and biomedical consequences of internal melanins. Pigment Cell Melanoma Res, 27(3), 327-338

Dubovy, P. \& Aldskogius, H. (1996). Degeneration and regeneration of cutaneous sensory nerve formations. Microsc Res Tech, 34(4), 362-375

Dupin, E., Real, C., Glavieux-Pardanaud, C., Vaigot, P. and Le Douarin, N. M. (2003). Reversal of developmental restrictions in neural crest lineages: transition from Schwann cells to glial-melanocytic precursors in vitro. Proc Natl Acad Sci U S A, 100(9), 5229-5233

Eckhart, L., Reinisch, C., Inoue, S., Messner, P., Dockal, M., Mayer, C. and Tschachler, E. (2003). A basement membrane-like matrix formed by cell-released proteins at the medium/air interface supports growth of keratinocytes. Eur J Cell Biol, 82(11), 549-555

Eckhart, L., Lippens, S., Tschachler, E. and Declercq, W. (2013). Cell death by cornification. Biochim Biophys Acta, 1833(12), 3471-3480

Eisinger, M. \& Marko, O. (1982). Selective proliferation of normal human melanocytes in vitro in the presence of phorbol ester and cholera toxin. Proc Natl Acad Sci U S A, 79(6), 2018-2022

el-Harake, W. A., Furman, M. A., Cook, B., Nair, K. S., Kukowski, J. and Brodsky, I. G. (1998). Measurement of dermal collagen synthesis rate in vivo in humans. Am J Physiol, 274(4 Pt 1), E586591

El Ghalbzouri, A. \& Ponec, M. (2004). Diffusible factors released by fibroblasts support epidermal morphogenesis and deposition of basement membrane components. Wound Repair Regen, 12(3), 359-367

English, K. B., Stayner, N., Krueger, G. G. and Tuckett, R. P. (1992). Functional innervation of cultured skin grafts. J Invest Dermatol, 99(2), 120-128

Evans, N. D., Oreffo, R. O., Healy, E., Thurner, P. J. and Man, Y. H. (2013). Epithelial mechanobiology, skin wound healing, and the stem cell niche. J Mech Behav Biomed Mater, 28, 397-409

Fessing, M. Y., Mardaryev, A. N., Gdula, M. R., Sharov, A. A., Sharova, T. Y., Rapisarda, V., . . Botchkarev, V. A. (2011). p63 regulates Satb1 to control tissue-specific chromatin remodeling during development of the epidermis. J Cell Biol, 194(6), 825-839

Festa, E., Fretz, J., Berry, R., Schmidt, B., Rodeheffer, M., Horowitz, M. and Horsley, V. (2011). Adipocyte lineage cells contribute to the skin stem cell niche to drive hair cycling. Cell, 146(5), 761-771

Fortunel, N. O. \& Martin, M. T. (2012). Cellular organization of the human epidermal basal layer: clues sustaining a hierarchical model. Int J Radiat Biol, 88(10), 677-681

Franzen, L., Mathes, C., Hansen, S. and Windbergs, M. (2013a). Advanced chemical imaging and comparison of human and porcine hair follicles for drug delivery by confocal Raman microscopy. J Biomed Opt, 18(6), 061210

Franzen, L., Selzer, D., Fluhr, J. W., Schaefer, U. F. and Windbergs, M. (2013b). Towards drug quantification in human skin with confocal Raman microscopy. Eur J Pharm Biopharm, 84(2), 437-444

Franzen, L., Anderski, J. and Windbergs, M. (2015). Quantitative detection of caffeine in human skin by 
confocal Raman spectroscopy--A systematic in vitro validation study. Eur J Pharm Biopharm, 95(Pt A), 110-116

Fridman, J. S. \& Lowe, S. W. (2003). Control of apoptosis by p53. Oncogene, 22(56), 9030-9040

Gabbiani, G., Chaponnier, C. and Huttner, I. (1978). Cytoplasmic filaments and gap junctions in epithelial cells and myofibroblasts during wound healing. J Cell Biol, 76(3), 561-568

Gay, D., Kwon, O., Zhang, Z., Spata, M., Plikus, M. V., Holler, P. D., . . Cotsarelis, G. (2013). Fgf9 from dermal gammadelta T cells induces hair follicle neogenesis after wounding. Nat Med, 19(7), 916-923

Gelse, K., Poschl, E. and Aigner, T. (2003). Collagens--structure, function, and biosynthesis. Adv Drug Deliv Rev, 55(12), 1531-1546

Gesta, S., Tseng, Y. H. and Kahn, C. R. (2007). Developmental origin of fat: tracking obesity to its source. Cell, 131(2), 242-256

Giralt, M. \& Villarroya, F. (2013). White, brown, beige/brite: different adipose cells for different functions? Endocrinology, 154(9), 2992-3000

Goldgeier, M. H., Klein, L. E., Klein-Angerer, S., Moellmann, G. and Nordlund, J. J. (1984). The distribution of melanocytes in the leptomeninges of the human brain. J Invest Dermatol, 82(3), 235238

Goodman, G. \& Bercovich, D. (2008). Melanin directly converts light for vertebrate metabolic use: heuristic thoughts on birds, Icarus and dark human skin. Med Hypotheses, 71(2), 190-202

Goodwin, A. M. (2007). In vitro assays of angiogenesis for assessment of angiogenic and anti-angiogenic agents. Microvasc Res, 74(2-3), 172-183

Green, H., Kehinde, O. and Thomas, J. (1979). Growth of cultured human epidermal cells into multiple epithelia suitable for grafting. Proc Natl Acad Sci U S A, 76(11), 5665-5668

Grone, A. (2002). Keratinocytes and cytokines. Vet Immunol Immunopathol, 88(1-2), 1-12

Gurtner, G. C., Werner, S., Barrandon, Y. and Longaker, M. T. (2008). Wound repair and regeneration. Nature, 453(7193), 314-321

Haeberle, H., Fujiwara, M., Chuang, J., Medina, M. M., Panditrao, M. V., Bechstedt, S., . . Lumpkin, E. A. (2004). Molecular profiling reveals synaptic release machinery in Merkel cells. Proc Natl Acad Sci U S A, 101(40), 14503-14508

Halaban, R., Ghosh, S. and Baird, A. (1987). bFGF is the putative natural growth factor for human melanocytes. In Vitro Cell Dev Biol, 23(1), 47-52

Hankin, C. S., Knispel, J., Lopes, M., Bronstone, A. and Maus, E. (2012). Clinical and cost efficacy of advanced wound care matrices for venous ulcers. J Manag Care Pharm, 18(5), 375-384

Harding, K., Sumner, M. and Cardinal, M. (2013). A prospective, multicentre, randomised controlled study of human fibroblast-derived dermal substitute (Dermagraft) in patients with venous leg ulcers. Int Wound J, 10(2), 132-137

Hardy, M. H. (1992). The secret life of the hair follicle. Trends Genet, 8(2), 55-61

Harle-Bachor, C. \& Boukamp, P. (1996). Telomerase activity in the regenerative basal layer of the epidermis inhuman skin and in immortal and carcinoma-derived skin keratinocytes. Proc Nat/ Acad Sci U S A, 93(13), 6476-6481

Harrison, C. A., Dalley, A. J. and Mac Neil, S. (2005). A simple in vitro model for investigating epithelial/ mesenchymal interactions: keratinocyte inhibition of fibroblast proliferation and fibronectin synthesis. Wound Repair Regen, 13(6), 543-550

Harrison, C. A., Gossiel, F., Bullock, A. J., Sun, T., Blumsohn, A. and Mac Neil, S. (2006). Investigation of keratinocyte regulation of collagen I synthesis by dermal fibroblasts in a simple in vitro model. Br J Dermatol, 154(3), 401-410

Harvey, K. A., Paranavitana, C. N., Zaloga, G. P. and Siddiqui, R. A. (2007). Diverse signaling pathways regulate fibroblast differentiation and transformation through Rho kinase activation. J Cell Physiol, 211(2), 353-363

Hennings, H., Holbrook, K., Steinert, P. and Yuspa, S. (1980). Growth and differentiation of mouse epidermal cells in culture: effects of extracellular calcium. Curr Probl Dermatol, 10, 3-25

Hensel, H., Andres, K. H. and von During, M. (1974). Structure and function of cold receptors. Pflugers Arch, 352(1), 1-10

Hirobe, T. (1983). Proliferation of epidermal melanocytes during the healing of skin wounds in newborn mice. J Exp Zool, 227(3), 423-431

Houben, E., De Paepe, K. and Rogiers, V. (2007). A keratinocyte's course of life. Skin Pharmacol Physiol, 20(3), 122-132

Huggenberger, R. \& Detmar, M. (2011). The cutaneous vascular system in chronic skin inflammation. J Investig Dermatol Symp Proc, 15(1), 24-32

Huveneers, S. \& Danen, E. H. (2009). Adhesion signaling - crosstalk between integrins, Src and Rho. J Cell Sci, 122(Pt 8), 1059-1069 
Hynes, R. O. (2002). Integrins: bidirectional, allosteric signaling machines. Cell, 110(6), 673-687

Ingber, D. E. (2003). Tensegrity II. How structural networks influence cellular information processing networks. J Cell Sci, 116(Pt 8), 1397-1408

Ito, M., Liu, Y., Yang, Z., Nguyen, J., Liang, F., Morris, R. J. and Cotsarelis, G. (2005). Stem cells in the hair follicle bulge contribute to wound repair but not to homeostasis of the epidermis. Nat Med, 11(12), 1351-1354

Ito, M., Yang, Z., Andl, T., Cui, C., Kim, N., Millar, S. E. and Cotsarelis, G. (2007). Wnt-dependent de novo hair follicle regeneration in adult mouse skin after wounding. Nature, 447(7142), 316-320

Janson, D., Saintigny, G., Mahe, C. and El Ghalbzouri, A. (2013). Papillary fibroblasts differentiate into reticular fibroblasts after prolonged in vitro culture. Exp Dermatol, 22(1), 48-53

Janson, D. G., Saintigny, G., van Adrichem, A., Mahe, C. and El Ghalbzouri, A. (2012). Different gene expression patterns in human papillary and reticular fibroblasts. J Invest Dermatol, 132(11), 2565-2572

Jinno, H., Morozova, O., Jones, K. L., Biernaskie, J. A., Paris, M., Hosokawa, R., . . Miller, F. D. (2010). Convergent genesis of an adult neural crest-like dermal stem cell from distinct developmental origins. Stem Cells, 28(11), 2027-2040

Johansson, J. A. \& Headon, D. J. (2014). Regionalisation of the skin. Semin Cell Dev Biol, 25-26, 3-10

Kang, J., Yoo, J., Lee, S., Tang, W., Aguilar, B., Ramu, S., . . Hong, Y. K. (2010). An exquisite cross-control mechanism among endothelial cell fate regulators directs the plasticity and heterogeneity of lymphatic endothelial cells. Blood, 116(1), 140-150

Kormos, B., Belső, N., Bebes, A., Szabad, G., Bacsa, S., Széll, M., . . . Bata-Csörgő, Z. (2011). In Vitro Dedifferentiation of Melanocytes from Adult Epidermis. PLoS One, 6(2), e17197

Kratz, G. (1998). Modeling of wound healing processes in human skin using tissue culture. Microsc Res Tech, 42(5), 345-350

Krieg, T. \& Aumailley, M. (2011). The extracellular matrix of the dermis: flexible structures with dynamic functions. Exp Dermatol, 20(8), 689-695

Larjava, H., Salo, T., Haapasalmi, K., Kramer, R. H. and Heino, J. (1993). Expression of integrins and basement membrane components by wound keratinocytes. J Clin Invest, 92(3), 1425-1435

Lassalle, M. W., Igarashi, S., Sasaki, M., Wakamatsu, K., Ito, S. and Horikoshi, T. (2003). Effects of melanogenesis-inducing nitric oxide and histamine on the production of eumelanin and pheomelanin in cultured human melanocytes. Pigment Cell Res, 16(1), 81-84

Laurikkala, J., Mikkola, M. L., James, M., Tummers, M., Mills, A. A. and Thesleff, I. (2006). p63 regulates multiple signalling pathways required for ectodermal organogenesis and differentiation. Development, 133(8), 1553-1563

Lebonvallet, N., Boulais, N., Le Gall, C., Pereira, U., Gauché, D., Gobin, E., . . Misery, L. (2012). Effects of the re-innervation of organotypic skin explants on the epidermis. Experimental Dermatology, 21(2), 156-158

Lee, J. H. \& Fisher, D. E. (2014). Melanocyte stem cells as potential therapeutics in skin disorders. Expert Opin Biol Ther, 14(11), 1569-1579

Lee, P., Werner, C. D., Kebebew, E. and Celi, F. S. (2014). Functional thermogenic beige adipogenesis is inducible in human neck fat. Int J Obes (Lond), 38(2), 170-176

Leiros, G. J., Kusinsky, A. G., Drago, H., Bossi, S., Sturla, F., Castellanos, M. L., . . Balana, M. E. (2014). Dermal papilla cells improve the wound healing process and generate hair bud-like structures in grafted skin substitutes using hair follicle stem cells. Stem Cells Trans/ Med, 3(10), 1209-1219

Levrero, M., De Laurenzi, V., Costanzo, A., Gong, J., Wang, J. Y. and Melino, G. (2000). The p53/p63/ p73 family of transcription factors: overlapping and distinct functions. J Cell Sci, 113 ( Pt 10), $1661-1670$

Lidell, M. E., Betz, M. J. and Enerback, S. (2014). Two types of brown adipose tissue in humans. Adipocyte, 3(1), 63-66

Lin, S. J. \& Chuong, C. M. (2011). Toward the isolation and culture of melanocyte stem cells. J Invest Dermatol, 131(12), 2341-2343

Lindholm, C., Bergsten, A. and Berglund, E. (1999). Chronic wounds and nursing care. J Wound Care, 8(1), 5-10

Lindholm, C., Andersson, H., Fossum, B. and Jorbeck, H. (2005). Wounds scrutiny in a Swedish hospital: prevalence, nursing care and bacteriology, including MRSA. J Wound Care, 14(7), 313-319

Mao, Y. \& Baum, B. (2015). Tug of war--the influence of opposing physical forces on epithelial cell morphology. Dev Biol, 401(1), 92-102

Mastrogiannaki, M., Lichtenberger, B. M., Reimer, A., Collins, C. A., Driskell, R. R. and Watt, F. M. (2016). beta-catenin stabilization in skin fibroblasts causes fibrotic lesions by preventing adipocyte differentiation of the reticular dermis. Journal of Investigative Dermatology(Epub ahead of 
print)

Matsumura, T., Yamanaka, T., Hashizume, S., Irie, Y. and Nitta, K. (1975). Tissue dispersion, cell harvest and fluid suspension culture by the use of bacterial neutral protease. Jpn J Exp Med, 45(5), 377-382

Matsusaki, M., Fujimoto, K., Shirakata, Y., Hirakawa, S., Hashimoto, K. and Akashi, M. (2015). Development of full-thickness human skin equivalents with blood and lymph-like capillary networks by cell coating technology. J Biomed Mater Res A, 103(10), 3386-3396

Mauviel, A., Temime, N., Charron, D., Loyau, G. and Pujol, J. P. (1991). Induction of interleukin-1 beta production in human dermal fibroblasts by interleukin-1 alpha and tumor necrosis factor-alpha. Involvement of protein kinase-dependent and adenylate cyclase-dependent regulatory pathways. J Cell Biochem, 47(2), 174-183

McMullan, R., Lax, S., Robertson, V. H., Radford, D. J., Broad, S., Watt, F. M., ... Hotchin, N. A. (2003). Keratinocyte differentiation is regulated by the Rho and ROCK signaling pathway. Curr Biol, 13(24), 2185-2189

Merkel, F. (1875). Tastzellen und Tastkörperchen bei den Hausthieren und beim Menschen. Archiv für mikroskopische Anatomie, 11(1), 636-652

Millar, S. E. (2002). Molecular mechanisms regulating hair follicle development. J Invest Dermatol, $118(2), 216-225$

Minwalla, L., Zhao, Y., Le Poole, I. C., Wickett, R. R. and Boissy, R. E. (2001). Keratinocytes play a role in regulating distribution patterns of recipient melanosomes in vitro. J Invest Dermatol, 117(2), 341-347

Nagase, T., Matsumoto, D., Nagase, M., Yoshimura, K., Shigeura, T., Inoue, M., . . Machida, M. (2007). Neurospheres from human adipose tissue transplanted into cultured mouse embryos can contribute to craniofacial morphogenesis: a preliminary report. J Craniofac Surg, 18(1), 4953; discussion 60-41

Nakatani, M., Maksimovic, S., Baba, Y. and Lumpkin, E. A. (2015). Mechanotransduction in epidermal Merkel cells. Pflugers Arch, 467(1), 101-108

Nanba, D., Toki, F., Matsushita, N., Matsushita, S., Higashiyama, S. and Barrandon, Y. (2013). Actin filament dynamics impacts keratinocyte stem cell maintenance. EMBO Mol Med, 5(4), 640-653

Narisawa, Y., Hashimoto, K., Nihei, Y. and Pietruk, T. (1992). Biological significance of dermal Merkel cells in development of cutaneous nerves in human fetal skin. J Histochem Cytochem, 40(1), 65-71

Natesan, S., Zhang, G., Baer, D. G., Walters, T. J., Christy, R. J. and Suggs, L. J. (2011). A bilayer construct controls adipose-derived stem cell differentiation into endothelial cells and pericytes without growth factor stimulation. Tissue Eng Part A, 17(7-8), 941-953

O'Connor, N., Mulliken, J., Banks-Schlegel, S., Kehinde and Green, H. (1981). Grafting of burns with cultured epithelium prepared from autologous epidermal cells. Lancet, 1(8211), 75-78

Olry, R. \& Haines, D. E. (2000). NEUROwords. 9. Vater, Pacini, Wagner, Meissner, Golgi, Mazzoni, Ruffini, Merkel and Krause: were their nerves all on edge? J Hist Neurosci, 9(3), 311-313

Orphanidou, C., McCargar, L., Birmingham, C. L., Mathieson, J. and Goldner, E. (1994). Accuracy of subcutaneous fat measurement: comparison of skinfold calipers, ultrasound, and computed tomography. J Am Diet Assoc, 94(8), 855-858

Oshima, H., Rochat, A., Kedzia, C., Kobayashi, K. and Barrandon, Y. (2001). Morphogenesis and renewal of hair follicles from adult multipotent stem cells. Cell, 104(2), 233-245

Pan, X., Hobbs, R. P. and Coulombe, P. A. (2013). The expanding significance of keratin intermediate filaments in normal and diseased epithelia. Curr Opin Cell Biol, 25(1), 47-56

Pare, M., Elde, R., Mazurkiewicz, J. E., Smith, A. M. and Rice, F. L. (2001). The Meissner corpuscle revised: a multiafferented mechanoreceptor with nociceptor immunochemical properties. $J$ Neurosci, 21(18), 7236-7246

Park, A., Kim, W. K. and Bae, K. H. (2014). Distinction of white, beige and brown adipocytes derived from mesenchymal stem cells. World J Stem Cells, 6(1), 33-42

Paus, R. \& Cotsarelis, G. (1999). The biology of hair follicles. N Engl J Med, 341(7), 491-497

Pilcher, B. K., Dumin, J. A., Sudbeck, B. D., Krane, S. M., Welgus, H. G. and Parks, W. C. (1997). The activity of collagenase-1 is required for keratinocyte migration on a type I collagen matrix. J Cell Biol, 137(6), 1445-1457

Pittman, R. N. (2011). Chapter 2: The Circulatory System and Oxygen Transport Regulation of Tissue Oxygenation. San Rafael (CA).

Posnett, J., Gottrup, F., Lundgren, H. and Saal, G. (2009). The resource impact of wounds on health-care providers in Europe. J Wound Care, 18(4), 154-161

Potten, C. S. \& Loeffler, M. (1990). Stem cells: attributes, cycles, spirals, pitfalls and uncertainties. Lessons for and from the crypt. Development, 110(4), 1001-1020 
Pozzi, S., Zambelli, F., Merico, D., Pavesi, G., Robert, A., Maltere, P., . . Vigano, M. A. (2009). Transcriptional network of p63 in human keratinocytes. PLoS One, 4(3), e5008

Purves, D., Augustine, G., Fitzpatrick, D. and al., e. (2001). Mechanoreceptors Specialized to Receive Tactile Information. In S. (MA) (Ed.), Neuroscience. 2nd edition: Sinauer Associates.

Querleux, B., Cornillon, C., Jolivet, O. and Bittoun, J. (2002). Anatomy and physiology of subcutaneous adipose tissue by in vivo magnetic resonance imaging and spectroscopy: relationships with sex and presence of cellulite. Skin Res Technol, 8(2), 118-124

Rady, P. L., Cadet, P., Bui, T. K., Tyring, S. K., Baron, S., Stanton, G. J. and Hughes, T. K. (1995). Production of interferon gamma messenger RNA by cells of non-immune origin. Cytokine, 7(8), 793-798

Rakar, J., Krammer, M. P. and Kratz, G. (2015). Human melanocytes mitigate keratinocyte-dependent contraction in an in vitro collagen contraction assay. Burns, 41(5), 1035-1042

Randhawa, M., Huff, T., Valencia, J. C., Younossi, Z., Chandhoke, V., Hearing, V. J. and Baranova, A. (2009). Evidence for the ectopic synthesis of melanin in human adipose tissue. FASEB J, 23(3), 835-843

Real, C., Glavieux-Pardanaud, C., Vaigot, P., Le-Douarin, N. and Dupin, E. (2005). The instability of the neural crest phenotypes: Schwann cells can differentiate into myofibroblasts. Int J Dev Biol, 49(2-3), 151-159

Rees, J. L. (2000). The melanocortin 1 receptor (MC1R): more than just red hair. Pigment Cell Res, 13(3), 135-140

Rheinwald, J. G. \& Green, H. (1975a). Formation of a keratinizing epithelium in culture by a cloned cell line derived from a teratoma. Cell, 6(3), 317-330

Rheinwald, J. G. \& Green, H. (1975b). Serial cultivation of strains of human epidermal keratinocytes: the formation of keratinizing colonies from single cells. Cell, 6(3), 331-343

Rice, J. B., Desai, U., Ristovska, L., Cummings, A. K., Birnbaum, H. G., Skornicki, M., . . Parsons, N. B. (2015). Economic outcomes among Medicare patients receiving bioengineered cellular technologies for treatment of diabetic foot ulcers. J Med Econ, 1-10

Roggenkamp, D., Kopnick, S., Stab, F., Wenck, H., Schmelz, M. and Neufang, G. (2013). Epidermal nerve fibers modulate keratinocyte growth via neuropeptide signaling in an innervated skin model. J Invest Dermatol, 133(6), 1620-1628

Romano, R. A. \& Sinha, S. (2011). Dynamic life of a skin keratinocyte: an intimate tryst with the master regulator p63. Indian J Exp Biol, 49(10), 721-731

Roshan, A., Murai, K., Fowler, J., Simons, B. D., Nikolaidou-Neokosmidou, V. and Jones, P. H. (2016). Human keratinocytes have two interconvertible modes of proliferation. Nat Cell Biol, 18(2), 145-156

Sbarbati, A., Accorsi, D., Benati, D., Marchetti, L., Orsini, G., Rigotti, G. and Panettiere, P. (2010). Subcutaneous adipose tissue classification. Eur J Histochem, 54(4), e48

Schepers, R. J. \& Ringkamp, M. (2010). Thermoreceptors and thermosensitive afferents. Neurosci Biobehav Rev, 34(2), 177-184

Schlader, Z. J., Perry, B. G., Jusoh, M. R., Hodges, L. D., Stannard, S. R. and Mundel, T. (2013). Human temperature regulation when given the opportunity to behave. Eur J Appl Physiol, 113(5), 1291-1301

Schlüter, H., Paquet-Fifield, S., Gangatirkar, P., Li, J. and Kaur, P. (2011). Functional characterization of quiescent keratinocyte stem cells and their progeny reveals a hierarchical organization in human skin epidermis. Stem Cells, 29(8), 1256-1268

Schmidt, B. A. \& Horsley, V. (2013). Intradermal adipocytes mediate fibroblast recruitment during skin wound healing. Development, 140(7), 1517-1527

Sen, C. K., Gordillo, G. M., Roy, S., Kirsner, R., Lambert, L., Hunt, T. K., . . Longaker, M. T. (2009). Human skin wounds: a major and snowballing threat to public health and the economy. Wound Repair Regen, 17(6), 763-771

Serrero, G. \& Mills, D. (1991). Physiological role of epidermal growth factor on adipose tissue development in vivo. Proc Natl Acad Sci U S A, 88(9), 3912-3916

Sidelmann, J. J., Gram, J., Jespersen, J. and Kluft, C. (2000). Fibrin clot formation and lysis: basic mechanisms. Semin Thromb Hemost, 26(6), 605-618

Sieber-Blum, M. \& Grim, M. (2004). The adult hair follicle: cradle for pluripotent neural crest stem cells. Birth Defects Res C Embryo Today, 72(2), 162-172

Singer, A. J. \& Clark, R. A. (1999). Cutaneous wound healing. N Engl J Med, 341(10), 738-746

Skobe, M. \& Detmar, M. (2000). Structure, function, and molecular control of the skin lymphatic system. J Investig Dermatol Symp Proc, 5(1), 14-19

Slominski, A., Wortsman, J., Plonka, P. M., Schallreuter, K. U., Paus, R. and Tobin, D. J. (2005). Hair Follicle Pigmentation. Journal of Investigative Dermatology, 124(1), 13-21

Smith, D. R., Spaulding, D. T., Glenn, H. M. and Fuller, B. B. (2004). The relationship between $\mathrm{Na}+\mathrm{H}+$ 
exchanger expression and tyrosinase activity in human melanocytes. Experimental Cell Research, 298(2), 521-534

Smorlesi, A., Frontini, A., Giordano, A. and Cinti, S. (2012). The adipose organ: white-brown adipocyte plasticity and metabolic inflammation. Obes Rev, 13 Supp/ 2, 83-96

Sorrell, J. M. \& Caplan, A. I. (2009). Fibroblasts-a diverse population at the center of it all. Int Rev Cell Mol Biol, 276, 161-214

Spalding, K. L., Arner, E., Westermark, P. O., Bernard, S., Buchholz, B. A., Bergmann, O., . . Arner, P. (2008). Dynamics of fat cell turnover in humans. Nature, 453(7196), 783-787

Spiegelman, B. M. \& Flier, J. S. (2001). Obesity and the regulation of energy balance. Cell, 104(4), 531543

Stephens, P., Wood, E. J. and Raxworthy, M. J. (1996). Development of a multilayered in vitro model for studying events associated with wound healing. Wound Repair Regen, 4(3), 393-401

Suh, J. M., Zeve, D., McKay, R., Seo, J., Salo, Z., Li, R., . . Graff, J. M. (2007). Adipose Is a Conserved Dosage-Sensitive Antiobesity Gene. Cell Metabolism, 6(3), 195-207

Sun, T. T. \& Green, H. (1976). Differentiation of the epidermal keratinocyte in cell culture: formation of the cornified envelope. Cell, 9(4 Pt 1), 511-521

Swerlick, R. A. (1997). The structure and function of the cutaneous vasculature. J Dermatol, 24(11), 734-738

Tachibana, M. (1999). Sound needs sound melanocytes to be heard. Pigment Cell Res, 12(6), 344-354

Tajima, S. \& Pinnell, S. R. (1981). Collagen synthesis by human skin fibroblasts in culture: studies of fibroblasts explanted from papillary and reticular dermis. J Invest Dermatol, 77(5), 410-412

Thingnes, J., Lavelle, T. J., Hovig, E. and Omholt, S. W. (2012). Understanding the melanocyte distribution in human epidermis: an agent-based computational model approach. PLoS One, 7(7), e40377

Thompson-Torgerson, C. S., Holowatz, L. A. and Kenney, W. L. (2008). Altered mechanisms of thermoregulatory vasoconstriction in aged human skin. Exerc Sport Sci Rev, 36(3), 122-127

Tilling, T., Wladykowski, E., Failla, A. V., Houdek, P., Brandner, J. M. and Moll, I. (2014). Immunohistochemical analyses point to epidermal origin of human Merkel cells. Histochem Cell Biol, 141(4), 407-421

Topol, B., Haimes, H., Dubertret, L. and Bell, E. (1986). Transfer of Melanosomes in a Skin Equivalent Model In Vitro. Journal of Investigative Dermatology, 87(5), 642-647

Torkian, B. A., Yeh, A. T., Engel, R., Sun, C. H., Tromberg, B. J. and Wong, B. J. (2004). Modeling aberrant wound healing using tissue-engineered skin constructs and multiphoton microscopy. Arch Facial Plast Surg, 6(3), 180-187

Tschachler, E., Reinisch, C. M., Mayer, C., Paiha, K., Lassmann, H. and Weninger, W. (2004). Sheet preparations expose the dermal nerve plexus of human skin and render the dermal nerve end organ accessible to extensive analysis. J Invest Dermatol, 122(1), 177-182

Uehara, S., Izumi, Y., Kubo, Y., Wang, C. C., Mineta, K., Ikeo, K., .. Y Yamamoto, H. (2009). Specific expression of Gsta4 in mouse cochlear melanocytes: a novel role for hearing and melanocyte differentiation. Pigment Cell Melanoma Res, 22(1), 111-119

Wabik, A. \& Jones, P. H. (2015). Switching roles: the functional plasticity of adult tissue stem cells. EMBO J, 34(9), 1164-1179

Walker, G. E., Verti, B., Marzullo, P., Savia, G., Mencarelli, M., Zurleni, F., . . Di Blasio, A. M. (2007). Deep subcutaneous adipose tissue: a distinct abdominal adipose depot. Obesity (Silver Spring), 15(8), 1933-1943

Watt, F. M. \& Green, H. (1981). Involucrin synthesis is correlated with cell size in human epidermal cultures. J Cell Biol, 90(3), 738-742

Watt, F. M. \& Green, H. (1982). Stratification and terminal differentiation of cultured epidermal cells. Nature, 295(5848), 434-436

Watt, F. M. \& Jensen, K. B. (2009). Epidermal stem cell diversity and quiescence. EMBO Mol Med, 1(5), 260-267

Weiner, L., Fu, W., Chirico, W. J. and Brissette, J. L. (2014). Skin as a living coloring book: how epithelial cells create patterns of pigmentation. Pigment Cell Melanoma Res, 27(6), 1014-1031

Werner, S. \& Grose, R. (2003). Regulation of wound healing by growth factors and cytokines. Physiol $\operatorname{Rev}, 83(3), 835-870$

Werner, S., Krieg, T. and Smola, H. (2007). Keratinocyte-fibroblast interactions in wound healing. J Invest Dermatol, 127(5), 998-1008

Widera, D., Hauser, S., Kaltschmidt, C. and Kaltschmidt, B. (2012). Origin and regenerative potential of vertebrate mechanoreceptor-associated stem cells. Anat Res Int, 2012, 837626

Woo, S. H., Ranade, S., Weyer, A. D., Dubin, A. E., Baba, Y., Qiu, Z., . . Patapoutian, A. (2014). Piezo2 is required for Merkel-cell mechanotransduction. Nature, 509(7502), 622-626 
Wu, J., Bostrom, P., Sparks, L. M., Ye, L., Choi, J. H., Giang, A. H., . . Spiegelman, B. M. (2012). Beige adipocytes are a distinct type of thermogenic fat cell in mouse and human. Cell, 150(2), 366-376

Wu, X. \& Hammer, J. A. (2014). Melanosome transfer: it is best to give and receive. Curr Opin Cell Biol, 29, 1-7

Yaar, M. \& Gilchrest, B. A. (1991). Human Melanocyte Growth and Differentiation: A Decade of New Data. Journal of Investigative Dermatology, 97(4), 611-617

Yamaguchi, Y., Brenner, M. and Hearing, V. J. (2007). The regulation of skin pigmentation. J Biol Chem, 282(38), 27557-27561

Zecca, L., Zucca, F. A., Wilms, H. and Sulzer, D. (2003). Neuromelanin of the substantia nigra: a neuronal black hole with protective and toxic characteristics. Trends Neurosci, 26(11), 578-580 


\section{GENERAL MATERIALS \& METHODS}

\subsection{Cell culture}

The most substantial confounding factor of any cellular experiment is encompassed by the in vitro effect. It is unclear to what extent cells under culture conditions are different from those in our bodies. The substrate upon which adherent cells are cultured is often rigid polystyrene plastic flasks and petri dishes. The medium that is provided contains an approximation of the nutritional requirements of most cells and a cocktail of supplemented factors known to be important for the cell type, at approximate ratios and concentrations.

\subsubsection{Cell sources \& isolation procedures}

A useful source of cells and a supporting laboratory environment is required to investigate cell behavior in culture. Our lab is fortunate to obtain fibroblasts, endothelial cells, keratinocytes, melanocytes, preadipocytes and vascular smooth muscle cells (VSMC) from resected human skin discarded after surgery. Occasionally, human umbilical vein endothelial cells (HUVEC) and VSMC are obtained from discarded umbilical cords obtained from the neonatal ward, and other cell types can be obtained from other types of discarded tissue (such as bone and cartilage). The cells used for the projects in this thesis are isolated from human skin under aseptic conditions.

\subsubsection{Isolation of fibroblasts}

Rescued skin is rinsed in PBS and trimmed of subcutaneous fat (this may be used for preadipocyte isolation). The lean skin is then cut into manageable pieces (between approximately 2 and $8 \mathrm{~cm}^{2}$ ). Specific dissection of the dermis is then performed by using fine scissors to cut two- to three-hundred $1-3 \mathrm{~mm}^{2}$ pieces and placing them in an enzyme mixture. The enzymes, Collagenase (type I) and Dispase ${ }^{\mathrm{Tm}}$, break down the extracellular matrix during an overnight incubation at $37^{\circ} \mathrm{C}$ after which the cells can be washed, filtered (through 100 $\mu \mathrm{m}$ strainer), and plated at a density of choice (maybe at 5,000 cells $/ \mathrm{cm}^{2}$ ). Basic nutrients are provided by DMEM to avoid starvation during the incubation.

Fibroblasts are normally cultured in DMEM with 10\% FCS (v/v) and antibiotics $(50 \mathrm{U} / \mathrm{ml}$ penicillin and $50 \mu \mathrm{g} / \mathrm{ml}$ streptomycin). 


\subsubsection{Isolation of keratinocytes}

Rescued skin is rinsed in PBS and trimmed of subcutaneous fat (this may again be used for preadipocyte isolation). The lean skin is then cut into small pieces (preferably strips of $4 \times 10 \mathrm{~mm}$ ) containing dermis and epidermis. Incubation with Dispase allows the epidermis to be pulled away from the dermis (at this stage the dermis may be used for fibroblast isolation). The small pieces of epidermis are finely cut into a fairly homogenous sludge and this is further incubated in trypsin to cause cell release. This procedure inadvertently removes most terminally differentiated keratinocytes and causes a selection of proliferating keratinocytes (transit amplifying population).

Keratinocytes are normally cultured in KSFM (keratiniocyte serum-free medium) supplemented with bovine pituitary extract, EGF, and antibiotics.

\subsubsection{Isolation of preadipocytes}

The subcutaneous fat is dissected from below the dermis and minced by scissors. Thirty-minute incubation in trypsin is sufficient to dissociate adherent cells from the ECM around the fat lobules. These fibroblastic cells are strained through $100 \mu \mathrm{m}$ filter, washed and plated.

Preadipocytes are cultured in preadipocyte maintenance medium (PAM) consisting of DMEM/F12 (1:1) with 10\% FCS and antibiotics. 


\subsubsection{Isolation of melanocytes}

Melanocytes are isolated by mincing the epidermal layer, followed by incubation in Trypsin-EDTA (1:1) for $40 \mathrm{~min}$ at $37^{\circ} \mathrm{C}$ while continuously stirring the suspension. The tissue is allowed to sediment and the supernatant collected and plated.

Melanocytes are cultured in melanocyte growth medium (MGM) containing PC-1 base medium supplemented with 2\% PC-1 Sterile Supplement, 1\% L-glutamine, $5 \mathrm{ng} / \mathrm{ml} \mathrm{FGF2,} 246 \mu \mathrm{g} / \mathrm{ml} \mathrm{dbAMP}$, and antibiotics.

\subsubsection{Ethical approval}

Use of human material in research is normally subject to approval from the board of ethics. However, the use of de-identified tissue rescued from being discarded after surgery is allowed without expressed informed consent, and does not require explicit ethical approval. The three defining characteristics of such material is 1) that the source cannot be traced back from the obtained materials (all identifying data is removed and blinded to researchers); 2) the rescue of the tissue material had no bearing on the surgical procedure and would otherwise be destroyed; and, 3) no biobank may be created for systematic long-term storage of cells. The use of rescued material is important for obtaining primary human cells suitable for cell and tissue research. The laws and guidelines can be found through the board of ethics for human material at Linköping University and the County council of the Region of Östergötland.

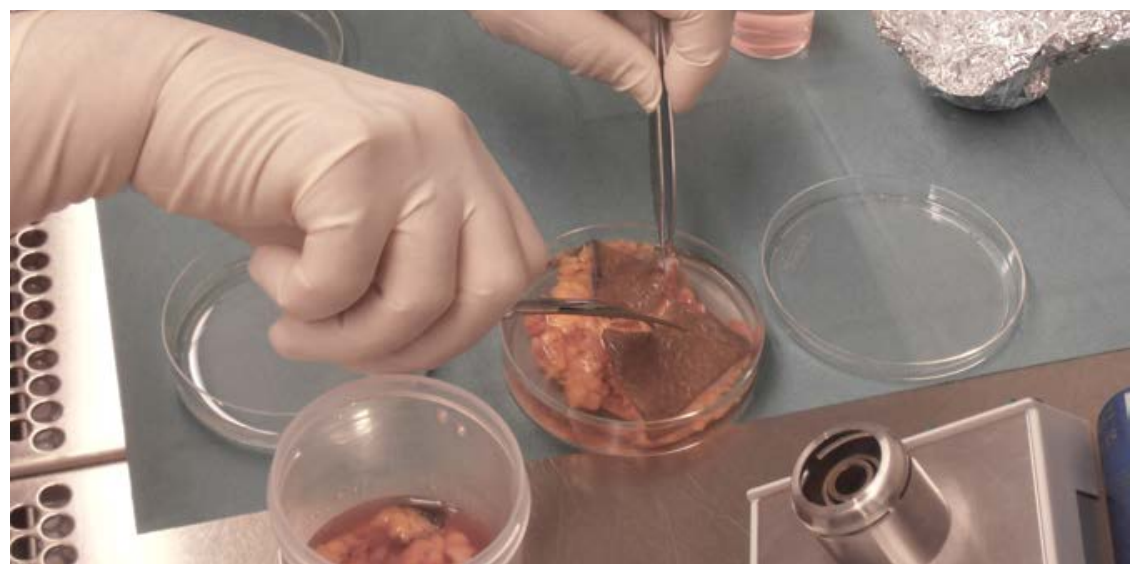

Hands preparing a human skin sample for cell isolation. 


\subsection{Preparation of skin models}

\subsubsection{Using collagen hydrogels}

Collagen gels were usually cast in 12-well plate inserts, or other formats, after mixing bovine collagen type I or rat tail collagen type I (between 3 and $5 \mathrm{mg} /$ $\mathrm{ml}$ ) with either 10X PBS or cells suspended in growth medium. The solution gelled by titration with $\mathrm{NaOH}$ and incubating at $37^{\circ} \mathrm{C}$ for an hour. Several modifications have been attempted by changing cell combinations and numbers inside and outside the gels. A diverse range of molecular constituents have been tried, such as coating the surface with, or embedding in the gel, collagen IV, fibrinogen and thrombin, fibronectin, elastin, hyaluronic acid, microcarriers and other molecules.

The media used depends on the cell types, but combinations of standard growth media (such as PAM/MGM 1:1 for melanocyte and preadipocyte co-cultures) have been easy to consider. In several cases we formulated new media to attempt to create improvements to the epidermal or dermal compartments.

\subsubsection{Human skin in vitro}

Human skin is rinsed and dissected into uniform samples, subcutis usually removed to extend feasibility in culture and other features, such as scars or hairs, are noted/selected for each sample piece (matched/grouped as required). The tissue is kept in DMEM with serum and antibiotics, and is viable for at least three weeks. Modifications or treatments are readily introduced to the model.

For standard-wound studies, we used a $3 \mathrm{~mm}$ biopsy punch to create a full-thickness wound. The wound site is then excised from the sample using a $6 \mathrm{~mm}$ biopsy punch, with the wound centered. The wounds can be kept submerged or at the air-liquid interface. Re-epithelialization occurs within 14 days. 


\subsection{Microscopy}

We predominantly use three types of microscopy: phase-contrast for viewing cell cultures, fluorescence microscopy for viewing antibody-stained cultures and thin slices, and confocal fluorescence microscopy for viewing thicker slices of tissue stained with fluorescent antibodies. We have used Olympus IX-51 for light microscopy, fitted with binocular lenses and 4X, 10X, 20X and 40X planar objectives with the option of a green-tint filter for contrast enhancement. The inverted microscope is suitable for observing cell cultures, and is also fitted with dual Eppendorf micromanipulators for single-cell handling of living cells. Occasionally, the filter cubes from the fluorescence microscope have been mounted together with its light-source to view transfected or stained living cells in culture. The objectives are not optimized for fluorescence viewing, but non-borderline fluorescence can be subjectively judged anyway. We use an Olympus BX-71 microscope with binocular lenses and 2X and 4X planar objectives, and 10X, 20X and 40X fluorescence objectives and a 100X oil-immersion fluorescence objective. The light-source is changed after every 200 hours of use. This upright microscope is fitted with three Olympus fluorescence filter cubes, configured for highpass excitation and bandpass emission detection around UV, green and red fluorescence wavelengths (typically DAPI, FITC and TRITC). Both the upright and the inverted microscopes are fitted with an Olympus DP-70 CCD camera each, controlled by a PC running Olympus control software used to take digital photographs.

While using confocal microscopy sparingly, we have access to an LM Zeiss fitted with 10X, 20X, 40X, 60X and 100X objectives. The system is controlled by Zeiss Zen software, and digital photographs and stacks are analyzed in ImageJ. We did not use this microscope as often as we would have wanted.

We also have access to electron microscopy, but we have only used the scanning electron microscope a few times, supervised. Hopefully, we can have supervised access to a transmission electron microscope to complete Paper IV. 


\subsection{Protein expression and analysis}

Detection of protein is instrumental to the characterization of cells. Indirect immunofluorescence, or immunohistochemistry (IHC), utilizes antibodies against specific proteins, and anti-antibody antibodies (secondary antibodies) conjugated with specific fluorochromes detectable through fluorescence microscopy. We use secondary antibodies from Goat, targeting mouse or rabbit primary antibodies raised against human-reactive antigens. This allows two-color IHC as well as DAPI for triple-staining assays.

Analysis of IHC is a subjective matter. We do not try to quantify the fluorescence because of the inherent sources of errors of such quantification. Instead, we rely on judgement of the qualitative expression of proteins based on fluorescence signal. Digital thresholding can be used, as we did in Paper II, to define the minimum pixel intensity for a positive signal. Viewing samples in such a way that the background is clearly visible helps to determine signal from autofluorescence. Our filter for green fluorescence (488) allows some longer wavelengths to penetrate, meaning that autofluorescence is easily distinguished from the ALEXA-signal by the hue of green (longer wavelengths red-shift the hue to become more yellowish-green or brown-green). The red channel does not have the same discriminatory power. However, looking at the background in both channels allows a fair estimation of autofluorescence, as long as the assumption is true of more-or-less uniform autofluorescence across both ranges of wavelengths.

The most difficult task is to judge primary antibody specificity. Some staining patterns are characteristic of unspecific staining (such as the cornified envelope of skin sections, or the nuclear staining of certain necrotic cultures). Using a positive control is recommended, but not always possible. Instead, using different antibodies for similar markers (or different markers for the same cell) allows judgement by consensus staining (we used both anti-MiTF and anti-tyrosinase to find melanocytes).

On occasion, IHC findings are confirmed using Western Blotting (WB). The papers included in this thesis do not present such results, but the presence of PPARg, Sox9 and Runx2 was confirmed post-publication in the differentiated fibroblast cultures (paper I), using WB-verified antibodies. We also used WB to confirm knock-down of NRSF/REST using lipid-transfected siRNA in fibroblasts during investigations into neuronal differentiation (unpublished data). 


\subsection{Gene expression analysis}

The central dogma states that DNA is transcribed into genes, cleaned up to become message RNA (mRNA), which is translated into amino acid sequences, that fold into proteins. The methods of detecting specific mRNA are simpler than detecting specific active DNA sites or specific proteins. Finding mRNA indicates that the gene is actively transcribed, and that the protein might be produced. However, finding the gene does not prove that the cells contain the finished protein, and this is a weakness of gene expression analysis when trying to extrapolate to cellular phenotype.

While protein detection requires specific antibodies created in animals (or analogue systems), the synthesis of primers and probes to detect mRNA through hybridization is a more industrially feasible method. Synthesis of polynucleotides allows specific sequences to be manufactured. These can be used as specific oligomers attached to a microarray substrate to interrogate an RNA extract for several complementary sequences simultaneously, or to create primer pairs and probes for use in PCR (qRT2-PCR; real-time, reverse transcriptase, semi-quantitative PCR is implied in this text).

Microarray technology allows probing of several thousand mRNA sequences simultaneously, while PCR is limited to a few multiplexed reactions. We used Affymetrix HuGene 1.0ST full expression arrays that probed nearly thirty thousand genes at once, and used Applied Biosystems 7500HT fast reactions with TaqMan assays in single-plex PCR.

An endogeneous control is needed in semi-quantitative PCR, to normalize cDNA amounts in each reactions. The assumption is that each cell, across samples, expresses this gene to the same extent. Based on a series of experiments that tested several endogenous controls for a number of samples, as we set up our PCR method, our choice of hydroxymethyl-bilane synthase (HMBS) has stuck with us. Ideally, we should repeat these experiments again, to make sure that the gene is stable under our current culture paradigms. 


\subsection{General data analysis and statistics}

We have used statistical methods to describe our data and draw conclusions from it, and we have usually relied on GraphPad Prism software to perform the mathematics. A number of assumptions are generally pervasive in our experiments and should at least be acknowledged. Most notable is that a 95\% confidence interval, or a p-value less than 0.05 , can be considered significant. The measure signifies that the value obtained is within the true distribution of the variable, to a given certainty of $95 \%$. In a simplified case, this means that the statistical variation of 100 measurements should be equal to the distribution of the population variability, resulting in the true average. This can be used to compare two or more groups by statistically testing if the data in each group describes the same variation.

We use Student's t-test and ANOVA, with multiple-testing corrections when applicable. Mann-Whitney and Kruskal-Wallis tests are used when the data is not considered Gaussian. We tend to prefer non-parametric testing to avoid another pervasive assumption in biology: that biological variables are always normally distributed. In principle, a biological trait is seen as varying normally around the true mean, resulting in a normal distribution. However, there is little reason to assume a normal distribution when tests for normality are available. Non-parametric tests tend to be stricter than parametric, so erring on the side of caution may instead dictate assuming no normal distribution.

Regardless of these assumptions on statistical distribution, the larger question is to what extent statistical significance is reflected in biological significance. A statistical difference in epidermal thickness may not necessarily mean that the difference has any useful meaning for the biological system. Similarly, using fold-change cut-off of 2 in gene expression is based on convention, and not on actual biological relevance.

Given the often questionable meaning of significance and the sometimes arbitrary application of statistical methods, and considering the prevalent insufficient use of them in biology, perhaps it is best to apply statistics sparingly and descriptively. In the service of mass data-sets, such as bioinformatics and the different omics, a more advanced and detailed use of statistics is undeniably necessary, but in reports such as most of the ones included in this thesis we ought to continue to keep things as simple as possible. 


\section{Errors and control}

Hypothesis testing relies on the correct interpretation of results. A single data-point is dependent on errors accrued over all steps of the experimental procedure. Errors are systematic or random by either being built into the experiment design (or lack thereof), or varying through stochastic events during the experimental procedures and measurements. Technical errors relate to the physics of the methods and biological errors relate to the unaccounted for biological differences and variations inherent to the materials.

In general, we strive to include both positive and negative controls for variables in any given experiment to ensure that comparisons can be made with an appreciation for the range of the variable. This is especially important in qualitative or semi-quantitative analyses, and also provides a comparative measurement for the efficacy of the chosen method in relation to alternatives or variations described in other scientific literature. Checkpoint analyses are also used in many cases, involving sacrificing some material after important procedural steps to evaluate the quality of the material before proceeding with further methods.

Overcoming biological variation can be difficult. In cell cultures, each cell contributes to the final results but cell-specific variations are usually averaged out by the sheer number of cells included in the sample. In some cell samples, there can exist small sub-populations such as contaminant cell types that have radically different phenotypes which, while in a minority, significantly pollutes the sample results. Conversely, judging the results of a specific treatment on a cell sample may be offset by the averaging-effect. It may be impossible to know if a small sub-set of cells respond vigorously, or if all of the cells respond only slightly to the treatment.

Biological variations inherent to the source, that is individual variation, can also be difficult to control for or quantify. In some cases, it is pertinent to use only one individual as a source of cells to ensure that the biological background remains the same. Another way to solve this is by repeating the experiments for several unique biological sources and instead obtain an appreciation of the variation as it relates to biological background. The down-side to this approach is knowing how many individuals are enough to provide a reasonable estimation of the universality of the end-results. In certain cases, it may be useful to pool cells from different sources, or even cell samples prior to analysis, but doing so also risks hiding errors and biases that could be of interest.

Knowledge of methods needs to be deep enough that there is an understanding of which controls are required to minimize the confounding effects of expected errors. Technical specifications for advanced machines usually relate sensitivi- 
ty/resolution, ranges and thresholds of detection, and this is considered during the experiment pipeline design. Technical replicates are commonly used to allow averaging out the variation inherent to the measurements of these machines, but can also be used to average out errors relating to sample preparation depending on the relative contribution of each error to the data variation.

This one data-point, coupled to so many errors, only becomes meaningful as part of a data-set. Replicates create a population of data-points that hopefully hover around a true average. Systematic errors bias the experimental population average and can only really be controlled by running different types of experiments, with differently prepared samples, aimed at answering the same questions. Ultimately, systematic errors are made evident only by analyzing study replications performed by other groups of scientists at other lab sites, with no human or technical resource overlap. 


\section{DISCUSSIONS OF PAPERS \\ - Considerations and ideas}

$\infty$

The following section expands on the motivation behind each study included in this thesis and their main findings. Considerations relating to the results and the methodology are also discussed here, including suggestions for progress. To review the full results and conclusions, please refer to each paper attached to the end of this thesis. 


\section{Paper I: Fibroblast phenotype shifts}

Interpreted gene expression of human dermal fibroblasts after adipo-, chondro-, and osteogenic phenotype shifts

J. Rakar et al., Differentiation, 2012

Motivation and aim: to investigate gene expression changes of induced fibroblast phenotypes ${ }^{11}$ in replicated differentiation studies.

There has been relatively little research done on the medium-induced differentiation of fibroblasts. In general, the view of the terminally differentiated state of fibroblasts has been so engrained that fibroblasts are more common as negative controls in studies of MSC differentiation.

The cell isolation, culture and differentiation methods used are direct replications of previous research, with unique sample origins. The use of immunohistochemical methods reflects their use in previous studies, with a large degree of overlap in antibody clones. To this extent, results were in concordance with the replicated study. The selection of protein markers was biased towards functional proteins, not CD markers. This was motivated by a philosophy of looking for functional changes and not just profile changes to the phenotype.

We continued to investigate the gene expression patterns in each group using semi-quantitative real-time reverse transcriptase polymerase chain reaction (qRT2-PCR; forthwith abbreviated: PCR), for a selection of genes, and Affymetrix HuGene 1.0ST full transcript microarray, for all mRNA in the samples. The assay selection for PCR afforded us a degree of confirmation of immunohistochemical findings, as well as for the microarray findings. Cross-checking results using different methods at different biological levels strengthened the trustworthiness of our findings but also highlighted certain discrepancies.

Much of our efforts were targeting the key regulating transcription factors relevant for the target lineages. For chondrogenic differentiation we were looking for SOX9 (Sox9), for osteogenic differentiation we were looking for RUNX2 (Runx2/Cbfa1) and for adipogenic differentiation we were looking for PPARG $(\operatorname{PPAR} \gamma)$. We checked for these at the gene and protein levels, but we did not always obtain coherent gene expression findings with both PCR and the microarray.

While these findings were very interesting, it also became clear that the expression profiles of differentiated fibroblasts and those of the positive controls were not the same. Given our previous publications that explored the differentiation

11. We included endothelial differentiation at the outset, but soon decided to split the endothelial differentiation into a separate paper due to the availability of additional experiments that had been performed in parallel (Junker et al., 2013). 
capacity of fibroblasts at a qualitative level, we had decided to have a look at the gene expression landscape of these cells. While we naively intended to use the gene expression methods to further prove the efficacy of the differentiation we instead discovered a much more complex reality. We revised the way we looked at the differentiation to instead see it as a phenotype shift, softening the categorical expectations implied by the term differentiation (or transdifferentiation) while adhering to the idea of a primed phenotypic continuum.

\section{Considerations in microarray analysis}

The interesting, and frustrating, part of this project was the microarray dataset. The raw .CEL-file data was imported into Agilent GeneSpring GX and analyzed in several different ways before finding a suitable approach to reaching biologically interesting indicators. We opted for RMA16 normalization, primarily based on Affymetrix recommendations and scientific literature; other options, such as MAS5, provided overlapping datasets that were similar but not identical. We set a 20th percentile threshold on noise as recommended by Affymetrix. When compared, the threshold had little effect on the overall gene set enrichment interpretations that were later obtained, but did influence the presence of a number of genes.

We compared the positive references and the induced fibroblast group with the control fibroblasts, then constructed separate Venn diagrams showing the gene set comparison overlaps separated into up- and down-regulated genes. This was done for each of the differentiation lineages: adipocytes, osteoblasts and chondrocytes. We also checked the data using direct comparisons between induced fibroblasts and reference cells, as well as checking the effects of multiple testing.

We concluded that the additional statistical treatment of gene sets did not add reliability to the results, merely confounded the procedure, so we opted for the simpler approach. The focus remained on the data sets as separated by the Venn diagrams, and these were fed into gene set enrichment analyses against transcription factor databases, pathway databases and Gene Ontology.

\section{Comments on gene expression fold-changes}

It was evident quite early on that most of the genes found in both PCR and microarray were directionally coherent, but showing different levels of foldchange. Part of the explanation is the difference in dynamic range of the methods, the differently destructive data treatment in both cases and the differences in the represented sample pool.

The Affymetrix scanner has 1024 theoretical levels of signal detection at each 
probe (16-bit ${ }^{12}$ ), but the probe-set clustering performs an early averaging that quantifies the gene of interest. It is unclear how the run-to-run variation compares to the detection range, but it is likely that any given hybridization will only use a portion of the 1024-step range owing to differences in minimal and maximal staining.

In contrast, the Applied Biosystems 7500HT fast thermal cycler, while supporting 9 logs of linear dynamic range ${ }^{13}$ (512 levels), detects the TaqMan signal and normalizes against ROX dye in a single assay, then we calibrate the signal to a housekeeper assay to obtain comparable relative expression levels. The reliance on a single endogenous control introduces an unquantified reference bias. This is also hampered by run-to-run variation, but the preceding steps are quite different and more focused for each single assay than in a microarray.

The PCR fold-change calculation, based on a theoretical doubling at each cycle, becomes over-predictive since the efficiency is not $100 \%$ in practice. Some early calculations showed amplification typically between 1.97- and 1.99-fold per cycle instead of 2-fold, for some tested genes. At 10 cycles that can show overestimation of more than $10 \%$ for 1.99 efficiency, or more than $30 \%$ for 1.97 efficiency using the $\Delta \Delta \mathrm{C}^{\mathrm{q}}$ method (2ycle difference).

The PCR was afforded many more sample cultures, and at different timepoints, giving more robust evidence for gene expression changes compared to the two cultures per group that were used in the microarray. These differences in procedures explain much of the variation between expression analyses using PCR and microarray. Both methods will detect up- or down-regulation (above threshold) which is why directional coherence was considered a methodological validation, and we accept that the true relative expression value is not necessarily represented by our fold-change numbers. This application of PCR becomes semi-quantitative at best, and significantly indicative at worst.

\section{Adipocytes}

The control adipocytes, differentiated from primary preadipocytes, were by far our best positive controls. The phenotype was easy to identify, the markers were easily detectable and the number of regulated genes were higher versus control fibroblasts than the other two reference groups (osteoblasts and chondrocytes). The results are of course discussed in more detail in the original paper.

Our main observation was that all three up-regulated gene sets showed GSEA

12. http://media.affymetrix.com/support/technical/datasheets/scanner3000_datasheet.pdf

13. https://tools.thermofisher.com/content/sfs/brochures/cms_072493.pdf 
results relating to adipogenesis and associated metabolism. This indicated to us that there were different genes up-regulated in induced and reference groups that were related to the same functions. That may be explained both by the different starting configurations of preadipocytes and fibroblasts when initiating adipogenesis, and by different genes that can result in similar functions. Differences in IGF receptor family may account for some of these effects.

Key elements of adipogenesis, such as CEBP-family and PPARG, were indirectly found in induced groups, and more directly in references. The key regulator PPARG fell below the 2-fold cut off, but was higher in induced than control fibroblasts. Maintaining a 2-fold cut off was a choice of consistency and adherence to norms, but does not necessarily represent a biologically valid choice. Furthermore, the use of GSEA meant that robust results are less sensitive to the cut off choice.

\section{Osteoblasts}

The osteoblast reference group was difficult to evaluate. We found that most GSEA terms (GO and pathways) relating to chromatin and DNA conformation changes and cell cycle differences. We found support in the scientific literature that such changes are related to the state of osteoblasts. Many common genes were related to bone mineralization and ossification, and we found activity relating to TCF3 which may function as an osteogenic driver through canonical Wnt-signaling (W. Liu et al., 2013). We also found NR3C1-related activity which may relate to the induction with Dexamethasone, and its effect on osteogenesis (Rauch et al., 2011).

An interesting find in the osteoblast references was the up-regulation of PPARG compared to fibroblasts. Both adipogenic and osteogenic induced fibroblasts shared approximate $50 \%$ of their up-regulated genes. While we expected some sort of inversely regulated gene patterns between adipogenesis and osteogenesis (James, 2013), we instead found many similarities. About 30 of the genes more highly expressed in reference osteoblasts were also shared with adipocytes, comparable to their respective induced fibroblasts (unpublished data). For the induced cultures, the number of shared up-regulated genes was almost 60 . Half of the genes down-regulated in reference osteoblasts were also shared with reference adipocytes but the adipocytes showed so many more differentially regulated genes that the intersect only accounted for $20 \%$ of that reference group.

Taken together, this indicates weaknesses in the osteoblast reference group in terms of the osteoblast phenotype, perhaps on account of functional dedifferentiation. It is also likely that similarities in induction, such as the use of Dexamethasone, resulted in similar expression changes. 


\section{Chondrocytes}

Out of the three induced shifts, the chondrocyte induction provided the least convincing GSEA results. While the PCR, the IHC and the Alcian Blue staining all showed positive results, the differential gene regulation seemed impoverished, owing to the mere 14 genes that both the induced group and the reference chondrocyte group had commonly up-regulated compared to control fibroblasts. These included genes related to the transcriptional repressors BACH1/2 (Oyake et al., 1996), and adipogenic/PPAR signaling pathways. Surprisingly, genes relating to adipogenic pathways were up-regulated in all three sets.

The degree of dedifferentiation of the chondrocyte culture was not ascertained, but the induction of chondrogenesis overall resulted in a greater degree of down-regulation events than up-regulations, and greater than in both osteogenic and adipogenic induced groups. Expression of JUN, a $\beta$-catenin target, may be sufficient to induce dedifferentiation of chondrocytes (Ryu et al., 2002), which may support the idea of dedifferentiation in both groups. The actions of beta-catenin are reportedly paradoxical, enhancing and counteracting chondrogenesis in different settings (Kirton et al., 2007). It is also known to regulate adipogenesis, although the context here is too uncertain as to speculate on whether JUN activity could cause both dedifferentiation in chondrocytes and increases in adipogenic genes of the same groups. The control fibroblasts showed higher expression of DACT1 compared to all other groups, a $\beta$-catenin antagonist. We also found that FARP1 was more expressed in control fibroblasts than chondrocyte references (Koyano et al., 1997), further suggesting dedifferentiated chondrocytes.

We expected more chondrocyte-relevant genes to appear in our analysis, such as SOX5, 6, and 9, but as noted in the discussion of the paper, several genes (FMOD, BGN, FN) including SOX9 are already expressed in fibroblasts and may not be further up-regulated by chondrogenic stimuli. None of these SOXes were even found either up- or down-regulated in chondrocytes compared to control fibroblasts.

\section{Fibroblasts}

The human dermal fibroblasts show a very broad repertoire of signaling readiness, ready to adapt to many different types of signaling such as retinoic acid binding, neural growth factor, Activin A, TGF- $\beta$, TNF. The results also indicate expression of several transcription factor networks, including key regulators for most mesodermal lineages, leading us to conclude some evidence of lineage priming. The mesodermal identity is broadly detectable in the fibroblasts, and again motivates the question of their relation with MSC/pericytes. 
We did not properly take into account the differences between papillary and reticular fibroblasts (D. G. Janson et al., 2012), so our data is an agglomeration of their gene expression patterns. This may profoundly affect the interpretation and validity of our study, particular in our discussion of fibroblasts (and consequently figure 5 of the paper). Knowing that a sub-set of fibroblasts may have a developmental disposition, or conversely a lineage restriction, that directly relates to adipogenic differentiation probably weakens the relevance of our study design. Future study replications should consider taking into account some differential markers (Driskell et al., 2013), and look at the distribution of these among the cultures.

The fibroblast, being both ubiquitous and mundane, may be subject to a comparatively benign amount of genomic regulation during stages of human development. Consider that cells busy with tissue development during the division of germ layers, and further on during lineage specification, all need supportive environments in the form of specialized stroma with physical and chemical supporting cues. To what extent would an embryonic fibroblast, charged with supporting a K8/18 primordial epithelium, need to differ from a mature dermal fibroblast, charged with supporting a K5/14 basal keratinocyte?

There may be significant energy savings for an organism in having a minimally restricted phenotype that adapts to its stricter controlled surroundings. Such a state of liberal regulation may also have evolutionary advantages in a population context (Lorenzi et al., 2015), and such developmental cell regulation may even provide a source of redundancy, aiding in situations of tissue deficiency. Fibroblasts produce and maintain extracellular matrix, and maintain a signaling homeostasis with neighboring tissues that have other specific tasks to perform. Experiments focused on characterizing the epigenetic landscape are needed to explore this hypothesis further.

\section{Evaluating differentiation}

Finally, it seems clear that some IHC and histological stains are not sufficient to evaluate a differentiation. To show multilineage differentiation we need to develop more informative palettes of techniques. Trends in phenotypes, such as those seen in the induced fibroblast groups, are sufficient to show some degree of differentiation but it seems obvious that we should invest more effort in finding better differentiation stimuli and growth conditions. Using gene set comparisons as we have done is a useful way to look at overlapping gene expression.

A big problem with this approach is to figure out what the differences in starting population means to the gene expression profiles, and to select appropriate reference groups. Trying to find ways of dealing with relative comparisons 
leads to the problem with cellular identity. No matter which cultures we use as reference cells, we will always fall short in understanding the differences in initial states, and the resultant differentiated states. Perhaps focusing on regulation of function together with the genetic cascades that support functional specification will allow us to define biologically relevant events, that can be translated into clinical use somewhere down the road. 


\section{Paper II: Microcarriers in re-epithelialization}

Biodegradable gelatin microcarriers facilitate re-epithelialization of human cutaneous wounds - an in vitro study in human skin

S. Lönnqvist et al., PLoS ONE, 2015

There are a few ways of going about investigating different aspects of wound-healing in humans. The most straight-forward approach is to perform a clinical study, and the simplest approach is to use cell culture experiments. Neither approach is perfect. Clinical experimentation is cumbersome and limited by the safety and discomfort of the subjects; the materials available for analyses become severely limited.

The cell culture approach is instead severely lacking in complexity, meaning that while any number of cells are available for analyses, the results will not be representative for what happens in a wound environment. In summary, skin models are necessary to probe deeper into skin biology. A very useful model was used in this paper: standardized wounds in excised, viable, human skin in vitro. It contains all the components of the dermis and epidermis in a native configuration.

The process of re-epithelialization is important for proper closure of a skin wound, and is aberrant in cases of chronic wounds. Can the application of a non-static biodegradable (and FDA approved) scaffold aid the process? We used microcarriers as the scaffold and looked for the answer by staining and quantifying the extent of re-epithelialization in the excised human skin model. Previous research on the microcarriers showed positive effects when combined with cells in a wound-setting, but there was no previous data on the effects of the microcarriers alone.

\section{Quality of re-epithelialization}

We found a significantly thicker neoepidermis, on average, formed in wounds with microcarriers. We believe that the pores of the microcarriers create a larger surface area than the wound bed itself, while not being as flat, which creates a seemingly thicker neoepidermis as the keratinocytes populate the material.

One major concern with the morphological features of the material-assisted neoepidermis is the uncertainty of the effect of the seemingly irregular surface on its permeability, compared to a normal neoepidermis. Since we used vertical sections (perpendicular to the tissue surface) we have very limited information on the uniformity of the wound bed covering. It is conceivable that small areas between or through the material are not fully covered by keratinocytes, potentially impacting the development of the epidermis in the short-term. While we have seen no particular evidence to this effect, we are still unable to 
rule it out, especially given the non-uniform pancytokeratin staining in the vertical sections.

Methods for viewing the wound surface, or carefully selected transverse sections, might provide more information on the neoepidermal topography. A series of approximately thirty thick vertical sections of about $100 \mu \mathrm{m}$ might also be an option for creating high resolution confocal imaging stacks across the whole wound area, allowing a 3D-rendering to be constructed.

The model was investigated over a week, which allowed full neoepidermal covering, but this was not enough time to see how the histology might look after full resorption of the material. The assumption, based on the polarity of keratinocytes, is that the neoepidermis would eventually reorganize into a normal epidermis. The basal layer components would simultaneously become contiguous through the healed area. Further experimentation would indicate whether these assumptions are correct, and how other components, such as the melanocytes and pigmentation, are affected by the material-assisted healing.

\section{Limits and development of the excised skin model}

Using real human skin has the obvious drawback of limited availability. It is also impossible to properly control many of the basic factors of the model, as the particulars of the skin vary between individuals, operating procedures, and anatomical source. There may also be questions of biosafety, in terms of viral load or microorganism colonization, that can be difficult to ascertain.

The tissue includes tissue resident immune cells, but to what extent they remain unchallenged is not yet determined. A more thorough investigation of the prevalence of immune cells may add valuable knowledge about their potential for activation as well as their activity during the wound-creation and contributions to the healing phases.

The lack of a circulatory system hinders the proper formation of a blood-clot which may have a biologically relevant impact on the normal progression of wound healing. Analyzing differences in the healing progression of wounds at different depths of the skin might provide more information about the model's limits. It would be especially interesting to ascertain how neovascularization occurs in the sub-epidermal capillary bed, in terms of speed and organization. The lack of significant bleeding may interfere with normal progression.

Conceivably, the model may be constructed around a fenestrated tube, through which serum-containing media is pumped using a more advanced bioreactor system. This may provide a mode through which controlled delivery of substances may mimic physiological blood-flow into the skin. Other culture configurations could be considered that allowed for co-culture systems that in- 
clude immune cells, allowing soluble factors to be exchanged with the wounded area.

The model is still early in development, but with additional characterization it may become a very useful tool for studying aspects of skin biology.

\section{Microcarriers}

The enhanced re-epithelialization is linked to the use of the microcarriers. The lack of additional bioactive agents and cells shows that the material, and its configuration, are responsible for facilitating this neoepidermal organization. As with previous studies, we observe that the gelatin material, in this microspherical and porous configuration, is both biocompatible and biodegradeable in conjunction with human tissue.

The application of microcarriers to the wound was relatively unrefined. The material was added with minimal fluid, at high concentration, to saturate the wound void. In some cases, the added material was washed away by the medium surrounding the excised skin in culture, resulting in few microcarriers remaining in the wound. The particulate nature of the material solution is amenable to pipetting and injection, but lacks internal stabilizing capacity without addition of molecular glue, enzymes that expose sticky ends of collagen (gelatin), or cells that hold the microcarriers together.

These sources of error may be eliminated by developing the method of adding microcarriers to the wound. One might consider creating a semi-solid surface of microcarriers and using the same diameter tissue punch as was used for wound creation to create a reasonably sized patch of the material to be applied to the wound. This may both stabilize the addition of material, as well as standardize the amount of material added to the standardized wound. However, this does remove an advantage of the material - the way that the microcarriers fill out the defect based on space rather than pre-configuration. An approach using molecular glue may improve stability, while keeping this advantage.

The biodegradation rate of the microcarriers depends on the environment in which they reside. It would be useful to better determine these rates for wound healing applications. This type of excised skin model may be helpful in such determination. By modifying the cross-linking during the production of the material, or by deliberate additions of enzymes or chemicals to the microcarrier solution, the stability may be altered to adhere to a time-frame of degradation better suited to facilitate the organization of the epidermis after initial healing.

The turnover of peptides released during matrix remodeling may also be an interesting aspect to investigate further. If the degradation is primarily facilitated 
by cells, then it is plausible that the turnover ability of the cells is the rate-limiting step. In that case, degradation proceeds within physiological boundaries. If the degradation is also facilitated by other means, it is possible that the vicinity of the material becomes overburdened with material residues which may impact how the tissue organization proceeds. Owing to the biocompatible nature of the material, this may only impact short- to mid-term organization of the tissue, or until the local cells are able to reorganize the matrix. Perhaps this can influence how nutrition travels around the tissue, or how metabolic products and matrix-deposited proteins are distributed. Previous uses of the material did not show any encapsulation or inflammatory reactions, so these concerns may be unfounded.

We have demonstrated the relevance of this model for skin biology research by publishing this work, despite also recognizing that numerous questions remain. The microcarriers have obvious potential for clinical utility, and have been proven safe enough in previous studies that further detailed research into human use is motivated. Unlike other types of material, such as those based on synthetic polymers, the gelatin is both physiologically relevant, and compatible with tissues able to handle a collagenous extracellular matrix. 


\section{Paper III: Contraction assay in skin model}

Human melanocytes mitigate keratinocyte-dependent contraction in an in vitro collagen contraction assay

J. Rakar et al., Burns, 2014

We wanted to investigate a suggestion coming from clinically experienced sources that melanocyte transplantation seems to soften scarred skin. To investigate this claim we decided to use keratinocytes, melanocytes and fibroblasts and employ a relatively simple skin model based on collagen hydrogels.

Much initial work was focused on obtaining a suitable format of gel and on obtaining easily measurable variables. We were mostly unable to rely on microscopy techniques due to the thickness of the constructs. Furthermore, the amount of samples required to approach stable measurements made time-series measurements using destructive techniques impractical. We therefore opted to avoid paraffin sectioning and staining.

The remaining solution that seemed most practical was to photograph the constructs and digitally measure the geometry. We standardized both the use of the digital camera, as well as how to carry out the digital measurements.

\section{Contraction}

In general, gel contraction was very prominent by both fibroblasts and keratinocytes. They contracted the gels if seeded in monoculture, and the contraction was compounded by seeding in co-cultures. Melanocytes did not cause such contraction. The measurements were further complicated by the progressive degradation of the collagen gels. Degradation was expected to be correlated to cell amounts, but the contribution to gel-size of the two different components (contraction and degradation) was not separately analyzed.

Figure $3 \mathrm{~A}$ of the paper shows that melanocytes mitigated the keratinocyte-dependent surface contraction of the collagen lattice. The bulk diameter also decreased less. Fibroblasts, not unexpectedly, added their own contractile forces alongside the keratinocytes, and maximized contraction of the collagen gel.

We also found that both cell-contact and soluble factors influenced the contraction dynamics, but we did not investigate which factors mediated the two modes of influence. We did not exercise specific control of the melanocyte phenotype (in terms of melanin-production), nor were we certain of the organization or distribution of the different cell types and how that could influence contraction as we measure it. 


\section{Reliability of data, and strength of conclusions}

We concluded that melanocytes can mitigate keratinocyte contraction, in this collagen model. The results are not controversial, nor unexpected, but has not previously (to our knowledge) been shown in such a focused approach. There are a few weaknesses in our report. First and foremost is the variability shown in the gel constructs. This forced us to use much of our resources to replicate the data to gain analysis power, taking time that otherwise would have been used on cell and interaction analysis. The added samples to investigate which modes of interaction (contact or soluble factors) influenced gel size were relevant and informative.

Another big issue was cell numbers. All cell types have some form of protease activity, with the potential to break down ECM. All cells also have focal adhesions (or hemidesmosomes) that anchor cells to the ECM and also exert forces. It would be useful to better characterize the relative strengths of these actions in melanocytes, keratinocytes and fibroblasts so that the data could better be analyzed in light of cell numbers. We used samples with all different combinations of cell numbers for each cell type (most data not shown), but continued experiments with those that provided best discriminating power. Adding too many cells (in total, or in either compartment) resulted in complete degradation of the gel within the experiment times. Adding too few cells also made measurements impossible by not being reliably discernible using the photography measurements.

The many optimizations relating to the collagen gel system make it difficult to directly translate these findings into an in vivo setting. We cannot conclude that the mitigation of contraction occurs similarly in natural physiology based solely on these experiments. However, we have shown that a relationship may exist, and hinted at how to proceed with further investigations. Using another model system might shed more light on these data.

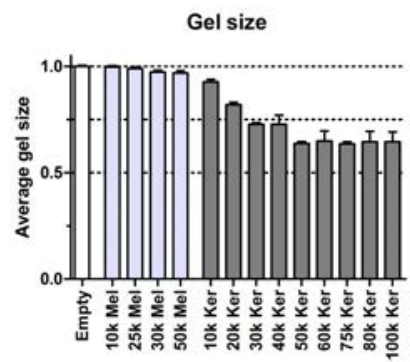

Some early data on gel size, summarized by group. Melanocytes had insignificant effects on gel size, whereas 50,000 keratinocytes were enough to reach maximal contractile effects. This data is part of the pilot data-set obtained prior to the start of experiments included in the paper. 


\section{Paper IV: Thermogenesis in fibroblasts}

Thermogenesis activated in human primary fibroblasts in vitro by medium supplementation

J. Rakar et al., Manuscript (Differentiation)

During our work with adipogenic differentiation (Paper I) we concluded that the adipocyte phenotype that we observed was most similar to the WAT cells (White Adipose Tissue), not BAT (Brown Adipose Tissue), based on the absence of up-regulation of UCP1. The comment betrayed a lack of knowledge of the field of adipocyte thermogenesis.

The microarray results obtained in Paper I led us to conclude that distinct programs were induced, rather than changing the complete phenotypic identity of the cells. Upon considering the seemingly successful functional regulation of several adipocyte mechanisms in the induced fibroblasts, we speculated that thermogenesis was a very distinct and easily testable attribute that could be induced in fibroblasts as well.

\section{Temperatures and measurements}

An unexpected difficulty with these experiments was the control and evaluation of temperature. The incubators were set to standard temperature and pressure, but temperature fluctuations during observations and medium-changes may well influence the results by differential thermal stimuli. We tried to keep this systematically similar for all sample groups. Samples in multiwell plates were staggered so each group had as many wells in the center and the periphery of the plate. Plates were not stacked, and their location in the incubators were normalized as much as possible. We also standardized the time for temperature normalization before measurements, but as our results show, we did not provide enough time for equilibration to room temperature to occur (we were off by 20-40 minutes). Also, we discovered that room temperature increased while working, and correlated with the number of people in the room. The variation in room temperature was between approximately $20^{\circ} \mathrm{C}$ and $25^{\circ} \mathrm{C}$.

A thermal camera was our main method for measuring temperature in the cultures. This really measured surface temperature, and so the volume of medium in each well suddenly became a source of error. We measured medium for each well individually when replacing media, but could not verify that volumes were precisely equal prior to measurements, nor could we ensure that the wells were completely empty before adding new medium. Perhaps one may also expect a different rate of evaporation depending on temperature.

There were problems with finding out exactly how warm the cultures were. We did not use a reference temperature plate because we were unable to obtain one 
that could hold a uniform and exact temperature. Instead, we decided that relative temperatures between cultures were sufficiently discriminating. This also allowed us to normalize plates measured at different times, since we relied only on the temperature differences between the groups on each plate measured at the same time.

We have developed a multithermistor device that would allow measurement of six wells simultaneously and continuously in culture. Again, because of calibration difficulties, the absolute temperatures would not be comparable to the thermal camera data, but relative temperatures of the culture media should provide sufficient data for determining differences related to thermogenesis. Furthermore, temperature changes correlating to differentiation would become apparent with continuous measurements.

\section{Manuscript status and additional work}

Beside the strengthening of thermal measurements, additional experiments have been planned to better characterize the starting populations. We wish to use the basic panel of MSC-markers to look at starting population distribution, and a marker for preadipocytes (PREF1) to ensure that the populations are distinct.

We also need to strengthen the IHC characterizations with better antibodies against CD137 and myogenic markers. The morphological differences between WAT and BAT are traditionally seen in the distribution of lipid vesicles, and using electron microscopy might be one way of imaging this. TEM also allows quantification of mitochondria with conjugated antibodies. We have prepared for TEM staining of UCP1 with gold-conjugated secondary antibodies, and the mitochondrial marker COX-IV (cyclooxygenase IV).

Much of the complications in the manuscript arise from using both fibroblasts and preadipocytes, each differentiated to both adipocytes and thermogenic adipocytes, and additionally differentiating each group along the other lineage after four weeks (fibroblasts to adipogenic to thermogenic, and fibroblasts to thermogenic then to adipogenic, etc). This severely complicates the study design and did not show very interesting results, so future experimentation should adhere to a simpler approach. In a similar vein, the thermogenic medium should be the most potent version, without additional variations until specific hypotheses direct us to investigate additional factors. We would use preadipocytes and fibroblasts differentiated to thermogenic cells using medium containing (at least) isoprenalin, insulin, IBMX, dexamethasone, T3 and FGF21. 
We also performed an experiment with excised skin, with some adipose maintained, cultured under thermogenic medium (data not shown). We did not detect UCP1 staining in the adipose tissue, but this experiment should be repeated with improved media.

Finally, the marker profile for IHC and PCR should be expanded. We would use CIDEA, EVA1, EBF3, TMEM26, TBX1 and COX-IV in both PCR and IHC, and we have already purchased the assays and antibodies. Selected markers, UCP1 and COX-IV, should also be verified with WB. They would provide relative abundance of mitochondria (COX-IV; increase in mitochondria is a feature of BAT), and proof of UCP1 protein expression.

\section{Section References}

Driskell, R. R., Lichtenberger, B. M., Hoste, E., Kretzschmar, K., Simons, B. D., Charalambous, M., . . Watt, F. M. (2013). Distinct fibroblast lineages determine dermal architecture in skin development and repair. Nature, 504(7479), 277-281

James, A. W. (2013). Review of Signaling Pathways Governing MSC Osteogenic and Adipogenic Differentiation. Scientifica, 2013, 17

Janson, D. G., Saintigny, G., van Adrichem, A., Mahe, C. and El Ghalbzouri, A. (2012). Different gene expression patterns in human papillary and reticular fibroblasts. J Invest Dermatol, 132(11), 2565-2572

Junker, J. P., Lonnqvist, S., Rakar, J., Karlsson, L. K., Grenegard, M. and Kratz, G. (2013). Differentiation of human dermal fibroblasts towards endothelial cells. Differentiation, 85(3), 67-77

Kirton, J. P., Crofts, N. J., George, S. J., Brennan, K. and Canfield, A. E. (2007). Wnt/beta-catenin signaling stimulates chondrogenic and inhibits adipogenic differentiation of pericytes: potential relevance to vascular disease? Circ Res, 101(6), 581-589

Koyano, Y., Kawamoto, T., Shen, M., Yan, W., Noshiro, M., Fujii, K. and Kato, Y. (1997). Molecular cloning and characterization of CDEP, a novel human protein containing the ezrin-like domain of the band 4.1 superfamily and the Dbl homology domain of Rho guanine nucleotide exchange factors. Biochem Biophys Res Commun, 241(2), 369-375

Liu, W., Liu, Y., Guo, T., Hu, C., Luo, H., Zhang, L., . . . Jin, Y. (2013). TCF3, a novel positive regulator of osteogenesis, plays a crucial role in miR-17 modulating the diverse effect of canonical Wnt signaling in different microenvironments. Cell Death Dis, 4, e539

Lorenzi, T., Chisholm, R. H., Desvillettes, L. and Hughes, B. D. (2015). Dissecting the dynamics of epigenetic changes in phenotype-structured populations exposed to fluctuating environments. $J$ Theor Biol, 386, 166-176

Oyake, T., Itoh, K., Motohashi, H., Hayashi, N., Hoshino, H., Nishizawa, M., . . Igarashi, K. (1996). Bach proteins belong to a novel family of BTB-basic leucine zipper transcription factors that interact with MafK and regulate transcription through the NF-E2 site. Mol Cell Biol, 16(11), 6083-6095

Rauch, A., Gossye, V., Bracke, D., Gevaert, E., Jacques, P., Van Beneden, K., . . De Bosscher, K. (2011). An anti-inflammatory selective glucocorticoid receptor modulator preserves osteoblast differentiation. FASEB J, 25(4), 1323-1332

Ryu, J. H., Kim, S. J., Kim, S. H., Oh, C. D., Hwang, S. G., Chun, C. H., . . Chun, J. S. (2002). Regulation of the chondrocyte phenotype by beta-catenin. Development, 129(23), 5541-5550 


\section{THE END - AND ONWARDS}

Since I began these doctoral studies in 2011 several questions have been answered and ideas realized by the larger scientific community. In the field of in vitro human cell differentiation, promising indications for reprogramming approaches that allow fibroblast-to-anything-else differentiation are paving the way for a new level of skin constructs. These will be used to create creative new therapies for wound healing in the clinic.

On a larger arena, the dissolution of a classic nomenclature surrounding cellular identity is being brought about by strides in epigenetic experimentation and classification. Induced pluripotent stem cells are still only beginning to reform stem cell biology research, and already the balance between hierarchical and stochastic theories of differentiation seems to be shifting. Methods of epigenetic analysis in conjunction with genetically modified cultures will continue to delineate important molecular cascades that drive cellular behavior, and consequently tissue development.

Tissue engineering will finally live up to its name. Materials and factors can indeed be engineered and finely controlled, but so far, cells have been the chaotic and somewhat esoteric component of tissue engineering. With genetic control and understanding of intra- and extracellular processes, cells will increasingly be purposely regulated to produce the tissues we want.

As for this thesis... the projects were just coherent enough to combine into a book, but several different paths of inquiry can spawn from our work. Applying fresh technologies to investigate the dermal fibroblasts in their phenotypic state might lead to a definitive answer on the phenotypic continuum and the distinct differences between sub-populations. Further characterizations of the thermogenic activity, and the cascades that lead to its activation, might shed some light on the commonalities between adipocytes and fibroblasts. Thermogenic skin substitutes may even be useful for certain wound types.

The construction of skin substitutes should continually be developed, starting with establishing quicker and easier protocols than collagen type I hydrogels. We are in a good position to directly compare the human in vitro skin model with engineered skin substitutes, but we need to establish more methods for non-destructive analyses. We should also apply the models to investigate aspects of vitiligo, scarring and hormone treatments, and other issues relevant to the service of the reconstructive surgeons at the university hospital. Only through true interdisciplinary understanding can we achieve success in applied medical biology. 


\section{Acknowledgements}

Thank you, Gunnar! I appreciate the freedom you afforded me, and the optimism with which you pointed us towards new unknowns.

Thank you, Ingemar, for the few but long discussions of genetic regulation, and for being the silent partner watching over me from the esoteric realm of the emeriti.

Susanna, you have been a most excellent point of reference; my endogenous control, housekeeper, calibrator, in all matters office-related and administrative. Only through you could I understand whether I was up- or down-regulated when the world was undetermined. Logarithmic effort, exponential happiness!

Junker, I appreciate the contrast you pathologically present in every discussion we have, and I am grateful for the social existence you bestowed upon me in Linköping. I have often strolled past those I began to follow, but in your case I may need to start running.

I am glad to have made so many good friends during my time at Linköping University. You have all contributed to my willingness and ability to finish my Ph.D (especially Jonas, Anders and Micke who too often made me look like a n00b).

Kristina: tack för alla lärdomar om cellodling och slabblabbande. I den perfekta världen är alla människor jag träffar som du är.

Apologies to my former students - Eva, Markus, Diana, Stefan - if I had known what I now know, I would have made you do things very differently. Also, thanks to Lena Thunell and Wolfgang Holnthoner, who supplied me with competent and hard-working Austrians.

Thank you, LiU co-workers, who gave me your time to discuss science and let me learn a little about a great number of things. Anita Lönn, Pehr Sommar, Erika Nyman, Camilla Fredriksson, Häns Wintertune-Viking MD PhD ADHD, Micke Sigvardsson, Jan-Ingvar Jönsson, Helene Karlsson, Bijar Ghafouri, Charlotta Enerbäck, Björn Granseth, Åsa \& Annette, Flow-Flo and many more.

Thank you, Christophe Egles, for helpful discussions about skin engineering.

I was part of Forum Scientium - made possible by the admirable work of Stefan Klintström, Charlotte Immerstrand and Anette Andersson. Thank you for your enthusiasm and support!

Sofie och Miranda, nu är ni mitt liv igen 额 


\section{Full Bibliography}

Aasen, T., Raya, A., Barrero, M. J., Garreta, E., Consiglio, A., Gonzalez, F., . . I Izpisua Belmonte, J. C. (2008). Efficient and rapid generation of induced pluripotent stem cells from human keratinocytes. Nat Biotechnol, 26(11), 1276-1284

Abdel-Malek, Z., Scott, M. C., Suzuki, I., Tada, A., Im, S., Lamoreux, L., . . Hearing, V. J. (2000). The melanocortin-1 receptor is a key regulator of human cutaneous pigmentation. Pigment Cell Res, 13 Supp/ 8, 156-162

Addison, W. N., Azari, F., Sorensen, E. S., Kaartinen, M. T. and McKee, M. D. (2007). Pyrophosphate inhibits mineralization of osteoblast cultures by binding to mineral, up-regulating osteopontin, and inhibiting alkaline phosphatase activity. J Biol Chem, 282(21), 15872-15883

Ahmed, M., Ghanbari, H., Cousins, B. G., Hamilton, G. and Seifalian, A. M. (2011). Small calibre polyhedral oligomeric silsesquioxane nanocomposite cardiovascular grafts: influence of porosity on the structure, haemocompatibility and mechanical properties. Acta Biomater, 7(11), 3857-3867

Alepee, N., Hibatallah, J., Klaric, M., Mewes, K. R., Pfannenbecker, U. and McNamee, P. (2016). Assessment of Cosmetic Ingredients in the In Vitro Reconstructed Human Epidermis Test Method EpiSkin Using HPLC/UPLC-Spectrophotometry in the MTT-Reduction Assay. Toxicol In Vitro

Alexander, C. M., Kasza, I., Yen, C. L., Reeder, S. B., Hernando, D., Gallo, R. L., . . MacDougald, O. A. (2015). Dermal white adipose tissue: a new component of the thermogenic response. J Lipid Res, 56(11), 2061-2069

Ananta, M., Brown, R. A. and Mudera, V. (2012). A rapid fabricated living dermal equivalent for skin tissue engineering: an in vivo evaluation in an acute wound model. Tissue Eng Part A, 18(34), 353-361

Anokye-Danso, F., Trivedi, C. M., Juhr, D., Gupta, M., Cui, Z., Tian, Y., ... Morrisey, E. E. (2011). Highly efficient miRNA-mediated reprogramming of mouse and human somatic cells to pluripotency. Cell Stem Cell, 8(4), 376-388

Ansorge, H. L., Meng, X., Zhang, G., Veit, G., Sun, M., Klement, J. F., . . Birk, D. E. (2009). Type XIV Collagen Regulates Fibrillogenesis: PREMATURE COLLAGEN FIBRIL GROWTH AND TISSUE DYSFUNCTION IN NULL MICE. J Biol Chem, 284(13), 8427-8438

Arthur, R. P. \& Shelley, W. B. (1959). The innervation of human epidermis. J Invest Dermatol, 32(3), 397-411

Askenasy, N., Yaniv, I., Stein, J. and Sharkis, S. J. (2006). Our perception of developmental plasticity: esse est percipi (to be is to be perceived)? Curr Stem Cell Res Ther, 1(1), 85-94

Atala, A., Guzman, L. and Retik, A. B. (1999). A novel inert collagen matrix for hypospadias repair. J Urol, 162(3 Pt 2), 1148-1151

Atala, A., Bauer, S. B., Soker, S., Yoo, J. J. and Retik, A. B. (2006). Tissue-engineered autologous bladders for patients needing cystoplasty. Lancet, 367(9518), 1241-1246

Atala, A., Danilevskiy, M., Lyundup, A., Glybochko, P., Butnaru, D., Vinarov, A. and Yoo, J. J. (2015). The potential role of tissue-engineered urethral substitution: clinical and preclinical studies. $J$ Tissue Eng Regen Med

Aumailley, M., Has, C., Tunggal, L. and Bruckner-Tuderman, L. (2006). Molecular basis of inherited skin-blistering disorders, and therapeutic implications. Expert Rev Mol Med, 8(24), 1-21

Banks-Schlegel, S. \& Green, H. (1981). Involucrin synthesis and tissue assembly by keratinocytes in natural and cultured human epithelia. J Cell Biol, 90(3), 732-737

Bartosh, T. J., Ylostalo, J. H., Mohammadipoor, A., Bazhanov, N., Coble, K., Claypool, K., . . Prockop, D. J. (2010). Aggregation of human mesenchymal stromal cells (MSCs) into 3D spheroids enhances their antiinflammatory properties. Proc Natl Acad Sci U S A, 107(31), 13724-13729

Bashir, M. M., Sharma, M. R. and Werth, V. P. (2009). TNF-alpha production in the skin. Arch Dermatol Res, 301(1), 87-91

Beam, J. W. (2007). Management of superficial to partial-thickness wounds. J Athl Train, 42(3), 422424

Becker, A. J., Mc, C. E. and Till, J. E. (1963). Cytological demonstration of the clonal nature of spleen colonies derived from transplanted mouse marrow cells. Nature, 197, 452-454

Behrens, D. T., Villone, D., Koch, M., Brunner, G., Sorokin, L., Robenek, H., . . Hansen, U. (2012). The epidermal basement membrane is a composite of separate laminin- or collagen IV-containing networks connected by aggregated perlecan, but not by nidogens. J Biol Chem, 287(22), 18700-18709

Bell, E., Ehrlich, H. P., Buttle, D. J. and Nakatsuji, T. (1981). Living tissue formed in vitro and accepted as skin-equivalent tissue of full thickness. Science, 211(4486), 1052-1054 
Bell, E., Sher, S. and Hull, B. (1984). The living skin-equivalent as a structural and immunological model in skin grafting. Scan Electron Microsc(Pt 4), 1957-1962

Bell, E. (1991). Tissue engineering: a perspective. J Cell Biochem, 45(3), 239-241

Bell, E. (2000). TISSUE ENGINEERING IN PERSPECTIVE A2 - Vacanti, Robert P. LanzaRobert LangerJoseph Principles of Tissue Engineering (Second Edition) (pp. xxxv-xli). San Diego: Academic Press.

Bergers, G. \& Song, S. (2005). The role of pericytes in blood-vessel formation and maintenance. Neuro Oncol, 7(4), 452-464

Bernstein, E., Kim, S. Y., Carmell, M. A., Murchison, E. P., Alcorn, H., Li, M. Z., . . Hannon, G. J. (2003). Dicer is essential for mouse development. Nat Genet, 35(3), 215-217

Bertani, N., Malatesta, P., Volpi, G., Sonego, P. and Perris, R. (2005). Neurogenic potential of human mesenchymal stem cells revisited: analysis by immunostaining, time-lapse video and microarray. J Cell Sci, 118(Pt 17), 3925-3936

Bilousova, G., Chen, J. and Roop, D. R. (2011). Differentiation of mouse induced pluripotent stem cells into a multipotent keratinocyte lineage. J Invest Dermatol, 131(4), 857-864

Black, A. F., Berthod, F., L'Heureux, N., Germain, L. and Auger, F. A. (1998). In vitro reconstruction of a human capillary-like network in a tissue-engineered skin equivalent. FASEB J, 12(13), 13311340

Bonewald, L. F., Harris, S. E., Rosser, J., Dallas, M. R., Dallas, S. L., Camacho, N. P., . . Boskey, A. (2003). von Kossa staining alone is not sufficient to confirm that mineralization in vitro represents bone formation. Calcif Tissue Int, 72(5), 537-547

Bose, A., Teh, M. T., Mackenzie, I. C. and Waseem, A. (2013). Keratin k15 as a biomarker of epidermal stem cells. Int J Mol Sci, 14(10), 19385-19398

Bottcher-Haberzeth, S., Biedermann, T., Klar, A. S., Widmer, D. S., Neuhaus, K., Schiestl, C., . . Reichmann, E. (2015). Characterization of pigmented dermo-epidermal skin substitutes in a longterm in vivo assay. Exp Dermatol, 24(1), 16-21

Boulet, A. M., Moon, A. M., Arenkiel, B. R. and Capecchi, M. R. (2004). The roles of Fgf4 and Fgf8 in limb bud initiation and outgrowth. Developmental Biology, 273(2), 361-372

Boxman, I. L., Ruwhof, C., Boerman, O. C., Lowik, C. W. and Ponec, M. (1996). Role of fibroblasts in the regulation of proinflammatory interleukin IL-1, IL-6 and IL-8 levels induced by keratinocyte-derived IL-1. Arch Dermatol Res, 288(7), 391-398

Brenner, M. \& Hearing, V. J. (2008). The protective role of melanin against UV damage in human skin. Photochem Photobiol, 84(3), 539-549

Briggaman, R. A. \& Wheeler, C. E., Jr. (1971). Epidermal-dermal interactions in adult human skin. II. The nature of the dermal influence. J Invest Dermatol, 56(1), 18-26

Brittberg, M., Lindahl, A., Nilsson, A., Ohlsson, C., Isaksson, O. and Peterson, L. (1994). Treatment of Deep Cartilage Defects in the Knee with Autologous Chondrocyte Transplantation. New England Journal of Medicine, 331(14), 889-895

Bugge, T. H., Kombrinck, K. W., Flick, M. J., Daugherty, C. C., Danton, M. J. and Degen, J. L. (1996). Loss of fibrinogen rescues mice from the pleiotropic effects of plasminogen deficiency. Cell, 87(4), 709-719

Cao, Y., Vacanti, J. P., Paige, K. T., Upton, J. and Vacanti, C. A. (1997). Transplantation of chondrocytes utilizing a polymer-cell construct to produce tissue-engineered cartilage in the shape of a human ear. Plast Reconstr Surg, 100(2), 297-302; discussion 303-294

Caplan, A. I. (2008). All MSCs are pericytes? Cell Stem Cell, 3(3), 229-230

Carroll, D. K., Carroll, J. S., Leong, C. O., Cheng, F., Brown, M., Mills, A. A., . . Ellisen, L. W. (2006). p63 regulates an adhesion programme and cell survival in epithelial cells. Nat Cell Biol, 8(6), 551-561

Cawthorn, W. P., Scheller, E. L. and MacDougald, O. A. (2012). Adipose tissue stem cells meet preadipocyte commitment: going back to the future. J Lipid Res, 53(2), 227-246

Chadwick, S., Heath, R. and Shah, M. (2012). Abnormal pigmentation within cutaneous scars: A complication of wound healing. Indian J Plast Surg, 45(2), 403-411

Chaiken, S. \& Maheswaran, D. (1994). Heuristic processing can bias systematic processing: effects of source credibility, argument ambiguity, and task importance on attitude judgment. $J$ Pers Soc Psychol, 66(3), 460-473

Chakalova, L. \& Fraser, P. (2010). Organization of transcription. Cold Spring Harb Perspect Biol, 2(9), a000729

Chan, R. K., Zamora, D. O., Wrice, N. L., Baer, D. G., Renz, E. M., Christy, R. J. and Natesan, S. (2012). Development of a vascularized skin construct using adipose-derived stem cells from debrided burned skin. Stem Cells Int, 2012, 841203

Chang, H. Y., Chi, J. T., Dudoit, S., Bondre, C., van de Rijn, M., Botstein, D. and Brown, P. O. (2002). Diversity, topographic differentiation, and positional memory in human fibroblasts. Proc Natl 
Chavez-Munoz, C., Nguyen, K. T., Xu, W., Hong, S. J., Mustoe, T. A. and Galiano, R. D. (2013). Transdifferentiation of adipose-derived stem cells into keratinocyte-like cells: engineering a stratified epidermis. PLoS One, 8(12), e80587

Choi, K. (2002). The hemangioblast: a common progenitor of hematopoietic and endothelial cells. J Hematother Stem Cell Res, 11(1), 91-101

Chung, S. Y. (2006). Bladder tissue-engineering: a new practical solution? Lancet, 367(9518), 12151216

Chuquilin, M., Alghalith, Y. and Fernandez, K. H. (2016). Neurocutaneous disease: Cutaneous neuroanatomy and mechanisms of itch and pain. J Am Acad Dermatol, 74(2), 197-212

Coe, M. R., Summers, T. A., Parsons, S. J., Boskey, A. L. and Balian, G. (1992). Matrix mineralization in hypertrophic chondrocyte cultures. Beta glycerophosphate increases type $X$ collagen messenger RNA and the specific activity of pp60c-src kinase. Bone Miner, 18(2), 91-106

Collett, G., Wood, A., Alexander, M. Y., Varnum, B. C., Boot-Handford, R. P., Ohanian, V., . . Canfield, A. E. (2003). Receptor tyrosine kinase Axl modulates the osteogenic differentiation of pericytes. Circ Res, 92(10), 1123-1129

Colwell, A. S., Longaker, M. T. and Lorenz, H. P. (2003). Fetal wound healing. Front Biosci, 8, s1240-1248

Compton, C. C., Gill, J. M., Bradford, D. A., Regauer, S., Gallico, G. G. and O'Connor, N. E. (1989). Skin regenerated from cultured epithelial autografts on full-thickness burn wounds from 6 days to 5 years after grafting. A light, electron microscopic and immunohistochemical study. Lab Invest, 60(5), 600-612

Cosgrove, M. S. \& Wolberger, C. (2005). How does the histone code work? Biochem Cell Biol, 83(4), 468-476

Cotsarelis, G., Sun, T. T. and Lavker, R. M. (1990). Label-retaining cells reside in the bulge area of pilosebaceous unit: implications for follicular stem cells, hair cycle, and skin carcinogenesis. Cell, 61(7), 1329-1337

Crisan, M., Yap, S., Casteilla, L., Chen, C. W., Corselli, M., Park, T. S., .. Peault, B. (2008). A perivascular origin for mesenchymal stem cells in multiple human organs. Cell Stem Cell, 3(3), 301-313

Cristancho, A. G. \& Lazar, M. A. (2011). Forming functional fat: a growing understanding of adipocyte differentiation. Nat Rev Mol Cell Biol, 12(11), 722-734

Cserjesi, P., Brown, D., Ligon, K. L., Lyons, G. E., Copeland, N. G., Gilbert, D. J., . . . Olson, E. N. (1995). Scleraxis: a basic helix-loop-helix protein that prefigures skeletal formation during mouse embryogenesis. Development, 121(4), 1099-1110

D'Souza, S. E., Ginsberg, M. H. and Plow, E. F. (1991). Arginyl-glycyl-aspartic acid (RGD): a cell adhesion motif. Trends Biochem Sci, 16(7), 246-250

Daquinag, A. C., Souza, G. R. and Kolonin, M. G. (2013). Adipose tissue engineering in three-dimensional levitation tissue culture system based on magnetic nanoparticles. Tissue Eng Part $C$ Methods, 19(5), 336-344

Dausset, J. (1958). Immuno-hematologie des leucocytes. Bibl Paediatr, 14(66), 29-56

Dayem, M. A., Moreilhon, C., Turchi, L., Magnone, V., Christen, R., Ponzio, G. and Barbry, P. (2003). Early gene expression in wounded human keratinocytes revealed by DNA microarray analysis. Comp Funct Genomics, 4(1), 47-55

De Luca, M., D’Anna, F., Bondanza, S., Franzi, A. T. and Cancedda, R. (1988). Human epithelial cells induce human melanocyte growth in vitro but only skin keratinocytes regulate its proper differentiation in the absence of dermis. J Cell Biol, 107(5), 1919-1926

De Miguel, M. P., Arnalich Montiel, F., Lopez Iglesias, P., Blazquez Martinez, A. and Nistal, M. (2009). Epiblast-derived stem cells in embryonic and adult tissues. Int J Dev Biol, 53(8-10), 1529-1540

De Robertis, E. M. (2009). Spemann's organizer and the self-regulation of embryonic fields. Mech Dev, 126(11-12), 925-941

de Vries, R., Anderson, M. S. and Martinson, B. C. (2006). Normal Misbehavior: Scientists Talk about the Ethics of Research. J Empir Res Hum Res Ethics, 1(1), 43-50

Delaere, P. R. \& Van Raemdonck, D. (2014). The trachea: the first tissue-engineered organ? J Thorac Cardiovasc Surg, 147(4), 1128-1132

Dellavalle, A., Sampaolesi, M., Tonlorenzi, R., Tagliafico, E., Sacchetti, B., Perani, L., . . Cossu, G. (2007). Pericytes of human skeletal muscle are myogenic precursors distinct from satellite cells. Nat Cell Biol, 9(3), 255-267

Dezawa, M., Kanno, H., Hoshino, M., Cho, H., Matsumoto, N., Itokazu, Y., . . I Ide, C. (2004). Specific induction of neuronal cells from bone marrow stromal cells and application for autologous transplantation. J Clin Invest, 113(12), 1701-1710

Dingle, Y. T., Boutin, M. E., Chirila, A. M., Livi, L. L., Labriola, N. R., Jakubek, L. M., . . Hoffman-Kim, D. (2015). Three-Dimensional Neural Spheroid Culture: An In Vitro Model for Cortical Studies. 
Tissue Eng Part C Methods, 21(12), 1274-1283

Discher, D. E., Janmey, P. and Wang, Y. L. (2005). Tissue cells feel and respond to the stiffness of their substrate. Science, 310(5751), 1139-1143

Dominici, M., Le Blanc, K., Mueller, I., Slaper-Cortenbach, I., Marini, F., Krause, D., ... Horwitz, E. (2006). Minimal criteria for defining multipotent mesenchymal stromal cells. The International Society for Cellular Therapy position statement. Cytotherapy, 8(4), 315-317

Dore-Duffy, P. (2008). Pericytes: pluripotent cells of the blood brain barrier. Curr Pharm Des, 14(16), 1581-1593

Drew, P., Posnett, J., Rusling, L. and Wound Care Audit, T. (2007). The cost of wound care for a local population in England. Int Wound J, 4(2), 149-155

Driesch, H. (1893). Zur Verlagerung der Blastomeren des Echinideneies. Anatomischer Anzeiger, 8, 348-357

Driskell, R. R., Clavel, C., Rendl, M. and Watt, F. M. (2011). Hair follicle dermal papilla cells at a glance. J Cell Sci, 124(Pt 8), 1179-1182

Driskell, R. R., Lichtenberger, B. M., Hoste, E., Kretzschmar, K., Simons, B. D., Charalambous, M., . . . Watt, F. M. (2013). Distinct fibroblast lineages determine dermal architecture in skin development and repair. Nature, 504(7479), 277-281

Driskell, R. R., Jahoda, C. A., Chuong, C. M., Watt, F. M. and Horsley, V. (2014). Defining dermal adipose tissue. Exp Dermatol, 23(9), 629-631

Dubey, S. \& Roulin, A. (2014). Evolutionary and biomedical consequences of internal melanins. Pigment Cell Melanoma Res, 27(3), 327-338

Duboule, D. \& Morata, G. (1994). Colinearity and functional hierarchy among genes of the homeotic complexes. Trends in Genetics, 10(10), 358-364

Dubovy, P. \& Aldskogius, H. (1996). Degeneration and regeneration of cutaneous sensory nerve formations. Microsc Res Tech, 34(4), 362-375

Duckett, J. W., Coplen, D., Ewalt, D. and Baskin, L. S. (1995). Buccal mucosal urethral replacement. J Urol, 153(5), 1660-1663

Dunn, P. M. (2005). Ignac Semmelweis (1818-1865) of Budapest and the prevention of puerperal fever. Arch Dis Child Fetal Neonatal Ed, 90(4), F345-348

Dupin, E., Real, C., Glavieux-Pardanaud, C., Vaigot, P. and Le Douarin, N. M. (2003). Reversal of developmental restrictions in neural crest lineages: transition from Schwann cells to glial-melanocytic precursors in vitro. Proc Natl Acad Sci U S A, 100(9), 5229-5233

Dvorak, H. F. (1986). Tumors: wounds that do not heal. Similarities between tumor stroma generation and wound healing. N Engl J Med, 315(26), 1650-1659

Eagle, H. (1955). The minimum vitamin requirements of the $L$ and HeLa cells in tissue culture, the production of specific vitamin deficiencies, and their cure. J Exp Med, 102(5), 595-600

Eagle, H. (1958). Amino acid metabolism in human cell cultures. Fed Proc, 17(4), 985-986

Eckhart, L., Reinisch, C., Inoue, S., Messner, P., Dockal, M., Mayer, C. and Tschachler, E. (2003). A basement membrane-like matrix formed by cell-released proteins at the medium/air interface supports growth of keratinocytes. Eur J Cell Biol, 82(11), 549-555

Eckhart, L., Lippens, S., Tschachler, E. and Declercq, W. (2013). Cell death by cornification. Biochim Biophys Acta, 1833(12), 3471-3480

Eiraku, M., Takata, N., Ishibashi, H., Kawada, M., Sakakura, E., Okuda, S., . . Sasai, Y. (2011). Self-organizing optic-cup morphogenesis in three-dimensional culture. Nature, 472(7341), 51-56

Eiser, J. R. \& Pancer, S. M. (1979). Attitudinal effects of the use of evaluatively biased language. European Journal of Social Psychology, 9(1), 39-47

Eisinger, M. \& Marko, O. (1982). Selective proliferation of normal human melanocytes in vitro in the presence of phorbol ester and cholera toxin. Proc Natl Acad Sci U S A, 79(6), 2018-2022

el-Harake, W. A., Furman, M. A., Cook, B., Nair, K. S., Kukowski, J. and Brodsky, I. G. (1998). Measurement of dermal collagen synthesis rate in vivo in humans. Am J Physiol, 274(4 Pt 1), E586591

El Ghalbzouri, A. \& Ponec, M. (2004). Diffusible factors released by fibroblasts support epidermal morphogenesis and deposition of basement membrane components. Wound Repair Regen, 12(3), 359-367

Endres, M., Neumann, K., Haupl, T., Erggelet, C., Ringe, J., Sittinger, M. and Kaps, C. (2007). Synovial fluid recruits human mesenchymal progenitors from subchondral spongious bone marrow. $J$ Orthop Res, 25(10), 1299-1307

Engler, A. J., Sen, S., Sweeney, H. L. and Discher, D. E. (2006). Matrix elasticity directs stem cell lineage specification. Cell, 126(4), 677-689

English, K. B., Stayner, N., Krueger, G. G. and Tuckett, R. P. (1992). Functional innervation of cultured skin grafts. J Invest Dermatol, 99(2), 120-128 
Eseonu, O. I. \& De Bari, C. (2015). Homing of mesenchymal stem cells: mechanistic or stochastic? Implications for targeted delivery in arthritis. Rheumatology (Oxford), 54(2), 210-218

Etker, S. (1996). Re: Buccal mucosal urethral replacement. J Urol, 155(4), 1395

Evans, N. D., Oreffo, R. O., Healy, E., Thurner, P. J. and Man, Y. H. (2013). Epithelial mechanobiology, skin wound healing, and the stem cell niche. J Mech Behav Biomed Mater, 28, 397-409

Evans, R. A., Tian, Y. C., Steadman, R. and Phillips, A. O. (2003). TGF-beta1-mediated fibroblast-myofibroblast terminal differentiation-the role of Smad proteins. Exp Cell Res, 282(2), 90-100

Fagerholm, P., Lagali, N. S., Merrett, K., Jackson, W. B., Munger, R., Liu, Y., . . Griffith, M. (2010). A biosynthetic alternative to human donor tissue for inducing corneal regeneration: 24-month follow-up of a phase 1 clinical study. Sci Transl Med, 2(46), 46ra61

Fanelli, D. (2009). How many scientists fabricate and falsify research? A systematic review and meta-analysis of survey data. PLoS One, 4(5), e5738

Farrington-Rock, C., Crofts, N. J., Doherty, M. J., Ashton, B. A., Griffin-Jones, C. and Canfield, A. E. (2004). Chondrogenic and adipogenic potential of microvascular pericytes. Circulation, 110(15), 2226-2232

Ferreira, E., Porter, R. M., Wehling, N., O'Sullivan, R. P., Liu, F., Boskey, A., . . Wells, J. W. (2013). Inflammatory cytokines induce a unique mineralizing phenotype in mesenchymal stem cells derived from human bone marrow. J Biol Chem, 288(41), 29494-29505

Fessing, M. Y., Mardaryev, A. N., Gdula, M. R., Sharov, A. A., Sharova, T. Y., Rapisarda, V., . . Botchkarev, V. A. (2011). p63 regulates Satb1 to control tissue-specific chromatin remodeling during development of the epidermis. J Cell Biol, 194(6), 825-839

Festa, E., Fretz, J., Berry, R., Schmidt, B., Rodeheffer, M., Horowitz, M. and Horsley, V. (2011). Adipocyte lineage cells contribute to the skin stem cell niche to drive hair cycling. Cell, 146(5), 761-771

Fischer, U. M., Harting, M. T., Jimenez, F., Monzon-Posadas, W. O., Xue, H., Savitz, S. I., . . Cox, C. S., Jr. (2009). Pulmonary passage is a major obstacle for intravenous stem cell delivery: the pulmonary first-pass effect. Stem Cells Dev, 18(5), 683-692

Foresta, C., Strapazzon, G., De Toni, L., Gianesello, L., Calcagno, A., Pilon, C., . . . Vettor, R. (2010). Evidence for osteocalcin production by adipose tissue and its role in human metabolism. J Clin Endocrinol Metab, 95(7), 3502-3506

Fortunel, N. O. \& Martin, M. T. (2012). Cellular organization of the human epidermal basal layer: clues sustaining a hierarchical model. Int J Radiat Biol, 88(10), 677-681

Fossum, M., Svensson, J., Kratz, G. and Nordenskjold, A. (2007). Autologous in vitro cultured urothelium in hypospadias repair. J Pediatr Urol, 3(1), 10-18

Franzen, L., Mathes, C., Hansen, S. and Windbergs, M. (2013a). Advanced chemical imaging and comparison of human and porcine hair follicles for drug delivery by confocal Raman microscopy. J Biomed Opt, 18(6), 061210

Franzen, L., Selzer, D., Fluhr, J. W., Schaefer, U. F. and Windbergs, M. (2013b). Towards drug quantification in human skin with confocal Raman microscopy. Eur J Pharm Biopharm, 84(2), 437-444

Franzen, L., Anderski, J. and Windbergs, M. (2015). Quantitative detection of caffeine in human skin by confocal Raman spectroscopy--A systematic in vitro validation study. Eur J Pharm Biopharm, 95(Pt A), 110-116

Freiberger, H., Grove, D., Sivarajah, A. and Pinnell, S. R. (1980). Procollagen I synthesis in human skin fibroblasts: effect on culture conditions on biosynthesis. J Invest Dermatol, 75(5), 425-430

Frenette, P. S., Pinho, S., Lucas, D. and Scheiermann, C. (2013). Mesenchymal stem cell: keystone of the hematopoietic stem cell niche and a stepping-stone for regenerative medicine. Annu Rev Immunol, 31, 285-316

Fridman, J. S. \& Lowe, S. W. (2003). Control of apoptosis by p53. Oncogene, 22(56), 9030-9040

Friedenstein, A. J., Deriglasova, U. F., Kulagina, N. N., Panasuk, A. F., Rudakowa, S. F., Luria, E. A. and Ruadkow, I. A. (1974). Precursors for fibroblasts in different populations of hematopoietic cells as detected by the in vitro colony assay method. Exp Hematol, 2(2), 83-92

Friedenstein, A. J., Gorskaja, J. F. and Kulagina, N. N. (1976). Fibroblast precursors in normal and irradiated mouse hematopoietic organs. Exp Hematol, 4(5), 267-274

Friedenstein, A. J. (1989). Stromal-hematopoietic interrelationships: Maximov's ideas and modern models. Haematol Blood Transfus, 32, 159-167

Frobel, J., Hemeda, H., Lenz, M., Abagnale, G., Joussen, S., Denecke, B., . . Wagner, W. (2014). Epigenetic rejuvenation of mesenchymal stromal cells derived from induced pluripotent stem cells. Stem Cell Reports, 3(3), 414-422

Fujie, Y., Fusaki, N., Katayama, T., Hamasaki, M., Soejima, Y., Soga, M., ... Era, T. (2014). New type of Sendai virus vector provides transgene-free iPS cells derived from chimpanzee blood. PLOS One, 9(12), e113052

Fusaki, N., Ban, H., Nishiyama, A., Saeki, K. and Hasegawa, M. (2009). Efficient induction of trans- 
gene-free human pluripotent stem cells using a vector based on Sendai virus, an RNA virus that does not integrate into the host genome. Proc Jpn Acad Ser B Phys Biol Sci, 85(8), 348362

Gabbiani, G., Chaponnier, C. and Huttner, I. (1978). Cytoplasmic filaments and gap junctions in epithelial cells and myofibroblasts during wound healing. J Cell Biol, 76(3), 561-568

Galli, A., Robay, D., Osterwalder, M., Bao, X., Bénazet, J.-D., Tariq, M., . . . Zeller, R. (2010). Distinct Roles of Hand2 in Initiating Polarity and Posterior Shh Expression during the Onset of Mouse Limb Bud Development. PLoS Genet, 6(4), e1000901

Gay, D., Kwon, O., Zhang, Z., Spata, M., Plikus, M. V., Holler, P. D., . . Cotsarelis, G. (2013). Fgf9 from dermal gammadelta T cells induces hair follicle neogenesis after wounding. Nat Med, 19(7), 916-923

Gelse, K., Poschl, E. and Aigner, T. (2003). Collagens--structure, function, and biosynthesis. Adv Drug Deliv Rev, 55(12), 1531-1546

Gesta, S., Tseng, Y. H. and Kahn, C. R. (2007). Developmental origin of fat: tracking obesity to its source. Cell, 131(2), 242-256

Giralt, M. \& Villarroya, F. (2013). White, brown, beige/brite: different adipose cells for different functions? Endocrinology, 154(9), 2992-3000

Gleeson, B. M., Martin, K., Ali, M. T., Kumar, A. H., Pillai, M. G., Kumar, S. P., . . Caplice, N. M. (2015). Bone Marrow-Derived Mesenchymal Stem Cells Have Innate Procoagulant Activity and Cause Microvascular Obstruction Following Intracoronary Delivery: Amelioration by Antithrombin Therapy. Stem Cells, 33(9), 2726-2737

Goktas, M., Cinar, G., Orujalipoor, I., Ide, S., Tekinay, A. B. and Guler, M. O. (2015). Self-assembled peptide amphiphile nanofibers and peg composite hydrogels as tunable ECM mimetic microenvironment. Biomacromolecules, 16(4), 1247-1258

Goldberg, A. D., Allis, C. D. and Bernstein, E. (2007). Epigenetics: a landscape takes shape. Cell, 128(4), 635-638

Goldgeier, M. H., Klein, L. E., Klein-Angerer, S., Moellmann, G. and Nordlund, J. J. (1984). The distribution of melanocytes in the leptomeninges of the human brain. J Invest Dermatol, 82(3), 235238

Goldstein, S., Clarke, D. R., Walsh, S. P., Black, K. S. and O’Brien, M. F. (2000). Transpecies heart valve transplant: advanced studies of a bioengineered xeno-autograft. Ann Thorac Surg, 70(6), 1962-1969

Golembiewski, R. T. (1964). Authority as a Problem in Overlays: A Concept for Action and Analysis. Administrative Science Quarterly, 9(1), 23-49

Gonzalez-Perez, O. (2012). Neural stem cells in the adult human brain. Biol Biomed Rep, 2(1), 59-69

Goodman, G. \& Bercovich, D. (2008). Melanin directly converts light for vertebrate metabolic use: heuristic thoughts on birds, Icarus and dark human skin. Med Hypotheses, 71(2), 190-202

Goodman, S. \& Greenland, S. (2007). Why most published research findings are false: problems in the analysis. PLoS Med, 4(4), e168

Goodwin, A. M. (2007). In vitro assays of angiogenesis for assessment of angiogenic and anti-angiogenic agents. Microvasc Res, 74(2-3), 172-183

Green, H., Kehinde, O. and Thomas, J. (1979). Growth of cultured human epidermal cells into multiple epithelia suitable for grafting. Proc Natl Acad Sci U S A, 76(11), 5665-5668

Gregoire, F. M., Smas, C. M. and Sul, H. S. (1998). Understanding adipocyte differentiation. Physiol Rev, 78(3), 783-809

Greider, C. W. \& Blackburn, E. H. (1985). Identification of a specific telomere terminal transferase activity in Tetrahymena extracts. Cell, 43(2 Pt 1), 405-413

Grone, A. (2002). Keratinocytes and cytokines. Vet Immunol Immunopathol, 88(1-2), 1-12

Guillemette, M. D., Cui, B., Roy, E., Gauvin, R., Giasson, C. J., Esch, M. B., . . Auger, F. A. (2009). Surface topography induces 3D self-orientation of cells and extracellular matrix resulting in improved tissue function. Integr Biol (Camb), 1(2), 196-204

Gurdon, J. B., Elsdale, T. R. and Fischberg, M. (1958). Sexually mature individuals of Xenopus laevis from the transplantation of single somatic nuclei. Nature, 182(4627), 64-65

Gurdon, J. B. (1962). The transplantation of nuclei between two species of Xenopus. Dev Biol, 5, 68-83

Gurdon, J. B., Laskey, R. A. and Reeves, O. R. (1975). The developmental capacity of nuclei transplanted from keratinized skin cells of adult frogs. J Embryol Exp Morphol, 34(1), 93-112

Gurtner, G. C., Werner, S., Barrandon, Y. and Longaker, M. T. (2008). Wound repair and regeneration. Nature, 453(7193), 314-321

Haeberle, H., Fujiwara, M., Chuang, J., Medina, M. M., Panditrao, M. V., Bechstedt, S., . . Lumpkin, E. A. (2004). Molecular profiling reveals synaptic release machinery in Merkel cells. Proc Natl Acad Sci U S A, 101(40), 14503-14508 
Hakenberg, O. W. (2006). Re: tissue-engineered autologous bladders for patients needing cystoplasty. Eur Urol, 50(2), 382-383

Halaban, R., Ghosh, S. and Baird, A. (1987). bFGF is the putative natural growth factor for human melanocytes. In Vitro Cell Dev Biol, 23(1), 47-52

Haniffa, M. A., Collin, M. P., Buckley, C. D. and Dazzi, F. (2009). Mesenchymal stem cells: the fibroblasts' new clothes? Haematologica, 94(2), 258-263

Hankin, C. S., Knispel, J., Lopes, M., Bronstone, A. and Maus, E. (2012). Clinical and cost efficacy of advanced wound care matrices for venous ulcers. J Manag Care Pharm, 18(5), 375-384

Harding, K., Sumner, M. and Cardinal, M. (2013). A prospective, multicentre, randomised controlled study of human fibroblast-derived dermal substitute (Dermagraft) in patients with venous leg ulcers. Int Wound J, 10(2), 132-137

Hardy, M. H. (1992). The secret life of the hair follicle. Trends Genet, 8(2), 55-61

Harle-Bachor, C. \& Boukamp, P. (1996). Telomerase activity in the regenerative basal layer of the epidermis inhuman skin and in immortal and carcinoma-derived skin keratinocytes. Proc Natl Acad Sci U S A, 93(13), 6476-6481

Harrison, C. A., Dalley, A. J. and Mac Neil, S. (2005). A simple in vitro model for investigating epithelial/ mesenchymal interactions: keratinocyte inhibition of fibroblast proliferation and fibronectin synthesis. Wound Repair Regen, 13(6), 543-550

Harrison, C. A., Gossiel, F., Bullock, A. J., Sun, T., Blumsohn, A. and Mac Neil, S. (2006). Investigation of keratinocyte regulation of collagen I synthesis by dermal fibroblasts in a simple in vitro model. Br J Dermatol, 154(3), 401-410

Harvey, K. A., Paranavitana, C. N., Zaloga, G. P. and Siddiqui, R. A. (2007). Diverse signaling pathways regulate fibroblast differentiation and transformation through Rho kinase activation. J Cell Physiol, 211(2), 353-363

Hasher, L., Goldstein, D. and Toppino, T. (1977). Frequency and the conference of referential validity. Journal of Verbal Learning and Verbal Behavior, 16(1), 107-112

Hass, R., Kasper, C., Bohm, S. and Jacobs, R. (2011). Different populations and sources of human mesenchymal stem cells (MSC): A comparison of adult and neonatal tissue-derived MSC. Cell Commun Signal, 9, 12

Hayflick, L. \& Moorhead, P. S. (1961). The serial cultivation of human diploid cell strains. Exp Cell Res, $25,585-621$

Hendren, W. H. \& Crooks, K. K. (1980). Tubed free skin graft for construction of male urethra. J Urol, 123(6), 858-861

Henig, I. \& Zuckerman, T. (2014). Hematopoietic stem cell transplantation-50 years of evolution and future perspectives. Rambam Maimonides Med J, 5(4), e0028

Hennings, H., Holbrook, K., Steinert, P. and Yuspa, S. (1980). Growth and differentiation of mouse epidermal cells in culture: effects of extracellular calcium. Curr Probl Dermatol, 10, 3-25

Hensel, H., Andres, K. H. and von During, M. (1974). Structure and function of cold receptors. Pflugers Arch, 352(1), 1-10

Hertwig, O. (1894) [Book]. Zeit- und Streitfragen der Biologie / von Prof. Dr. Oscar Hertwig (Vol. 1). Jena :, G. Fischer.

Hertwig, O. (1900) [Book]. Die Elemente der Entwicklungslehre des Menschen und der Wirbeltiere : Anleitung und Repetitorium für Studierende und Aertze. Jena :, G. Fischer.

Hewitt, K. J., Shamis, Y., Hayman, R. B., Margvelashvili, M., Dong, S., Carlson, M. W. and Garlick, J. A. (2011). Epigenetic and phenotypic profile of fibroblasts derived from induced pluripotent stem cells. PLoS One, 6(2), e17128

Hirobe, T. (1983). Proliferation of epidermal melanocytes during the healing of skin wounds in newborn mice. J Exp Zool, 227(3), 423-431

Hohwy, J. (2007). Functional Integration and the Mind. Synthese, 159(3), 315-328

Holland, J. L. (1985) [Book]. Making vocational choices: a theory of vocational personalities and work environments. Prentice-Hall.

Horwitz, E. M., Le Blanc, K., Dominici, M., Mueller, I., Slaper-Cortenbach, I., Marini, F. C., . . International Society for Cellular, T. (2005). Clarification of the nomenclature for MSC: The International Society for Cellular Therapy position statement. Cytotherapy, 7(5), 393-395

Houben, E., De Paepe, K. and Rogiers, V. (2007). A keratinocyte's course of life. Skin Pharmacol Physiol, 20(3), 122-132

Hu, M., Yao, J., Cai, L., Bachman, K. E., van den Brule, F., Velculescu, V. and Polyak, K. (2005). Distinct epigenetic changes in the stromal cells of breast cancers. Nat Genet, 37(8), 899-905

Huggenberger, R. \& Detmar, M. (2011). The cutaneous vascular system in chronic skin inflammation. J Investig Dermatol Symp Proc, 15(1), 24-32

Huss, F. R., Nyman, E., Bolin, J. S. and Kratz, G. (2010). Use of macroporous gelatine spheres as a bio- 
degradable scaffold for guided tissue regeneration of healthy dermis in humans: an in vivo study. J Plast Reconstr Aesthet Surg, 63(5), 848-857

Huveneers, S. \& Danen, E. H. (2009). Adhesion signaling - crosstalk between integrins, Src and Rho. J Cell Sci, 122(Pt 8), 1059-1069

Hynes, R. O. (2002). Integrins: bidirectional, allosteric signaling machines. Cell, 110(6), 673-687

Iborra, F. J., Pombo, A., Jackson, D. A. and Cook, P. R. (1996). Active RNA polymerases are localized within discrete transcription "factories' in human nuclei. J Cell Sci, 109 ( Pt 6), 1427-1436

leda, M., Fu, J. D., Delgado-Olguin, P., Vedantham, V., Hayashi, Y., Bruneau, B. G. and Srivastava, D. (2010). Direct reprogramming of fibroblasts into functional cardiomyocytes by defined factors. Cell, 142(3), 375-386

Ingber, D. E. (2003). Tensegrity II. How structural networks influence cellular information processing networks. J Cell Sci, 116(Pt 8), 1397-1408

loannidis, J. P. (2005). Why most published research findings are false. PLoS Med, 2(8), e124

Ioannidis, J. P. (2007). Why most published research findings are false: author's reply to Goodman and Greenland. PLoS Med, 4(6), e215

Ioannidis, J. P. (2014). Discussion: Why "An estimate of the science-wise false discovery rate and application to the top medical literature" is false. Biostatistics, 15(1), 28-36; discussion 39-45

Ito, M., Liu, Y., Yang, Z., Nguyen, J., Liang, F., Morris, R. J. and Cotsarelis, G. (2005). Stem cells in the hair follicle bulge contribute to wound repair but not to homeostasis of the epidermis. Nat Med, 11(12), 1351-1354

Ito, M., Yang, Z., Andl, T., Cui, C., Kim, N., Millar, S. E. and Cotsarelis, G. (2007). Wnt-dependent de novo hair follicle regeneration in adult mouse skin after wounding. Nature, 447(7142), 316-320

Ivanov, N. A., Tao, R., Chenoweth, J. G., Brandtjen, A., Mighdoll, M. I., Genova, J. D., . . Jaffe, A. E. (2016). Strong Components of Epigenetic Memory in Cultured Human Fibroblasts Related to Site of Origin and Donor Age. PLoS Genet, 12(2), e1005819

Jager, L. R. \& Leek, J. T. (2014). An estimate of the science-wise false discovery rate and application to the top medical literature. Biostatistics, 15(1), 1-12

Jakab, K., Neagu, A., Mironov, V., Markwald, R. R. and Forgacs, G. (2004). Engineering biological structures of prescribed shape using self-assembling multicellular systems. Proc Natl Acad Sci U S A, 101(9), 2864-2869

James, A. W. (2013). Review of Signaling Pathways Governing MSC Osteogenic and Adipogenic Differentiation. Scientifica, 2013, 17

Janson, D., Saintigny, G., Mahe, C. and El Ghalbzouri, A. (2013). Papillary fibroblasts differentiate into reticular fibroblasts after prolonged in vitro culture. Exp Dermatol, 22(1), 48-53

Janson, D. G., Saintigny, G., van Adrichem, A., Mahe, C. and El Ghalbzouri, A. (2012). Different gene expression patterns in human papillary and reticular fibroblasts. J Invest Dermatol, 132(11), 2565-2572

Jayme, D., Watanabe, T. and Shimada, T. (1997). Basal medium development for serum-free culture: a historical perspective. Cytotechnology, 23(1-3), 95-101

Jeong, G. S., Chang, J. Y., Park, J. S., Lee, S. A., Park, D., Woo, J., . . Lee, S. H. (2015). Networked neural spheroid by neuro-bundle mimicking nervous system created by topology effect. Mol Brain, 8,17

Jinno, H., Morozova, O., Jones, K. L., Biernaskie, J. A., Paris, M., Hosokawa, R., . . Miller, F. D. (2010). Convergent genesis of an adult neural crest-like dermal stem cell from distinct developmental origins. Stem Cells, 28(11), 2027-2040

Johansson, J. A. \& Headon, D. J. (2014). Regionalisation of the skin. Semin Cell Dev Biol, 25-26, 3-10

Judson, R. L., Babiarz, J. E., Venere, M. and Blelloch, R. (2009). Embryonic stem cell-specific microRNAs promote induced pluripotency. Nat Biotechnol, 27(5), 459-461

Jungebluth, P., Alici, E., Baiguera, S., Le Blanc, K., Blomberg, P., Bozoky, B., . . Macchiarini, P. (2011). Tracheobronchial transplantation with a stem-cell-seeded bioartificial nanocomposite: a proof-of-concept study. Lancet, 378(9808), 1997-2004

Junker, J. P., Kratz, C., Tollback, A. and Kratz, G. (2008). Mechanical tension stimulates the transdifferentiation of fibroblasts into myofibroblasts in human burn scars. Burns, 34(7), 942-946

Junker, J. P., Sommar, P., Skog, M., Johnson, H. and Kratz, G. (2010). Adipogenic, chondrogenic and osteogenic differentiation of clonally derived human dermal fibroblasts. Cells Tissues Organs, 191(2), 105-118

Junker, J. P., Lonnqvist, S., Rakar, J., Karlsson, L. K., Grenegard, M. and Kratz, G. (2013). Differentiation of human dermal fibroblasts towards endothelial cells. Differentiation, 85(3), 67-77

Kalluri, R. \& Zeisberg, M. (2006). Fibroblasts in cancer. Nat Rev Cancer, 6(5), 392-401

Kang, J., Yoo, J., Lee, S., Tang, W., Aguilar, B., Ramu, S., . . Hong, Y. K. (2010). An exquisite cross-control mechanism among endothelial cell fate regulators directs the plasticity and heterogeneity 
of lymphatic endothelial cells. Blood, 116(1), 140-150

Karp, J. M. \& Leng Teo, G. S. (2009). Mesenchymal stem cell homing: the devil is in the details. Cell Stem Cell, 4(3), 206-216

Kiecker, C., Bates, T. and Bell, E. (2016). Molecular specification of germ layers in vertebrate embryos. Cell Mol Life Sci, 73(5), 923-947

Kiel, M. J., Yilmaz, O. H., Iwashita, T., Yilmaz, O. H., Terhorst, C. and Morrison, S. J. (2005). SLAM family receptors distinguish hematopoietic stem and progenitor cells and reveal endothelial niches for stem cells. Cell, 121(7), 1109-1121

Kim, Y., Jeong, J., Kang, H., Lim, J., Heo, J., Ratajczak, J., . . Shin, D. M. (2014). The molecular nature of very small embryonic-like stem cells in adult tissues. Int J Stem Cells, 7(2), 55-62

Kirton, J. P., Crofts, N. J., George, S. J., Brennan, K. and Canfield, A. E. (2007). Wnt/beta-catenin signaling stimulates chondrogenic and inhibits adipogenic differentiation of pericytes: potential relevance to vascular disease? Circ Res, 101(6), 581-589

Kollar, E. J. (1986). Tissue interactions in development of teeth and related ectodermal derivatives. Dev Biol (N Y 1985), 4, 297-313

Konno, D., Kasukawa, T., Hashimoto, K., Itoh, T., Suetsugu, T., Miura, I., . . . Matsuzaki, F. (2015). STAP cells are derived from ES cells. Nature, 525(7570), E4-E5

Kormos, B., Belső, N., Bebes, A., Szabad, G., Bacsa, S., Széll, M., . . Bata-Csörgő, Z. (2011). In Vitro Dedifferentiation of Melanocytes from Adult Epidermis. PLoS One, 6(2), e17197

Koyano, Y., Kawamoto, T., Shen, M., Yan, W., Noshiro, M., Fujii, K. and Kato, Y. (1997). Molecular cloning and characterization of CDEP, a novel human protein containing the ezrin-like domain of the band 4.1 superfamily and the Dbl homology domain of Rho guanine nucleotide exchange factors. Biochem Biophys Res Commun, 241(2), 369-375

Kratz, G. (1998). Modeling of wound healing processes in human skin using tissue culture. Microsc Res Tech, 42(5), 345-350

Kratz, G. (2005). Body parts from the laboratory bench. Br J Surg, 92(4), 385-386

Krieg, T. \& Aumailley, M. (2011). The extracellular matrix of the dermis: flexible structures with dynamic functions. Exp Dermatol, 20(8), 689-695

Krueger, M. \& Bechmann, I. (2010). CNS pericytes: concepts, misconceptions, and a way out. Glia, 58(1), 1-10

Kruger, J. \& Dunning, D. (1999). Unskilled and unaware of it: how difficulties in recognizing one's own incompetence lead to inflated self-assessments. J Pers Soc Psychol, 77(6), 1121-1134

Kucia, M., Machalinski, B. and Ratajczak, M. Z. (2006). The developmental deposition of epiblast/germ cell-line derived cells in various organs as a hypothetical explanation of stem cell plasticity? Acta Neurobiol Exp (Wars), 66(4), 331-341

Kuhn, T. S. (1962) [Book]. The structure of scientific revolutions. Chicago, Univ. of Chicago Pr.

Kuznetsov, S. A., Friedenstein, A. J. and Robey, P. G. (1997). Factors required for bone marrow stromal fibroblast colony formation in vitro. Br J Haematol, 97(3), 561-570

Lambshead, J. W., Meagher, L., O'Brien, C. and Laslett, A. L. (2013). Defining synthetic surfaces for human pluripotent stem cell culture. Cell Regen (Lond), 2(1), 7

Larjava, H., Salo, T., Haapasalmi, K., Kramer, R. H. and Heino, J. (1993). Expression of integrins and basement membrane components by wound keratinocytes. J Clin Invest, 92(3), 1425-1435

Lassalle, M. W., Igarashi, S., Sasaki, M., Wakamatsu, K., Ito, S. and Horikoshi, T. (2003). Effects of melanogenesis-inducing nitric oxide and histamine on the production of eumelanin and pheomelanin in cultured human melanocytes. Pigment Cell Res, 16(1), 81-84

Laurikkala, J., Mikkola, M. L., James, M., Tummers, M., Mills, A. A. and Thesleff, I. (2006). p63 regulates multiple signalling pathways required for ectodermal organogenesis and differentiation. Development, 133(8), 1553-1563

Le Blanc, K., Tammik, C., Rosendahl, K., Zetterberg, E. and Ringden, O. (2003). HLA expression and immunologic properties of differentiated and undifferentiated mesenchymal stem cells. Exp Hematol, 31(10), 890-896

Leblond, C. P., Cairnie, A. B., Lala, P. K., Osmond, D. G. and University, M. (1976) [Book]. Stem cells of renewing cell populations: proceedings of a symposium held in October 1975 at McGill University, Montreal, in tribute to C. P. Leblond on the occasion of his sixty-fifth birthday. Academic Press.

Lebonvallet, N., Boulais, N., Le Gall, C., Pereira, U., Gauché, D., Gobin, E., . . Misery, L. (2012). Effects of the re-innervation of organotypic skin explants on the epidermis. Experimental Dermatology, 21(2), 156-158

Lee, D. S., Shin, J. Y., Tonge, P. D., Puri, M. C., Lee, S., Park, H., . . Seo, J. S. (2014). An epigenomic roadmap to induced pluripotency reveals DNA methylation as a reprogramming modulator. Nat Commun, 5, 5619 
Lee, J. H. \& Fisher, D. E. (2014). Melanocyte stem cells as potential therapeutics in skin disorders. Expert Opin Biol Ther, 14(11), 1569-1579

Lee, P., Werner, C. D., Kebebew, E. and Celi, F. S. (2014). Functional thermogenic beige adipogenesis is inducible in human neck fat. Int J Obes (Lond), 38(2), 170-176

Lee, T. I., Jenner, R. G., Boyer, L. A., Guenther, M. G., Levine, S. S., Kumar, R. M., . . Young, R. A. (2006). Control of developmental regulators by Polycomb in human embryonic stem cells. Cell, 125(2), 301-313

Leek, J. T. \& Peng, R. D. (2015). Statistics: P values are just the tip of the iceberg. Nature, 520(7549), 612

Leiros, G. J., Kusinsky, A. G., Drago, H., Bossi, S., Sturla, F., Castellanos, M. L., . . Balana, M. E. (2014). Dermal papilla cells improve the wound healing process and generate hair bud-like structures in grafted skin substitutes using hair follicle stem cells. Stem Cells Transl Med, 3(10), 1209-1219

Lenz, M., Goetzke, R., Schenk, A., Schubert, C., Veeck, J., Hemeda, H., . . Wagner, W. (2015). Epigenetic biomarker to support classification into pluripotent and non-pluripotent cells. Sci Rep, 5, 8973

Levenson, J. M. \& Sweatt, J. D. (2005). Epigenetic mechanisms in memory formation. Nat Rev Neurosci, 6(2), 108-118

Levrero, M., De Laurenzi, V., Costanzo, A., Gong, J., Wang, J. Y. and Melino, G. (2000). The p53/p63/ p73 family of transcription factors: overlapping and distinct functions. J Cell Sci, 113 ( Pt 10), $1661-1670$

Li, X. \& Zhao, X. (2008). Epigenetic regulation of mammalian stem cells. Stem Cells Dev, 17(6), 10431052

Lidell, M. E., Betz, M. J. and Enerback, S. (2014). Two types of brown adipose tissue in humans. Adipocyte, 3(1), 63-66

Lin, C. S., Xin, Z. C., Deng, C. H., Ning, H., Lin, G. and Lue, T. F. (2010). Defining adipose tissue-derived stem cells in tissue and in culture. Histol Histopathol, 25(6), 807-815

Lin, S. J. \& Chuong, C. M. (2011). Toward the isolation and culture of melanocyte stem cells. J Invest Dermatol, 131(12), 2341-2343

Lindholm, C., Bergsten, A. and Berglund, E. (1999). Chronic wounds and nursing care. J Wound Care, $8(1), 5-10$

Lindholm, C., Andersson, H., Fossum, B. and Jorbeck, H. (2005). Wounds scrutiny in a Swedish hospital: prevalence, nursing care and bacteriology, including MRSA. J Wound Care, 14(7), 313-319

Lister, R., Pelizzola, M., Kida, Y. S., Hawkins, R. D., Nery, J. R., Hon, G., . . Ecker, J. R. (2011). Hotspots of aberrant epigenomic reprogramming in human induced pluripotent stem cells. Nature, 471(7336), 68-73

Liu, J., Carmell, M. A., Rivas, F. V., Marsden, C. G., Thomson, J. M., Song, J. J., . . Hannon, G. J. (2004). Argonaute2 is the catalytic engine of mammalian RNAi. Science, 305(5689), 1437-1441

Liu, W., Liu, Y., Guo, T., Hu, C., Luo, H., Zhang, L., . . Jin, Y. (2013). TCF3, a novel positive regulator of osteogenesis, plays a crucial role in miR-17 modulating the diverse effect of canonical Wnt signaling in different microenvironments. Cell Death Dis, 4, e539

Lloyd-Evans, M. (2004). Regulating tissue engineering. Materials Today, 7(5), 48-55

Loh, Y. H., Agarwal, S., Park, I. H., Urbach, A., Huo, H., Heffner, G. C., . . Daley, G. Q. (2009). Generation of induced pluripotent stem cells from human blood. Blood, 113(22), 5476-5479

Lojewski, X., Srimasorn, S., Rauh, J., Francke, S., Wobus, M., Taylor, V., ... Hermann, A. (2015). Perivascular Mesenchymal Stem Cells From the Adult Human Brain Harbor No Instrinsic Neuroectodermal but High Mesodermal Differentiation Potential. Stem Cells Transl Med, 4(10), 1223-1233

Loos, E., Meulemans, J., Vranckx, J., Poorten, V. V. and Delaere, P. (2015). Tracheal Autotransplantation for Functional Reconstruction of Extended Hemilaryngectomy Defects: A Single-Center Experience in $\mathbf{3 0}$ Patients. Ann Surg Oncol

Lorenzi, T., Chisholm, R. H., Desvillettes, L. and Hughes, B. D. (2015). Dissecting the dynamics of epigenetic changes in phenotype-structured populations exposed to fluctuating environments. J Theor Biol, 386, 166-176

Loudon, I. (2005). Semmelweis and his thesis. J R Soc Med, 98(12), 555

Lu, R., Bian, F., Lin, J., Su, Z., Qu, Y., Pflugfelder, S. C. and Li, D. Q. (2012). Identification of human fibroblast cell lines as a feeder layer for human corneal epithelial regeneration. PLoS One, 7(6), e38825

Lucas, J. S., Bossen, C. and Murre, C. (2011). Transcription and recombination factories: common features? Curr Opin Cell Biol, 23(3), 318-324

Lujan, E., Chanda, S., Ahlenius, H., Sudhof, T. C. and Wernig, M. (2012). Direct conversion of mouse fi- 
broblasts to self-renewing, tripotent neural precursor cells. Proc Natl Acad Sci U S A, 109(7), 2527-2532

Lunyak, V. V. \& Rosenfeld, M. G. (2008). Epigenetic regulation of stem cell fate. Hum Mol Genet, 17(R1), R28-36

Lönnqvist, S., Rakar, J., Briheim, K. and Kratz, G. (2015). Biodegradable Gelatin Microcarriers Facilitate Re-Epithelialization of Human Cutaneous Wounds - An In Vitro Study in Human Skin. PLoS One, 10(6), e0128093

Macchiarini, P., Jungebluth, P., Go, T., Asnaghi, M. A., Rees, L. E., Cogan, T. A., ... Birchall, M. A. (2008). Clinical transplantation of a tissue-engineered airway. Lancet, 372(9655), 2023-2030

Maehle, A.-H. (2011). Ambiguous cells: the emergence of the stem cell concept in the nineteenth and twentieth centuries. Notes and Records of the Royal Society

Mandal, P. K. \& Rossi, D. J. (2013). Reprogramming human fibroblasts to pluripotency using modified mRNA. Nat Protoc, 8(3), 568-582

Mao, Y. \& Baum, B. (2015). Tug of war--the influence of opposing physical forces on epithelial cell morphology. Dev Biol, 401(1), 92-102

Mariani, F. V., Ahn, C. P. and Martin, G. R. (2008). Genetic evidence that FGFs have an instructive role in limb proximal-distal patterning. Nature, 453(7193), 401-405

Martinson, B. C., Anderson, M. S. and de Vries, R. (2005). Scientists behaving badly. Nature, 435(7043), 737-738

Mastrogiannaki, M., Lichtenberger, B. M., Reimer, A., Collins, C. A., Driskell, R. R. and Watt, F. M. (2016). beta-catenin stabilization in skin fibroblasts causes fibrotic lesions by preventing adipocyte differentiation of the reticular dermis. Journal of Investigative Dermatology(Epub ahead of print)

Matsumura, G., Hibino, N., Ikada, Y., Kurosawa, H. and Shin'oka, T. (2003). Successful application of tissue engineered vascular autografts: clinical experience. Biomaterials, 24(13), 2303-2308

Matsumura, T., Yamanaka, T., Hashizume, S., Irie, Y. and Nitta, K. (1975). Tissue dispersion, cell harvest and fluid suspension culture by the use of bacterial neutral protease. Jpn J Exp Med, 45(5), 377-382

Matsusaki, M., Fujimoto, K., Shirakata, Y., Hirakawa, S., Hashimoto, K. and Akashi, M. (2015). Development of full-thickness human skin equivalents with blood and lymph-like capillary networks by cell coating technology. J Biomed Mater Res A, 103(10), 3386-3396

Mauviel, A., Temime, N., Charron, D., Loyau, G. and Pujol, J. P. (1991). Induction of interleukin-1 beta production in human dermal fibroblasts by interleukin-1 alpha and tumor necrosis factor-alpha. Involvement of protein kinase-dependent and adenylate cyclase-dependent regulatory pathways. J Cell Biochem, 47(2), 174-183

Maximow, A. A. (1902) [Book]. Experimentelle Untersuchungen über die entzündliche Neubildung von Bindegewebe. G. Fischer.

Maxwell, D. S. \& Kruger, L. (1965). Small Blood Vessels and the Origin of Phagocytes in the Rat Cerebral Cortex Following Heavy Particle Irradiation. Exp Neurol, 12, 33-54

McBeath, R., Pirone, D. M., Nelson, C. M., Bhadriraju, K. and Chen, C. S. (2004). Cell shape, cytoskeletal tension, and RhoA regulate stem cell lineage commitment. Dev Cell, 6(4), 483-495

McMullan, R., Lax, S., Robertson, V. H., Radford, D. J., Broad, S., Watt, F. M., ... Hotchin, N. A. (2003). Keratinocyte differentiation is regulated by the Rho and ROCK signaling pathway. Curr Biol, 13(24), 2185-2189

Medina, A., Kilani, R. T., Carr, N., Brown, E. and Ghahary, A. (2007). Transdifferentiation of peripheral blood mononuclear cells into epithelial-like cells. Am J Pathol, 171(4), 1140-1152

Medina, A., Brown, E., Carr, N. and Ghahary, A. (2009). Circulating monocytes have the capacity to be transdifferentiated into keratinocyte-like cells. Wound Repair Regen, 17(2), 268-277

Mendez, J. J., Ghaedi, M., Steinbacher, D. and Niklason, L. E. (2014). Epithelial cell differentiation of human mesenchymal stromal cells in decellularized lung scaffolds. Tissue Eng Part A, 20(1112), 1735-1746

Merkel, F. (1875). Tastzellen und Tastkörperchen bei den Hausthieren und beim Menschen. Archiv für mikroskopische Anatomie, 11(1), 636-652

Mertsching, H., Walles, T. and Macchiarini, P. (2004). Replacement of the trachea with an autologous aortic graft. Ann Thorac Surg, 78(3), 1132-1133; author reply 1133

Millar, S. E. (2002). Molecular mechanisms regulating hair follicle development. J Invest Dermatol, 118(2), 216-225

Minasi, M. G., Riminucci, M., De Angelis, L., Borello, U., Berarducci, B., Innocenzi, A., . . Cossu, G. (2002). The meso-angioblast: a multipotent, self-renewing cell that originates from the dorsal aorta and differentiates into most mesodermal tissues. Development, 129(11), 2773-2783

Minwalla, L., Zhao, Y., Le Poole, I. C., Wickett, R. R. and Boissy, R. E. (2001). Keratinocytes play a role in regulating distribution patterns of recipient melanosomes in vitro. J Invest Dermatol, 117(2), 341-347 
Miyanishi, M., Mori, Y., Seita, J., Chen, J. Y., Karten, S., Chan, C. K., . . . Weissman, I. L. (2013). Do pluripotent stem cells exist in adult mice as very small embryonic stem cells? Stem Cell Reports, 1(2), 198-208

Nagase, T., Matsumoto, D., Nagase, M., Yoshimura, K., Shigeura, T., Inoue, M., .. . Machida, M. (2007). Neurospheres from human adipose tissue transplanted into cultured mouse embryos can contribute to craniofacial morphogenesis: a preliminary report. J Craniofac Surg, 18(1), 4953; discussion 60-41

Nakatani, M., Maksimovic, S., Baba, Y. and Lumpkin, E. A. (2015). Mechanotransduction in epidermal Merkel cells. Pflugers Arch, 467(1), 101-108

Nanba, D., Toki, F., Matsushita, N., Matsushita, S., Higashiyama, S. and Barrandon, Y. (2013). Actin filament dynamics impacts keratinocyte stem cell maintenance. EMBO Mol Med, 5(4), 640-653

Narisawa, Y., Hashimoto, K., Nihei, Y. and Pietruk, T. (1992). Biological significance of dermal Merkel cells in development of cutaneous nerves in human fetal skin. J Histochem Cytochem, 40(1), 65-71

Natesan, S., Zhang, G., Baer, D. G., Walters, T. J., Christy, R. J. and Suggs, L. J. (2011). A bilayer construct controls adipose-derived stem cell differentiation into endothelial cells and pericytes without growth factor stimulation. Tissue Eng Part A, 17(7-8), 941-953

Natesan, S., Zamora, D. O., Wrice, N. L., Baer, D. G. and Christy, R. J. (2013). Bilayer hydrogel with autologous stem cells derived from debrided human burn skin for improved skin regeneration. $J$ Burn Care Res, 34(1), 18-30

Nerem, R. M. (2006). Tissue engineering: the hope, the hype, and the future. Tissue Eng, 12(5), 11431150

Niemann, H. \& Petersen, B. (2016). The production of multi-transgenic pigs: update and perspectives for xenotransplantation. Transgenic Res

Nishida, K., Yamato, M., Hayashida, Y., Watanabe, K., Yamamoto, K., Adachi, E., .. . Tano, Y. (2004). Corneal reconstruction with tissue-engineered cell sheets composed of autologous oral mucosal epithelium. N Engl J Med, 351(12), 1187-1196

Nishino, K., Toyoda, M., Yamazaki-Inoue, M., Fukawatase, Y., Chikazawa, E., Sakaguchi, H., . . . Umezawa, A. (2011). DNA methylation dynamics in human induced pluripotent stem cells over time. PLoS Genet, 7(5), e1002085

Nuzzo, R. (2015). How scientists fool themselves - and how they can stop. Nature, 526(7572), $182-185$

O'Connor, N., Mulliken, J., Banks-Schlegel, S., Kehinde and Green, H. (1981). Grafting of burns with cultured epithelium prepared from autologous epidermal cells. Lancet, 1(8211), 75-78

Oberpenning, F., Meng, J., Yoo, J. J. and Atala, A. (1999). De novo reconstitution of a functional mammalian urinary bladder by tissue engineering. Nat Biotechnol, 17(2), 149-155

Obokata, H., Wakayama, T., Sasai, Y., Kojima, K., Vacanti, M. P., Niwa, H., . . Vacanti, C. A. (2014). Retraction: Stimulus-triggered fate conversion of somatic cells into pluripotency. Nature, 511(7507), 112

Oda, D., Gown, A. M., Vande Berg, J. S. and Stern, R. (1988). The fibroblast-like nature of myofibroblasts. Exp Mol Pathol, 49(3), 316-329

Olry, R. \& Haines, D. E. (2000). NEUROwords. 9. Vater, Pacini, Wagner, Meissner, Golgi, Mazzoni, Ruffini, Merkel and Krause: were their nerves all on edge? J Hist Neurosci, 9(3), 311-313

Olumi, A. F., Grossfeld, G. D., Hayward, S. W., Carroll, P. R., Tlsty, T. D. and Cunha, G. R. (1999). Carcinoma-associated fibroblasts direct tumor progression of initiated human prostatic epithelium. Cancer Res, 59(19), 5002-5011

Orphanidou, C., McCargar, L., Birmingham, C. L., Mathieson, J. and Goldner, E. (1994). Accuracy of subcutaneous fat measurement: comparison of skinfold calipers, ultrasound, and computed tomography. J Am Diet Assoc, 94(8), 855-858

Oshima, H., Rochat, A., Kedzia, C., Kobayashi, K. and Barrandon, Y. (2001). Morphogenesis and renewal of hair follicles from adult multipotent stem cells. Cell, 104(2), 233-245

Ott, H. C., Matthiesen, T. S., Goh, S. K., Black, L. D., Kren, S. M., Netoff, T. I. and Taylor, D. A. (2008). Perfusion-decellularized matrix: using nature's platform to engineer a bioartificial heart. Nat Med, 14(2), 213-221

Ott, H. C., Clippinger, B., Conrad, C., Schuetz, C., Pomerantseva, I., Ikonomou, L., . . Vacanti, J. P. (2010). Regeneration and orthotopic transplantation of a bioartificial lung. Nat Med, 16(8), 927-933

Oyake, T., Itoh, K., Motohashi, H., Hayashi, N., Hoshino, H., Nishizawa, M., . . Igarashi, K. (1996). Bach proteins belong to a novel family of BTB-basic leucine zipper transcription factors that interact with MafK and regulate transcription through the NF-E2 site. Mol Cell Biol, 16(11), 6083-6095

Pan, X., Hobbs, R. P. and Coulombe, P. A. (2013). The expanding significance of keratin intermediate filaments in normal and diseased epithelia. Curr Opin Cell Biol, 25(1), 47-56

Pare, M., Elde, R., Mazurkiewicz, J. E., Smith, A. M. and Rice, F. L. (2001). The Meissner corpuscle revised: a multiafferented mechanoreceptor with nociceptor immunochemical properties. $J$ 
Neurosci, 21(18), 7236-7246

Park, A., Kim, W. K. and Bae, K. H. (2014). Distinction of white, beige and brown adipocytes derived from mesenchymal stem cells. World J Stem Cells, 6(1), 33-42

Paunescu, V., Deak, E., Herman, D., Siska, I. R., Tanasie, G., Bunu, C., .. . Seifried, E. (2007). In vitro differentiation of human mesenchymal stem cells to epithelial lineage. J Cell Mol Med, 11(3), 502-508

Paus, R. \& Cotsarelis, G. (1999). The biology of hair follicles. N Engl J Med, 341(7), 491-497

Pilcher, B. K., Dumin, J. A., Sudbeck, B. D., Krane, S. M., Welgus, H. G. and Parks, W. C. (1997). The activity of collagenase-1 is required for keratinocyte migration on a type I collagen matrix. J Cell Biol, 137(6), 1445-1457

Pittenger, M. F., Mackay, A. M., Beck, S. C., Jaiswal, R. K., Douglas, R., Mosca, J. D., . . Marshak, D. R. (1999). Multilineage potential of adult human mesenchymal stem cells. Science, 284(5411), 143-147

Pittman, R. N. (2011). Chapter 2: The Circulatory System and Oxygen Transport Regulation of Tissue Oxygenation. San Rafael (CA).

Posnett, J., Gottrup, F., Lundgren, H. and Saal, G. (2009). The resource impact of wounds on health-care providers in Europe. J Wound Care, 18(4), 154-161

Postmes, T., Spears, R. and Cihangir, S. (2001). Quality of decision making and group norms. J Pers Soc Psychol, 80(6), 918-930

Potten, C. S. (1986). Cell cycles in cell hierarchies. Int J Radiat Biol Relat Stud Phys Chem Med, 49(2), 257-278

Potten, C. S. \& Loeffler, M. (1990). Stem cells: attributes, cycles, spirals, pitfalls and uncertainties. Lessons for and from the crypt. Development, 110(4), 1001-1020

Pozzi, S., Zambelli, F., Merico, D., Pavesi, G., Robert, A., Maltere, P., ... Vigano, M. A. (2009). Transcriptional network of p63 in human keratinocytes. PLoS One, 4(3), e5008

Purves, D., Augustine, G., Fitzpatrick, D. and al., e. (2001). Mechanoreceptors Specialized to Receive Tactile Information. In S. (MA) (Ed.), Neuroscience. 2nd edition: Sinauer Associates.

Querleux, B., Cornillon, C., Jolivet, O. and Bittoun, J. (2002). Anatomy and physiology of subcutaneous adipose tissue by in vivo magnetic resonance imaging and spectroscopy: relationships with sex and presence of cellulite. Skin Res Technol, 8(2), 118-124

Qureshi, I. A. \& Mehler, M. F. (2010). Impact of nuclear organization and dynamics on epigenetic regulation in the central nervous system: implications for neurological disease states. Ann NY Acad Sci, 1204 Suppl, E20-37

Rackham, O. J., Firas, J., Fang, H., Oates, M. E., Holmes, M. L., Knaupp, A. S., . . Gough, J. (2016). A predictive computational framework for direct reprogramming between human cell types. Nat Genet

Rady, P. L., Cadet, P., Bui, T. K., Tyring, S. K., Baron, S., Stanton, G. J. and Hughes, T. K. (1995). Production of interferon gamma messenger RNA by cells of non-immune origin. Cytokine, 7(8), 793-798

Rajagopal, J. \& Stanger, B. Z. (2016). Plasticity in the Adult: How Should the Waddington Diagram Be Applied to Regenerating Tissues? Developmental Cell, 36(2), 133-137

Rakar, J., Krammer, M. P. and Kratz, G. (2015). Human melanocytes mitigate keratinocyte-dependent contraction in an in vitro collagen contraction assay. Burns, 41(5), 1035-1042

Ramalho-Santos, M. \& Willenbring, H. (2007). On the Origin of the Term 'Stem Cell'. Cell Stem Cell, $1(1), 35-38$

Randhawa, M., Huff, T., Valencia, J. C., Younossi, Z., Chandhoke, V., Hearing, V. J. and Baranova, A. (2009). Evidence for the ectopic synthesis of melanin in human adipose tissue. FASEB J, 23(3), 835-843

Rao, M. S. \& Malik, N. (2012). Assessing iPSC reprogramming methods for their suitability in translational medicine. J Cell Biochem, 113(10), 3061-3068

Rauch, A., Gossye, V., Bracke, D., Gevaert, E., Jacques, P., Van Beneden, K., . . . De Bosscher, K. (2011). An anti-inflammatory selective glucocorticoid receptor modulator preserves osteoblast differentiation. FASEB J, 25(4), 1323-1332

Real, C., Glavieux-Pardanaud, C., Vaigot, P., Le-Douarin, N. and Dupin, E. (2005). The instability of the neural crest phenotypes: Schwann cells can differentiate into myofibroblasts. Int J Dev Biol, 49(2-3), 151-159

Rees, J. L. (2000). The melanocortin 1 receptor (MC1R): more than just red hair. Pigment Cell Res, 13(3), 135-140

Rekers, P. E., Coulter, M. P. and Warren, S. L. (1950). Effect of transplantation of bone marrow into irradiated animals. Archives of Surgery, 60(4), 635-667

Reynolds, B. A., Tetzlaff, W. and Weiss, S. (1992). A multipotent EGF-responsive striatal embryonic progenitor cell produces neurons and astrocytes. J Neurosci, 12(11), 4565-4574

Rheinwald, J. G. \& Green, H. (1975a). Formation of a keratinizing epithelium in culture by a cloned cell 
line derived from a teratoma. Cell, 6(3), 317-330

Rheinwald, J. G. \& Green, H. (1975b). Serial cultivation of strains of human epidermal keratinocytes: the formation of keratinizing colonies from single cells. Cell, 6(3), 331-343

Rice, J. B., Desai, U., Ristovska, L., Cummings, A. K., Birnbaum, H. G., Skornicki, M., . . Parsons, N. B. (2015). Economic outcomes among Medicare patients receiving bioengineered cellular technologies for treatment of diabetic foot ulcers. J Med Econ, 1-10

Rim, N. G., Shin, C. S. and Shin, H. (2013). Current approaches to electrospun nanofibers for tissue engineering. Biomed Mater, 8(1), 014102

Rinkevich, Y., Walmsley, G. G., Hu, M. S., Maan, Z. N., Newman, A. M., Drukker, M., ... Longaker, M. T. (2015). Skin fibrosis. Identification and isolation of a dermal lineage with intrinsic fibrogenic potential. Science, 348(6232), aaa2151

Rinn, J. L., Wang, J. K., Allen, N., Brugmann, S. A., Mikels, A. J., Liu, H., . . Chang, H. Y. (2008). A dermal HOX transcriptional program regulates site-specific epidermal fate. Genes Dev, 22(3), 303307

Roggenkamp, D., Kopnick, S., Stab, F., Wenck, H., Schmelz, M. and Neufang, G. (2013). Epidermal nerve fibers modulate keratinocyte growth via neuropeptide signaling in an innervated skin model. J Invest Dermatol, 133(6), 1620-1628

Romano, R. A. \& Sinha, S. (2011). Dynamic life of a skin keratinocyte: an intimate tryst with the master regulator p63. Indian J Exp Biol, 49(10), 721-731

Roshan, A., Murai, K., Fowler, J., Simons, B. D., Nikolaidou-Neokosmidou, V. and Jones, P. H. (2016). Human keratinocytes have two interconvertible modes of proliferation. Nat Cell Biol, 18(2), 145-156

Roux, W. (1881) [Book]. Der Kampf der Theile im Organismus. Ein Beitrag zur vervollständigung der mechanischen Zweckmässigkeitslehre, von Wilhelm Roux. Leipzig, W. Engelmann.

Ryu, J. H., Kim, S. J., Kim, S. H., Oh, C. D., Hwang, S. G., Chun, C. H., ... Chun, J. S. (2002). Regulation of the chondrocyte phenotype by beta-catenin. Development, 129(23), 5541-5550

Sacchetti, B., Funari, A., Michienzi, S., Di Cesare, S., Piersanti, S., Saggio, I., . . Bianco, P. (2007). Self-renewing osteoprogenitors in bone marrow sinusoids can organize a hematopoietic microenvironment. Cell, 131(2), 324-336

Sanai, N., Tramontin, A. D., Quinones-Hinojosa, A., Barbaro, N. M., Gupta, N., Kunwar, S., ... Alvarez-Buylla, A. (2004). Unique astrocyte ribbon in adult human brain contains neural stem cells but lacks chain migration. Nature, 427(6976), 740-744

Sbarbati, A., Accorsi, D., Benati, D., Marchetti, L., Orsini, G., Rigotti, G. and Panettiere, P. (2010). Subcutaneous adipose tissue classification. Eur J Histochem, 54(4), e48

Schack, L. M., Noack, S., Winkler, R., Wissmann, G., Behrens, P., Wellmann, M., . . Hoffmann, A. (2013). The Phosphate Source Influences Gene Expression and Quality of Mineralization during Osteogenic Differentiation of Human Mesenchymal Stem Cells. PLoS One, 8(6), e65943

Schepers, R. J. \& Ringkamp, M. (2010). Thermoreceptors and thermosensitive afferents. Neurosci Biobehav Rev, 34(2), 177-184

Schlader, Z. J., Perry, B. G., Jusoh, M. R., Hodges, L. D., Stannard, S. R. and Mundel, T. (2013). Human temperature regulation when given the opportunity to behave. Eur J Appl Physiol, 113(5), 1291-1301

Schlüter, H., Paquet-Fifield, S., Gangatirkar, P., Li, J. and Kaur, P. (2011). Functional characterization of quiescent keratinocyte stem cells and their progeny reveals a hierarchical organization in human skin epidermis. Stem Cells, 29(8), 1256-1268

Schmidt, B. A. \& Horsley, V. (2013). Intradermal adipocytes mediate fibroblast recruitment during skin wound healing. Development, 140(7), 1517-1527

Schor, A. M., Canfield, A. E., Sutton, A. B., Arciniegas, E. and Allen, T. D. (1995). Pericyte differentiation. Clin Orthop Relat Res(313), 81-91

Schrepfer, S., Deuse, T., Reichenspurner, H., Fischbein, M. P., Robbins, R. C. and Pelletier, M. P. (2007). Stem cell transplantation: the lung barrier. Transplant Proc, 39(2), 573-576

Scott, M. A., Nguyen, V. T., Levi, B. and James, A. W. (2011). Current methods of adipogenic differentiation of mesenchymal stem cells. Stem Cells Dev, 20(10), 1793-1804

Sen, C. K., Gordillo, G. M., Roy, S., Kirsner, R., Lambert, L., Hunt, T. K., .. . Longaker, M. T. (2009). Human skin wounds: a major and snowballing threat to public health and the economy. Wound Repair Regen, 17(6), 763-771

Serrero, G. \& Mills, D. (1991). Physiological role of epidermal growth factor on adipose tissue development in vivo. Proc Natl Acad Sci U S A, 88(9), 3912-3916

Shin'oka, T., Imai, Y. and Ikada, Y. (2001). Transplantation of a tissue-engineered pulmonary artery. $N$ Engl J Med, 344(7), 532-533

Shin'oka, T., Matsumura, G., Hibino, N., Naito, Y., Watanabe, M., Konuma, T., ... Kurosawa, H. (2005). Midterm clinical result of tissue-engineered vascular autografts seeded with autologous 
bone marrow cells. J Thorac Cardiovasc Surg, 129(6), 1330-1338

Shinoka, T. \& Breuer, C. (2008). Tissue-engineered blood vessels in pediatric cardiac surgery. Yale J Biol Med, 81(4), 161-166

Sidelmann, J. J., Gram, J., Jespersen, J. and Kluft, C. (2000). Fibrin clot formation and lysis: basic mechanisms. Semin Thromb Hemost, 26(6), 605-618

Sieber-Blum, M. \& Grim, M. (2004). The adult hair follicle: cradle for pluripotent neural crest stem cells. Birth Defects Res C Embryo Today, 72(2), 162-172

Singer, A. J. \& Clark, R. A. (1999). Cutaneous wound healing. N Engl J Med, 341(10), 738-746

Skobe, M. \& Detmar, M. (2000). Structure, function, and molecular control of the skin lymphatic system. J Investig Dermatol Symp Proc, 5(1), 14-19

Slack, J. M. (2002). Conrad Hal Waddington: the last Renaissance biologist? Nat Rev Genet, 3(11), 889895

Slominski, A., Wortsman, J., Plonka, P. M., Schallreuter, K. U., Paus, R. and Tobin, D. J. (2005). Hair Follicle Pigmentation. Journal of Investigative Dermatology, 124(1), 13-21

Smith, D. R., Spaulding, D. T., Glenn, H. M. and Fuller, B. B. (2004). The relationship between $\mathrm{Na}+/ \mathbf{H +}$ exchanger expression and tyrosinase activity in human melanocytes. Experimental $\mathrm{Cell}$ Research, 298(2), 521-534

Smorlesi, A., Frontini, A., Giordano, A. and Cinti, S. (2012). The adipose organ: white-brown adipocyte plasticity and metabolic inflammation. Obes Rev, 13 Suppl 2, 83-96

Sommer, C. A., Sommer, A. G., Longmire, T. A., Christodoulou, C., Thomas, D. D., Gostissa, M., ... Mostoslavsky, G. (2010). Excision of reprogramming transgenes improves the differentiation potential of iPS cells generated with a single excisable vector. Stem Cells, 28(1), 64-74

Song, B., Niclis, J. C., Alikhan, M. A., Sakkal, S., Sylvain, A., Kerr, P. G., . . Ricardo, S. D. (2011). Generation of induced pluripotent stem cells from human kidney mesangial cells. J Am Soc Nephrol, 22(7), 1213-1220

Song, J. J., Guyette, J. P., Gilpin, S. E., Gonzalez, G., Vacanti, J. P. and Ott, H. C. (2013). Regeneration and experimental orthotopic transplantation of a bioengineered kidney. Nat Med, 19(5), 646651

Sorrell, J. M. \& Caplan, A. I. (2009). Fibroblasts-a diverse population at the center of it all. Int Rev Cell Mol Biol, 276, 161-214

Spalding, K. L., Arner, E., Westermark, P. O., Bernard, S., Buchholz, B. A., Bergmann, O., .. A Arner, P. (2008). Dynamics of fat cell turnover in humans. Nature, 453(7196), 783-787

Spiegelman, B. M. \& Flier, J. S. (2001). Obesity and the regulation of energy balance. Cell, 104(4), 531543

Sriram, G., Bigliardi, P. L. and Bigliardi-Qi, M. (2015). Fibroblast heterogeneity and its implications for engineering organotypic skin models in vitro. Eur J Cell Biol, 94(11), 483-512

Stadtfeld, M., Nagaya, M., Utikal, J., Weir, G. and Hochedlinger, K. (2008). Induced pluripotent stem cells generated without viral integration. Science, 322(5903), 945-949

Stephens, P., Wood, E. J. and Raxworthy, M. J. (1996). Development of a multilayered in vitro model for studying events associated with wound healing. Wound Repair Regen, 4(3), 393-401

Suh, J. M., Zeve, D., McKay, R., Seo, J., Salo, Z., Li, R., . . Graff, J. M. (2007). Adipose Is a Conserved Dosage-Sensitive Antiobesity Gene. Cell Metabolism, 6(3), 195-207

Sun, T. T. \& Green, H. (1976). Differentiation of the epidermal keratinocyte in cell culture: formation of the cornified envelope. Cell, 9(4 Pt 1), 511-521

Swerlick, R. A. (1997). The structure and function of the cutaneous vasculature. J Dermatol, 24(11), 734-738

Szostak, J. W. \& Blackburn, E. H. (1982). Cloning yeast telomeres on linear plasmid vectors. Cell, 29(1), 245-255

Tachibana, M. (1999). Sound needs sound melanocytes to be heard. Pigment Cell Res, 12(6), 344-354

Tajbakhsh, S. (2009). Stem cell: what's in a name? Nature Reports stem cells(Commentary)

Tajima, S. \& Pinnell, S. R. (1981). Collagen synthesis by human skin fibroblasts in culture: studies of fibroblasts explanted from papillary and reticular dermis. J Invest Dermatol, 77(5), 410-412

Takahashi, K. \& Yamanaka, S. (2006). Induction of pluripotent stem cells from mouse embryonic and adult fibroblast cultures by defined factors. Cell, 126(4), 663-676

Takahashi, K., Tanabe, K., Ohnuki, M., Narita, M., Ichisaka, T., Tomoda, K. and Yamanaka, S. (2007). Induction of pluripotent stem cells from adult human fibroblasts by defined factors. Cell, 131(5), 861-872

Tamayol, A., Akbari, M., Annabi, N., Paul, A., Khademhosseini, A. and Juncker, D. (2013). Fiber-based tissue engineering: Progress, challenges, and opportunities. Biotechnol Adv, 31(5), 669-687

Tang, M. K., Lo, L. M., Shi, W. T., Yao, Y., Lee, H. S. S. and Lee, K. K. H. (2014). Transient acid treatment cannot induce neonatal somatic cells to become pluripotent stem cells [version 1; referees: 2 approved]. F1000Research, 3(102) 
Tashiro, K., Kawabata, K., Inamura, M., Takayama, K., Furukawa, N., Sakurai, F., . . Mizuguchi, H. (2010). Adenovirus vector-mediated efficient transduction into human embryonic and induced pluripotent stem cells. Cell Reprogram, 12(5), 501-507

Tatsumi, K., Ohashi, K., Matsubara, Y., Kohori, A., Ohno, T., Kakidachi, H., . . . Okano, T. (2013). Tissue factor triggers procoagulation in transplanted mesenchymal stem cells leading to thromboembolism. Biochem Biophys Res Commun, 431(2), 203-209

Thingnes, J., Lavelle, T. J., Hovig, E. and Omholt, S. W. (2012). Understanding the melanocyte distribution in human epidermis: an agent-based computational model approach. PLoS One, 7(7), e40377

Thomas, E. D., Lochte, H. L., Jr., Lu, W. C. and Ferrebee, J. W. (1957). Intravenous infusion of bone marrow in patients receiving radiation and chemotherapy. $N$ Engl J Med, 257(11), 491-496

Thompson-Torgerson, C. S., Holowatz, L. A. and Kenney, W. L. (2008). Altered mechanisms of thermoregulatory vasoconstriction in aged human skin. Exerc Sport Sci Rev, 36(3), 122-127

Thomson, J. A., Itskovitz-Eldor, J., Shapiro, S. S., Waknitz, M. A., Swiergiel, J. J., Marshall, V. S. and Jones, J. M. (1998). Embryonic stem cell lines derived from human blastocysts. Science, 282(5391), $1145-1147$

Thoreau, H. (1854) [Book]. Walden; or, Life in the Woods. Ticknor and Fields: Boston.

Tilling, T., Wladykowski, E., Failla, A. V., Houdek, P., Brandner, J. M. and Moll, I. (2014). Immunohistochemical analyses point to epidermal origin of human Merkel cells. Histochem Cell Biol, 141(4), 407-421

Toma, C., Wagner, W. R., Bowry, S., Schwartz, A. and Villanueva, F. (2009). Fate of culture-expanded mesenchymal stem cells in the microvasculature: in vivo observations of cell kinetics. Circ Res, 104(3), 398-402

Topol, B., Haimes, H., Dubertret, L. and Bell, E. (1986). Transfer of Melanosomes in a Skin Equivalent Model In Vitro. Journal of Investigative Dermatology, 87(5), 642-647

Torkian, B. A., Yeh, A. T., Engel, R., Sun, C. H., Tromberg, B. J. and Wong, B. J. (2004). Modeling aberrant wound healing using tissue-engineered skin constructs and multiphoton microscopy. Arch Facial Plast Surg, 6(3), 180-187

Tschachler, E., Reinisch, C. M., Mayer, C., Paiha, K., Lassmann, H. and Weninger, W. (2004). Sheet preparations expose the dermal nerve plexus of human skin and render the dermal nerve end organ accessible to extensive analysis. J Invest Dermatol, 122(1), 177-182

Tversky, A. \& Kahneman, D. (1974). Judgment under Uncertainty: Heuristics and Biases. Science, 185(4157), 1124-1131

Uehara, S., Izumi, Y., Kubo, Y., Wang, C. C., Mineta, K., Ikeo, K., . . Yamamoto, H. (2009). Specific expression of Gsta4 in mouse cochlear melanocytes: a novel role for hearing and melanocyte differentiation. Pigment Cell Melanoma Res, 22(1), 111-119

Ulbricht, J., Jordan, R. and Luxenhofer, R. (2014). On the biodegradability of polyethylene glycol, polypeptoids and poly(2-oxazoline)s. Biomaterials, 35(17), 4848-4861

Wabik, A. \& Jones, P. H. (2015). Switching roles: the functional plasticity of adult tissue stem cells. EMBO J, 34(9), 1164-1179

Vacanti, J. P., Langer, R., Upton, J. and Marler, J. J. (1998). Transplantation of cells in matrices for tissue regeneration. Adv Drug Deliv Rev, 33(1-2), 165-182

Waddington, C. H. (1936). The Problems of Embryology. Br Med J, 2(3956), 862-864

Walker, G. E., Verti, B., Marzullo, P., Savia, G., Mencarelli, M., Zurleni, F., . . . Di Blasio, A. M. (2007). Deep subcutaneous adipose tissue: a distinct abdominal adipose depot. Obesity (Silver Spring), 15(8), 1933-1943

Warren, L., Manos, P. D., Ahfeldt, T., Loh, Y. H., Li, H., Lau, F., . . Rossi, D. J. (2010). Highly efficient reprogramming to pluripotency and directed differentiation of human cells with synthetic modified mRNA. Cell Stem Cell, 7(5), 618-630

Watt, F. M. \& Green, H. (1981). Involucrin synthesis is correlated with cell size in human epidermal cultures. J Cell Biol, 90(3), 738-742

Watt, F. M. \& Green, H. (1982). Stratification and terminal differentiation of cultured epidermal cells. Nature, 295(5848), 434-436

Watt, F. M. \& Jensen, K. B. (2009). Epidermal stem cell diversity and quiescence. EMBO Mol Med, 1(5), 260-267

Webber, J., Meran, S., Steadman, R. and Phillips, A. (2009). Hyaluronan orchestrates transforming growth factor-beta1-dependent maintenance of myofibroblast phenotype. J Biol Chem, 284(14), 9083-9092

Weiner, L., Fu, W., Chirico, W. J. and Brissette, J. L. (2014). Skin as a living coloring book: how epithelial cells create patterns of pigmentation. Pigment Cell Melanoma Res, 27(6), 1014-1031

Weismann, A., Parker, W. N. and Rönnfeldt, H. (1893) [Book]. The germ-plasm; a theory of heredity. New York, Scribner's. 
Werner, S. \& Grose, R. (2003). Regulation of wound healing by growth factors and cytokines. Physiol Rev, 83(3), 835-870

Werner, S., Krieg, T. and Smola, H. (2007). Keratinocyte-fibroblast interactions in wound healing. $J$ Invest Dermatol, 127(5), 998-1008

Whitesides, G. M. \& Grzybowski, B. (2002). Self-assembly at all scales. Science, 295(5564), 2418-2421

Widera, D., Hauser, S., Kaltschmidt, C. and Kaltschmidt, B. (2012). Origin and regenerative potential of vertebrate mechanoreceptor-associated stem cells. Anat Res Int, 2012, 837626

Vierbuchen, T., Ostermeier, A., Pang, Z. P., Kokubu, Y., Sudhof, T. C. and Wernig, M. (2010). Direct conversion of fibroblasts to functional neurons by defined factors. Nature, 463(7284), 1035 1041

Willerson, J. T. (2015). Stem cell therapy for cardiovascular diseases: a progressive journey. Curr Opin Cardiol, 30(3), 205-212

Wilmut, I., Schnieke, A. E., McWhir, J., Kind, A. J. and Campbell, K. H. (1997). Viable offspring derived from fetal and adult mammalian cells. Nature, 385(6619), 810-813

Viola, J., Lal, B. and Grad, O. (2003). The Emergence of Tissue Engineering as a Research Field (nsf0450). Retrieved from The National Science Foundation, 4201 Wilson Boulevard, Arlington, Virginia 22230, USA: http://www.nsf.gov/pubs/2004/nsf0450/start.htm

Woo, S. H., Ranade, S., Weyer, A. D., Dubin, A. E., Baba, Y., Qiu, Z., . . Patapoutian, A. (2014). Piezo2 is required for Merkel-cell mechanotransduction. Nature, 509(7502), 622-626

Woodbury, D., Schwarz, E. J., Prockop, D. J. and Black, I. B. (2000). Adult rat and human bone marrow stromal cells differentiate into neurons. J Neurosci Res, 61(4), 364-370

Wu, J., Sun, Z., Sun, H. S., Wu, J., Weisel, R. D., Keating, A., . . . Li, R. K. (2008). Intravenously administered bone marrow cells migrate to damaged brain tissue and improve neural function in ischemic rats. Cell Transplant, 16(10), 993-1005

Wu, J., Bostrom, P., Sparks, L. M., Ye, L., Choi, J. H., Giang, A. H., . . Spiegelman, B. M. (2012). Beige adipocytes are a distinct type of thermogenic fat cell in mouse and human. Cell, 150(2), 366-376

Wu, X. \& Hammer, J. A. (2014). Melanosome transfer: it is best to give and receive. Curr Opin Cell Biol, 29, 1-7

Yaar, M. \& Gilchrest, B. A. (1991). Human Melanocyte Growth and Differentiation: A Decade of New Data. Journal of Investigative Dermatology, 97(4), 611-617

Yamaguchi, Y., Brenner, M. and Hearing, V. J. (2007). The regulation of skin pigmentation. J Biol Chem, 282(38), 27557-27561

Yanez, R., Lamana, M. L., Garcia-Castro, J., Colmenero, I., Ramirez, M. and Bueren, J. A. (2006). Adipose tissue-derived mesenchymal stem cells have in vivo immunosuppressive properties applicable for the control of the graft-versus-host disease. Stem Cells, 24(11), 2582-2591

Yang, W. J., Yang, D. D., Na, S., Sandusky, G. E., Zhang, Q. and Zhao, G. (2005). Dicer is required for embryonic angiogenesis during mouse development. J Biol Chem, 280(10), 9330-9335

Yu, J., Vodyanik, M. A., Smuga-Otto, K., Antosiewicz-Bourget, J., Frane, J. L., Tian, S., . . Thomson, J. A. (2007). Induced pluripotent stem cell lines derived from human somatic cells. Science, 318(5858), 1917-1920

Zandi, S., Bryder, D. and Sigvardsson, M. (2010). Load and lock: the molecular mechanisms of B-lymphocyte commitment. Immunol Rev, 238(1), 47-62

Zecca, L., Zucca, F. A., Wilms, H. and Sulzer, D. (2003). Neuromelanin of the substantia nigra: a neuronal black hole with protective and toxic characteristics. Trends Neurosci, 26(11), 578-580

Zhou, Q., Brown, J., Kanarek, A., Rajagopal, J. and Melton, D. A. (2008). In vivo reprogramming of adult pancreatic exocrine cells to beta-cells. Nature, 455(7213), 627-632

Zhou, T., Benda, C., Duzinger, S., Huang, Y., Li, X., Li, Y., ... Esteban, M. A. (2011). Generation of induced pluripotent stem cells from urine. J Am Soc Nephrol, 22(7), 1221-1228

Zhou, W. \& Freed, C. R. (2009). Adenoviral gene delivery can reprogram human fibroblasts to induced pluripotent stem cells. Stem Cells, 27(11), 2667-2674

Zimmermann, K. W. (1923). Der feinere Bau der Blutcapillaren. Zeitschrift für Anatomie und Entwicklungsgeschichte, 68(1), 29-109

Zuk, P. A., Zhu, M., Mizuno, H., Huang, J., Futrell, J. W., Katz, A. J., . . . Hedrick, M. H. (2001). Multilineage cells from human adipose tissue: implications for cell-based therapies. Tissue Eng, $7(2)$, 211-228

Östman, A. \& Augsten, M. (2009). Cancer-associated fibroblasts and tumor growth--bystanders turning into key players. Curr Opin Genet Dev, 19(1), 67-73 


\section{Papers}

The articles associated with this thesis have been removed for copyright reasons. For more details about these see:

http://urn.kb.se/resolve?urn=urn:nbn:se:liu:diva- 125925 